\title{
PHOTOELECTROCHEMICAL WATER SPLITTING
}

OPTIMIZING INTERFACES AND LIGHT ABSORPTION 


\section{PROMOTIECOMMISSIE}

\section{VOORZITTER}

Prof. dr. ir. J.W.M. Hilgenkamp

\section{PROMOTOREN}

Prof. dr. G. Mul

Prof. dr. J. L. Herek

\section{LEDEN}

Prof. dr. J.G.E. Gardeniers

Prof. dr. ir. J. Huskens

Prof. dr. R. van de Krol

Prof. dr. K. Sivula

Prof. dr. B. Dam
Universiteit Twente, TNW

\author{
Universiteit Twente, TNW \\ Universiteit Twente, TNW
}

\author{
Universiteit Twente, TNW \\ Universiteit Twente, TNW \\ Helmholtz-Zentrum Berlin \\ École Polytechnique Fédérale de Lausanne \\ Technische Universiteit Delft
}

The research described in this thesis was carried out in the PhotoCatalytic Synthesis (PCS) group within the Faculty of Science and Technology (TNW), and the MESA+ Institute for Nanotechnology at University of Twente. A part of this research was carried out at the Korea Institute of Materials Science (KIMS). This work is part of the research programme of the Foundation for Fundamental Research on Matter (FOM, project 10TBSC07-1), which is part of the Netherlands Organization for Scientific Research (NWO). It was carried out within the framework of the national program on BioSolar Cells, co-financed by the Dutch Ministry of Economic Affairs, Agriculture, and Innovation.

\section{FOM O: UNIVERSITY OF TWENTE.}

Photoelectrochemical Water Splitting: Optimizing Interfaces and Light Absorption Sun-Young Park, PhD thesis, University of Twente, The Netherlands ISBN: 978-94-6233-082-5

DOI: $10.3990 / 1.9789462330825$

Copyright (C) 2015 by Sun-Young Park

Printed by Gildeprint, Enschede, The Netherlands

Cover design: www.MidasMentink.nl 


\title{
PHOTOELECTROCHEMICAL WATER SPLITTING OPTIMIZING INTERFACES AND LIGHT ABSORPTION
}

\section{PROEFSCHRIFT}

\author{
ter verkrijging van \\ de graad van doctor aan de Universiteit Twente, \\ op gezag van de rector magnificus, \\ Prof. dr. H. Brinksma, \\ volgens besluit van het College voor Promoties \\ in het openbaar te verdedigen \\ op donderdag 24 september 2015 om 12:45 uur
}

door

Sun-Young Park

geboren op 15 januari 1987

te Changwon, Zuid-Korea 
Dit proefschrift is goedgekeurd door de promotoren:

Prof. dr. G. Mul

Prof. dr. J. L. Herek 


\section{Contents}

1. Introduction 1

1.1 Solar energy to fuel approach 2

1.2 Methods to produce a solar fuel 2

1.3 State of the art of photoelectrochemical cells 3

1.4 Photoelectrochemical cells 5

$\begin{array}{ll}1.5 \text { Photoelectrochemical systems } & 10\end{array}$

$\begin{array}{ll}1.6 \text { Semiconductors and photo-electrode materials } & 11\end{array}$

$\begin{array}{ll}1.7 \text { This thesis } & 14\end{array}$

$\begin{array}{ll}1.8 \text { References } & 17\end{array}$

2. Characterization of photoelectrochemical cells 19

$\begin{array}{ll}2.1 \text { Solar simulator } & 21\end{array}$

2.2 Photoelectrochemical reactor 25

$\begin{array}{ll}2.3 \text { References } & 28\end{array}$

3. Size-dependent electrochemical characteristics of photoelectrochemical cells 29

$\begin{array}{ll}3.1 \text { Introduction } & 31\end{array}$

3.2 Experimental section $\quad 31$

3.3 Results and discussion $\quad 33$

3.4 Conclusions 41

$\begin{array}{ll}3.5 \text { References } & 42\end{array}$

3.6 Appendix 43

4. Selective modulation of charge-carrier transport of a photo-anode in a photoelectrochemical cell by a graphitized fullerene interfacial layer $\quad 45$

$\begin{array}{ll}4.1 \text { Introduction } & 47\end{array}$

4.2 Experimental section $\quad 48$

4.3 Results and discussion $\quad 49$

4.4 Conclusions $\quad 57$

4.5 References $\quad 57$

4.6 Appendix $\quad 59$

5. Metal assisted opto-electrical enhancement of tandem $\begin{array}{ll}\text { photoelectrochemical cells } & 65\end{array}$

$\begin{array}{ll}5.1 \text { Introduction } & 67\end{array}$

$\begin{array}{ll}5.2 \text { Experimental section } & 68\end{array}$

$\begin{array}{ll}5.3 \text { Results and discussion } & 70\end{array}$

$\begin{array}{ll}5.4 \text { Conclusions } & 77\end{array}$

$\begin{array}{ll}5.5 \text { References } & 78\end{array}$

$\begin{array}{lr}5.6 \text { Appendix } & 80\end{array}$ 
6. ATR infrared study of the photocatalytic behavior of $\mathrm{TiO}_{2}$ in physical contact with $\mathrm{SiO}_{2}$ or $\mathrm{Ag} @ \mathrm{SiO}_{2}$

6.1 Introduction

6.2 Experimental section

88

6.3 Results and discussion

90

6.4 Conclusions

103

6.5 References

104

6.6 Appendix

7. Stability and effect of $\mathrm{Ag} @ \mathrm{SiO}_{2}$ core-shell particles on efficacy of $\mathrm{WO}_{3}$ and $\mathrm{ZnO}$ in photocatalytic overall water splitting

7.1 Introduction

7.2 Experimental section

7.3 Results and discussion

7.4 Conclusions

7.5 References

7.6 Appendix

8. Summary and outlook

8.1 Summary

8.2 Outlook

8.3 References

Samenvatting

Acknowledgements

List of publications 


\title{
Chapter 1
}

\author{
Introduction
}

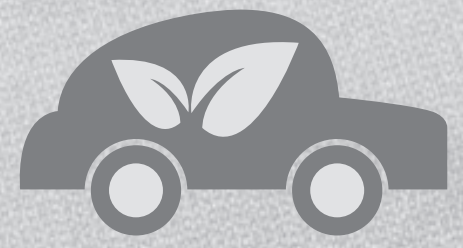

0

0

(2)

a 


\subsection{Solar energy to fuel approach}

It is clear that an increase in production of renewable energy is necessary to alleviate the environmental issues associated with the use (combustion) of fossil fuels. At the same time, storage of renewable energy is required, since various sources, and in particular solar energy, are intermittent, both on the short term (day vs. night) and the long term (summer vs. winter). Storage of solar energy in the form of hydrocarbon fuel molecules (by thermodynamically uphill conversion of $\mathrm{CO}_{2}$ and $\mathrm{H}_{2} \mathrm{O}$ ) provides a high energy density (ranging from 15-40 MJ/kg), significantly higher than can be achieved with for example batteries. The fuel produced by renewable energy should be made easily, with cheap and abundant catalysts, and in an energy efficient way. ${ }^{1}$ Among the renewable energy resources such as solar, geothermal, biomass, and wind etc., solar energy is one of the most attractive energy sources because of the surplus in energy, and thus solar energy is ideal to achieve various positive environmental effects: 1) reduction of greenhouse gases 2) prevention of emission of toxic gases (e.g. an issue with 'dirty' coal), and 3) reduction of the amount of required transmission lines in electricity grids. ${ }^{2,3}$ However, solar energy use is still relatively limited, and many researchers are focusing on the development of improved technologies for solar energy conversion. The furthest developed application of solar energy is to convert light to electricity by photovoltaic cells. Especially, Si based photovoltaic cells are available commercially with over $20 \%$ light to electricity efficiency. However, improved technologies are needed to efficiently store solar energy.

Mimicking natural photosynthesis to split water into hydrogen and oxygen is suggested as a possible solution to solve the problem of solar energy storage. Hydrogen is a valuable fuel for many reasons 1) hydrogen produces only water by burning, which contributes to reduction of the greenhouse effect, as compared to using fossil fuels, 2) hydrogen is used for chemical processing, such as in the synthesis of ammonia. Conversion of solar energy into hydrogen is necessary to establish a future for a hydrogen economy.

\subsection{Methods to produce a solar fuel}

For the development of solar fuels, several pathways have been proposed. These can roughly be divided in indirect and direct systems. ${ }^{4}$

\subsubsection{Indirect systems (photovoltaics-electrolysis)}

Essentially an indirect system is based on connecting two well developed technologies together, such as photovoltaic cells to convert light energy in electrical energy, and electrolyzers to convert electrical energy in chemical energy (hydrogen). Energy efficiencies achieved with such combined technologies are already reasonable. However, the indirect route has several disadvantages. Despite the already reasonable efficiency, the indirect 
photovoltaics-electrolysis system induces energy losses as a result of two energy conversion steps, which are the conversion of light energy to electrons, and electrons to hydrogen. In addition, the high equipment price is still an issue in further development of connected photovoltaics-electrolysis systems. In particular with respect to equipment price, solar to hydrogen converters might be more promising.

\subsubsection{Direct systems (photoelectrolysis or photocatalysis)}

To overcome the issues of the indirect systems, a direct system needs to produce hydrogen efficiently. Direct systems convert solar energy into a fuel without producing electricity. There are two possible approaches 1) using a heterogeneous photocatalyst system in a slurry type reactor, or 2) construction of a photoelectrochemical cell. In both applications, semiconductor materials are used to drive oxidation of water and reduction of protons to hydrogen. In case of powdered photocatalyst systems, photocatalyst powders are dispersed in a container with water, consisting of transparent windows. Powdered photocatalyst systems are easy to scale-up, but the accurate measurement of performance of a photocatalyst is difficult, since hydrogen and oxygen are typically formed in the same compartment, inducing possible reverse reaction of hydrogen and oxygen to water.

Therefore, this thesis focuses on the development of a device based on a photoelectrochemical cell to produce hydrogen from water splitting. In the next part of the introduction, it will provide general information about photoelectrochemical cells, followed by a description of the general aims of the study reported in this thesis.

\subsection{State of the art of photoelectrochemical cells}

As aforementioned, a photoelectrochemical cell for water splitting to produce hydrogen is one of the most attractive methods to enhance utilization of renewable energy technologies. Photoelectrochemical cells use solar energy as light source to generate a sufficiently high voltage to split water into hydrogen and oxygen. Typically semiconductors are used to absorb the photons of solar light, and these need to be functionalized with catalysts to establish the chemical reactions of water splitting, being water oxidation and proton reduction. To improve efficiencies of photoelectrochemical cells, several challenges need to be addressed, including: 1) the photons available in the solar spectrum need to be absorbed as much as possible (small band gap materials) 2) the semiconductor needs to have a high stability against corrosion, 3) semiconductor materials with a low internal resistance need to be applied, and 4) the processing cost of the semiconductor needs to be low. Addressing these requirements of semiconductors in photoelectrochemical cells will be described in following sections. 


\subsubsection{History of photoelectrochemical cells based on a semiconductor}

Fujishima and Honda first demonstrated in 1972 that water splitting at a $\mathrm{TiO}_{2}$ (rutile) photo-anode under UV light illumination was feasible if the photo-anode was connected to a Pt cathode. ${ }^{5}$ Since this demonstration, water splitting based on semiconductors has been studied extensively. However, a lot of semiconductors have limited efficiency, suffer from instability, or have band gaps allowing absorption of light with minimal overlap with the solar spectrum. To resolve band gap related limitations, combining different semiconductors is a promising strategy. In Figure 1.1, solar to hydrogen conversion efficiency of photoelectrochemical cells, as a function of year of publication, are compared.

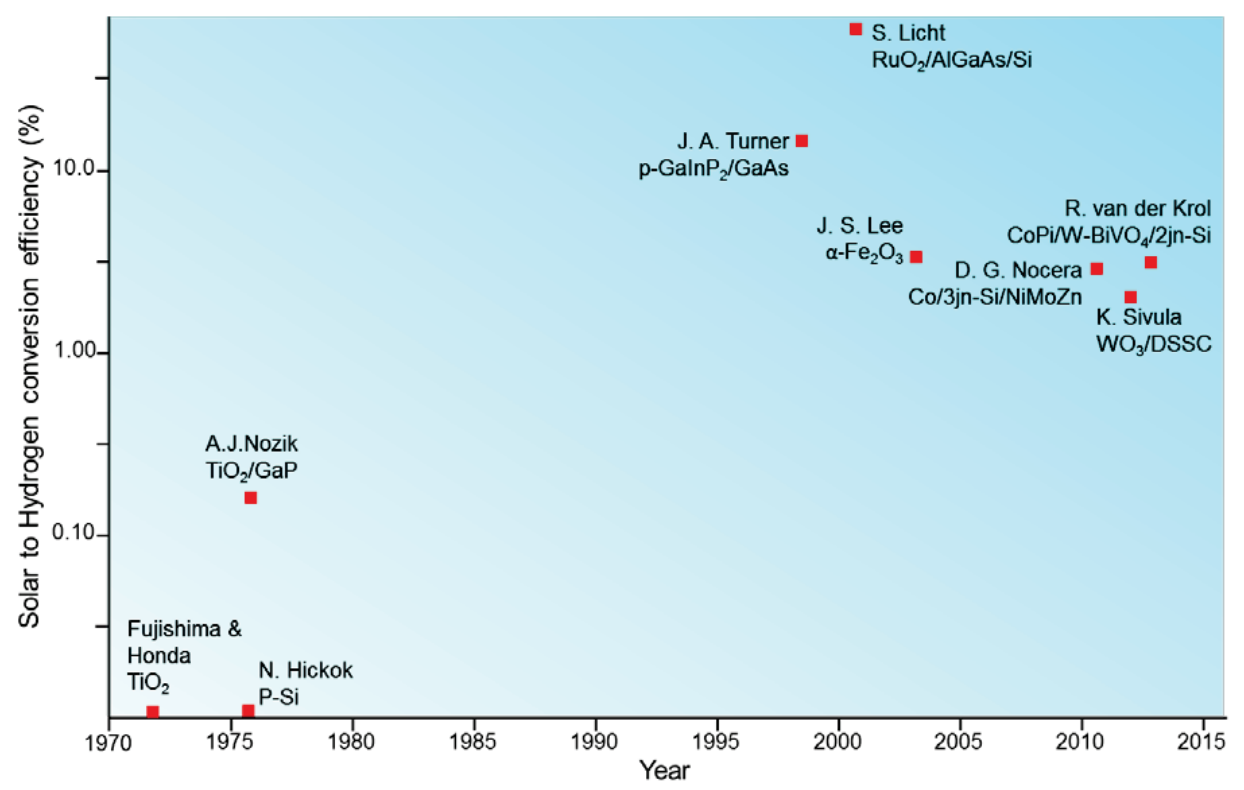

Figure 1.1. Remarkable solar to hydrogen conversion efficiencies reported since the discovery of Fujishima and Honda. ${ }^{5}$

Single crystal phosphides are very effective as photo-cathode for proton reduction. In 1976, A. J. Nozik reported a water splitting device which could split water without an external bias, constituting of a n- $\mathrm{TiO}_{2} / \mathrm{p}-\mathrm{GaP}$ heterojunction system. ${ }^{6} \mathrm{~J}$. A. Turner introduced a direct photoelectrochemical cell based on a $\mathrm{p}$-GaInP $2 / \mathrm{GaAs}$ electrode, which showed $12.4 \%$ hydrogen production efficiency in $1998 .^{7}$ After this discovery, S. Licht demonstrated a very effective device based on $\mathrm{RuO}_{2} / \mathrm{AlGaAs} / \mathrm{Si}$ in $2001 .^{8}$ This device showed a maximum photovoltage of $1.30 \mathrm{~V}$ and a solar to hydrogen efficiency of $18.3 \%$. Despite the world record 
efficiency of crystalline phosphide based devices, the high cost of the materials inhibits practical application, and moreover stability issues still have to be resolved. Gallium and indium phosphides are certainly not ideal in the view of scale up. Si is a promising candidate to function as a photo-cathode in a so-called tandem device. The first demonstration of water splitting based on Si was provided in 1976 by N. Hickok. ${ }^{9}$ As an example, D. G. Nocera described a device with and without connecting wires based on a triple junction amorphous $\mathrm{Si}$ photovoltaic cell in 2011. ${ }^{10}$ The wired configuration shows $4.7 \%$, and the configuration without wires $2.5 \%$ solar to hydrogen efficiency. R. van der Krol achieved $4.9 \%$ solar to hydrogen efficiency with a $\mathrm{BiVO}_{4}-\mathrm{Si}$ tandem photo-electrode in $2013 .{ }^{11}$ Instead of $\mathrm{Si}$ photovoltaic cells, organic photovoltaic cells are also attractive candidates to construct a tandem device based photoelectrochemical cell. In 2012, K. Sivula showed an efficiency of $3.1 \%$ in solar to hydrogen with a $\mathrm{WO}_{3} / \mathrm{DSSCs}$ (dye sensitized solar cells) combination. DSSCs provide more than $1 \mathrm{~V}$ of photovoltage at 1 sun condition. ${ }^{12}$ In case of single semiconductor materials, $\alpha-\mathrm{Fe}_{2} \mathrm{O}_{3}$ has the highest solar to hydrogen efficiency. J. S. Lee showed a $5.3 \%$ solar to hydrogen efficiency with wormlike $\alpha-\mathrm{Fe}_{2} \mathrm{O}_{3}{ }^{13}$

Since the first discovery of water splitting devices, there are still several problems remaining to approach the ideal device performance and reach the target of a solar to fuel efficiency of at least $10 \%$. There are many possible research directions to overcome these problems. Therefore, we anticipate photoelectrochemical cells will be an essential technology to produce fuels from solar energy and water for the next decades. In the following paragraphs further detail on the operating mechanism of photoelectrochemical cells will be provided.

\subsection{Photoelectrochemical cells}

\subsubsection{The semiconductor}

Semiconductors are important materials in many research fields, for example, in development of electrical devices. By absorbing photons of sufficient energy, electron-hole pairs are formed in semiconductors. The energy of the photons needs to be sufficient to overcome the so-called band gap energy. Then electrons are excited from the valence band (highest energy level with filled electrons) to the conduction band (lowest energy level with unfilled electrons). The formation of a so-called electron-hole pair is shown in Figure 1.2. Depending on the size of the band gap, materials are classified into insulators (too large band gap for excitation) or metals (overlap of conduction band and valence band, no band gap). Also, semiconductors can be classified into n-type or p-type, depending on the nature of the dopants present in the semiconductor lattice. Dopants can improve the conductivity of semiconductors, in the sense that a higher mobility of electron-hole pairs is achieved, which 
typically prevents (thermal or radiative) recombination before the desired redox reactions of water oxidation and proton reduction occur on the surface.

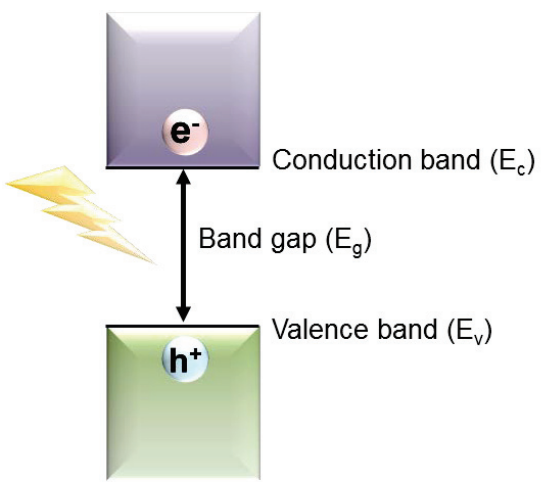

Figure 1.2. Photo-generation of electron-hole pairs in a semiconductor.

\subsubsection{The concept of photoelectrochemical cell}

The basic configuration of a photoelectrochemical cell is shown in Figure 1.3. It consists of two electrodes immersed in an aqueous electrolyte solution. One or both of the electrodes contain a photoactive semiconductor. Figure 1.3 shows the configuration with one semiconductor as photo-electrode (in this case, n-type semiconductor as photo-anode), and a metal (in this case, Pt) as the cathode in the electrolyte. This configuration was used by Fujishima and Honda ${ }^{5}$. Under illumination with solar light, electron-hole pairs are generated in the semiconductor. Then, photo-generated electrons transfer to the metal cathode through the external circuit. The photo-anode needs to oxidize water to produce oxygen efficiently, while for the metal a low overpotential for reduction of protons to hydrogen is required. 


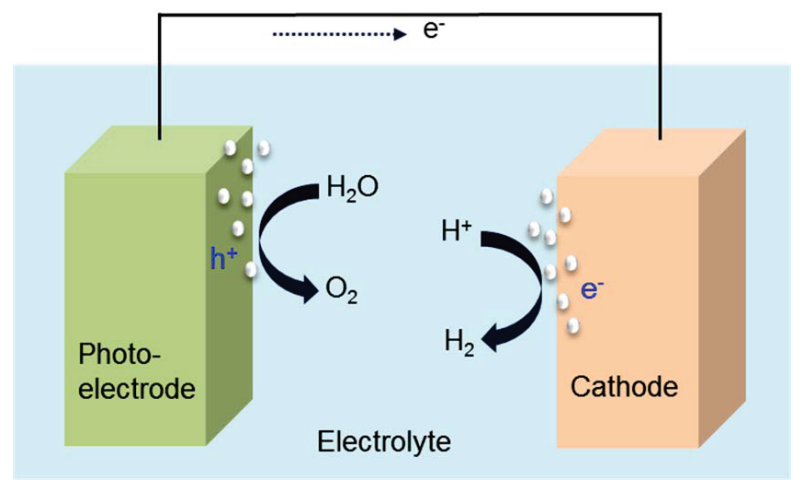

Figure 1.3. Scheme of basic concept of photoelectrochemical cell.

The redox reactions involved in photoelectrochemical water splitting can be summarized as follows:

Photo-electrode (semiconductor) : $2 h v \rightarrow 2 \mathrm{e}^{-}+2 \mathrm{~h}^{+}$

$$
\begin{array}{ll}
2 \mathrm{H}^{+}+2 \mathrm{e}^{-} \rightarrow \mathrm{H}_{2} & \mathrm{E}_{\mathrm{red}}=0 \mathrm{~V} v s . \mathrm{NHE} \\
(\text { Cathode) } & \\
\mathrm{H}_{2} \mathrm{O}+2 \mathrm{~h}^{+} \rightarrow 2 \mathrm{H}^{+}+1 / 2 \mathrm{O}_{2} & \mathrm{E}_{\mathrm{ox}}=1.23 \mathrm{~V} \text { vs. NHE } \\
\text { (Anode) } &
\end{array}
$$

The overall water splitting reaction can be summarized by:

$$
\mathrm{H}_{2} \mathrm{O} \rightarrow \mathrm{H}_{2}+1 / 2 \mathrm{O}_{2}
$$

\subsubsection{Interface between semiconductor and electrolyte}

For photoelectrochemical water splitting, the semiconductors are immersed in an aqueous electrolyte solution. ${ }^{14,15}$ When the semiconductor makes contact with the aqueous solution, electrons transfer from the semiconductor to the electrolyte, until equilibrium of Fermi levels of semiconductor and electrolyte is established. In dark conditions, after equilibrium of the two Fermi levels, band bending at the interface of semiconductor and electrolyte is typically upward, and surfaces of semiconductors are charged positively. This positively charged zone is typically called the space charge region or depletion layer. At the same time, the aqueous solution near the semiconductor is charged negatively, and typically referred to as the Helmholtz layer. The space charge region stimulates charge separation by the induced electric 
field, with holes being transferred to the surface of the semiconductor, and electrons transferred in the opposite direction to the back contact, when the electrode is illuminated.

In Figure 1.4, an n-type semiconductor configuration is shown, which has as majority carriers electrons, while holes can oxidize water at the surface. In case of p-type semiconductors, the situation is opposite, and therefore these are typically used as photocathodes.
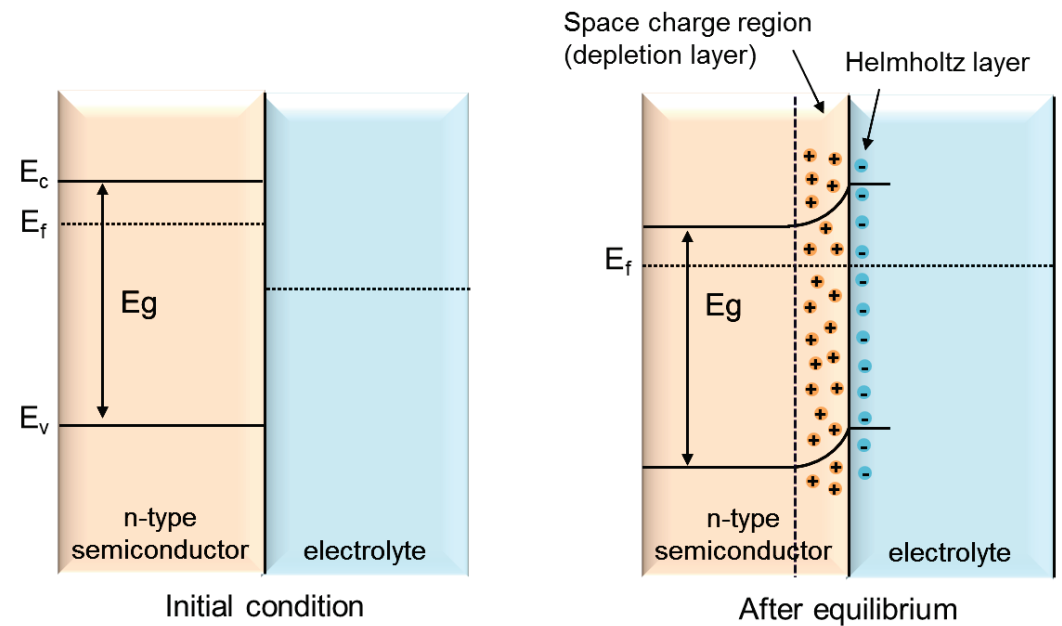

Figure 1.4. Band bending at the (n-type)semiconductor-electrolyte interface in aqueous electrolyte solution.

\subsubsection{Requirements of the semiconductor}

Water splitting will occur with solar energy, if semiconductors meet the following requirements ${ }^{16,17}$ :

1) A minimum thermodynamic potential is required of $1.23 \mathrm{eV}$. In practice, the potential needs to be 1.6-2.0 eV, as a result of the overpotential of water oxidation, and potential losses due to cell resistances.

2) The band gap of the semiconductor should be small to absorb as much solar light as possible.

3) The conduction band edge of the semiconductor should be more negative than the water reduction potential, and the valence band edge of the semiconductor should be more positive than the oxidation potential of water.

4) A good stability in the aqueous electrolyte solution is required under illumination. 
5) Charge-carrier mobility should be high, as well as the lifetime to prevent charge recombination.

6) High catalytic activity for either proton reduction or water oxidation. A fast surface reaction is essential to prevent charge recombination.

7) The material should be non-toxic, earth abundant, and have a low cost.

Figure 1.5 shows many of possible semiconductors as candidates for water splitting. ${ }^{18,19}$ Most of the semiconductors are not suitable to fulfill the above indicated 7 requirements for water splitting. $\mathrm{TiO}_{2}$ meets most of the required conditions to split water, however, $\mathrm{TiO}_{2}$ can only absorb the UV region of the solar spectrum. Therefore, the efficiency in solar to hydrogen conversion is very low. To overcome these limitations of semiconductors, several device configurations are introduced to achieve more efficient solar to hydrogen production.

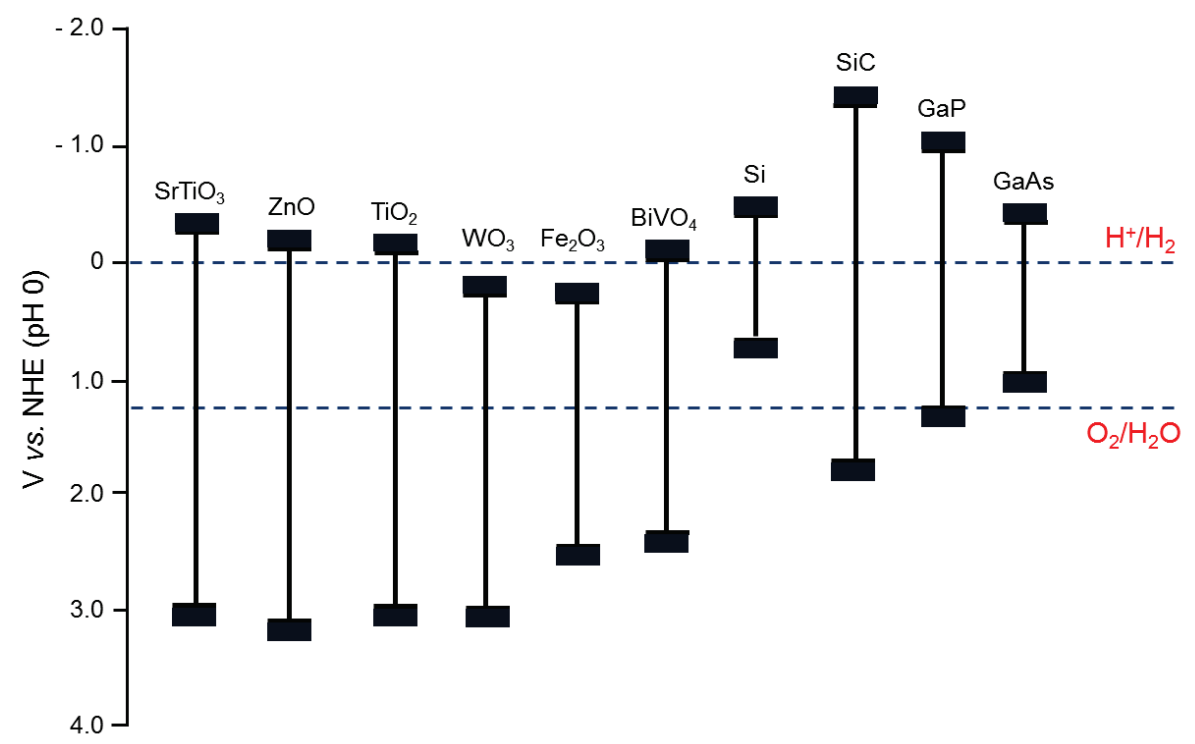

Figure 1.5. Band positions of semiconductors with respect to the thermodynamic potentials of water splitting. 


\subsection{Photoelectrochemical systems}

\subsubsection{Single photo-electrode photoelectrochemical system}

Figure 1.6 shows a scheme of a single photo-electrode photoelectrochemical system. The water splitting device of Fujishima and Honda is one of the examples of such single photoelectrochemical system, with $\mathrm{TiO}_{2}$ as photo-anode and $\mathrm{Pt}$ as counter electrode. As previously stated, novel semiconductors need to be developed as photo-electrode in a photoelectrochemical system, to obtain a high solar to hydrogen efficiency and to overcome the present limitations of single photo-electrode photoelectochemical systems.

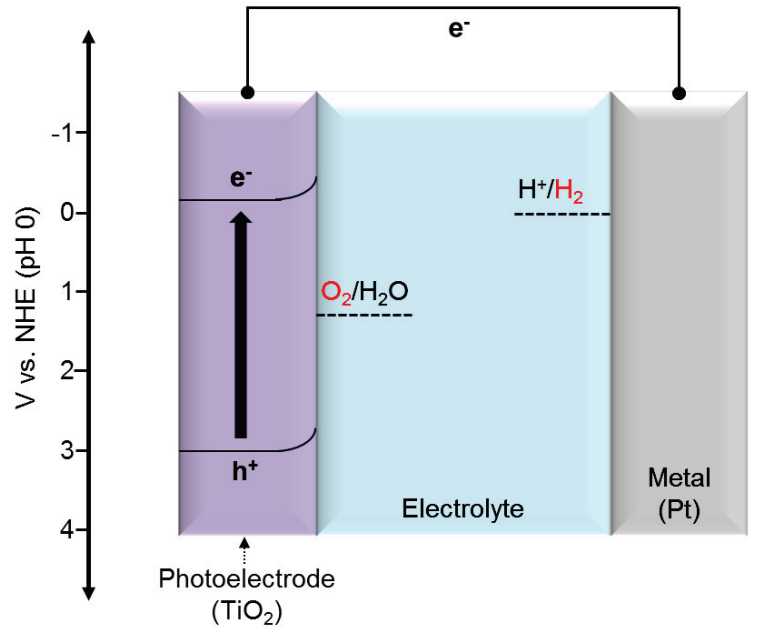

Figure 1.6. Scheme of a single photo-electrode photoelectrochemical system.

\subsubsection{A dual photo-electrode photoelectrochemical system}

Thermodynamically, the water splitting reaction requires a minimum energy of $1.23 \mathrm{eV}$. This means a photo-electrode excited by UV irradiation is typically capable of water splitting without external bias. However, UV irradiation is accounting for just $\sim 4 \%$ of the solar spectrum. In order to utilize a broader range of the solar spectrum efficiently, two or more semiconductors can be combined, in particular when these absorb photons from solar light of different energy, as shown in Figure 1.7. Small band gap semiconductors will absorb low energy photons, and wide band gap semiconductors will absorb photons of a higher energy. Figure 1.7 is a representative tandem device structure based on $\mathrm{WO}_{3}$ and a $\mathrm{Si}$ photovoltaic cell. In this thesis, $\mathrm{WO}_{3}$ was selected as photo-anode metal oxide material and $\mathrm{Si}$ was 
introduced to create a so-called tandem device or Z-scheme. The small band gap of $\mathrm{Si}$ provides absorption of low energy photons, while the photo-excited electron has sufficient energy to drive proton reduction. The photo-generated hole in $\mathrm{Si}$ can recombine with the photo-generated electron in $\mathrm{WO}_{3}$, whereas the hole generated upon photoexcitation of $\mathrm{WO}_{3}$ will be capable of oxidizing water. More detailed information about $\mathrm{WO}_{3}$ and $\mathrm{Si}$ will be provided in the next section.

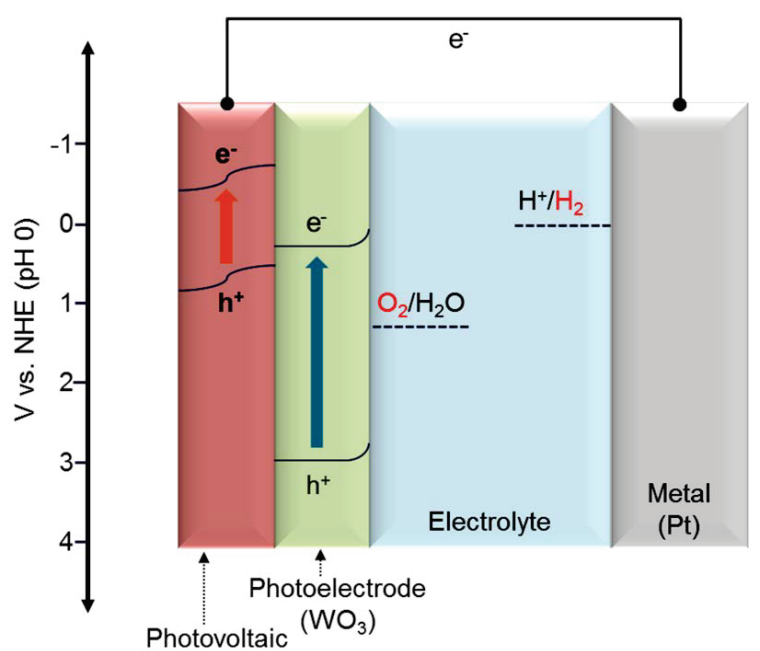

(Si)

Figure 1.7. Scheme of dual photo-electrode photoelectrochemical system.

\subsection{Semiconductors and photo-electrode materials}

\subsubsection{Tungsten oxide $\left(\mathrm{WO}_{3}\right)$ as photo-anode material}

To date, various metal oxides have been investigated as photo-anode in photoelectrochemical cells. The most common metal oxides are $\mathrm{TiO}_{2}, \mathrm{ZnO}, \mathrm{WO}_{3}, \mathrm{Fe}_{2} \mathrm{O}_{3}$, and $\mathrm{BiVO}_{4}$. Among these materials, $\mathrm{WO}_{3}$ is promising due to its long term stability in acidic aqueous conditions $(\mathrm{pH}<4)$ under illumination, and capability of absorption in the visible light region of the solar spectrum (about 12\%). In addition, $\mathrm{WO}_{3}$ has a longer hole diffusion length $(\sim 150 \mathrm{~nm})$ than other types of metal oxide materials, such as $\mathrm{Fe}_{2} \mathrm{O}_{3}(\sim 2-4 \mathrm{~nm}){ }^{20-22}$ The first demonstration of water splitting based on $\mathrm{WO}_{3}$ was reported in 1976 by Hodes. ${ }^{23}$ They showed the onset potential was around $0.6 \mathrm{~V}$ and a photocurrent density of $0.2 \mathrm{~mA} / \mathrm{cm}^{2}$ was achieved. The common limitations of $\mathrm{WO}_{3}$ as photo-electrode for water splitting are induced by the fabrication method, and include morphology control, crystallinity, charge-carrier 
separation and transport, and recombination of charge-carriers when $\mathrm{WO}_{3}$ contains defects. In addition, the band edge position of $\mathrm{WO}_{3}$ lies below the reduction potential of water (protons). The valence band edge of $\mathrm{WO}_{3}$ is positive enough for the oxidation of water. Therefore, $\mathrm{WO}_{3}$ can be merged with another types of photo-electrode materials which have a conduction band edge sufficiently negative for the reduction of water, as shown in Figure 1.7 previously.

\subsubsection{Si as photo-cathode material}

To function as a photo-cathode, the conduction band of the semiconductor needs to be positioned sufficiently negative with respect to the reduction potential of water (protons). Single crystalline phosphide materials such as $\mathrm{p}-\mathrm{GaP}$, $\mathrm{p}-\mathrm{InP}$, or $\mathrm{p}-\mathrm{GaInP}_{2}$ are promising candidates as a photo-cathode. Also, chalcogenide materials such as $\mathrm{p}-\mathrm{CuIn}{ }_{1-\mathrm{x}} \mathrm{Ga}_{\mathrm{x}} \mathrm{Se}_{2}$ or $\mathrm{p}-\mathrm{CuGaSe}_{2}$ are principally effective. However, cost and long term stability are important issues of these materials. ${ }^{24} \mathrm{Si}$ is another promising candidate, due to the earth abundance and suitable band gap energy $(1.1 \mathrm{eV})$, absorbing a large fraction of solar light. ${ }^{25}$ However, Si itself has poor stability in the photoelectrochemical reaction. To improve the performance of $\mathrm{Si}$, many studies have been reported on 1) micro/nano-structuring to increase the surface area and light absorption, 2) morphology control with doping, and 3) surface treatment to passivate Si. Based on the poor stability in aqueous conditions, protecting the surface of $\mathrm{Si}$ is an important issue. Therefore, combination of stable photo-anodes and $\mathrm{Si}$ is attractive. A frequently studied photo-anode material with high stability (in acidic conditions) is $\mathrm{WO}_{3}$. Table 1.1 shows a comparison of the photocurrent density achieved with our $\mathrm{WO}_{3} / \mathrm{Au} / \mathrm{p}^{+} \mathrm{n}$ Si tandem device to be discussed in chapter 5 , to data reported in the literature for $\mathrm{WO}_{3}$ and/or Si based photo-anode in overall water splitting. The overview is divided in anodes composed of 1$) \mathrm{WO}_{3}$ as single component, 2) $\mathrm{WO}_{3}$ in combination with other semiconductors, and 3) Si containing anodes. 
Table 1.1. Comparison of photocurrent densities reported in the literature for $\mathrm{WO}_{3}$ and/or $\mathrm{Si}$ based photo-anode in overall water splitting.

\begin{tabular}{|c|c|c|c|c|c|c|}
\hline $\begin{array}{c}\text { Device } \\
\text { structure }\end{array}$ & Materials & $\begin{array}{c}\text { Preparation } \\
\text { method }\end{array}$ & Incident light & Electrolyte & $\begin{array}{c}\text { Photocurrent } \\
\text { density }\end{array}$ & Ref \\
\hline \multirow{6}{*}{$\begin{array}{l}\text { Single } \\
\text { layer }\end{array}$} & $\begin{array}{l}\mathrm{WO}_{3} \\
(2 \mathrm{D})\end{array}$ & Electro-spray & $100 \mathrm{~mW} / \mathrm{cm}^{2}$ & $\begin{array}{c}0.5 \mathrm{M} \\
\mathrm{Na}_{2} \mathrm{SO}_{4}\end{array}$ & $\begin{array}{c}0.4 \mathrm{~mA} / \mathrm{cm}^{2} \\
\text { at } 1.2 \mathrm{~V} v s \\
\mathrm{Ag} / \mathrm{AgCl}\end{array}$ & 26 \\
\hline & $\begin{array}{l}\mathrm{WO}_{3} \\
(2 \mathrm{D})\end{array}$ & $\begin{array}{l}\text { Magnetron } \\
\text { sputtering }\end{array}$ & $\begin{array}{c}\text { Mercury-xenon } \\
\text { lamp } \\
\text { filtered light } \\
(400 \sim 700 \mathrm{~nm})\end{array}$ & $\begin{array}{c}0.5 \mathrm{M} \\
\mathrm{NaClO}_{4}\end{array}$ & $\begin{array}{c}2.5 \mathrm{~mA} / \mathrm{cm}^{2} \\
\text { at } 1 \mathrm{~V} v s \\
\mathrm{Ag} / \mathrm{AgCl}\end{array}$ & 27 \\
\hline & $\begin{array}{l}\mathrm{WO}_{3} \\
(2 \mathrm{D})\end{array}$ & $\begin{array}{c}\text { Chemical vapor } \\
\text { deposition }\end{array}$ & $45 \mathrm{~mW} / \mathrm{cm}^{2}$ & $\begin{array}{c}0.1 \mathrm{M} \\
\mathrm{Na}_{2} \mathrm{SO}_{4}\end{array}$ & $\begin{array}{c}0.4 \mathrm{~mA} / \mathrm{cm}^{2} \\
\text { at } 1 \mathrm{~V} v s . \mathrm{SCE}\end{array}$ & 28 \\
\hline & $\begin{array}{l}\mathrm{WO}_{3} \\
(2 \mathrm{D})\end{array}$ & Doctor-blade & $\begin{array}{c}500 \mathrm{~W} \text { Xe lamp } \\
\text { UV-cut-filter } \\
\lambda>390 \mathrm{~nm} \\
100 \mathrm{~mW} / \mathrm{cm}^{2}\end{array}$ & $\begin{array}{c}0.1 \mathrm{M} \\
\text { phosphate } \\
\text { solution }\end{array}$ & $\begin{array}{c}1.8 \mathrm{~mA} / \mathrm{cm}^{2} \\
\text { at } 1.0 \mathrm{~V} v s \\
\mathrm{Ag} / \mathrm{AgCl}\end{array}$ & 29 \\
\hline & $\begin{array}{l}\mathrm{WO}_{3} \\
(3 \mathrm{D})\end{array}$ & $\begin{array}{c}\text { RF sputtering } \\
\& \\
\text { anodizing }\end{array}$ & $\begin{array}{c}\text { UV-NIR } \\
\text { deuterium } \\
\text { tungsten } \\
\text { halogen source } \\
\text { (Ocean Optics) }\end{array}$ & $\begin{array}{c}0.1 \mathrm{M} \\
\mathrm{Na}_{2} \mathrm{SO}_{4}\end{array}$ & $\begin{array}{c}40 \mu \mathrm{A} / \mathrm{cm}^{2} \\
\text { (without } \\
\text { external } \\
\text { voltage) }\end{array}$ & 30 \\
\hline & $\begin{array}{l}\mathrm{WO}_{3} \\
(3 \mathrm{D})\end{array}$ & $\begin{array}{c}\text { Electro- } \\
\text { deposition }\end{array}$ & $\begin{array}{c}\text { AM } 1.5 \\
400 \mathrm{~mW} / \mathrm{cm}^{2}\end{array}$ & $\begin{array}{c}0.1 \mathrm{M} \\
\mathrm{CH}_{3} \mathrm{COONa}\end{array}$ & $\begin{array}{c}1.4 \mathrm{~mA} / \mathrm{cm}^{2} \\
\text { at } 1.0 \mathrm{~V} v s \\
\mathrm{Ag} / \mathrm{AgCl}\end{array}$ & 31 \\
\hline \multirow{5}{*}{$\begin{array}{l}\text { Combi- } \\
\text { nation }\end{array}$} & $\begin{array}{c}\mathrm{WO}_{3}-\mathrm{NRs} \\
(3 \mathrm{D})\end{array}$ & $\begin{array}{c}\text { Glancing angle } \\
\text { depostion }\end{array}$ & \multirow{3}{*}{$\begin{array}{c}\text { Solar simulator } \\
\text { (PEC-L01, } \\
\text { Peccel Co.). } \\
\text { NREL } \\
\text { calibrated } \\
\text { photodetector }\end{array}$} & \multirow{3}{*}{$\begin{array}{r}0.5 \mathrm{M} \\
\mathrm{Na}_{2} \mathrm{SO}_{4}\end{array}$} & $\begin{array}{c}0.55 \mathrm{~mA} / \mathrm{cm}^{2} \\
\text { at } 1.23 \mathrm{~V} v s . \\
\text { RHE }\end{array}$ & \multirow{3}{*}{32} \\
\hline & $\begin{array}{l}\mathrm{WO}_{3}-\mathrm{NRs} \\
/ \mathrm{BiVO}_{4}\end{array}$ & $\begin{array}{c}\text { Glancing angle } \\
\text { depostion }\end{array}$ & & & $\begin{array}{c}2.1 \mathrm{~mA} / \mathrm{cm}^{2} \\
\text { at } 1.23 \mathrm{~V} v s . \\
\text { RHE }\end{array}$ & \\
\hline & $\begin{array}{c}\mathrm{WO}_{3}-\mathrm{NRs} \\
\mathrm{BiVO}_{4} \\
+\mathrm{CoPi}\end{array}$ & $\begin{array}{c}\text { Electro- } \\
\text { deposition }\end{array}$ & & & $\begin{array}{c}3.2 \mathrm{~mA} / \mathrm{cm}^{2} \\
\text { at } 1.23 \mathrm{~V} v s . \\
\text { RHE }\end{array}$ & \\
\hline & $\begin{array}{c}\mathrm{WO}_{3} \\
\text { nanoflakes } \\
(3 \mathrm{D})\end{array}$ & Hydrothermal & \multirow{2}{*}{$\begin{array}{c}450 \mathrm{~W} \\
\text { Xe lamp, } \\
\text { AM } 1.5 \mathrm{global} \\
\text { filter } \\
100 \mathrm{~mW} / \mathrm{cm}^{2}\end{array}$} & \multirow{2}{*}{$\begin{array}{c}0.1 \mathrm{M} \\
\mathrm{Na}_{2} \mathrm{SO}_{4}\end{array}$} & $\begin{array}{c}0.69 \mathrm{~mA} / \mathrm{cm}^{2} \\
\text { at } 1.23 \mathrm{~V} v s . \\
\mathrm{RHE}\end{array}$ & \multirow{2}{*}{33} \\
\hline & $\begin{array}{c}\text { Fe-doping } \\
\mathrm{WO}_{3} \\
\text { nanoflakes }\end{array}$ & Hydrothermal & & & $\begin{array}{c}0.88 \mathrm{~mA} / \mathrm{cm}^{2} \\
\text { at } 1.23 \mathrm{~V} v s . \\
\text { RHE }\end{array}$ & \\
\hline
\end{tabular}




\begin{tabular}{|c|c|c|c|c|c|c|}
\hline \multirow{7}{*}{ Tandem } & $\begin{array}{c}\mathrm{WO}_{3} / \mathrm{W} / \mathrm{Si} \\
(2 \mathrm{D})\end{array}$ & $\begin{array}{l}\text { Magnetron } \\
\text { sputtering }\end{array}$ & $\begin{array}{c}\text { AM } 1.5 \\
100 \mathrm{~mW} / \mathrm{cm}^{2}\end{array}$ & $\begin{array}{c}0.5 \mathrm{M} \\
\mathrm{Na}_{2} \mathrm{SO}_{4}\end{array}$ & $\begin{array}{c}80 \mu \mathrm{A} / \mathrm{cm}^{2} \\
\text { at } 0.8 \mathrm{~V} v s . \\
\mathrm{SCE}\end{array}$ & 34 \\
\hline & $\begin{array}{l}\mathrm{WO}_{3} / \mathrm{Si} \\
(2 \mathrm{D})\end{array}$ & $\begin{array}{l}\text { Galvanodynamic } \\
\text { electrodeposition }\end{array}$ & $\begin{array}{c}\mathrm{AM} 1.5 \\
100 \mathrm{~mW} / \mathrm{cm}^{2}\end{array}$ & $1.0 \mathrm{M} \mathrm{HCl}$ & $\begin{array}{c}0.02 \mathrm{~mA} / \mathrm{cm}^{2} \\
\text { at } 1.0 \mathrm{~V} v s . \\
\mathrm{SCE}\end{array}$ & 35 \\
\hline & $\begin{array}{l}\mathrm{TiO}_{2} / \mathrm{Si} \\
(3 \mathrm{D})\end{array}$ & Hydrothermal & $\begin{array}{l}\text { AM } 1.5 \\
3 \text { sun }\end{array}$ & $\begin{array}{l}0.5 \mathrm{M} \\
\mathrm{H}_{2} \mathrm{SO}_{4}\end{array}$ & $\begin{array}{l}0.7 \mathrm{~mA} / \mathrm{cm}^{2} \\
\text { (without } \\
\text { external } \\
\text { voltage) }\end{array}$ & 36 \\
\hline & $\begin{array}{c}\mathrm{Fe}_{2} \mathrm{O}_{3} / \mathrm{Si} \\
(3 \mathrm{D})\end{array}$ & ALD & $\begin{array}{c}\mathrm{AM} 1.5 \\
100 \mathrm{~mW} / \mathrm{cm}^{2}\end{array}$ & $\begin{array}{l}1.0 \mathrm{M} \\
\mathrm{NaOH}\end{array}$ & $\begin{array}{c}0.6 \mathrm{~mA} / \mathrm{cm}^{2} \\
\text { at } 1 \mathrm{~V} v s . \text { RHE }\end{array}$ & 37 \\
\hline & $\begin{array}{c}\mathrm{WO}_{3} / \mathrm{ITO} / \\
\mathrm{Si} \\
(3 \mathrm{D})\end{array}$ & $\begin{array}{l}\text { Electro- } \\
\text { deposition }\end{array}$ & $\begin{array}{l}150 \mathrm{~W}, \\
\text { Xe lamp } \\
\text { AM } 1.5\end{array}$ & $\begin{array}{c}\mathrm{CH}_{3} \mathrm{CN} \\
+100 \mathrm{mM} \\
\mathrm{TBA}^{-\mathrm{HSO}_{4}}\end{array}$ & $\begin{array}{c}0.15 \mathrm{~mA} / \mathrm{cm}^{2} \\
\text { at } 1.5 \mathrm{~V} \mathrm{vs} \text {. } \\
\mathrm{Ag} / \mathrm{AgCl}\end{array}$ & 38 \\
\hline & $\begin{array}{c}\mathrm{WO}_{3} / \mathrm{ITO} / \\
\mathrm{p}^{+} \mathrm{n} \mathrm{Si} \\
(3 \mathrm{D})\end{array}$ & $\begin{array}{c}\text { Electro- } \\
\text { deposition }\end{array}$ & $\begin{array}{c}\text { Xe lamp (Oriel } \\
67005) \\
\text { AM } 1.5\end{array}$ & $1 \mathrm{M} \mathrm{H}_{2} \mathrm{SO}_{4}$ & $\begin{array}{l}0.58 \mathrm{~mA} / \mathrm{cm}^{2} \\
\text { at } 1.23 \mathrm{~V} v s . \\
\text { RHE }\end{array}$ & 39 \\
\hline & $\begin{array}{c}\mathrm{WO}_{3} / \mathrm{Au} / \\
\mathrm{p}^{+} \mathrm{nSi}(3 \mathrm{D})\end{array}$ & $\begin{array}{c}\text { Magnetron } \\
\text { sputtering }\end{array}$ & $\begin{array}{c}300 \mathrm{~W} \text { Xe lamp } \\
\text { AM } 1.5 \\
100 \mathrm{~mA} / \mathrm{cm}^{2}\end{array}$ & $\begin{array}{c}0.1 \mathrm{M} \\
\mathrm{Na}_{2} \mathrm{SO}_{4}\end{array}$ & $\begin{array}{c}1.09 \mathrm{~mA} / \mathrm{cm}^{2} \\
\text { at } 1.23 \mathrm{~V} v s . \\
\text { RHE }\end{array}$ & $\begin{array}{c}\text { Our } \\
\text { work }\end{array}$ \\
\hline
\end{tabular}

\subsection{This thesis}

In this thesis, focus is on $\mathrm{WO}_{3}$ as photo-anode in a photoelectrochemical system for overall solar water splitting. Particular attention will be paid to interfacing a $\mathrm{WO}_{3}$ film with either FTO functionalized conductive glass, to determine interfacial resistances, or Si in pillared configuration and functionalized with $\mathrm{p}^{+} \mathrm{n}$ junctions (see Figure 1.8), to evaluate the options of such tandem device to obtain high photocurrents. Interfacial materials applied include fullerene derivatives, and thin metal layers. Furthermore, we also attempted to improve light absorption of the device by adding $\mathrm{Ag} @ \mathrm{SiO}_{2}$ core-shell particles to the structures. ${ }^{40}$ In the following the contents of the respective chapters are briefly described. 


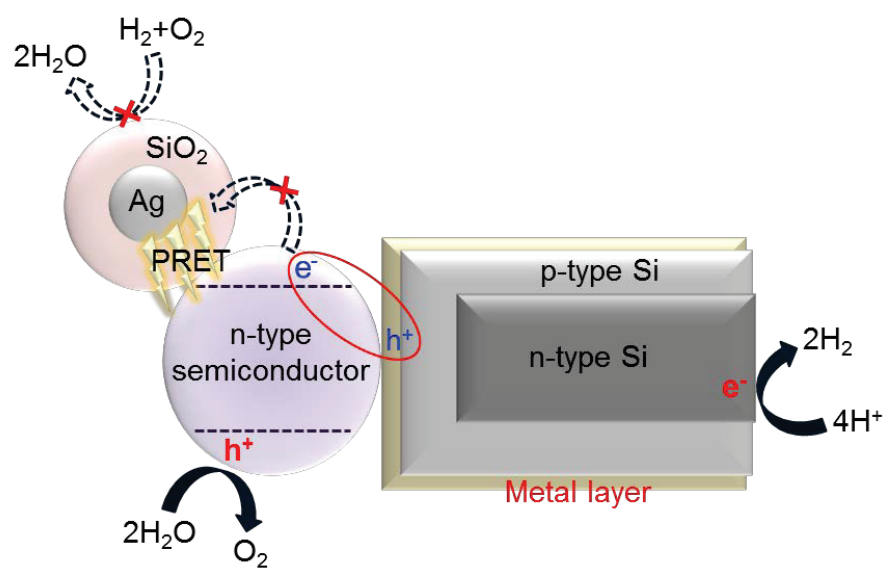

Figure 1.8. Concept of the water splitting tandem cell.

\subsubsection{Considering interfacial resistances of photoelectrochemical cells}

In scale up of photovoltaic cells, resistances have been recognized as being extremely important. However, little is known about the role of interfacial resistances in limiting achievable photocurrents in photoelectrochemical cells. In chapter 3, the resistances of a photo-anode consisting of $\mathrm{WO}_{3}$ film on FTO glass, have been evaluated. With increasing photoactive area, the measured photocurrent density decreased. Interfacial resistances will be demonstrated to be a major cause of this observation.

\subsubsection{Reduction of the interfacial resistances}

To reduce the interfacial resistances, in chapter 4 the introduction of additional material between $\mathrm{WO}_{3}$ and FTO is described. Such material should stimulate separation of photogenerated electron-hole pairs, since a long life time of charge-carriers is recognized as a dominant factor in achieving a high performance of photoelectrochemical cells. ${ }^{41,42}$ Fullerene is used as interfacial layer to reduce resistances and stimulate transport of photo-generated electrons from $\mathrm{WO}_{3}$ to FTO glass. The enhancement of charge separation by such interfacial layer is demonstrated with several analysis techniques.

\subsubsection{Integration of photo-anode and photo-cathode}

Construction of a tandem device structure based on $\mathrm{WO}_{3}$ as photo-anode and $\mathrm{p}^{+} \mathrm{n} \mathrm{Si}$ as photo-cathode is one of the strategies to fulfill the requirements for overall water splitting. In addition, Si pillars provide for a high surface area, and short diffusion length of charge- 
carries. ${ }^{43}$ Again, an efficient interface between the light absorbing materials is critical for the device to perform efficiently. ${ }^{44}$ Generally, the two materials should be connected with ohmic behavior, to prevent energy losses. In addition, the interfacial material should be transparent, to allow illumination of the 'bottom cell' material. Finally, the interfacial material should allow effective recombination of the photo-generated electrons in $\mathrm{WO}_{3}$, with the photogenerated holes of $\mathrm{p}^{+} \mathrm{n} \mathrm{Si}$. In chapter $5, \mathrm{p}^{+} \mathrm{n}$ Si micro-pillar arrays as photo-cathode, are functionalized with $\mathrm{WO}_{3}$ as photo-anode. A thin metal interfacial layer between $\mathrm{WO}_{3}$ and $\mathrm{p}^{+} \mathrm{n}$ Si micro-pillars was introduced to reduce interfacial resistance, and allow effective (desired) electron-hole recombination. Depending on the type of metal ( $\mathrm{Pt}$ or $\mathrm{Au}$ ), the device performance was different. This is correlated to the structure and chemical composition of the metal film, while plasmonic effects of Au nanoparticles will be demonstrated to stimulate light absorption in particular by Si.

\subsubsection{Application of $\mathrm{Ag} @ \mathrm{SiO}_{2}$ core-shell particles to stimulate $\mathrm{TiO}_{2}$ photocatalysis in selective photo-oxidation of organic compounds}

Based on the positive effects of the Au nanoparticles in stimulating light absorption, also the use of $\mathrm{Ag} @ \mathrm{SiO}_{2}$ core-shell particles was attempted to stimulate photocatalysis and photoelectrochemistry. The aim of the $\mathrm{SiO}_{2}$ shell was to protect $\mathrm{Ag}$ from oxidation by oxidative radicals, and to prevent $\mathrm{Ag}$ induced reduction reactions (the photo-electrons of $\mathrm{WO}_{3}$ should recombine with holes of $\mathrm{Si}$ in the device concept, see Figure 1.8). One of the important applications in photocatalysis is the selective photo-oxidation of organic compounds. In chapter 6, the effect of the $\mathrm{Ag} @ \mathrm{SiO}_{2}$ core-shell particles on activity of $\mathrm{TiO}_{2}(\mathrm{P} 25)$ as photocatalyst in the selective oxidation of methylcyclohexane is reported. Incorporation of $\mathrm{SiO}_{2}$ (TUD-1) is shown to enhance selectivity towards ketones during the oxidation reaction. However $\mathrm{Ag} @ \mathrm{SiO}_{2}$ core-shell particles did not promote activity, and instability of $\mathrm{Ag}$ towards oxidation was demonstrated.

\subsubsection{Improvement of absorption of photon into the semiconductor}

As stated previously, one of the limitations of $\mathrm{WO}_{3}$ might be ineffective light absorption. In chapter 7, addition of $\mathrm{Ag} @ \mathrm{SiO}_{2}$ core-shell particles was attempted to improve the performance of photo-electrodes based on $\mathrm{WO}_{3}$ and $\mathrm{ZnO}$. In addition, analysis of hydrogen production by Pt-loaded $\mathrm{ZnO}$ in the absence or presence of $\mathrm{Ag} @ \mathrm{SiO}_{2}$ is reported. The results show that plasmonic effects are not effective, and that the Ag core is not stable against oxidation. Oxidation curves of Ag have been observed in photoelectrochemical experiments, whereas TEM analysis demonstrates shrinkage of the $\mathrm{Ag}$ core, and redeposition of $\mathrm{Ag}$ nanoparticles on Pt-loaded $\mathrm{ZnO}$, even in a photocatalytic slurry configuration.

In the final chapter of this thesis, the results are summarized, and a perspective is provided on the use of conducting polymers as photo-electrode in photoelectrochemical cells. 


\subsection{References}

1. Taibi, E.; Gielen, D.; Bazilian, M. Renewable Sustainable Energy Rev. 2012, 16, 735-744.

2. Hernandez, R. R.; Easter, S. B.; Murphy-Mariscal, M. L.; Maestre, F. T.; Tavassoli, M.; Allen, E. B.; Barrows, C. W.; Belnap, J.; Ochoa-Hueso, R.; Ravi, S.; Allen, M. F. Renewable Sustainable Energy Rev. 2014, 29, 766-779.

3. Tsoutsos, T.; Frantzeskaki, N.; Gekas, V. Energy Policy 2005, 33, 289-296.

4. Styring, S. Ambio 2012, 41, 156-162.

5. Fujishima, A.; Honda, K. Nature 1972, 238, 37-38.

6. Nozik, A. J. Appl. Phys. Lett. 1976, 29, 150-153.

7. Khaselev, O.; Turner, J. A. Science 1998, 280, 425-427.

8. Licht, S.; Wang, B.; Mukerji, S.; Soga, T.; Umeno, M.; Tributsch, H. Int. J. Hydrogen Energy 2001, 26, 653-659.

9. Candea, R. M.; Kastner, M.; Goodman, R.; Hickok, N. J. Appl. Phys. 1976, 47, 2724-2726.

10. Reece, S. Y.; Hamel, J. A.; Sung, K.; Jarvi, T. D.; Esswein, A. J.; Pijpers, J. J. H.; Nocera, D. G. Science 2011, 334, 645-648.

11. Abdi, F. F.; Han, L.; Smets, A. H. M.; Zeman, M.; Dam, B.; van de Krol, R. Nat. Commun. 2013, 4, 1-7.

12. Brillet, J.; Yum, J.-H.; Cornuz, M.; Hisatomi, T.; Solarska, R.; Augustynski, J.; Grätzel, M.; Sivula, K. Nat. Photonics 2012, 6, 824-828.

13. Kim, J. Y.; Magesh, G.; Youn, D. H.; Jang, J.-W.; Kubota, J.; Domen, K.; Lee, J. S. Sci. Rep. 2013, 3, 1-8.

14. Bignozzi, C. A.; Caramori, S.; Cristino, V.; Argazzi, R.; Meda, L.; Tacca, A. Chem. Soc. Rev. 2013, 42, 2228-2246.

15. Nozik, A. J.; Memming, R. J. Phys. Chem. 1996, 100, 13061-13078.

16. Peter, L. M.; Wijayantha, K. G. U. ChemPhysChem 2014, 15, 1983-1995.

17. Walter, M. G.; Warren, E. L.; McKone, J. R.; Boettcher, S. W.; Mi, Q.; Santori, E. A.; Lewis, N. S. Chem. Rev. 2010, 110, 6446-6473.

18. Kudo, A.; Miseki, Y. Chem. Soc. Rev. 2009, 38, 253-278.

19. Yang, L.; Zhou, H.; Fan, T.; Zhang, D. Phys. Chem. Chem. Phys. 2014, 16, 6810-6826.

20. Liu, X.; Wang, F.; Wang, Q. Phys. Chem. Chem. Phys. 2012, 14, 7894-7911.

21. Zhu, T.; Chong, M. N.; Chan, E. S. ChemSusChem 2014, 7, 2974-2997.

22. Valdés, Á.; Kroes, G. -J. J. Chem. Phys. 2009, 130, 114701.

23. Hodes, G.; Cahen, D.; Manassen, J. Nature 1976, 260, 312-313.

24. Prevot, M. S.; Sivula, K. J. Phys. Chem. C 2013, 117, 17879-17893.

25. Spurgeon, J. M.; Walter, M. G.; Zhou, J.; Kohl, P. A.; Lewis, N. S. Energy Environ. Sci. 2011, 4, 1772-1780.

26. Ghimbeu, C. M.; van Landschoot, R. C.; Schoonman, J.; Lumbreras, M. Thin Solid Films 2007, 515, 5498-5504.

27. Vidyarthi, V. S.; Hofmann, M.; Sayan, A.; Sliozberg, K.; Kőnig, D.; Beranek, R.; Schuhmann, W.; Ludwig, A. Int. J. Hydrogen Energy 2011, 36, 4724-4731. 
28. Jiao, Z.; Wang, J.; Ke, L.; Sun, X. W.; Demir, H. V. ACS Appl. Mater. Interfaces 2011, 3, 229-236.

29. Zhang, X.; Chandra, D.; Kajita, M.; Takahashi, H.; Dong, L.; Shoji, A.; Saito, K.; Yui, T.; Yagi, M. Int. J. Hydrogen Energy 2014, 39, 20736-20743.

30. Zheng, H.; Sadek, A. Z.; Latham, K.; Kalantar-Zadeh, K. Electrochem. Commun. 2009, 11, 768-771.

31. Hill, J. C.; Choi, K.-S. J. Phys. Chem. C 2012, 116, 7612-7620.

32. Pihosh, Y.; Turkevych, I.; Mawatari, K.; Asai, T.; Hisatomi, T.; Uemura, J.; Tosa, M.; Shimamura, K.; Kubota, J.; Domen, K.; Kitamori, T. Small 2014, 10, 3692-3699.

33. Zhang, T.; Zhu, Z.; Chen, H.; Bai, Y.; Xiao, S.; Zheng, X.; Xue, Q.; Yang, S. Nanoscale 2015, 7, 2933-2940.

34. Xing, Z.; Shen, S.; Wang, M.; Ren, F.; Liu, Y.; Zheng, X.; Liu, Y.; Xiao, X.; Wu, W.; Jiang, C. Appl. Phys. Lett. 2014, 105, 143902.

35. Coridan, R. H.; Shaner, M.; Wiggenhorn, C.; Brunschwig, B. S.; Lewis, N. S. J. Phys. Chem. C 2013, 117, 6949-6957.

36. Liu, C.; Tang, J.; Chen, H. M.; Liu, B.; Yang, P. Nano Lett. 2013, 13, 2989-2992.

37. Mayer, M. T.; Du, C.; Wang, D. J. Am. Chem. Soc. 2012, 134, 12406-12409.

38. Coridan, R. H.; Arpin, K. A.; Brunschwig, B. S.; Braun, P. V.; Lewis, N. S. Nano Lett. 2014, 14, 2310-2317.

39. Shaner, M. R.; Fountaine, K. T.; Ardo, S.; Coridan, R. H.; Atwater, H. A.; Lewis, N. S. Energy Environ. Sci. 2014, 7, 779-790.

40. Hisatomi, T.; Kubota, J.; Domen, K. Chem. Soc. Rev. 2014, 43, 7520-7535.

41. Cowan, A. J.; Durrant, J. R. Chem. Soc. Rev. 2013, 42, 2281-2293.

42. Moniz, S. J. A.; Shevlin, S. A.; Martin, D. J.; Guo, Z.-X.; Tang, J. Energy Environ. Sci. 2015, 8, 731-759.

43. Ronge, J.; Bosserez, T.; Martel, D.; Nervi, C.; Boarino, L.; Taulelle, F.; Decher, G.; Bordiga, S.; Martens, J. A. Chem. Soc. Rev. 2014, 43, 7963-7981.

44. Cox, C. R.; Winkler, M. T.; Pijpers, J. J. H.; Buonassisi, T.; Nocera, D. G. Energy Environ. Sci. 2013, 6, 532-538. 


\section{Chapter 2}

Characterization of photoelectrochemical cells

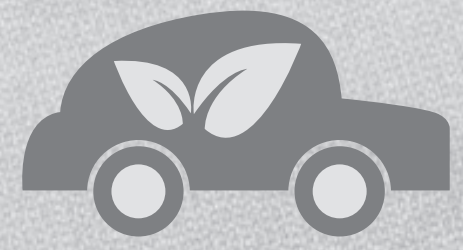




\section{Abstract}

This chapter describes a set-up and reactor that were used to characterize photoelectrochemical cells in this thesis. 


\subsection{Solar simulator}

In the solar energy research field, the critical parameter for measurement of device performance is the standard condition of simulated solar light intensity. This is usually referred to as 1 sun at air mass 1.5 global (AM $1.5 \mathrm{G}$ ), and amounts to $100 \mathrm{~mW} / \mathrm{cm}^{2}$. Generally, the characteristics (e.g., photocurrent or photovoltage) of devices are determined by solar light intensity. ${ }^{1-8}$ Therefore, the accurate control of simulated solar light is crucial to evaluate sample performance in solar energy research. ${ }^{9}$ Accurate measurement is also necessary to compare performance of photo-electrodes in photoelectrochemical cell configurations. In this thesis, a set-up was used for photoelectrochemical measurements, assembled by optical components and filters provided by the company Newport. Detailed specifications of each component are shown in the Table 2.1 .

Table 2.1. Specification of each component.

\begin{tabular}{ll}
\hline Specifications & \\
\hline Light source & $300 \mathrm{~W}$ Xe ozone free lamp \\
& Air mass 1.5 global filter \\
& $309 \mathrm{~nm}$ cut-off $(325-2700 \mathrm{~nm}$ transmittance range) \\
Filter & $570 \mathrm{~nm}$ cut-off $(580-2750 \mathrm{~nm}$ transmittance range) \\
& Motorized filter wheel $25.4 \mathrm{~mm}$ diameter (for cut-off filter) \\
Filter wheel & Electronic shutter \\
Shutter & Fused silica window cornerstone \\
Monoch $2601 / 4 \mathrm{~m}$ \\
& GRAT 1200L/MM 350RBLZ 260i \\
& GRAT 1200L/MM 750RBLZ 260i \\
& Mirror for CS260 \\
\hline
\end{tabular}

With the asssembled set-up, it is possible to measure photocurrents under white light illumination, or with monochromatic light, by controlling the direction of light with mirrors and gratings located inside the monochromator housing. The assembled set-up is shown in Figure 2.1. 


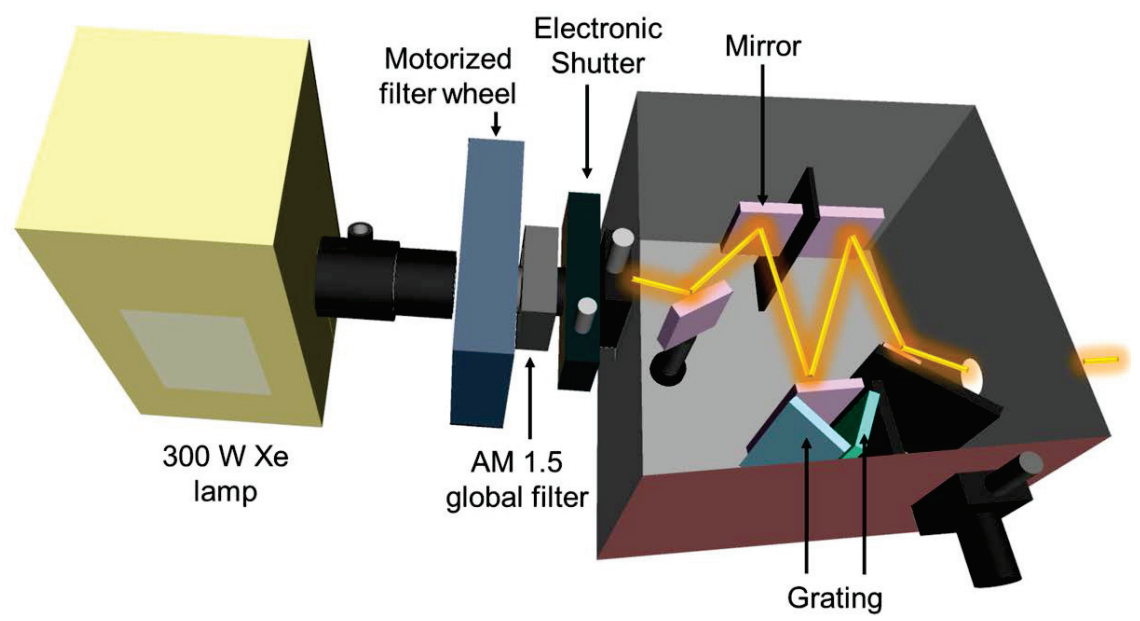

Figure 2.1. White light path way to measure a photoelectrochemical cell under 1 sun condition. Note that the light is exposed to the mirror.

Integrated light (white light) can be reflected against mirrors in a lateral direction. The integrated light intensity can be confirmed to be standard 1 sun illumination conditions, by using a reference $\mathrm{Si}$ solar cell $(2 \times 2 \mathrm{~cm})$. The reference cell made of monocrystalline $\mathrm{Si}$ displays light intensity in 'sun' units: 1 sun represents $100 \mathrm{~mW} / \mathrm{cm}^{2}$ at $25{ }^{\circ} \mathrm{C}$ and using the AM 1.5 filter. A shutter is used to chop the light during the measurement of a photoelectrochemical cell, allowing so-called chronoamperometry experiments. The shutter was controlled by a home-made lab view program.

A potentiostat is used to control the potential applied to the electrodes of the photoelectrochemical cell and to measure the performance of the photo-electrodes.

The light response of a photo-electrode can also be measured by varying wavelength of the light. Then, white light can be exposed to a grating, as shown in Figure 2.2. Obviously, the light intensity is lower than in the case of white light. The desired wavelength is set by rotating the grating. The grating is controlled by a home-made lab view program. The beam intensity through the monochromator was measured with a calibrated UV Si detector (300$1000 \mathrm{~nm}, 1 \times 1 \mathrm{~cm}$ square) and optical power/energy meter. 


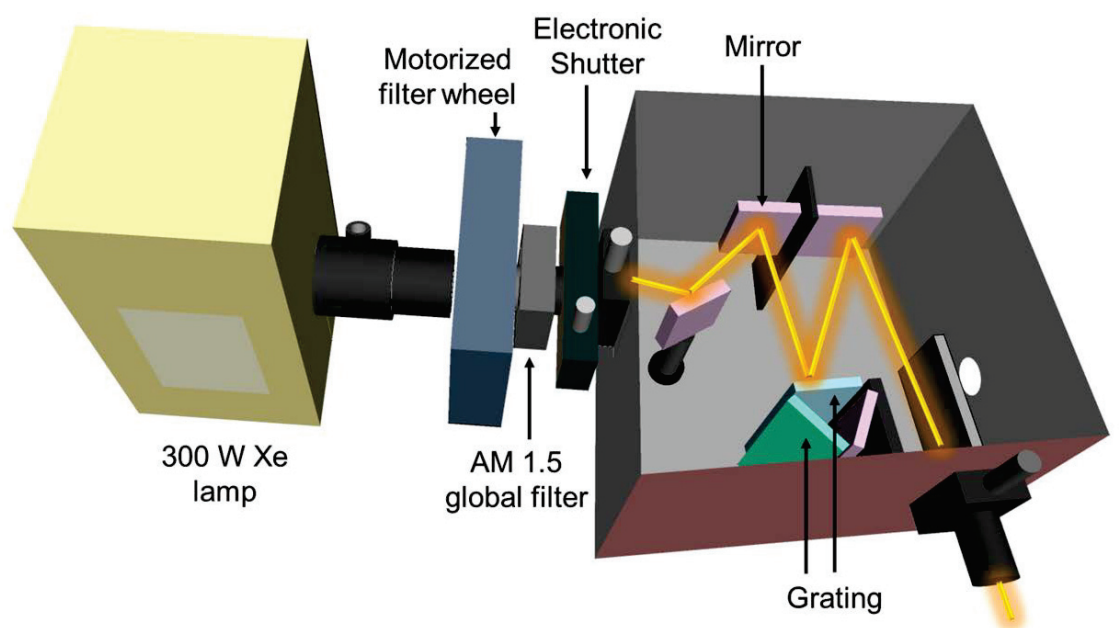

Figure 2.2. Monochromatic light path way to measure a photoelectrochemical cell under a desired wavelength of light.

Figure 2.3 shows the measured power spectrum as a function of wavelength. This spectrum was obtained with light sent through the monochromator, and using a UV Si detector to measure the power of light.

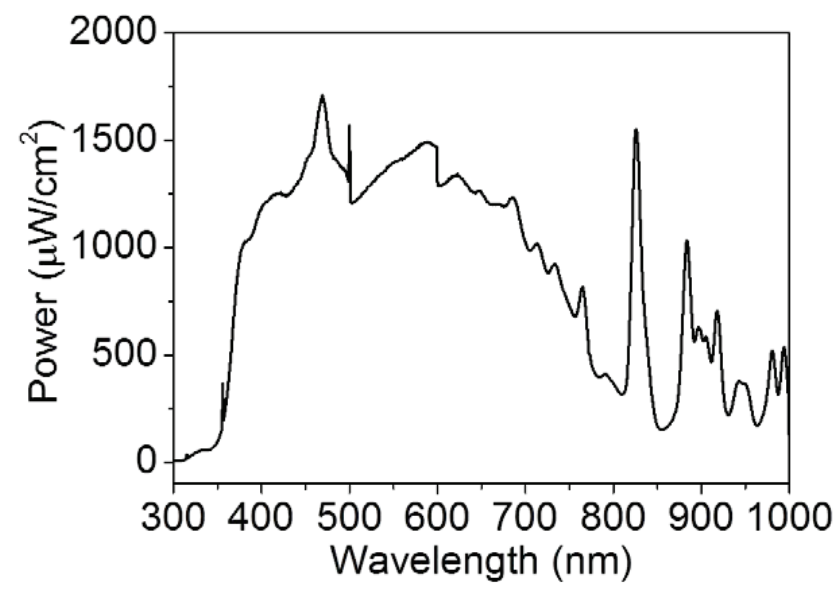

Figure 2.3. The power spectrum of the solar simulator as a function of wavelength. 
Figure 2.4 shows the current density of a $\mathrm{WO}_{3}$ film on FTO as a function of (white) light intensity. The current density obviously increases linearly with light intensity for the $\mathrm{WO}_{3}$ film at $1.23 \mathrm{~V} v s$. RHE, revealing light intensity is an important factor determining cell performance. In this thesis, experiments were performed under 1 sun conditions.
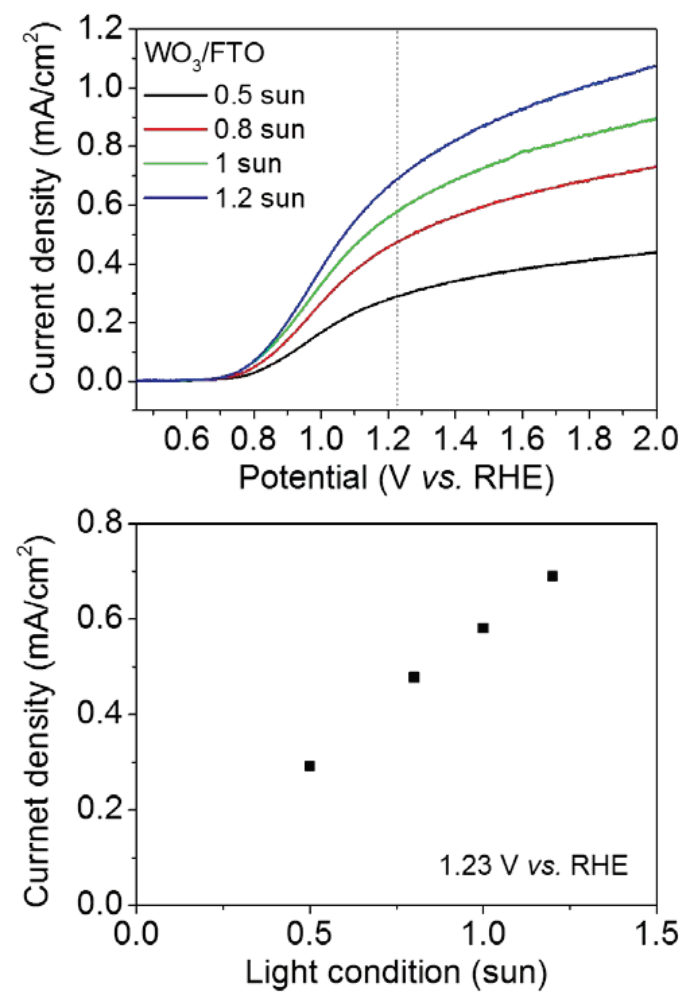

Figure 2.4. (a) LSV curves for $\mathrm{WO}_{3}$ films with variable light intensity. (b) Current density increases linearly with light intensity for the $\mathrm{WO}_{3}$ film at $1.23 \mathrm{~V} v s$. RHE. 


\subsection{Photoelectrochemical reactor}

A photoelectrochemical reactor (ZAHNER, PECC-2) was used to characterize the photoelectrodes. A detailed specification of each component of the cell is shown in Table 2.2.

Table 2.2. Specification of the reactor of ZAHNER, type PECC-2.

\begin{tabular}{ll}
\hline Specifications & \\
\hline Physical dimensions $(\mathrm{W} \times \mathrm{D} \times \mathrm{H})$ & $6 \times 2.5 \times 8 \mathrm{~cm}$ \\
Optical window diameter & $1.8 \mathrm{~cm}$ \\
Optical window material & Quartz \\
Sample diameter & $1.8 \mathrm{~cm}$ \\
Electrolyte volume & $7.2 \mathrm{~cm}^{3}$ \\
Light path length in electrolyte & $1.8 \mathrm{~cm}$ \\
Solid material & $\mathrm{Kel}-\mathrm{F}(\mathrm{PCTFE})$ \\
Reference electrode & $\mathrm{Ag} / \mathrm{AgCl}$ \\
Counter electrode & $\mathrm{Pt}$ coil \\
Working electrode & Solid and transparent \\
Gas inlet/outlet & Yes \\
\hline
\end{tabular}

Figure 2.5 shows a scheme of the reactor from the front and back side. The reactor body has good chemical stability in a broad $\mathrm{pH}$ range of aqueous electrolyte. The window material in the reactor is made of quartz glass to allow transmission from the UV to the IR region. Pt is used as counter electrode and is tightened to the top of the reactor with a connector. Pt coil faces the photo-electrode (as working electrode) symmetrically. $\mathrm{Ag} / \mathrm{AgCl}$ is used as reference electrode ( $3 \mathrm{M} \mathrm{NaCl}, \mathrm{BASi})$ which is located on the top of the reactor, held by a screw and oring.

All of the results in this thesis are shown with reference to the RHE (reversible hydrogen electrode). The measured potential against the $\mathrm{Ag} / \mathrm{AgCl}$ electrode can be converted to the RHE with the following equation:

$$
\mathrm{E}_{\mathrm{RHE}}=\mathrm{E}_{\mathrm{Ag} / \mathrm{AgCl}}+\mathrm{E}_{\mathrm{Ag} / \mathrm{AgCl} \text { vs. } \mathrm{SHE}}^{\mathrm{o}}+0.059 \times \mathrm{pH}
$$

$\mathrm{E}^{\mathrm{o}} \mathrm{Ag} / \mathrm{AgCl}$ vs. SHE is the potential of the $\mathrm{Ag} / \mathrm{AgCl}$ electrode against the standard hydrogen electrode (SHE). 
The photo-electrode (working electrode) is mounted with aid of a detachable aluminum holder, which is connected to the housing of the reactor with screws. Samples based on a transparent conducting oxide substrate, are electrically connected to a potentiostat by an $\mathrm{Al}$ mesh (or $\mathrm{Cu}$ plate). Front and back-side illumination is possible with the reactor. In case of non-transparent samples (e.g., Si), the back-side of the conducting electrode is directly connected to the Al holder with screws.

The sample surface is pressed on an o-ring to prevent leakage of electrolyte. This also ensures that the illuminated and contact area with electrolyte are the same for each sample. For each photo-electrode, the electrolyte should be selected with caution to prevent corrosion. In the reactor, three-electrodes (working electrode, counter electrode and reference electrode) are fixed in exactly the same position, allowing accurate comparison of the performance of all of the photo-electrodes.

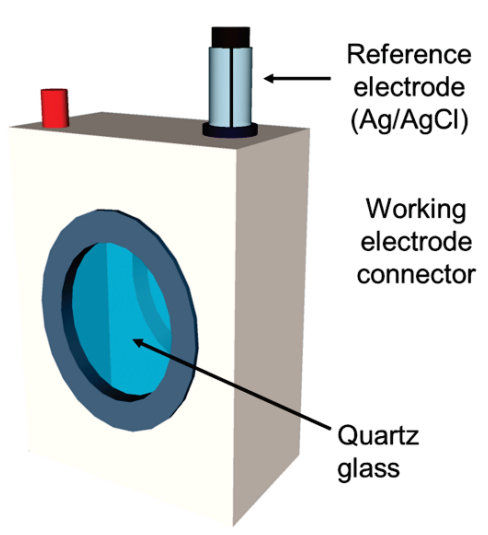

Front-side of reactor

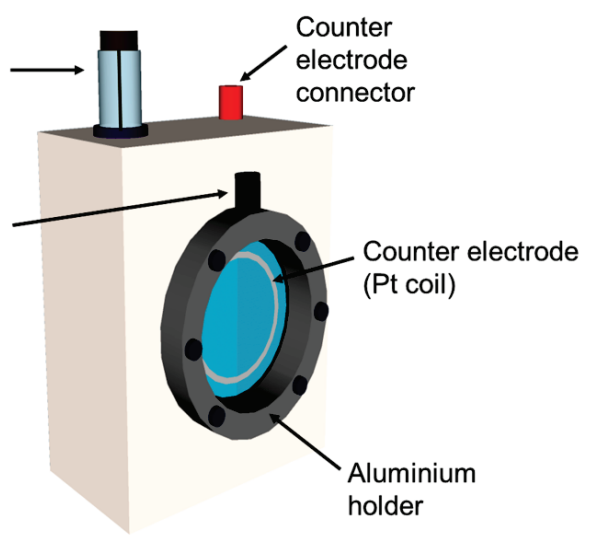

Back-side of reactor

Figure 2.5. Scheme of the reactor (a) front-side, (b) back-side.

The commercial reactor has the disadvantage that photo-electrode substrates smaller than $1.8 \mathrm{~cm}$ diameter cannot be easily measured. Therefore, new working electrode mounting holders for various photoactive sizes of diameters of $0.5,1.0,1.14$, and $1.4 \mathrm{~cm}$ were developed allowing sample testing without additional wire connections or masking processes. The dimensions of the holders are shown in Figure 2.6. O-rings are used to mount the photoelectrode on the mounting holders. 


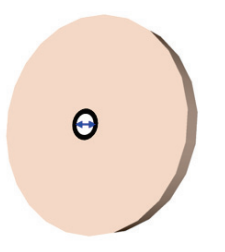

$\mathrm{d}=0.5 \mathrm{~cm}$

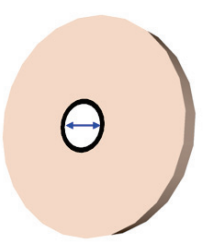

$\mathrm{d}=1.0 \mathrm{~cm}$

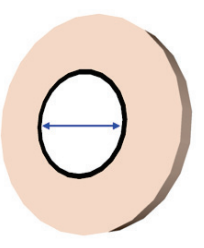

$\mathrm{d}=1.14 \mathrm{~cm}$

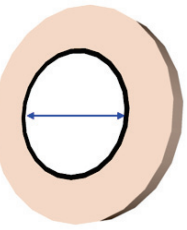

$\mathrm{d}=1.4 \mathrm{~cm}$

Figure 2.6. Photo-electrode mounting holders with different diameters to vary the photoactive size.

Figure 2.7 shows the assembly steps with an extra home-made mounting holder for the working electrode. The photoactive area of the photo-electrode can be varied in light exposed area and exposed to the electrolyte for reaction. The Al holder screwed onto the housing of the cell, holds the photo-electrode and home-made mounting holder in place. In case of standard size $(\mathrm{d}=1.8 \mathrm{~cm})$ measurements, obviously the home-made mounting holder was omitted. Specifically, in chapter 3, the effect of the size of the photoactive area on photocurrent was accurately investigated with the home-made photo-electrode mounting holders.

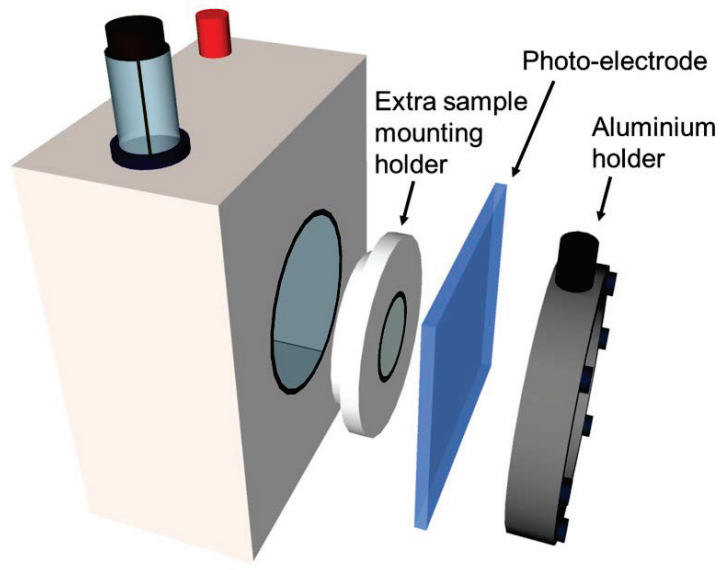

Figure 2.7. Mounting of the photo-electrode in the reactor.

In this thesis, the solar simulator and photoelectrochemical reactor were mainly used to characterize $\mathrm{WO}_{3}$ based photo-anodes (chapters 3, 4, 5, and 7). The specifically applied experimental procedures will be described in each chapter separately. 


\subsection{References}

1. Sun, K.; Shen, S.; Cheung, J. S.; Pang, X.; Park, N.; Zhou, J.; Hu, Y.; Sun, Z.; Noh, S. Y.; Riley, C. T.; Yu, P. K. L.; Jin, S.; Wang, D. Phys. Chem. Chem. Phys. 2014, 16, 46124625.

2. Kim, H.-S.; Lee, C.-R.; Im, J.-H.; Lee, K.-B.; Moehl, T.; Marchioro, A.; Moon, S.-J.; Humphry-Baker, R.; Yum, J.-H.; Moser, J. E.; Grätzel, M.; Park, N.-G. Sci. Rep. 2012, 2 , $1-7$.

3. Li, L.; Auer, E.; Liao, M.; Fang, X.; Zhai, T.; Gautam, U. K.; Lugstein, A.; Koide, Y.; Bando, Y.; Golberg, D. Nanoscale 2011, 3, 1120-1126.

4. Li, Y.; Xu, C.-Y.; Wang, J.-Y.; Zhen, L. Sci. Rep. 2014, 4, 1-8.

5. Xiang, D.; Han, C.; Zhang, J.; Chen, W. Sci. Rep. 2014, 4, 1-6.

6. Xie, C.; Luo, L.-B.; Zeng, L.-H.; Zhu, L.; Chen, J.-J.; Nie, B.; Hu, J.-G.; Li, Q.; Wu, C.-Y.; Wang, L.; Jie, J.-S. CrystEngComm 2012, 14, 7222-7228.

7. You, J.; Dou, L.; Yoshimura, K.; Kato, T.; Ohya, K.; Moriarty, T.; Emery, K.; Chen, C.C.; Gao, J.; Li, G.; Yang, Y. Nat. Commun. 2013, 4, 1-10.

8. Yum, J.-H.; Holcombe, T. W.; Kim, Y.; Rakstys, K.; Moehl, T.; Teuscher, J.; Delcamp, J. H.; Nazeeruddin, M. K.; Grätzel, M. Sci. Rep. 2013, 3, 1-8.

9. Chen, Z.; Jaramillo, T. F.; Deutsch, T. G.; Kleiman-Shwarsctein, A.; Forman, A. J.; Gaillard, N.; Garland, R.; Takanabe, K.; Heske, C.; Sunkara, M.; McFarland, E. W.; Domen, K.; Miller, E. L.; Turner, J. A.; Dinh, H. N. J. Mater. Res. 2010, 25, 3-16. 


\section{Chapter 3}

Size-dependent electrochemical characteristics of photoelectrochemical cells

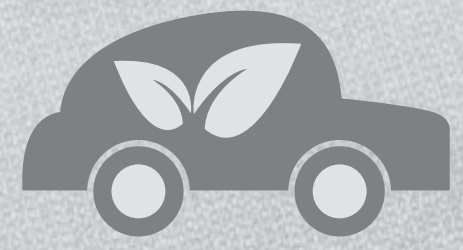

This chapter has been submitted: S.-Y. Park, E.M. Hong, J.-Y. Lee, D.C. Lim,

G. Mul, Size-dependent electrochemical characteristics of photoelectrochemical cells. 


\begin{abstract}
We demonstrate that the experimentally obtained photocurrent density $\left(\mathrm{mA} / \mathrm{cm}^{2}\right)$ of a $\mathrm{WO}_{3}$ based photoelectrochemical (PEC) cell decreases as a function of increasing photoactive area. This trend is predominantly caused by a non-linear decrease in resistance of the interface between the conducting FTO electrode and the photoactive material $\left(\mathrm{WO}_{3}\right)$, as determined by electrochemical impedance spectroscopy. In agreement with this observation is that the relatively high interfacial resistance of large area electrodes can be reduced by introduction of conductive layers, as evident from improved photocurrents obtained for relatively large, $\mathrm{C}_{70}$ modified $\mathrm{WO}_{3}$ photo-electrodes. It is recommended that photocurrent densities reported in the literature are considered with caution, in particular when upscaling and practical application of PEC cells is aimed for.
\end{abstract}




\subsection{Introduction}

Production of hydrogen by water splitting is one of the most promising solutions to mitigate the problems associated with intermittency in solar electricity production. ${ }^{1-3} \mathrm{~A}$ photoelectrochemical (PEC) cell is a well-known device to achieve water splitting by conversion of solar energy. However, to construct economically attractive PEC cells, several challenges have to be addressed. In particular improvement of the solar to hydrogen efficiency (STH) is necessary. Common strategies to enhance the overall solar to hydrogen efficiency of PEC cells include 1) increasing the photon absorption efficiency, 2) improving photo-generated charge separation, and 3) enhancing electrochemical rates by modifying the surface of the photo-electrodes with effective catalysts. Another challenge lies in the improvement of the stability and lifetime of various photoactive materials, which has been achieved by e.g. surface passivation. ${ }^{4-10}$ What has been less frequently addressed in the literature, is the scalability of a PEC cell. In particular, PEC cells with a relatively large photoactive area need to be developed, to realize commercial application of solar energy to hydrogen converters. Significant size dependent effects on photocurrent densities can be expected, since increasing power density losses have been frequently reported for photovoltaic (PV) cells when scaled-up. These are typically assigned to sheet resistances of transparent conductors, such as indium tin oxide (ITO), or their best substitutes. ${ }^{11-14}$ In the present study we report on the effect of size of the photoactive area of a $\mathrm{WO}_{3} / \mathrm{FTO}$ (fluorinedoped tin oxide) photo-anode on the photocurrent density obtained, and provide explanations for the trend observed.

\subsection{Experimental section}

\subsubsection{Preparation of $\mathrm{WO}_{3}$ film as photo-anode}

The preparation of the $\mathrm{WO}_{3}$ photo-anode was performed as follows. First a $\mathrm{WO}_{3}$ precursor solution was prepared, by dissolving $1.14 \mathrm{~g}$ of tungsten hexachloride (Sigma Aldrich) in 20 $\mathrm{mL}$ of ethanol in an inert atmosphere. It took several days to dissolve the $\mathrm{WCl}_{6}$ salt accompanied by the disappearance of the original blue colour, finally resulting in a transparent colourless liquid. The possible reaction path for the dissolution of tungsten hexachloride in ethanol is described elsewhere. ${ }^{15}$ For the preparation of the $\mathrm{WO}_{3}$ film, the $\mathrm{WO}_{3}$ precursor solution was spin coated on fluorine-doped tin oxide glass (FTO; a thickness of $\sim 600 \mathrm{~nm}, 16 \Omega / \mathrm{cm}^{2}$ ) at $600 \mathrm{rpm}$ for $30 \mathrm{sec}$. After spin coating, the glass was heated on a hot plate at $100{ }^{\circ} \mathrm{C}$ for $1 \mathrm{~min}$, and cooled. This process was repeated three consecutive times to create $\mathrm{WO}_{3}$ films with a thickness of $\sim 300 \mathrm{~nm}$. Finally the samples were heated in a calcination oven at $500{ }^{\circ} \mathrm{C}$ for $2 \mathrm{hr}$ in static air. The preparation procedure and detailed characterization of the electrodes containing the graphitized $\mathrm{C}_{70}$ interfacial layer can be found elsewhere (chapter 4). ${ }^{16}$ 


\subsubsection{Analysis of the samples}

The $\mathrm{WO}_{3}$ film was analysed using a field emission scanning electron microscope (FE-SEM, Zeiss LEO 1550). The crystal structure of the samples was determined in air by X-ray diffraction (XRD, Bruker D2 phaser).

\subsubsection{Determination of photocurrent densities}

The photoelectrochemical properties of the photo-electrodes were determined in an aqueous electrolyte solution containing $0.05,0.1,0.5$, or $1 \mathrm{M}$ of sodium sulfate $(\mathrm{pH} \sim 3.5$, Sigma Aldrich). Sulfuric acid (95-97\%, Sigma Aldrich) were used to adjust the $\mathrm{pH}$. The potential of the working electrode was controlled by a potentiostat (VERSASTAT 4, Princeton applied research). In three-electrode measurements, a Pt wire and a $\mathrm{Ag} / \mathrm{AgCl}$ electrode ( $3 \mathrm{M} \mathrm{NaCl}, \mathrm{BASi})$ were used as the counter and reference electrode, respectively. The photoactive area was defined by a mask of variable sizes, positioned in front of the $\mathrm{WO}_{3}$ film, creating areas of respectively $0.19,1.02,1.53$, and $2.54 \mathrm{~cm}^{2}$. An O-ring was pressed against the $\mathrm{WO}_{3}$ film to prevent contact of unexposed $\mathrm{WO}_{3}$ with the electrolyte. This ensures that the illuminated and contact area with the electrolyte are same for each sample. Photocurrents were measured by illumination with an AM 1.5 solar simulator $\left(100 \mathrm{~mW} / \mathrm{cm}^{2}\right)$, equipped with a $300 \mathrm{Xe}$ lamp, and an air mass 1.5 global filter. The intensity of the simulated sunlight was calibrated using a standard reference Si solar cell.

\subsubsection{Measurement of Resistances in the photoelectrochemical cell}

Electrochemical impedance spectroscopy (EIS) was conducted in a 1.0 M sodium sulfate aqueous solution at stepped potentials of $+0.80 \mathrm{~V}$ ( vs. SCE) while exposing the electrodes to AM 1.5 solar illumination $\left(100 \mathrm{~mW} / \mathrm{cm}^{2}\right)$ illumination, using a BUNKOUKEIKI Co., Ltd. Modem BS-520BK spectrometer with a Si photodiode detector. The potential was controlled by a potentiostat (VERSASTAT 4, Princeton applied research).

Electrical properties (resistivity and carrier concentration) were also measured by determination of the Hall effect (MODUSYS, PS-OT70 apparatus). For this measurement, the photoactive area was defined exactly by using a patterned $\mathrm{Al}$ shadow mask, and Ag paste to make 4 contact points. A 4-probe pin was positioned on a $\mathrm{Ag}$ contact before the measurements. 


\subsection{Results and discussion}

\subsubsection{Schematic concept and characteristic of photo-anode film}

Figure 3.1a shows the schematic concept of the photoelectrochemical cell configuration used in this study, highlighting the various electrolyte $/ \mathrm{WO}_{3} / \mathrm{FTO}$ interfaces and accompanying resistances. Four different types of resistance can be identified, including 1) the $\mathrm{WO}_{3}$ llelectrolyte resistance $\left.\left(\mathrm{R}_{1}\right), 2\right)$ the resistance of the $\mathrm{WO}_{3}$ film $\left.\left(\mathrm{R}_{2}\right), 3\right)$ the resistance of the $\mathrm{WO}_{3}$ IFTO interface $\left(\mathrm{R}_{3}\right)$, and 4$)$ the internal resistance of the FTO $\left(\mathrm{R}_{\mathrm{FTO}}\right)\left(\mathrm{R}_{4}\right)$. The field emission scanning electron micrograph of the $\mathrm{WO}_{3} \| \mathrm{FTO}$ interface is shown in Figure 3.1b. The FTO layer consists of densely packed crystals of sizes in the range of 200-500 nm, whereas the $\mathrm{WO}_{3}$ film is composed of crystals of similar sizes, with somewhat higher porosity. The $\mathrm{WO}_{3}$ layer thickness is estimated to be around $300 \mathrm{~nm}$. The crystalline $\mathrm{WO}_{3}$ film consists of the monoclinic phase (JCPDF 83-0951), as determined by X-ray diffraction (Figure 3.1c). 
(a)

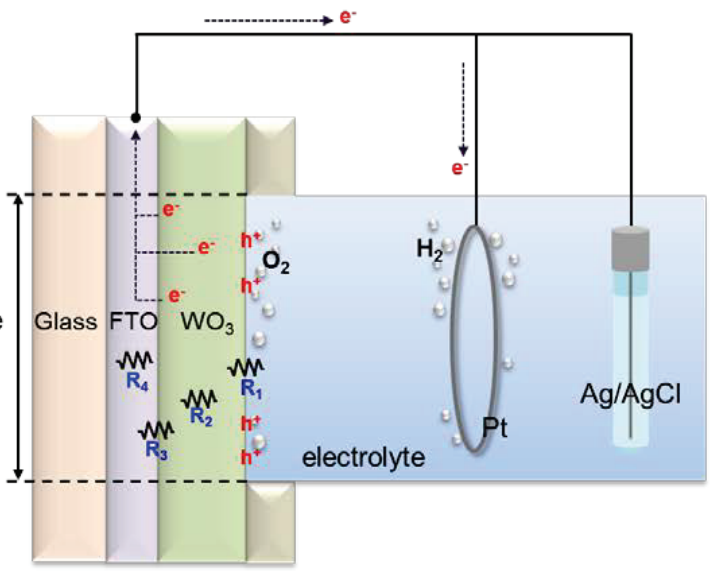

(b)

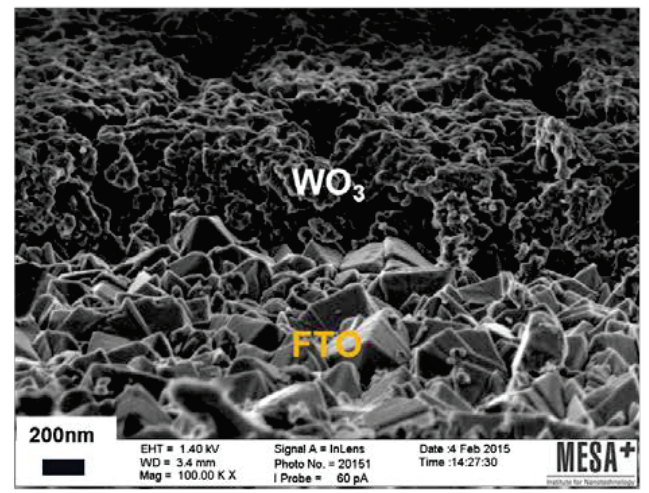

(c)

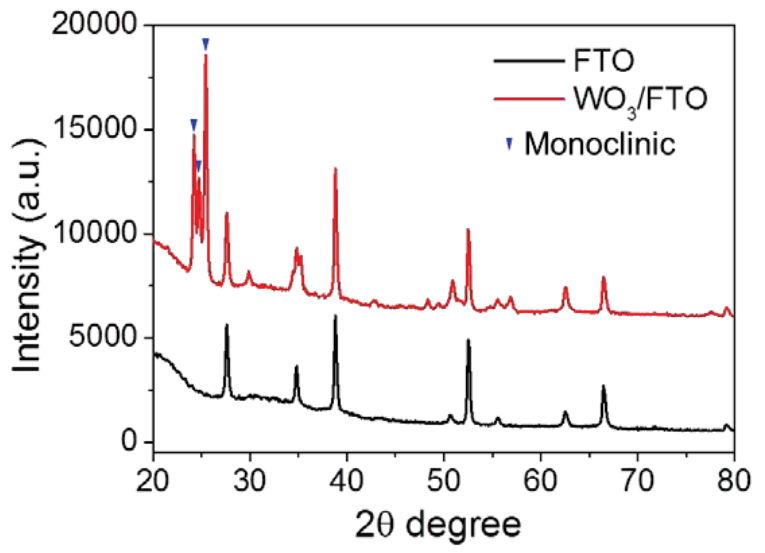

Figure 3.1. (a) Schematic illustration of the photoelectrochemical cell and definition of the photoactive area, (b) Cross sectional SEM image of the $\mathrm{WO}_{3} / \mathrm{FTO}$ film, and (c) XRD patterns of FTO and $\mathrm{WO}_{3} / \mathrm{FTO}$, by which the monoclinic phase of $\mathrm{WO}_{3}$ can be identified. 
3.3.2 Photocurrent characteristic depending on photoactive area and electrolyte concentration

Figures 3.2a-d show for variable electrolyte concentration ranging from 0.05 to $1.0 \mathrm{M}$ that the current density achieved with the $\mathrm{WO}_{3}$ film decreases as a function of increasing exposed photoactive area. The decrease is quite significant, and typically varies by a factor of $\sim 1.5$ between the most effective measurement with less than $1 \mathrm{~cm}^{2}$ photoactive area exposed, and the least effective measurement with the largest area exposed $\left(2.54 \mathrm{~cm}^{2}\right)$. Furthermore, increasing the electrolyte concentration (increasing from 0.05 to $1 \mathrm{M}$ ) results in a moderate increase in photocurrent density, as shown for the $1.02 \mathrm{~cm}^{2}$ sample in Figure 3.2e, suggesting the electrolyte- $\mathrm{WO}_{3}$ interface is not the main resistance causing the absence of scalability of the $\mathrm{WO}_{3}$ based photo-anodes. Still, it is recommended to use a relatively high electrolyte concentration to minimize this resistance. 

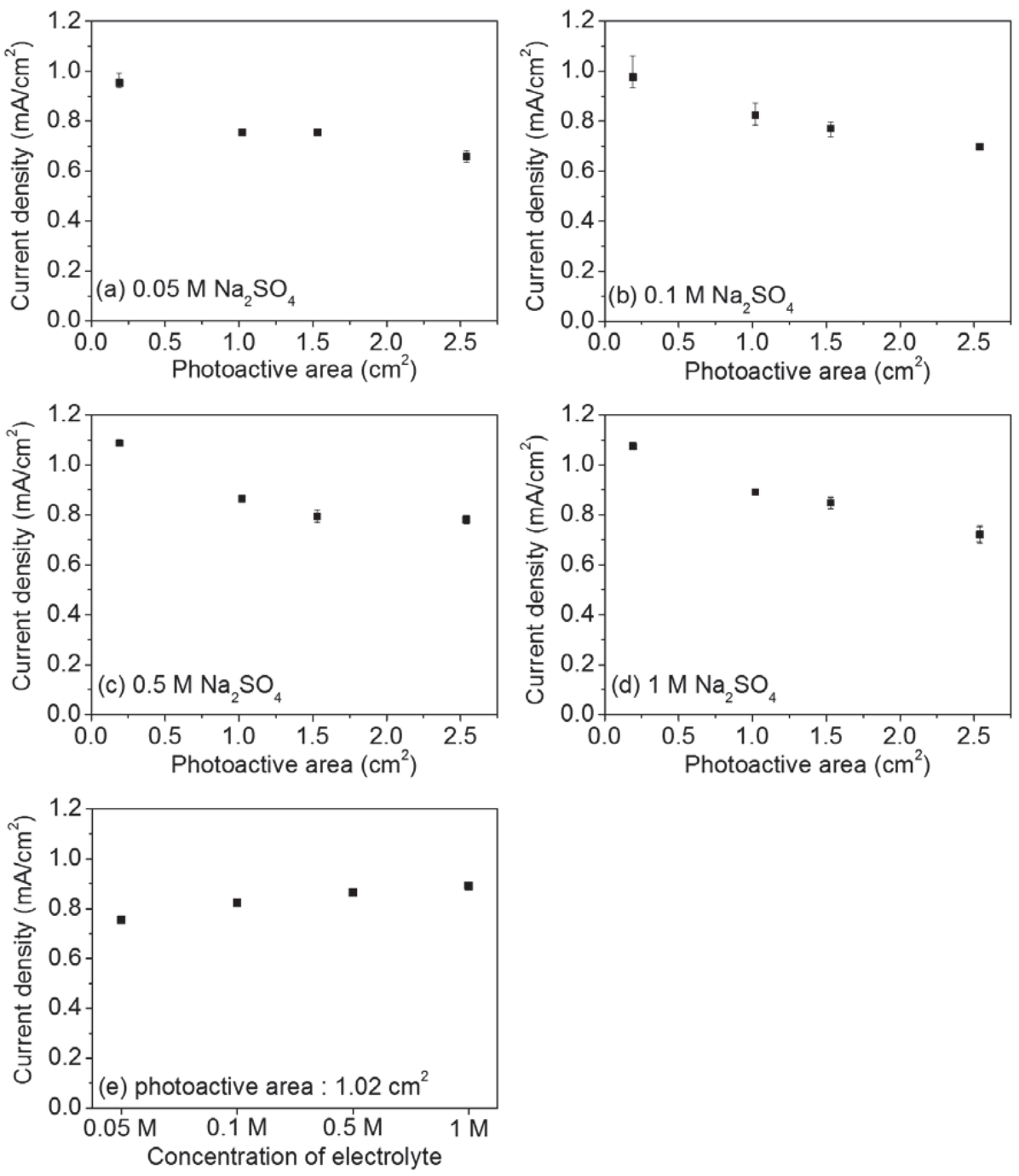

Figure 3.2. Dependence of the photocurrent density on the photoactive area, analysed for different concentrations of the electrolyte. (a) $0.05 \mathrm{M} \mathrm{Na}_{2} \mathrm{SO}_{4}$, (b) $0.1 \mathrm{M} \mathrm{Na}_{2} \mathrm{SO}_{4}$, (c) $0.5 \mathrm{M}$ $\mathrm{Na}_{2} \mathrm{SO}_{4}$, and (d) $1 \mathrm{M} \mathrm{Na}_{2} \mathrm{SO}_{4}$. Clearly the current density decreases as a function of increasing photoactive area. (e) Current density dependent on the concentration of electrolyte at $1.02 \mathrm{~cm}^{2}$ of photoactive area. 


\subsubsection{Electrochemical impedance spectroscopy of photo-anode film}

To identify which resistances are dominant, electrochemical impedance spectroscopy (EIS) was applied. Figure 3.3a shows the electrochemical impedance spectra (EIS) recorded in $1 \mathrm{M}$ sodium sulfate electrolyte. The experimental data were fitted to a 3-RC-circuit (three semicircles), in series, in analogy to what has been described for $\mathrm{Fe}_{2} \mathrm{O}_{3}$ based electrodes in the literature. ${ }^{9}$ Three semicircles can be assigned to the $\mathrm{R}_{1}, \mathrm{R}_{2}$, and $\mathrm{R}_{3}$ resistances, representing the main interfaces of the FTOlphoto-anodeslelectrolyte system (as illustrated in Figure 3.1a). The resistance increased in the order of $\mathrm{R}_{1}<\mathrm{R}_{2}<\mathrm{R}_{3}$. Apparently, the resistance of the interface of $\mathrm{WO}_{3}$ and FTO $\left(\mathrm{R}_{3}\right)$ represents the largest barrier for the transport of photogenerated charge-carriers from the $\mathrm{WO}_{3}$ based photo-anode, through the FTO layer to the Pt cathode in the PEC cell. Furthermore, the $n$ values of the constant phase element (CPE) were calculated to be in the range of 0.8-0.9. Given these values, the CPE can be interpreted as being a pseudo-capacitor. The capacitance (C) increased in the order of $\mathrm{C}_{3}<\mathrm{C}_{2}<\mathrm{C}_{1}$. The high value of $\mathrm{C}_{1}$ is likely related to the porosity of the prepared $\mathrm{WO}_{3}$ film, since the porosity results in a relatively large active area (see Figure $3.1 \mathrm{~b}$ ). The data of impedance spectroscopy are summarized in Table 3.1.

In Figure $3.3 \mathrm{~b}$, the photocurrents for $0.5 \mathrm{M}$ sodium sulfate are compared to the trend in $\mathrm{R}_{3}$ as a function of increasing exposed area. The trend in resistance as determined by electrochemical impedance spectroscopy is decreasing, but evidently non-linear. Clearly, for higher areas the decrease is less prominent, corresponding to the non-linear increase in photocurrent. In Figure 3.3b, photocurrents are also shown for photo-electrodes, in which the $\mathrm{WO}_{3} / \mathrm{FTO}$ interface was modified by a $\mathrm{C}_{70}$-derived interfacial layer. Clearly the deviation from linear photocurrent increase, is less significant, whereas also the decrease in resistance is more linear. LSV curves to determine current density at $1.23 \mathrm{~V} v s$. RHE for the smallest area as compared to the larger area are shown in the Appendix. The insertion of a $\mathrm{C}_{70}$-derived interfacial layer also reduces the capacitance values in all CPEs around 20-30\% (Table 3.1). These results demonstrating increased scalability of the electrode, when the interfacial resistance is decreased, are in agreement with the EIS results and confirm the interfacial resistance is likely the dominant cause of the absence of scalability of the electrodes. The effect of a $\mathrm{C}_{70}$-derived interfacial layer is also in agreement with chapter $4,{ }^{16}$ in which we will demonstrate that for an exposed electrode surface of $2.54 \mathrm{~cm}^{2}$, a $\mathrm{C}_{70}$-derived interfacial layer reduced the interfacial resistance and enhanced the efficiency of charge-carrier separation. 
(a)

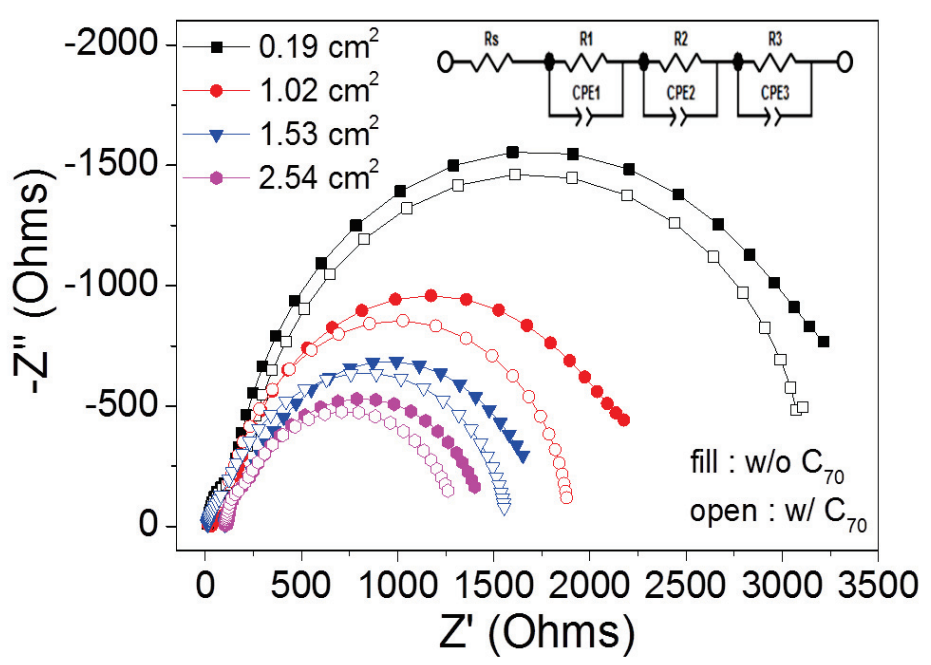

(b)

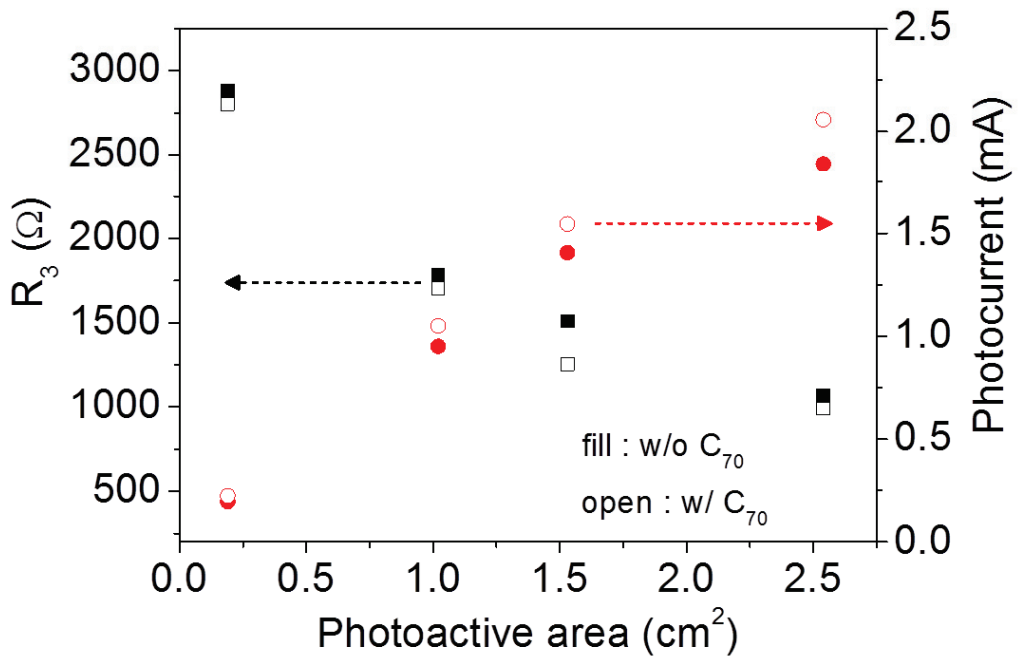

Figure 3.3. (a) Electrochemical impedance spectra of the $\mathrm{WO}_{3}$ film on FTO, determined for variable exposed electrode area, and with and without a $\mathrm{C}_{70}$-derived interfacial layer. The inset shows the circuit used for the fitting of the impedance spectra, (b) Dependency of $\mathrm{R}_{3}$ (resistance between $\mathrm{WO}_{3}$ and FTO) and photocurrent on the photoactive area, with and without a $\mathrm{C}_{70}$-derived interfacial layer. 
Table 3.1. The values of resistance $\left(R_{1}, R_{2}\right.$, and $\left.R_{3}\right)$ and capacitance of the $\mathrm{WO}_{3}$ films with different photoactive areas on FTO substrates in the absence or presence of the $\mathrm{C}_{70}$-derived interfacial layer.

\begin{tabular}{|c|c|c|c|c|c|}
\hline Area $/ \mathrm{cm}^{2}$ & $\mathrm{C}_{70}$ & $\mathrm{R}_{\mathrm{s}} / \Omega$ & $\begin{array}{c}\mathrm{R}_{1} / \Omega \\
\mathrm{C}_{1} / \mu \mathrm{F},(\mathrm{n})\end{array}$ & $\begin{array}{c}\mathrm{R}_{2} / \Omega \\
\mathrm{C}_{2} / \mu \mathrm{F},(\mathrm{n})\end{array}$ & $\begin{array}{c}\mathrm{R}_{3} / \Omega \\
\mathrm{C}_{3} / \mu \mathrm{F},(\mathrm{n})\end{array}$ \\
\hline \multirow{2}{*}{0.19} & w/o & 34.20 & $\begin{array}{c}903 \\
192,(0.54)\end{array}$ & $\begin{array}{c}1739 \\
76,(0.901)\end{array}$ & $\begin{array}{c}2880.33 \\
21,(0.92)\end{array}$ \\
\hline & w/ & 34.07 & $\begin{array}{c}733 \\
194,(0.53)\end{array}$ & $\begin{array}{c}1200.3 \\
13,(0.97)\end{array}$ & $\begin{array}{c}2804 \\
18,(0.90)\end{array}$ \\
\hline \multirow{2}{*}{1.02} & w/o & 25.32 & $\begin{array}{c}559 \\
1964,(0.54)\end{array}$ & $\begin{array}{c}1256.5 \\
115,(0.97)\end{array}$ & $\begin{array}{c}1782 \\
152,(0.91)\end{array}$ \\
\hline & w/ & 20.76 & $\begin{array}{c}487 \\
1476,(0.58)\end{array}$ & $\begin{array}{c}1160.2 \\
98,(0.86)\end{array}$ & $\begin{array}{c}1704 \\
118,(0.97)\end{array}$ \\
\hline \multirow{2}{*}{1.56} & w/o & 22.80 & $\begin{array}{c}281 \\
1961,(0.92)\end{array}$ & $\begin{array}{c}491.3 \\
361,(0.94)\end{array}$ & $\begin{array}{c}1509 \\
267,(0.93)\end{array}$ \\
\hline & w/ & 20.01 & $\begin{array}{c}241 \\
1555,(0.97)\end{array}$ & $\begin{array}{c}480 \\
199,(0.89)\end{array}$ & $\begin{array}{c}1254 \\
130,(0.96)\end{array}$ \\
\hline \multirow{2}{*}{2.54} & w/o & 19.20 & $\begin{array}{c}287 \\
2388,(0.94)\end{array}$ & $\begin{array}{c}257.2 \\
820,(0.67)\end{array}$ & $\begin{array}{c}1068 \\
267,(0.90)\end{array}$ \\
\hline & $\mathrm{w} /$ & 19.30 & $\begin{array}{c}158 \\
1926,(0.94)\end{array}$ & $\begin{array}{c}231.9 \\
780,(0.67)\end{array}$ & $\begin{array}{c}991 \\
164,(0.89)\end{array}$ \\
\hline
\end{tabular}

\subsubsection{Resistivity and carrier concentration of photo-anode film}

Finally, the resistivity and carrier concentration of bare FTO glass and $\mathrm{WO}_{3}$ film on glass is compared in Figure 3.4. The resistivity of FTO as well as $\mathrm{WO}_{3}$ increases as a function of increasing size of photoactive area, while the carrier concentration decreases accordingly. It is worth mentioning that resistivity of FTO and $\mathrm{WO}_{3}$ vary in a different range of eight orders of magnitude. 
(a)

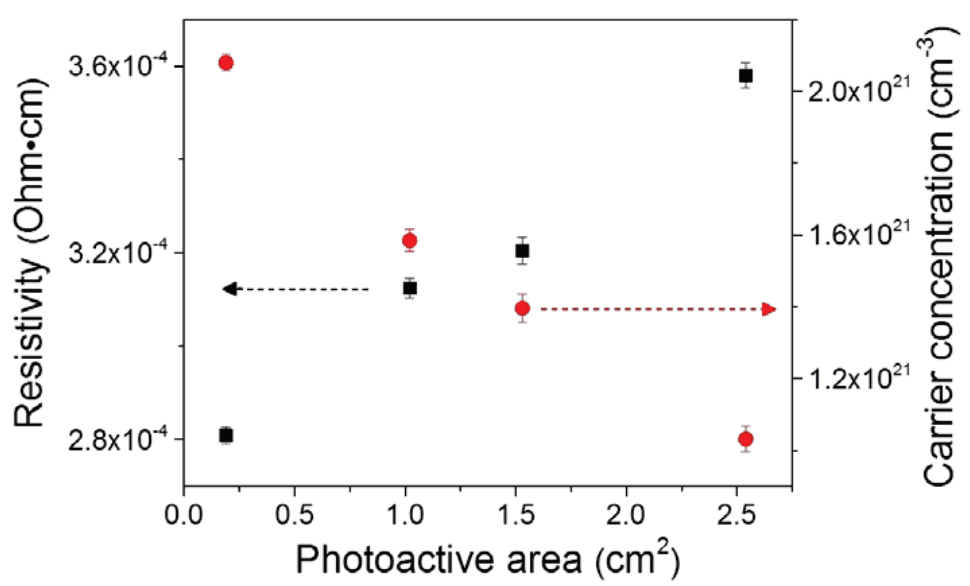

(b)

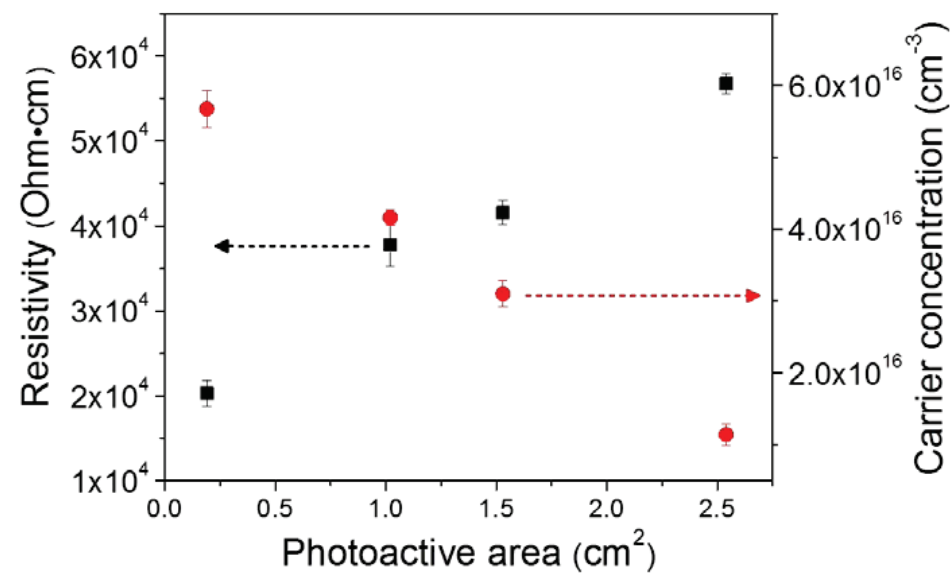

Figure 3.4. Hall effect measurements of (a) FTO glass and (b) $\mathrm{WO}_{3} /$ glass. Please note that the resistivity is 8 orders of magnitude higher for $\mathrm{WO}_{3}$.

Scheme 3.1 shows a schematic comparison of the number of charge-carriers formed upon illumination, and the number of highly resistive paths present for small or large electrode surface areas. We aim to illustrate that the increase in the number of charge-carriers due to the area increase is accompanied by a disproportional increasing number of resistive paths, which can be accounted for by geometrical considerations. We anticipate that this will lower the photo-electron transfer efficiency, and therefore will increase the probability of electron-hole recombination. Overall this results in a less effective photo-electrode and lower photocurrent density. It should be mentioned that the high resistance in $\mathrm{WO}_{3}$ itself, as determined by the Hall measurements, will reduce the probability that a photo-electron generated in the 
proximity of a highly resistive path will migrate to locations where low resistive paths are present.
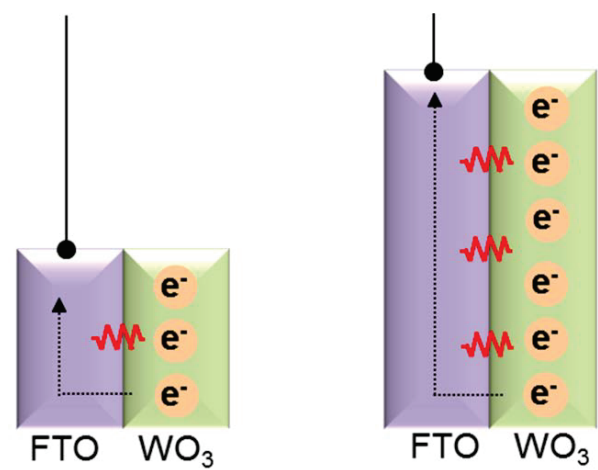

\section{light}

Scheme 3.1. Schematic illustration of the number of charge-carriers formed upon illumination, and interfacial resistances introduced by increasing the size in photoactive area of the photoelectrode.

\subsection{Conclusions}

In summary, we have shown that the experimentally determined photocurrent density of $\mathrm{WO}_{3} / \mathrm{FTO}$ PEC cells decreases as a function of increasing photoactive area under identical illumination intensity and electrolyte concentrations. Further, the analytical results of electrochemical impedance spectroscopy suggest that the non-linear decrease in interfacial resistance $\left(\mathrm{R}_{3}\right)$ between $\mathrm{WO}_{3}$ and $\mathrm{FTO}$, is the dominant factor in explaining this. The importance of the latter resistance $\left(\mathrm{R}_{3}\right)$ in determining high photocurrents was confirmed by the observed improvements when the interface was adapted by a $\mathrm{C}_{70}$-derived interfacial layer.

Based on the data presented here, it is clear that up-scaling of PEC cells requires careful evaluation of resistive losses typically addressed by the PV community. Besides commonly advocated factors, such as concentration of electrolyte, power density of light, and catalytic activity of electrodes, highly conductive substrates with minimized internal and interfacial resistances, should be considered in optimization and scale-up of PEC based overall water splitting. 


\subsection{References}

1. Walter, M. G.; Warren, E. L.; McKone, J. R.; Boettcher, S. W.; Mi, Q. X.; Santori, E. A.; Lewis, N. S. Chem. Rev. 2010, 110, 6446-6473.

2. Chen, X.; Shen, S.; Guo, L.; Mao, S. S. Chem. Rev. 2010, 110, 6503-6570.

3. Hisatomi, T.; Kubota, J.; Domen, K. Chem. Soc. Rev. 2014, 43, 7520-7535.

4. Sivula, K.; Formal, F.L.; Grätzel, M. ChemSusChem 2011, 4, 432-449.

5. Liang, Y.; Tsubota, T.; Mooij, L. P. A.; van de Krol, R. J. Phys. Chem. C 2011, 115, 17594-17598.

6. Dotan, H.; Kfir, O.; Sharlin, E.; Blank, O.; Gross, M.; Dumchin, I.; Ankonina, G.; Rothschild, A. Nat. Mater. 2013, 12, 158-164.

7. Bhande, S. S.; Kim, E. -K.; Shinde, D. V.; Patil, S.; Mane, R. S.; Han, S. -H. Int. J. Electrochem. Sci. 2013, 8, 11596-11605.

8. Zhang, K.; Shi, X.; Kim, J. K.; Lee, J. S.; Park, J. H. Nanoscale 2013, 5, 1939-1944.

9. Kim, J. Y.; Jang, J.-W.; Youn, D. H; Kim, J. Y.; Kim, E. S.; Lee, J. S. RSC Adv. 2012, 2, 9415-9422.

10. Paracchino, A.; Laporte, V.; Sivula, K.; Grätzel, M.; Thimsen, E. Nat. Mater. 2011, 10, 456-461.

11. Choi, S.; Potscavage, W. J.; Kippelen, B. J. Appl. Phys. 2009, 106, 054507.

12. Deb, S.; Ghosh, B. Sol. Cells 1984, 13, 145-162.

13. Lee, W. J.; Ramasamy, E.; Lee, D. Y. Sol. Energy Mater. Sol. Cells 2009, 93, 1448-1451.

14. Pandey, A. K.; Nunzi, J. M.; Ratier, B.; Moliton, A. Phys. Lett. A 2008, 372, 1333-1336.

15. Mwakikunga, B. W.; Forbes, A.; Sideras-Haddad, E.; Scriba, M.; Manikandan, E. Nanoscale Res. Lett. 2009, 5, 389-397.

16. Park, S.-Y.; Lim, D. C.; Hong, E. M.; Lee, J.-Y.; Heo, J.; Lim, J. H.; Lee, C.-L.; Kim, Y. D.; Mul, G. ChemSusChem 2015, 8, 172-176. 


\subsection{Appendix}

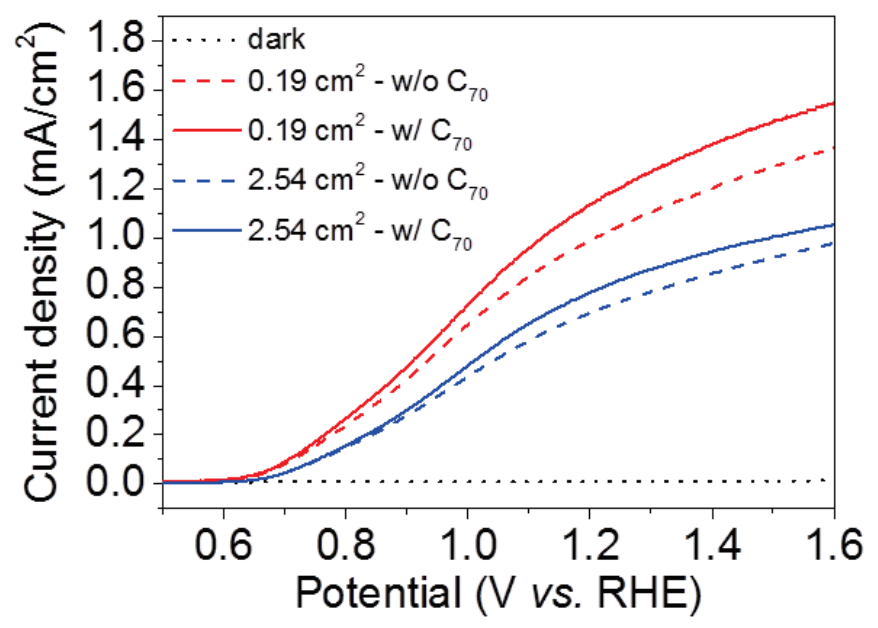

Figure A3.1. Curves of current density versus potential (V vs. RHE) of $\mathrm{WO}_{3}$ films for the smallest area as compared to the larger area. 



\section{Chapter 4}

Selective modulation of charge-carrier transport of a photo-anode in a photoelectrochemical cell by a graphitized fullerene interfacial layer

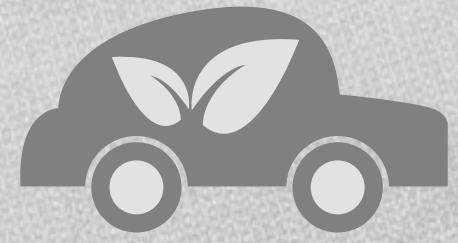

This chapter has been published: S.-Y. Park, D.C. Lim, E.M. Hong, J.-Y. Lee, J. Heo, J.H. Lim, C.-L. Lee, Y.D. Kim, G. Mul, Selective modulation of chargecarrier transport of a photoanode in a photoelectrochemical cell by a graphitized fullerene interfacial layer, ChemsusChem 8 172-17.6 (2015). 


\begin{abstract}
We show that a graphitic carbon interfacial layer, derived from $\mathrm{C}_{70}$ by annealing at $500{ }^{\circ} \mathrm{C}$, results in a significant increase in the attainable photocurrent of a photoelectrochemical cell that contains a $\mathrm{WO}_{3}$-functionalized fluorine-doped tin oxide (FTO) photo-anode. Timeresolved photoluminescence spectroscopy, photoconductive atomic force microscopy, Hall measurements, and electrochemical impedance spectroscopy show that the increase in photocurrent is the result of fast and selective electron transport from optically excited $\mathrm{WO}_{3}$ through the graphitic carbon interfacial layer to the FTO-coated glass electrode. Thus the energy efficiency of perspective solar-to-fuel devices can be improved by modification of the interface of semiconductors and conducting substrate electrodes by using graphitized fullerene derivatives.
\end{abstract}




\subsection{Introduction}

The production of hydrogen by water splitting using sunlight is one of the most promising methodologies to store solar energy in the form of chemical bonds. ${ }^{1-4}$ Hydrogen itself can be used as a fuel in fuel cell devices to generate electricity or can be used alternatively to convert $\mathrm{CO}_{2}$ catalytically into valuable chemicals such as $\mathrm{CO}$, methanol, formic acid, or methane. ${ }^{5}$ The chemical conversion of $\mathrm{CO}_{2}$ to chemicals using renewable hydrogen is more effective to mitigate $\mathrm{CO}_{2}$ emissions than $\mathrm{CO}_{2}$ storage, for example, in underground reservoirs.

Many studies reported in the literature focus on the evaluation of new semiconductor materials to be applied in photoelectrochemical (PEC) solar to hydrogen devices. In such devices, a photo-electrode that contains the semiconductor absorbs light of sufficient energy to yield electron-hole pairs. Hydrogen and oxygen are evolved by these electrons and holes on the cathode and anode of the device, respectively, if the band edges straddle the oxidation and reduction potential of water. If not, a so-called bias potential needs to be applied, which is usually set at $1.23 \mathrm{~V}$ versus the reversible hydrogen electrode (RHE) to compare the relative effectiveness of photo-anodes for water splitting. ${ }^{1-4}$ Primarily, the performance of solar-tohydrogen devices is dependent on the light-harvesting efficiency of the photo-electrodes. ${ }^{1-4}$ However, the effective separation of the photo-generated electrons and holes, which can increase the lifetime of the charges, is at least as important as light absorption.

The first device used for water splitting by solar light was based on $\mathrm{TiO}_{2}$, which is well known to be photocatalytically active. ${ }^{6}$ Recently, much effort has been devoted to the improvement of the efficiency of solar to hydrogen devices. ${ }^{1-4}$ For example, water splitting has been driven by semiconductors such as $\mathrm{Si}$ or $\mathrm{GaAs}$, and tandem assemblies of photovoltaic (PV) cells were utilized to increase the generated cell voltage. ${ }^{7,8}$ In addition, inorganic dyes such as $\mathrm{Ru}$ complexes have been attached to $\mathrm{TiO}_{2}$ nanoparticles to yield dyesensitized photo-anodes in PEC cells. ${ }^{9,} 10$ The design of molecular dyes and semiconductor inorganic materials to enhance the efficiency of solar-to-fuel systems has been of particular interest. ${ }^{10}$ Organic-inorganic hybrid materials such as $\mathrm{Si} /$ poly(3,4-ethylenedioxythiophene) (PEDOT) have also been used as a photo-anode. ${ }^{11}$ In addition, various inorganic oxide materials such as $\mathrm{BiVO}_{4}, \mathrm{WO}_{3}$, and $\mathrm{Fe}_{2} \mathrm{O}_{3}$ have shown promising results as photo-anodes in

the oxidation of water. ${ }^{12,13}$ Cocatalysts such as $\mathrm{Pt}$ and $\mathrm{Co}_{3} \mathrm{O}_{4}$ have been deposited on these photo-electrodes to improve reduction and oxidation efficiency by the enhancement of photogenerated electron-hole separation and/or catalysis of the reduction and oxidation reactions. $^{7,14}$

A potential limitation in solar to hydrogen devices that receives less attention is poor electron transfer from the semiconductor to the electrode substrate. Only a few studies have focused on the development of interfacial layers to optimize contact at the interface between the light-sensitive semiconductors and electrode substrate, such as indium tin oxide (ITO) or fluorine-doped tin oxide (FTO). In the present work, we used layers derived from thermally treated fullerene $\left(\mathrm{C}_{70}\right)$ as conductive interfaces between $\mathrm{WO}_{3}$, an interesting oxide often used in photo-anode assemblies, and a FTO-based conductive glass electrode. We show that $\mathrm{C}_{70^{-}}$ 
derived layers can decrease the electron transfer resistance effectively and diminish hole transfer from $\mathrm{WO}_{3}$ to the FTO electrode. Both effects result in a significant increase in achievable solar to hydrogen efficiency.

\subsection{Experimental section}

\subsubsection{Preparation of $\mathrm{WO}_{3}$ film on FTO glass}

The synthesis procedure of a $\mathrm{WO}_{3}$ sol-gel solution can be found on page 31 of chapter $3 .{ }^{15}$ For the preparation of the $\mathrm{WO}_{3}$ film, the $\mathrm{WO}_{3}$ solution was spin coated on FTO-coated glass at $600 \mathrm{rpm}$ for $30 \mathrm{sec}$. After coating, the glass was heated on a hot plate at $100{ }^{\circ} \mathrm{C}$ for $1 \mathrm{~min}$. This process was repeated several times to make $\mathrm{WO}_{3}$ films with various thicknesses, and then the samples were heated in an oven at $500{ }^{\circ} \mathrm{C}$ for $2 \mathrm{hr}$. To modify the $\mathrm{WO}_{3} / \mathrm{FTO}$ interfaces, $\mathrm{C}_{70}$ (12 mg, nano-c) was dissolved in 1,2-dichlorobenzene (1 ml, Sigma Aldrich). The dissolved solution was spin coated onto FTO-coated glass at $2000 \mathrm{rpm}$ for $40 \mathrm{sec}$. After coating, the glass was heated on a hot plate at $100{ }^{\circ} \mathrm{C}$ for $1 \mathrm{~min}$. Then, the $\mathrm{WO}_{3}$ film was added using the aforementioned process. The surface and interface structures of the photoelectrodes were analyzed by field-emission scanning electron microscopy (FE-SEM, Zeiss LEO 1550), high-resolution scanning transmission electron microscopy (HR-STEM, JEOL JEM-2100F), X-ray diffraction (XRD, Bruker D2 phaser), and Raman spectroscopy (HORIBA, LABRAM HR).

\subsubsection{Characterization of the PEC cell in water splitting}

The PEC properties of our photo-electrodes were determined in an aqueous electrolyte solution that contained $0.1 \mathrm{M}$ of sodium sulfate ( $\mathrm{pH} \sim 4.0$, Sigma Aldrich). The potential of the working electrode was controlled by a potentiostat (VERSASTAT 4, Princeton Applied Research). In three-electrode measurements, a Pt wire and a $\mathrm{Ag} / \mathrm{AgCl}$ electrode $(3 \mathrm{M} \mathrm{NaCl}$, BASi) were used as the counter and reference electrodes, respectively (Figure A4.1). Photocurrents under white light were measured under the illumination of an AM 1.5 solar simulator $\left(100 \mathrm{~mW} / \mathrm{cm}^{2}\right)$ with a $300 \mathrm{Xe}$ lamp and air mass 1.5 global filter. The intensity of the simulated sunlight was calibrated using a standard reference Si solar cell. Solar light was exposed to the front side of the $\mathrm{WO}_{3}$ layer. The photoactive area was $2.54 \mathrm{~cm}^{2}$.

\subsubsection{Measurement of electrochemical impedance spectroscopy}

EIS spectra were obtained in an aqueous electrolyte solution that consisted of $0.1 \mathrm{M}$ sodium sulfate. The DC potential was $1.23 \mathrm{~V}$ with respect to a reference hydrogen electrode, and the AC potential frequency was varied in the range of $100000-0.1 \mathrm{~Hz}$ with an amplitude of $10 \mathrm{mV}$ under illumination. A potentiostat (IVIUM, Compactstat) was used to apply the bias 
potential, and fitting of the experimental EIS data was performed in accordance with an equivalent circuit model.

\subsubsection{Measurement of photoconductive-AFM}

The photo-induced electrical properties (carrier concentration, charge separation and transport) of the $\mathrm{WO}_{3}$ photo-anodes with and without the $\mathrm{C}_{70}$ interfacial layer were analyzed by the Hall effect (MODUSIS, $100 \mathrm{~W}$ halogen lamp) and PC-AFM, which consisted of a current-sensing module (SEIKO, E-sweep mode SPM system that contained a $100 \mathrm{~W}$ halogen lamp and monochromator). The AFM was operated in contact mode with a rate of $0.3 \mathrm{~Hz}$ using Pt-coated cantilever tips (diameter: 15-20 nm) from Nanosensors, Switzerland (spring constant of $3 \mathrm{~N} \mathrm{~m}^{-1}$ and resonance frequency of $75 \mathrm{kHz}$ ). Topographic and photo-induced current images of the sample surface were recorded. The bias voltage between the sample electrode and the conducting cantilever tip (which was grounded) was $+2 \mathrm{~V}$ during all experiments to accelerate photo-generated charge transport. Photo-generated electrons flow to the direction of the FTO electrode, and photo-generated holes were detected by the cantilever tip. The lower limit of the PC-AFM setup for current measurements was $100 \mathrm{fA}$.

\subsubsection{Measurement of photoluminescence spectroscopy}

The interfacial electron transfer dynamics of the $\mathrm{WO}_{3}$ photo-anodes with and without a $\mathrm{C}_{70}$ interfacial layer were studied using regular photoluminescence spectroscopy (PL) and timeresolved photoluminescence spectroscopy (TRPL). Regular PL spectra were measured by using a HORIBA JOBIN YVON, LabRam HR800 spectrometer. In case of TRPL, samples were pumped using a He-Cd laser of a wavelength of $375 \mathrm{~nm}$. TRPL spectra were collected at $80 \mathrm{~K}$ in a vacuum of less than $5 \times \sim 10^{-6}$ torr. $\lambda_{\mathrm{exc}}=400 \mathrm{~nm}$, and the monitored wavelength of PL was $470 \mathrm{~nm}$.

\subsection{Results and discussion}

\subsubsection{Characterization of the photo-anode film}

The results of the characterization of $\mathrm{WO}_{3}$ layers with and without an interfacial layer made of $\mathrm{C}_{70}$ are shown in Figure 4.1. Here, the $\mathrm{WO}_{3}$ layers were deposited on conducting glass by three consecutive spin coating procedures. 

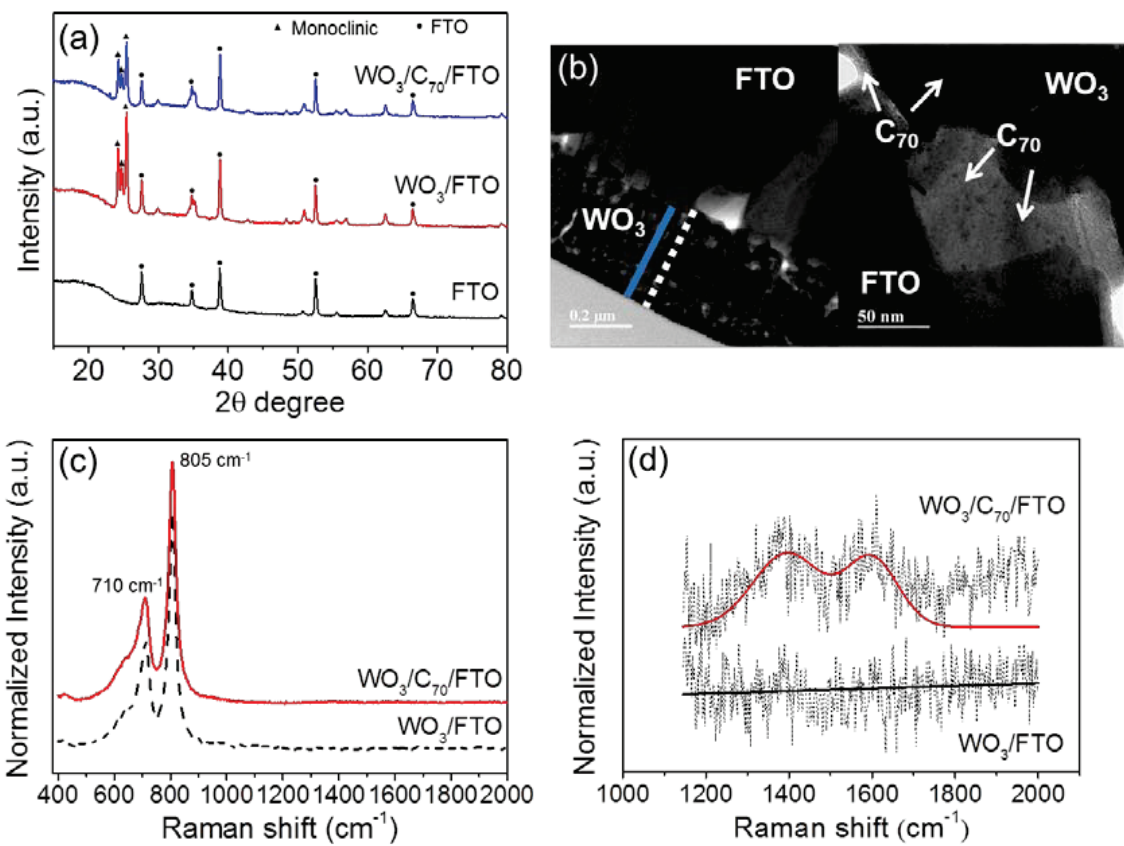

Figure 4.1. Characterization of photo-anodes with and without a graphitized $\mathrm{C}_{70}$ interfacial layer. (a) XRD patterns, (b) TEM images, (c) Raman spectra, and (d) a magnified view of the Raman spectra in (c).

In the XRD patterns, three pronounced diffraction lines between $2 \theta=23$ and $24.5^{\circ}$, which correspond to crystalline $\mathrm{WO}_{3}$ with a monoclinic phase (JCPDF 83-0951), could be observed after calcination in air at $500{ }^{\circ} \mathrm{C}$ for $2 \mathrm{hr}$. Notably, the XRD patterns of $\mathrm{WO}_{3} / \mathrm{FTO}$ and $\mathrm{WO}_{3} / \mathrm{C}_{70} / \mathrm{FTO}$ were almost identical. This result implies that interfacial layers created by $\mathrm{C}_{70}$ form a structure with a low crystallinity (or amorphous morphology) upon thermal treatment, and the existence of interfacial layer does not have any influence on the structure of the obtained $\mathrm{WO}_{3}$ morphology. The low crystallinity of the graphitized $\mathrm{C}_{70}$ is confirmed by XRD patterns of $\mathrm{C}_{70} / \mathrm{FTO}$ before and after heat treatment in the absence of $\mathrm{WO}_{3}$ (Figure A4.2). The graphitization of $\mathrm{C}_{70}$ is clearly not apparent. From the high-resolution transmission electron microscopy (HR-TEM) images shown in Figure 4.1b and Figure A4.3, the thickness of the $\mathrm{WO}_{3}$ layer was determined to be $\sim 300 \mathrm{~nm}$, that is, each coating process resulted in the formation of a $\mathrm{WO}_{3}$ layer of approximately $100 \mathrm{~nm}$ thick. This is confirmed by the SEM images presented in Figure A4.4. If interfacial layer between FTO and $\mathrm{WO}_{3}$ was prepared from $\mathrm{C}_{70}$, additional dark spots with a mean lateral size of $\sim 10-20 \mathrm{~nm}$ can be observed. Notably, some of the dark spots are incorporated within the $\mathrm{WO}_{3}$ layer, that is, upon heat treatment $\mathrm{C}_{70}$ diffused partially into this layer. 
The Raman spectra of $\mathrm{WO}_{3} / \mathrm{FTO}$ and $\mathrm{WO}_{3} / \mathrm{C}_{70} / \mathrm{FTO}$ show multiple bands below $\tilde{v}=1000$ $\mathrm{cm}^{-1}$, which can be assigned to a $\mathrm{WO}_{3}$ layer with high crystallinity. Specifically, Raman peaks at $\tilde{v}=710$ (shouldered) and $805 \mathrm{~cm}^{-1}$ correspond to W-O-W stretching modes. ${ }^{16,17}$ However, after close inspection, in the $\tilde{v}=1300-1700 \mathrm{~cm}^{-1}$ region, spectral features can be observed only in the spectrum of $\mathrm{WO}_{3} / \mathrm{C}_{70} / \mathrm{FTO}$, which are absent in that of $\mathrm{WO}_{3} / \mathrm{FTO}{ }^{18}$ The two bands observed can be attributed to the $\mathrm{D}$ and $\mathrm{G}$ peaks of disordered carbon and graphitic carbon, respectively (Figure 4.1d). This result implies that $\mathrm{C}_{70}$ did not survive during the photo-electrode preparation (annealing at $500{ }^{\circ} \mathrm{C}$ ) and the structure of $\mathrm{C}_{70}$ was at least partially destroyed. It is likely that a reaction between the $\mathrm{C}$ atoms of neighboring $\mathrm{C}_{70}$-entities occurs, which results in the appearance of the carbon signature in the Raman spectra. Therefore, one can suggest that the fabrication of interfacial layer using $\mathrm{C}_{70}$ actually yielded a graphitic carbon as a result of the annealing process used for the photo-electrode fabrication. Such a high annealing temperature is required to create $\mathrm{WO}_{3}$ layer with a high crystallinity, which is important to obtain a high light harvesting efficiency. $\mathrm{C}_{70}$ also decomposes to form graphitic carbon upon annealing at $500{ }^{\circ} \mathrm{C}$ without $\mathrm{WO}_{3}$ (Figure A4.5). There was no experimental indication for the formation of carbon-doped $\mathrm{WO}_{3}$ phases.

\subsubsection{Photoelectrochemical characterization of photo-anode film}

The photocurrent densities of the $\mathrm{WO}_{3}$ layer as a photo-anode in the absence or presence of an inserted interfacial layer under simulated sunlight with chopping are shown in Figure 4.2a. The photocurrent density shown in Figure $4.2 \mathrm{~b}$ was determined from the photocurrent value at $1.23 \mathrm{~V}$ from a curve of current density versus potential (V vs. RHE, Figure A4.6). The $\mathrm{WO}_{3}$ layer thickness was increased by repeating the spin coating process. The $\mathrm{WO}_{3}$ layer thickness shown in Figure 4.2b (x axis) is indicated by the number of spin coating processes used for $\mathrm{WO}_{3}$ film deposition, which varied from one to seven times ( $\left.\mathrm{t} 1 \ldots \mathrm{t} 7\right)$. This leads to a variation in thickness from $\sim 100-700 \mathrm{~nm}$. The photocurrent density of $\mathrm{WO}_{3}$ increased gradually with an increase in the thickness of the $\mathrm{WO}_{3}$ layer, most likely because of enhanced light absorption by the thicker $\mathrm{WO}_{3}$ layers. It is clear that the photocurrent was enhanced on insertion of the $\mathrm{C}_{70}$-derived graphitic carbon layer between $\mathrm{WO}_{3}$ and FTO (Figure 4.2). 

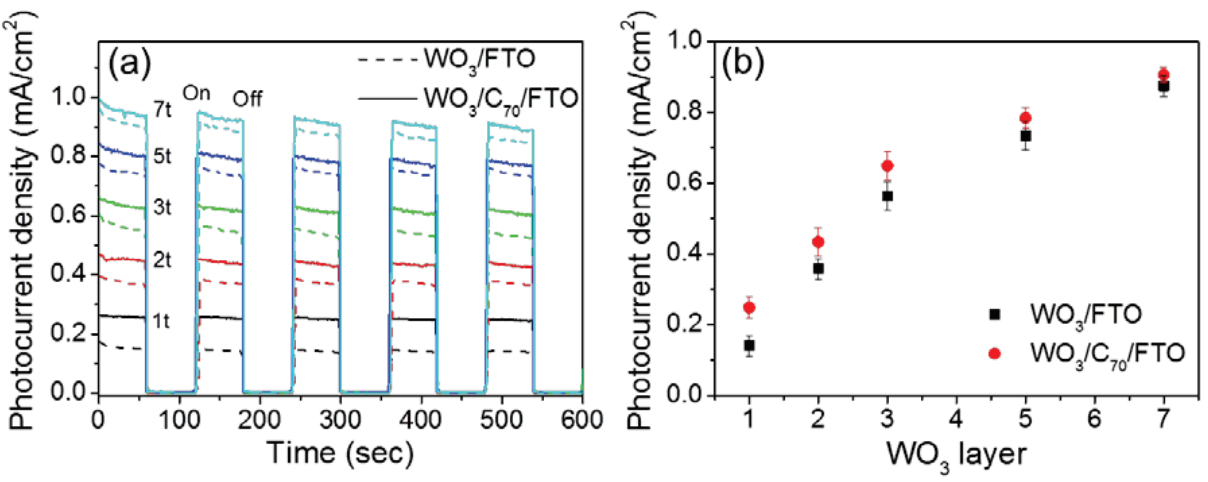

Figure 4.2. (a) Chronoamperometry at an applied potential of $1.23 \mathrm{~V} v s$. RHE under light chopping conditions. (b) Current density dependent on the number of $\mathrm{WO}_{3}$ layers in simulated AM 1.5 illumination for the $\mathrm{WO}_{3}$ film with and without a graphitized $\mathrm{C}_{70}$ interfacial layer.

In agreement, the photocurrent enhancement of $\mathrm{Fe}_{2} \mathrm{O}_{3}$ has been reported on insertion of a graphene thin film between FTO-coated glass and $\mathrm{Fe}_{2} \mathrm{O}_{3}{ }^{19} \mathrm{C}_{70}$-derived graphitic carbon has several advantages over other carbon based nanomaterials that function as an interfacial charge transport layer. In particular, the method of layer synthesis is simple, and the film thickness can be adjusted easily by changing the concentration of $\mathrm{C}_{70}$ in solution.

The effect of the variation in the $\mathrm{C}_{70}$ concentration is shown in Figure A4.7. Clearly, an increase of the $\mathrm{C}_{70}$ quantity yields an increasing photocurrent density under identical conditions after thermal graphitization. Attempts to increase the concentration above 30 $\mathrm{mg} / \mathrm{ml}$ (in 1,2-dichlorobenzene) did not result in homogeneous solutions, and therefore, did not yield a film coated homogeneously nor further improved photocurrent density. The graphitization of other fullerene derivatives, such as phenyl- $\mathrm{C}_{70}$-butyric acid methyl ester $\left(\mathrm{PC}_{70} \mathrm{BM}\right)$, yields similar positive effects in the promotion of the photocurrent density (Figure A4.8). Finally, the positive effect of the $\mathrm{C}_{70}$-derived graphite-like layer is also observed for a $\mathrm{ZnO}$ based photo-anode (Figure A4.9).

Contrary to the positive effect of the increased quantity $\mathrm{C}_{70}$, an increase of the thickness of the $\mathrm{WO}_{3}$ film decreased the positive effect of the graphitized interfacial layer. The photocurrent enhancement factor of $\sim 1.6$ is the highest if the $\mathrm{WO}_{3}$ thickness is the lowest. Additional $\mathrm{WO}_{3}$ layers result in lower multiplication factors, the origin of which will be the subject of a future study.

\subsubsection{Photoluminescence of photo-anode film}

To shed light on the origin of the enhanced photocurrent by the layer of graphitized $\mathrm{C}_{70}$, regular and time-resolved photoluminescence (PL) studies were performed (Figure 4.3). In 
the regular PL spectra (inset of Figure 4.3a), the PL process is quenched by the graphitized $\mathrm{C}_{70}$ interfacial layer. If we assume an exponential decay of the time-resolved PL data in Figure 4.3a, the lifetime of the electron-hole pairs created optically is $\sim 0.9$ and $0.8 \mathrm{~ns}$ for $\mathrm{WO}_{3} / \mathrm{FTO}$ and $\mathrm{WO}_{3} / \mathrm{C}_{70} / \mathrm{FTO}$, respectively (Figure $4.3 \mathrm{~b}$ ). If the graphitized $\mathrm{C}_{70}$ layer was deposited on top of the $\mathrm{WO}_{3}$ layer, the quenching of the $\mathrm{PL}$ of the $\mathrm{WO}_{3}$ layer by graphitized $\mathrm{C}_{70}$ was clearer and reduced the lifetime of the electron-hole pair to $\sim 0.7 \mathrm{~ns}$. This result shows clearly that an effective charge transfer from optically excited $\mathrm{WO}_{3}$ to graphitized $\mathrm{C}_{70}$ takes place, which results in the lower PL quantum yield.
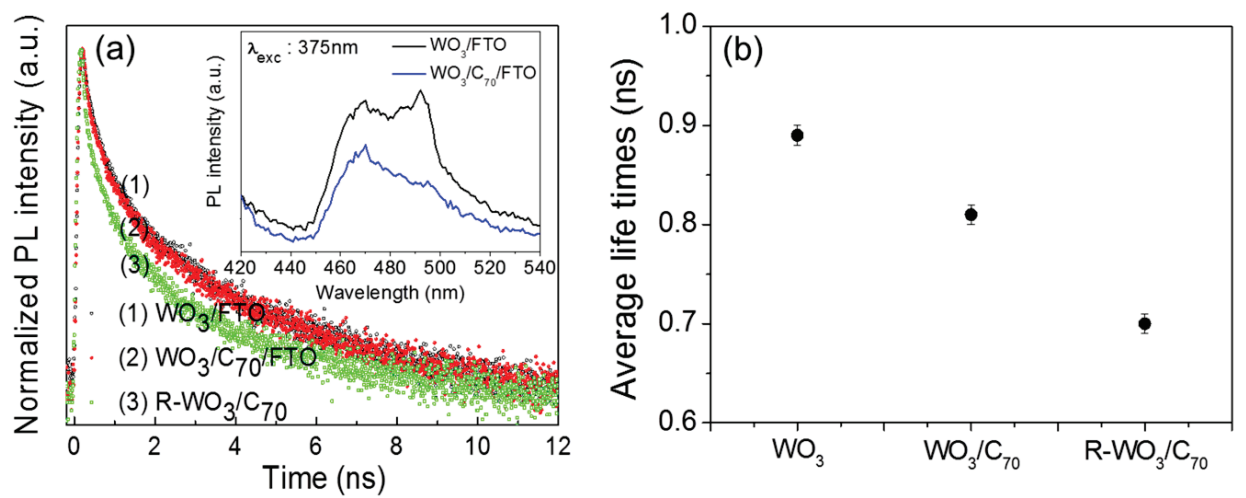

Figure 4.3. (a) Time-resolved PL spectra of $\mathrm{WO}_{3}$ films with and without a graphitized $\mathrm{C}_{70}$ interfacial layer. In the inset, regular PL spectra are compared. (b) Average lifetime of electron-hole pairs estimated from the curves shown in (a).

\subsubsection{Photoconductive atomic force microscopy of photo-anode film}

We performed studies using photoconductive atomic force microscopy (PC-AFM) to provide insight into the origin of the enhanced efficiency of the photo-electrodes that consist of $\mathrm{WO}_{3}$ in the presence of the graphitized $\mathrm{C}_{70}$ interfacial layer (Figure 4.4 and Table 4.1). Under dark conditions, the sample without graphitized $\mathrm{C}_{70}$ showed an average local current value of $0.33 \mu \mathrm{A}$, which is much lower than the respective value of $\mathrm{WO}_{3} /$ graphitized $\mathrm{C}_{70} / \mathrm{FTO}$ $(0.78 \mu \mathrm{A})$. Under light illumination, again, the obtained current value of the $\mathrm{WO}_{3} /$ graphitized $\mathrm{C}_{70} / \mathrm{FTO}$ sample was much higher than that of the $\mathrm{WO}_{3} / \mathrm{FTO}$ sample; the average local photocurrent values of $\mathrm{WO}_{3} /$ graphitized $\mathrm{C}_{70} / \mathrm{FTO}$ and $\mathrm{WO}_{3} / \mathrm{FTO}$ were 3.88 and $0.38 \mu \mathrm{A}$, respectively. Our observation that the dark current was enhanced by a factor of $\sim 2$ by the presence of the graphitized $\mathrm{C}_{70}$ interfacial layer indicates that this layer results in a decrease in the resistance of the $\mathrm{WO}_{3} / \mathrm{FTO}$ interface. 


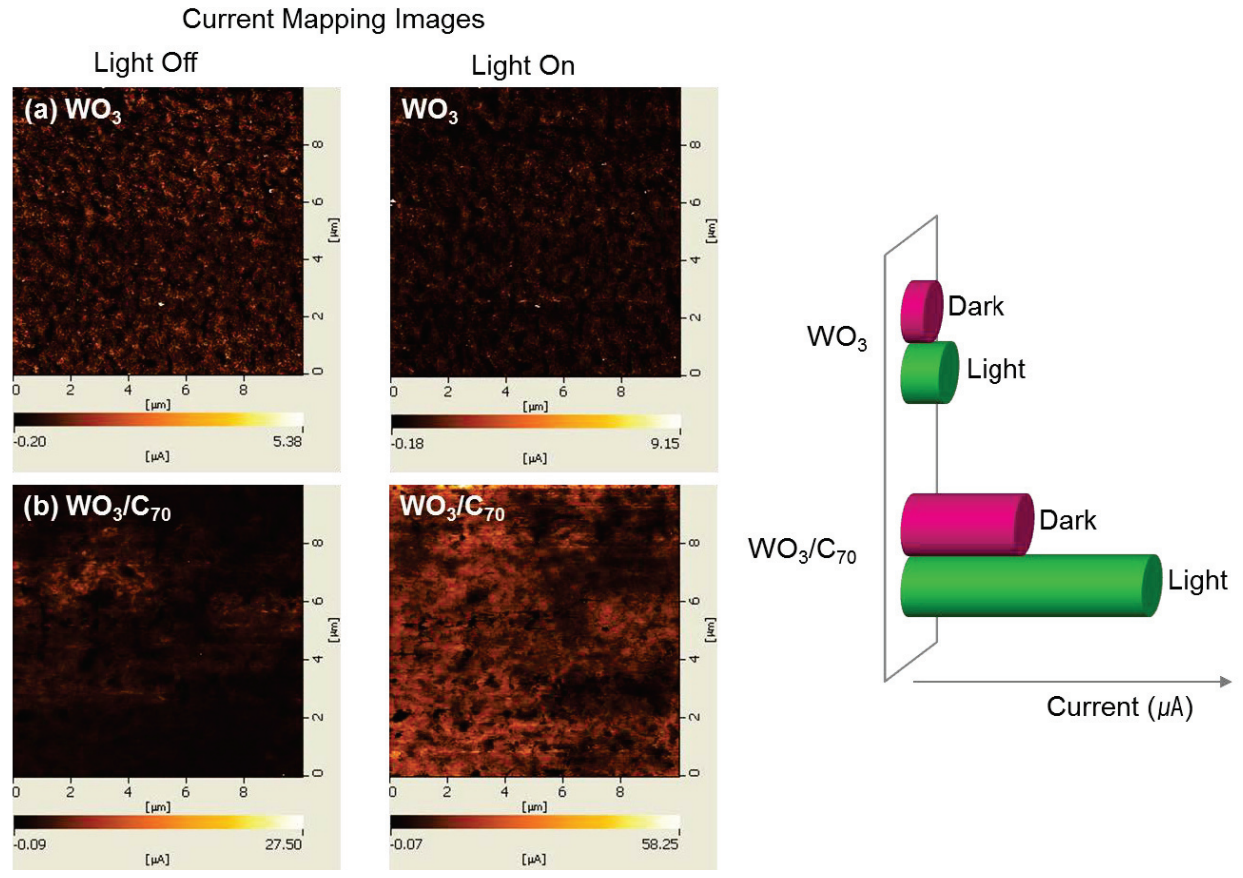

Figure 4.4. PC-AFM results of $\mathrm{WO}_{3}$ films with and without a graphitized $\mathrm{C}_{70}$ interfacial layer under light off and on conditions are compared. In the current-mapping images, a brighter area means a high conducting region, and average current values were extracted from the images (Table 4.1).

Table 4.1. Average current values extracted from PC-AFM images.

\begin{tabular}{c|c|c}
\hline \multirow{2}{*}{} & \multicolumn{2}{|c}{ Average current $(\mu \mathrm{A})$} \\
\cline { 2 - 3 } & Light off & Light on \\
\hline $\mathrm{WO}_{3} /$ FTO & 0.33 & 0.38 \\
\hline $\mathrm{WO}_{3} / \mathrm{C}_{70} / \mathrm{FTO}$ & 0.78 & 3.88 \\
\hline
\end{tabular}

Furthermore, the photocurrent of the photo-electrode was enhanced by a factor of $\sim 10$ in the presence of interfacial layer, which indicates that the optically excited electron can be transferred effectively, in agreement with the aforementioned PL results. The results of Hall measurements also support this hypothesis of effective charge transfer (Figure A4.10). The charge-carrier (electron) density was significantly increased both under dark and illumination 
conditions in the presence of the graphitized $\mathrm{C}_{70}$ interfacial layer, which implies that the recombination of electron-hole pairs within $\mathrm{WO}_{3}$ is reduced.

With regard to the root-mean-square (RMS) roughness from the (photo)current images, the current roughness of $\mathrm{WO}_{3} / \mathrm{FTO}$ was enhanced by a factor of $\sim 10$ in the presence of the $\mathrm{C}_{70^{-}}$ derived interfacial layer; the RMS roughness of the photocurrent of $\mathrm{WO}_{3} / \mathrm{FTO}$ was only 0.56 $\mathrm{mA}$, which increased to $5.1 \mathrm{~mA}$ in the presence of the graphitized $\mathrm{C}_{70}$ interfacial layer. This result could be in line with our SEM results (Figure A4.11), in which a slightly higher porosity of the $\mathrm{WO}_{3}$ layer surface was found in the presence of the graphitized $\mathrm{C}_{70}$ interfacial layer. A higher porosity of the $\mathrm{WO}_{3}$ film surface could increase the area of the active surface in contact with water, which could be a reason for the enhanced photocurrent observed in the presence of the graphitized $\mathrm{C}_{70}$-derived interfacial layer.

\subsubsection{Electrochemical impedance spectroscopy of photo-anode film}

Electrochemical impedance spectroscopy (EIS), which can provide a more complete view of the structure of the photo-anodes, was performed under illumination at different applied potentials to elucidate the correlation of charge transport within the $\mathrm{WO}_{3}$ matrix with and without the graphitized $\mathrm{C}_{70}$ interfacial layer. These cells consist of three impedance components, which can be assigned to the $\mathrm{WO}_{3}$ /electrolyte interfacial impedance, the $\mathrm{WO}_{3}$ film impedance, and the $\mathrm{WO}_{3}$ (+graphitized $\mathrm{C}_{70}$ interface)/FTO interfacial impedance. ${ }^{19}$ However, only one arc appeared in each of the Nyquist plots in the measurements shown in Figure 4.5. It is probable that other impedance components are hidden by the large $\mathrm{WO}_{3} /$ electrolyte interfacial impedance. ${ }^{20}$ The size of arc of the impedance spectra is related to the charge transfer resistance $\left(\mathrm{R}_{\mathrm{ct}}\right)$ at the $\mathrm{WO}_{3}$ /electrolyte interface, and a smaller arc means easier charge transport. Generally, this charge transport is affected by the charge recombination both in the matrix and at the interface. Therefore, the smaller charge transfer resistance observed for $\mathrm{WO}_{3}$ photo-anodes with a graphitized $\mathrm{C}_{70}$ interfacial layer should imply a lower recombination rate. This can be attributed to the fact that the graphitic carbon created from $\mathrm{C}_{70}$ within the $\mathrm{WO}_{3}$ layer may facilitate electron mobility in the $\mathrm{WO}_{3}$ layer and lower the recombination rate between photo-generated electrons and holes, which thus results in effective charge transfer for water oxidation at the $\mathrm{WO}_{3}$ /electrolyte interface. 


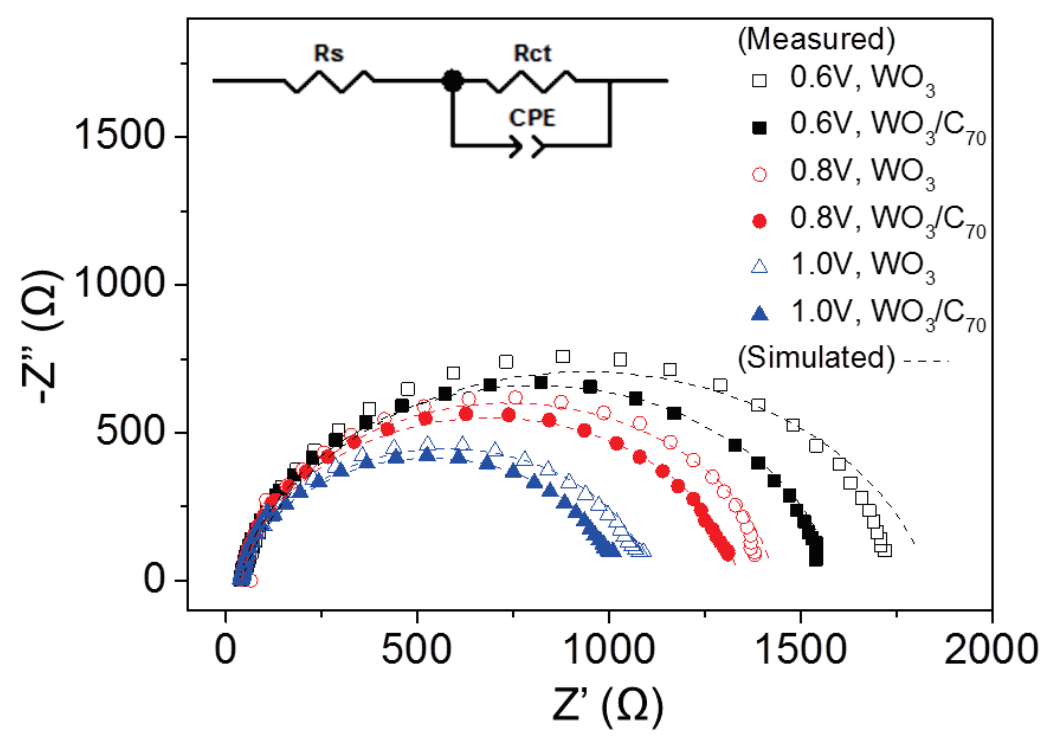

Figure 4.5. EIS spectra of $\mathrm{WO}_{3}$ films on $\mathrm{FTO}$ with and without the graphitized $\mathrm{C}_{70}$ interfacial layer at different applied potentials.

Table 4.2. Circuit parameters derived from the fitting of the EIS spectra.

\begin{tabular}{c|c|c|c|c|c}
\hline Potential & Samples & $\operatorname{Rs}(\Omega)$ & $\operatorname{Rct}(\Omega)$ & $\operatorname{CPE}(\mu \mathrm{F})$ & $\tau(\mathrm{s})$ \\
\hline \multirow{2}{*}{$0.6 \mathrm{~V}$} & w/o $\mathrm{C}_{70}$ & 41 & 1795 & 92 & 0.85 \\
\cline { 2 - 6 } & w/ $\mathrm{C}_{70}$ & 37 & 1542 & 69 & 0.56 \\
\hline \multirow{2}{*}{$0.8 \mathrm{~V}$} & w/o C 70 & 42 & 1390 & 100 & 0.69 \\
\cline { 2 - 6 } & w/ $C_{70}$ & 37 & 1303 & 78 & 0.45 \\
\hline \multirow{2}{*}{$1.0 \mathrm{~V}$} & w/o C 70 & 39 & 1073 & 118 & 0.56 \\
\cline { 2 - 6 } & w/ $C_{70}$ & 38 & 991 & 94 & 0.37 \\
\hline
\end{tabular}

The $\mathrm{R}_{\mathrm{ct}}$ and time constants $(\tau)$ of holes in the $\mathrm{WO}_{3}$ photo-anodes decrease with an increase in bias (Table 4.2). The photo-anodes with a graphitized $\mathrm{C}_{70}$ interfacial layer had a shorter time constant, which indicates a faster hole-transfer process at water oxidation sites caused by the facile transportation of unrecombined holes. The gradual decrease of $\Delta \mathrm{R}_{\mathrm{ct}}$ between photoanodes with and without a graphitized $\mathrm{C}_{70}$ interface was observed with increasing bias, and on the basis of this observation, a prediction can be made that the role of the graphitized $\mathrm{C}_{70}$ interfacial layer in the solar to fuel device is more effective at low overpotentials. 


\subsection{Conclusions}

We have demonstrated that interfacial layer fabricated from $\mathrm{C}_{70}$ inserted between $\mathrm{WO}_{3}$ and FTO-coated glass forms a discrete interlayer of graphitic carbon that is partially grown into the $\mathrm{WO}_{3}$ layer. These interfacial layers enhance the performance of $\mathrm{WO}_{3}$ photo-anodes for water splitting significantly. Regular and time-resolved photoluminescence spectroscopy, photoconductive atomic force microscopy, the Hall effect, and electrochemical impedance spectroscopy show that the graphitized $\mathrm{C}_{70}$ layer induces effective transfer of optically excited electrons from $\mathrm{WO}_{3}$ to FTO, while hole transfer is retarded. The modification of interfaces using graphitized carbon materials based on fullerene in photo-electrodes is thus crucial to fabricate cheap and highly efficient large-area solar to fuel devices.

\subsection{References}

1. Osterloh, F. E. Chem. Soc. Rev. 2013, 42, 2294-2320.

2. Li, Z.; Luo, W.; Zhang, M.; Feng, J.; Zou, Z. Energy Environ. Sci. 2013, 6, 347-370.

3. Joya, K. S.; Joya, Y. F.; Ocakoglu, K.; van de Krol, R. Angew. Chem., Int. Ed. Engl. 2013, 52, 10426-10437.

4. Ampelli, C.; Centi, G.; Passalacqua, R.; Perathoner, S. Energy Environ. Sci. 2010, 3, 292301.

5. Centi, G.; Quadrelli, E. A.; Perathoner, S. Energy Environ. Sci. 2013, 6, 1711-1731.

6. Fujishima, A.; Honda, K. Nature 1972, 238, 37-38.

7. Kibria, M. G.; Nguyen, H. P. T.; Cui, K.; Zhao, S.; Liu, D.; Guo, H.; Trudeau, M. L.; Paradis, S.; Hakima, A.-R.; Mi, Z. ACS Nano 2013, 7, 7886-7893.

8. Cox, C. R.; Winkler, M. T.; Pijpers, J. J. H.; Buonassisi, T.; Nocera, D. G. Energy Environ. Sci. 2013, 6, 532-538.

9. Youngblood, W. J.; Lee, S. H. A.; Maeda, K.; Mallouk, T. E. Acc. Chem. Res. 2009, 42, 1966-1973.

10. Alibabaei, L.; Brennaman, M. K.; Norris, M. R.; Kalanyan, B.; Song, W.; Losego, M. D.; Concepcion, J. J.; Binstead, R. A.; Parsons, G. N.; Meyer, T. J. Proc. Natl. Acad. Sci. USA 2013, 110, 20008-20013.

11. Li, X.; Lu, W.; Dong, W.; Chen, Q.; Wu, D.; Zhou, W.; Chen, L. Nanoscale 2013, 5, 5257-5261.

12. Peng, Q.; Kalanyan, B.; Hoertz, P. G.; Miller, A.; Kim, D. H.; Hanson, K.; Alibabaei, L.; Liu, J.; Meyer, T. J.; Parsons, G. N.; Glass, J. T. Nano Lett. 2013, 13, 1481-1488.

13. Higashi, M.; Domen, K.; Abe, R. Energy Environ. Sci. 2011, 4, 4138-4147.

14. Mubeen, S.; Lee, J.; Singh, N.; Krämer, S.; Stucky, G. D.; Moskovits, M. Nat. Nanotechnol. 2013, 8, 247-251.

15. Mwakikunga, B. W.; Forbes, A.; Sideras-Haddad, E.; Scriba, M.; Manikandan, E. Nanoscale Res. Lett. 2009, 5, 389-397. 
16. Valova, E.; Georgieva, J.; Armyanov, S.; Sotiropoulos, S.; Hubin, A.; Baert, K.; Raes, M. J. Electrochem. Soc. 2010, 157, D309-D315.

17. Vernardou, D.; Drosos, H.; Spanakis, E.; Koudoumas, E.; Savvakis, C.; Katsarakis, N. J. Mater. Chem. 2011, 21, 513-517.

18. Ferrari, A. C. Solid State Commun. 2007, 143, 47-57.

19. Zhang, K.; Shi, X.; Kim, J. K.; Lee, J. S.; Park, J. H. Nanoscale 2013, 5, 1939-1944.

20. Du, P.; Song, L.; Xiong, J.; Li, N.; Wang, L.; Xi, Z.; Wang, N.; Gao, L.; Zhu, H. Electrochim. Acta 2013, 87, 651-656. 


\subsection{Appendix}

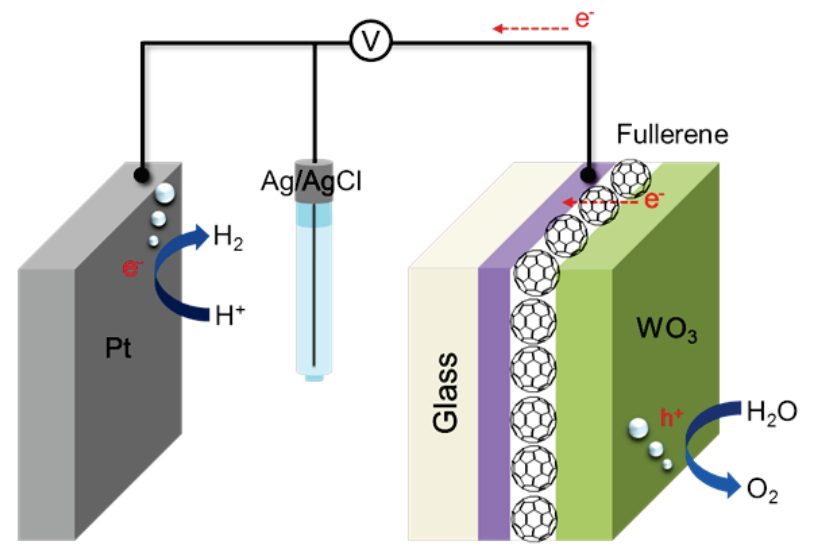

Figure A4.1. Schematic description of the applied PEC cell.

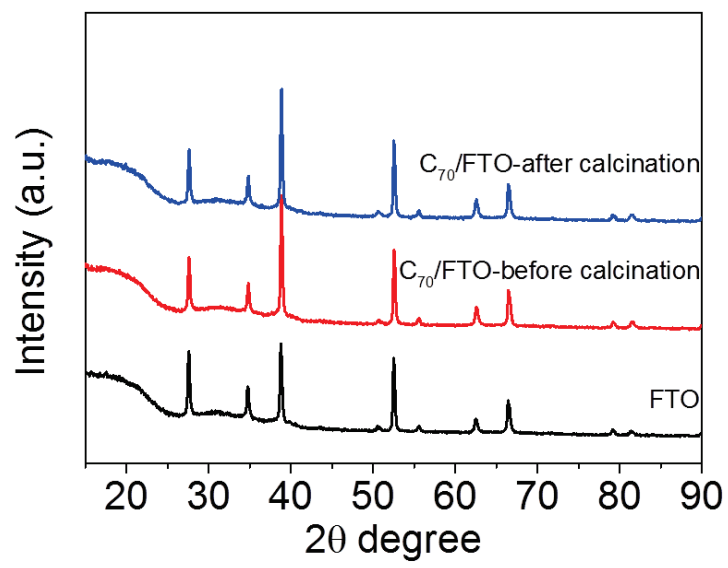

Figure A4.2. XRD patterns of $\mathrm{C}_{70} / \mathrm{FTO}$ before and after calcination. 

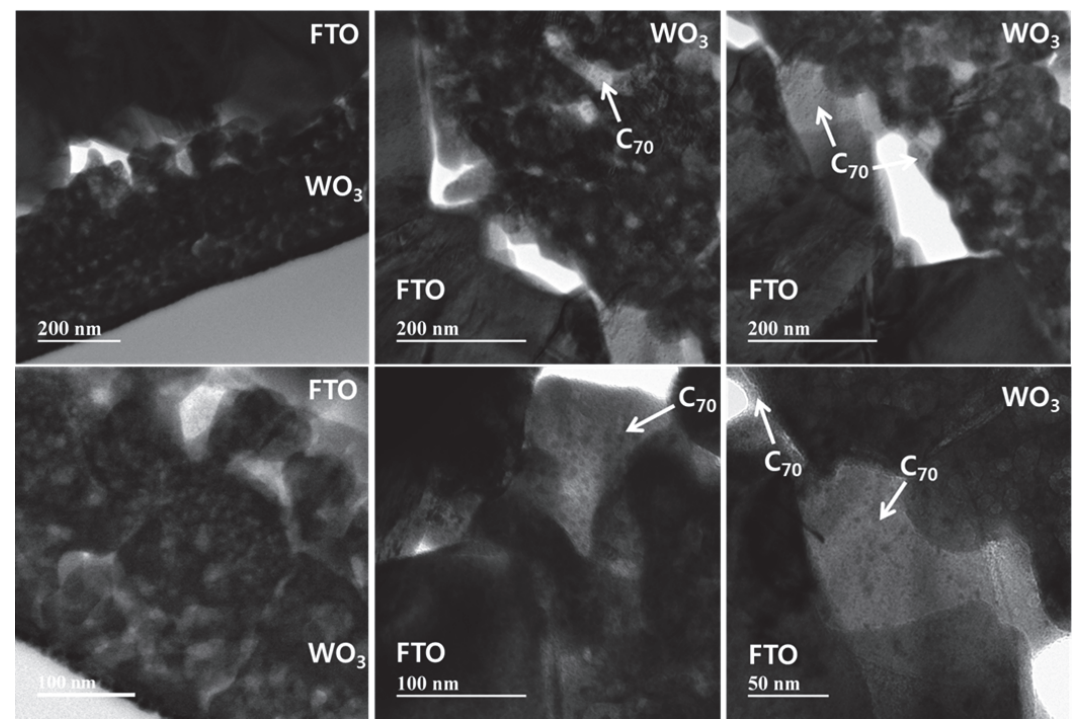

Figure A4.3. TEM images of $\mathrm{WO}_{3}$ films with and without the graphitized $\mathrm{C}_{70}$ interfacial layer.

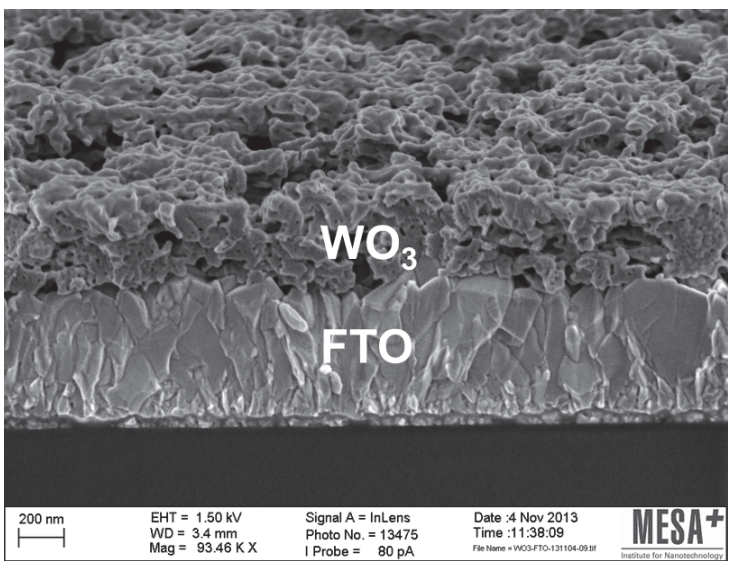

60 Figure A4.4. Cross sectional SEM images of the $\mathrm{WO}_{3}$ film. 


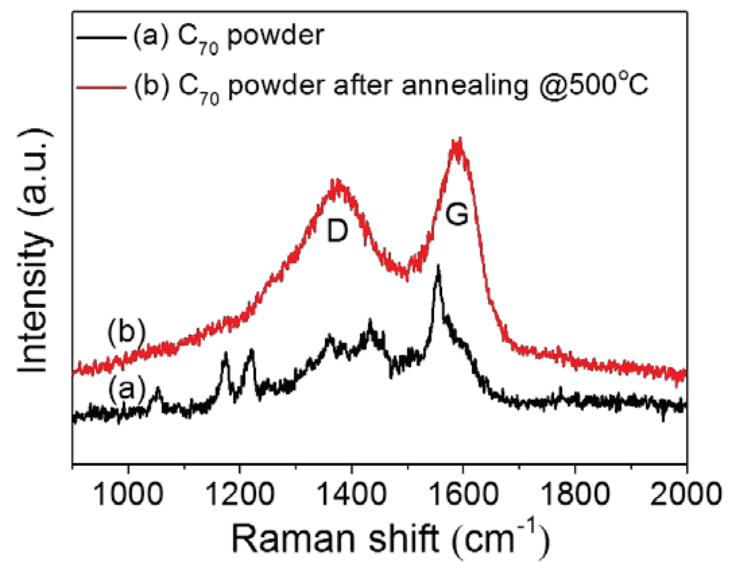

Figure A4.5. Raman spectra of $\mathrm{C}_{70}$ powder before and after annealing.

(a)

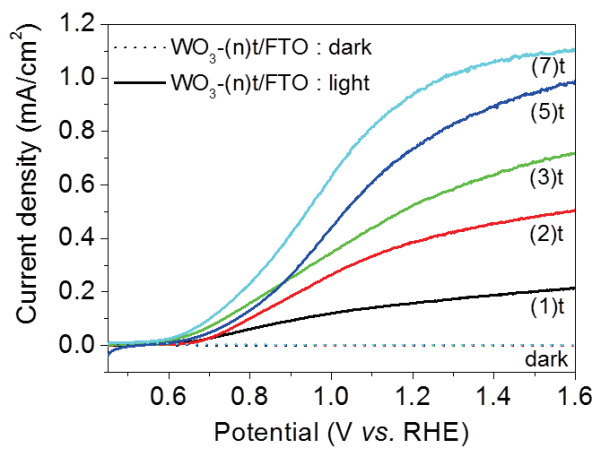

(b)

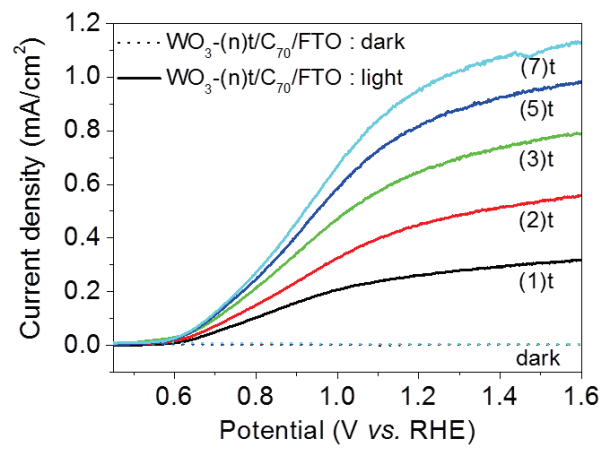

Figure A4.6. Curves of current density versus potential (V vs. RHE) for $\mathrm{WO}_{3}$ films with various thickness, $t$ indicating the number of coating cycles, (a) without the graphitized $\mathrm{C}_{70}$ interfacial layer and (b) with the graphitized $\mathrm{C}_{70}$ interfacial layer. 

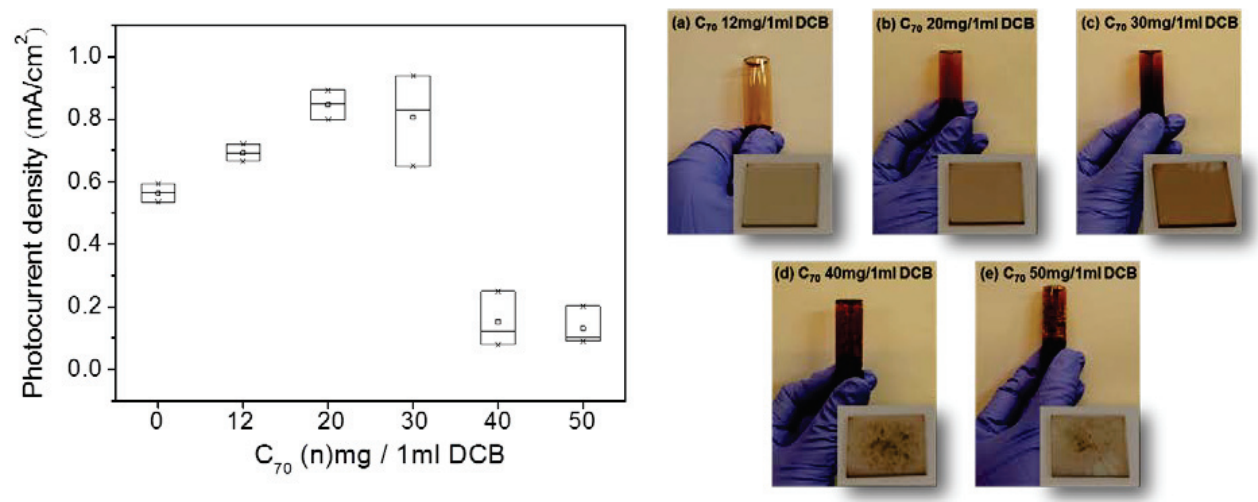

Figure A4.7. (left) Current density of $\mathrm{WO}_{3}$ films in simulated $\mathrm{AM} 1.5$ illumination depending on the concentration of $\mathrm{C}_{70}$ dissolved in 1,2-dichlorobenzene(DCB). Clearly increasing the $\mathrm{C}_{70}$ quantity yields an increasing photocurrent density after thermal graphitization. Attempts to increase the concentration above $30 \mathrm{mg} / \mathrm{mL}$ (in DCB) did not result in homogeneous solutions due to the limited solubility of $\mathrm{C}_{70}$ in $\mathrm{DCB}$, and therefore did not yield a homogeneous coating on FTO electrode (right side, photograph of $\mathrm{C}_{70}$ solution dissolved in DCB and $\mathrm{C}_{70}$ film coated on FTO electrode before annealing).
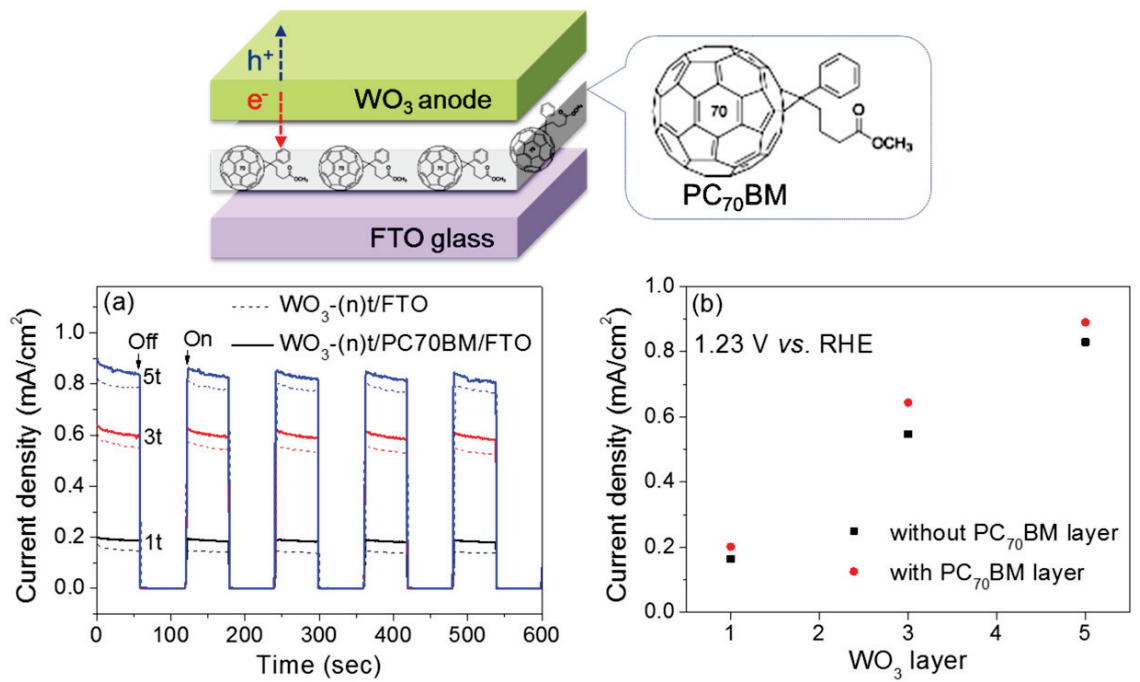

Figure A4.8. (a) Chronoamperometry at an applied potential of $1.23 \mathrm{~V} v$ s. RHE under light chopping condition. (b) Current density versus potential curves in simulated AM 1.5 illumination for the $\mathrm{WO}_{3}$ film with and without graphitized phenyl- $\mathrm{C}_{70}$-butyric acid methyl ester $\left(\mathrm{PC}_{70} \mathrm{BM}\right)$. 

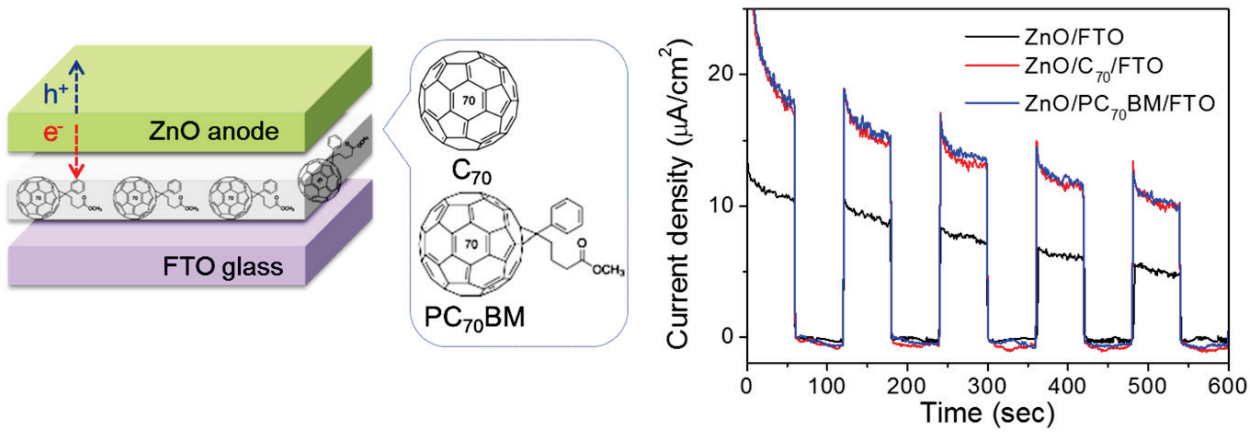

Figure A4.9. Chronoamperometry at an applied potential of $1.23 \mathrm{~V}$ vs. RHE under light chopping condition for $\mathrm{ZnO}$ photo-anode with graphitized $\mathrm{C}_{70}$ and graphitized $\mathrm{PC}_{70} \mathrm{BM}$ (electrolyte : $0.2 \mathrm{M} \mathrm{KHCO}_{3}$ ).

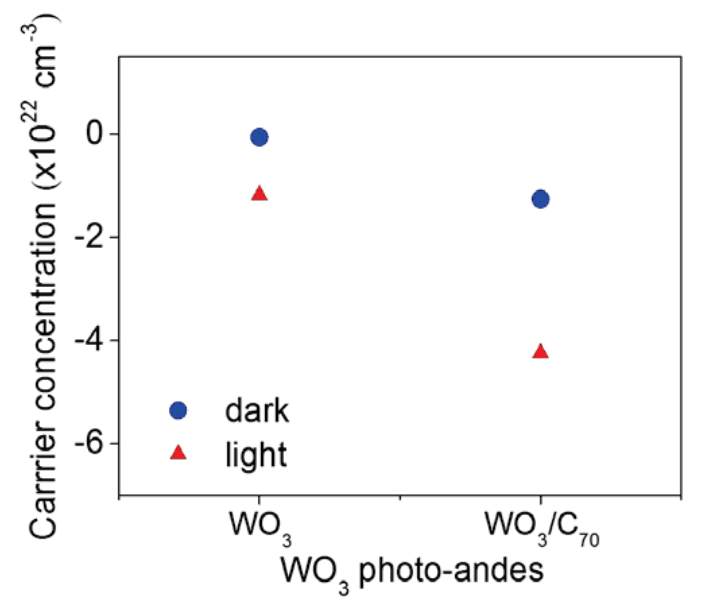

Figure A4.10. Hall effect measurement, comparing the carrier concentration in the absence or presence of the graphitized $\mathrm{C}_{70}$ interfacial layer. 

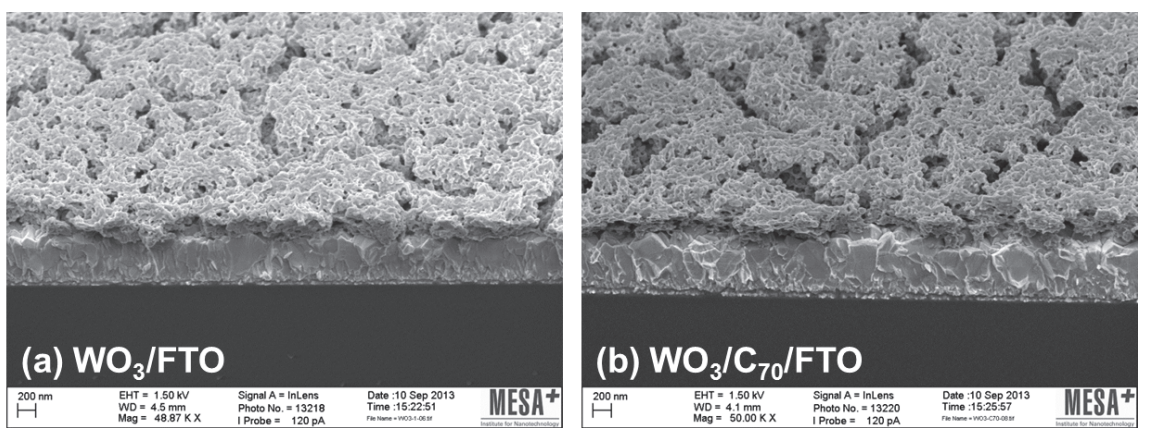

Figure A4.11. SEM images of $\mathrm{WO}_{3}$ films in the absence or presence of the graphitized $\mathrm{C}_{70}$ interfacial layer. 


\section{Chapter 5}

Metal assisted opto-electrical enhancement of tandem photoelectrochemical cells

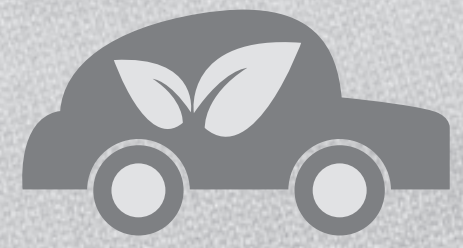

This chapter has been submitted: S.-Y. Park, E.M. Hong, R. Elbersen, Y. Song, J. Huskens, H. Gardeniers, J.-Y. Lee, J. Heo, D.C. Lim, G. Mul, Metal assisted opto-electrical enhancement of tandem photoelectrochemical cells. 


\begin{abstract}
Solar to hydrogen conversion by water splitting is a promising approach to alleviate problems associated with intermittency in supply and demand of solar electricity. We demonstrate the performance of novel anodes in photoelectrochemical (PEC) water splitting, composed of 1) $\mathrm{p}^{+} \mathrm{n}$ doped $\mathrm{Si}$ pillars, 2) an ultra-thin metal ( $\mathrm{Au}$ or $\mathrm{Pt}$ ) film prepared by electron-beam evaporation, and 3) $\mathrm{WO}_{3}$ as photoactive water oxidation catalyst. While Pt deposition by electron-beam evaporation resulted in a homogenous thin film, Au deposition lead to nanoparticles with well-ordered interspacing. This Au interface induced a significantly higher activity in overall water splitting as compared to $\mathrm{WO}_{3} / \mathrm{p}^{+} \mathrm{n}$ Si devices either without a metal interface, or equipped with the Pt film. The enhancement in performance by the $\mathrm{Au}$ nanoparticles is proposed to be the result of 1) improvement of exciton generation in $\mathrm{p}^{+} \mathrm{n} \mathrm{Si}$ induced by surface plasmon resonance, as evident from Raman spectroscopic analysis, and 2) high efficiency of favorable electron-hole recombination as demonstrated by photoconductive AFM studies. The unique opto-electronic properties of the Au nanoparticles hold promise for the construction of efficient tandem photo-anodes to be applied in PEC devices for efficient solar hydrogen formation.
\end{abstract}




\subsection{Introduction}

Photoelectrochemistry (PEC) is one of the technologies currently developed to enable light induced water splitting yielding hydrogen, based on the first discovery of UV light effective $\mathrm{TiO}_{2}$ photo-anodes by Fujishima and Honda. ${ }^{1}$ Many research efforts have focused on the development of visible light sensitive semiconductors to be used as photo-anode or photocathode, to increase the direct solar to hydrogen (STH) efficiency. One of the means to create a visible light-responsive STH device, is to construct a tandem photo-anode, of which the band positions of materials confirm to a so-called Z-scheme. An example is connecting a semiconductor by which the $\mathrm{O}_{2}$ evolution reaction (OER) is driven, such as $\mathrm{WO}_{3}$ or $\mathrm{BiVO}_{4}$, to a semiconductor with a relatively small band gap, such as $\mathrm{Si}, \mathrm{GaAs}$, or alternatively to dyesensitized photovoltaics. ${ }^{2-8}$ In such a configuration of the tandem photo-anode, an external bias voltage is principally no longer necessary to achieve overall water splitting, on the condition that the $\mathrm{Si}, \mathrm{GaAs}$, or dye-sensitized photovoltaic component of the layered photoanode is connected to an efficient cathode for $\mathrm{H}_{2}$ evolution. An important property of tandem based photo-anodes (or Z-scheme) is that two photons are required to generate one electronhole pair of sufficient energy to initiate overall water splitting, while the other electron-hole pair of lower energy needs to recombine efficiently to prevent energy loss of the former pair. Interfacial recombination is thus extremely important in achieving high photocurrents in advanced photoelectrochemical cells containing tandem based photo-anodes. ${ }^{9}$ However, the interface of tandem devices often shows non-ohmic behavior, thereby deteriorating performance. To create ohmic behavior between two semiconductors, one can introduce an intermittent conducting layer. An example of this concept has recently been demonstrated by Lewis et al., who introduced an indium tin oxide (ITO) layer between $\mathrm{WO}_{3}$ and Si to enhance the efficiency of interfacial charge recombination, and thus STH efficiency. ${ }^{10}$

In this study, we will discuss the performance of a device based on $\mathrm{WO}_{3}$ deposited on a radially doped $\mathrm{p}^{+} \mathrm{n}$ junction $\mathrm{Si}$ micro-pillar array. $\mathrm{WO}_{3}$ has been frequently reported as a stable (in acidic conditions) and effective photo-anode. At the same time, doped and pillared Si has the advantage of efficient long wavelength absorption, effective charge separation, and short radial internal diffusion lengths (of holes in this study). Furthermore, the combination of these two semiconductors satisfies the band edge requirements for Z-scheme (tandem) based STH conversion: the valence band maximum of $\mathrm{Si}$ is below the conduction band minimum of the photo-anode $\left(\mathrm{WO}_{3}\right) .{ }^{11}$ To establish ohmic contact between $\mathrm{WO}_{3}$ and (doped) $\mathrm{Si}$, rather than ITO or FTO, which two materials still induce considerable resistance, ${ }^{10}$ we introduced a metal film of Pt or Au between $\mathrm{WO}_{3}$ and the Si micro-pillar array as shown in Figure A5.1 in the Appendix. Pt and Au were considered as promising metals due to their favorable electrical conductivity and Fermi levels, anticipated to allow efficient (desired) recombination of the electron $\left(\mathrm{WO}_{3}\right)$-hole $(\mathrm{Si})$ pair of insufficient energy for proton reduction or water oxidation, respectively. ${ }^{12}$ The metal work function should be located between the valence band maximum of the photo-cathode $(\mathrm{Si})$ and conduction band minimum of photo-anode $\left(\mathrm{WO}_{3}\right)$ to create ohmic behaviour. The work function of $\mathrm{Au}$ is $4.8 \sim 5.1 \mathrm{eV}^{13,14}$ and of Pt $5.5 \sim 5.8 \mathrm{eV},,^{15,16}$ 
confirming to this requirement. The metal films need to be ultra-thin, to minimize optical attenuation. We will show that ultra-thin $\mathrm{Pt}$ and $\mathrm{Au}$ interfacial layers prepared by electronbeam evaporation can indeed improve the electrical contact between $\mathrm{WO}_{3}$ and doped $\mathrm{Si}$, resulting in a significant cathodic shift of the onset potential of water splitting in a PEC cell configuration. Furthermore, it will be shown that the interfacial layer consisting of $\mathrm{Au}$ nanoparticles promotes solar to hydrogen efficiency by plasmonic effects. These plasmonic effects are confirmed by in depth photoconductive atomic force microscopy (PC-AFM), and Raman analysis.

\subsection{Experimental section}

\subsubsection{Fabrication of the $p^{+} n$ micro-pillar Si array}

On n-type Si substrates, arrays of Si microstructures were fabricated. The height of the pillars was determined by the etch duration of deep reactive ion etching (DRIE), and was set to $10 \mathrm{~min}$, resulting in pillar heights of approximately $30 \mu \mathrm{m}$. The fabricated Si micro-pillar arrays were hexagonal with a packing density of $35 \%$ (diameter $4 \mu \mathrm{m}$, spacing $2 \mu \mathrm{m}$ ). Boron doping of flat n-type Si wafers or the arrays of the Si micro-pillars, was achieved using solid source dotation (SSD). The backside was covered with phosphorus oxide by low-pressure chemical vapor deposition (LPCVD), followed by a drive-in step at $1050{ }^{\circ} \mathrm{C}$ for $15 \mathrm{~min}$, to create $\mathrm{n}^{+}$doping, which was needed to ensure ohmic contact with $\mathrm{Al}$. Al was deposited on the back-side of the wafers in the final stage of preparation (see the following paragraph). The fabrication of the doped Si wafers, formation of the pillars, and the characterization of these samples has been described in more detail elsewhere. ${ }^{17}$

\subsubsection{Deposition of the metal layer, $\mathrm{WO}_{3}$, and the Al back contact}

A Pt or Au interfacial layer with a nominal thickness of $\sim 1 \mathrm{~nm}$ was formed on the surface of the $\mathrm{p}^{+} \mathrm{n} \mathrm{Si}$ wafers either in the absence or presence of the micro-pillar array, by using electron-beam evaporation. Before preparation of the metal interfacial layer, Si substrates were chemically etched using $5 \%$ aqueous HF solution to remove the native Si oxide.

$\mathrm{WO}_{3}$ films in the absence or presence of the metal interlayer and with a thickness of $\sim 250 \mathrm{~nm}$ were deposited on the $\mathrm{p}^{+} \mathrm{n}$ Si planar wafer, or $\mathrm{p}^{+} \mathrm{n}$ Si micro-pillar arrays, by using RF magnetron sputtering from a 3 inch $\mathrm{WO}_{3}$ target at room temperature and at a working pressure of 5 mTorr. At a constant RF power of $50 \mathrm{~W}$, Ar and $\mathrm{O}_{2}$ flow rates of $50 \mathrm{sccm}$ and $0.5 \mathrm{sccm}$ were applied, respectively. Subsequently, the Al contact was prepared on the back side of the Si wafer in an $\mathrm{Al}$ evaporation chamber. The final thickness of the Al films was fixed at $\sim 100 \mathrm{~nm}$. After deposition of $\mathrm{WO}_{3}$ and $\mathrm{Al}$, the various samples were treated at $500{ }^{\circ} \mathrm{C}$ for $2 \mathrm{hr}$ in aerobic conditions. One sample was prepared with a thicker $\mathrm{WO}_{3}$ layer, by 
increasing the power during RF sputtering from $50 \mathrm{~W}$ to $250 \mathrm{~W}$, and annealing the film after $\mathrm{Al}$ deposition at $600{ }^{\circ} \mathrm{C}$ for $4 \mathrm{hr}$ in aerobic conditions.

\subsubsection{Analysis of the photo-anodes}

The surface and interfacial structures of the photo-anodes were analyzed using a field emission scanning electron microscope (FE-SEM, Zeiss LEO 1550). Raman spectra of functionalized planar Si wafers were recorded using a Horiba, Labram HR instrument.

PC-AFM analysis was performed using an E-sweep SPM microscope (Seiko Instruments, Japan), interfaced with an external light source to observe the effects of light intensity and wavelength on the photoelectric characteristics. The cantilever tip used as the electrode was a conductive diamond coated Si tip doped with boron, and its resonance frequency and force constant were $105 \mathrm{kHz}$ and $6.2 \mathrm{~N} / \mathrm{m}$, respectively. PC-AFM analysis was performed at ambient temperature and pressure, and measurements were typically performed at a DC bias of $1 \mathrm{~V}$, applied between the conductive tip and the Al backside of the anode, to improve measurement efficiency. Dark current images of the surfaces were obtained after application of the DC bias only. This was followed by imaging of the currents under illumination. The set-up, and an exemplary scan of the doped Si pillars is shown in Figure A5.2. Photocurrents are clearly visible in the areas where the pillars are located.

For the modulation of light intensity, the power of a halogen lamp was increased from $0 \mathrm{~W}$ to $100 \mathrm{~W}$ at intervals of $10 \mathrm{~W}$, and the photocurrent was measured while the DC bias was swept from $-4 \mathrm{~V}$ to $4 \mathrm{~V}$ in each condition. The light-dependent threshold voltage $\left(\mathrm{V}_{\text {th }}\right)$, was determined from the intersect of the linear part of each curve with the $\mathrm{x}$-axis (voltage) of the measured I-V curves.

\subsubsection{Photoelectrochemical characterization}

Photoelectrochemical properties of the photo-anodes were determined in an aqueous electrolyte solution containing $0.1 \mathrm{M}$ of sodium sulfate of $\mathrm{pH} \sim 3.6$. The potential of the anode was controlled by a bi-potentiostat (CompactStat, IVIUM tech.). In three-electrode measurements, a Pt wire and a $\mathrm{Ag} / \mathrm{AgCl}$ electrode ( $3 \mathrm{M} \mathrm{NaCl}, \mathrm{BASi}$ ) were used as the counter and reference electrodes, respectively. Photocurrents were measured under illumination by an AM 1.5 solar simulator $\left(100 \mathrm{~mW} / \mathrm{cm}^{2}\right)$ with a $300 \mathrm{~W}$ Xe lamp and an air mass 1.5 global filter. The intensity of the simulated sunlight was calibrated using a standard reference Si solar cell. Solar light was exposed to the front side of the photo-anode $\left(\mathrm{WO}_{3}\right)$ layer. The photoactive area was $1.02 \mathrm{~cm}^{2}$. 


\subsection{Results and discussion}

\subsubsection{Characteristic of tandem device}

Figure 5.1a-h displays SEM images of the $\mathrm{WO}_{3}$-coated Si micro-pillar array devices of the following compositions; 1) without any interfacial layer (5.1a, d), 2) with a Pt interfacial layer $(5.1 \mathrm{~b}, \mathrm{e})$, and 3) with a $\mathrm{Au}$ interfacial layer $(5.1 \mathrm{c}, \mathrm{f})$. Cracks in the $\mathrm{WO}_{3}$ layer of the Aucontaining specimen (Figure 5.1f), formed during sample preparation, show a $\mathrm{WO}_{3}$ layer thickness of about $250 \mathrm{~nm}$ on top of the surface of the $\mathrm{p}^{+} \mathrm{n}$ Si pillars. Figures $5.1 \mathrm{~g}$ and $5.1 \mathrm{~h}$ show cross-sectional images of high magnification, in which the morphology of the metal interfacial layer of the $\mathrm{WO}_{3} / \mathrm{Pt} / \mathrm{p}^{+} \mathrm{n} \mathrm{Si}$ and $\mathrm{WO}_{3} / \mathrm{Au} / \mathrm{p}^{+} \mathrm{n}$ Si constructs is highlighted. The metal interfacial layers display different structures: Pt formed a thin film with a rough surface (Figure 5.1g), while Au showed a dotted structure of isolated, individual Au nanoparticles (Figure 5.1h). The mean diameter of the nanoparticles was estimated to be 10 to $12 \mathrm{~nm}$. Moreover the Au nanoparticles were separated by distances on the order of approximately 10 $\mathrm{nm}$. The difference in morphology of $\mathrm{Pt}$ and $\mathrm{Au}$, obtained after calcination at high temperature, is likely related to a difference of the respective metals in melting temperature, metal-metal interactions, and interaction with the (doped) Si surface. It is also worth mentioning that $\mathrm{Au}$ and $\mathrm{Si}$ might form a eutectic mixture containing approximately $15 \mathrm{~mol}-\%$ $\mathrm{Si}$ and melting at temperatures as low as $380{ }^{\circ} \mathrm{C}$, while this eutectic phase separates again upon cooling in $\mathrm{Au}$ and $\mathrm{Si}$. The high temperature formation of silicide, if any, will thus have very limited effect on the conductive (an optical) properties of the Au based interfacial layer. $^{18}$

Exemplary for the high transmittance of light by Pt and Au metal films prepared by e-beam evaporation, is the analysis on FTO glass shown in Figure A5.3. A transmittance of approximately $80 \%$ is apparent. However, compared to the $\mathrm{Pt}$ layer, a transmittance significantly lower than $80 \%$ can be observed for wavelengths above $\sim 500 \mathrm{~nm}$ for the $\mathrm{Au}$ layer, wavelengths where surface plasmon resonance (SPR)-related light absorption of $\mathrm{Au}$ is feasible. It is also well known that SPR and electric field $\left(\left|E^{2}\right|\right)$ enhancement effects nearly disappear in metal nanoparticles or films that are less than $2 \mathrm{~nm}$ in size or thickness, respectively. ${ }^{19,20}$ Therefore, the observed optical absorption suggest the Au particles in our samples are larger than $2 \mathrm{~nm}$, in agreement with the SEM micrographs shown in Figure 5.1.

XRD patterns (Figure A5.4) demonstrate that $\mathrm{WO}_{3}$ is of the monoclinic phase. Diffraction lines of $\mathrm{Pt}$ or $\mathrm{Au}$ were not observed in the XRD patterns of the photo-anodes, likely due to the low quantity and nm thickness of the Au or Pt present. Metal films of few nm thickness can only be observed by specific XRD instrument configurations. ${ }^{21}$ 

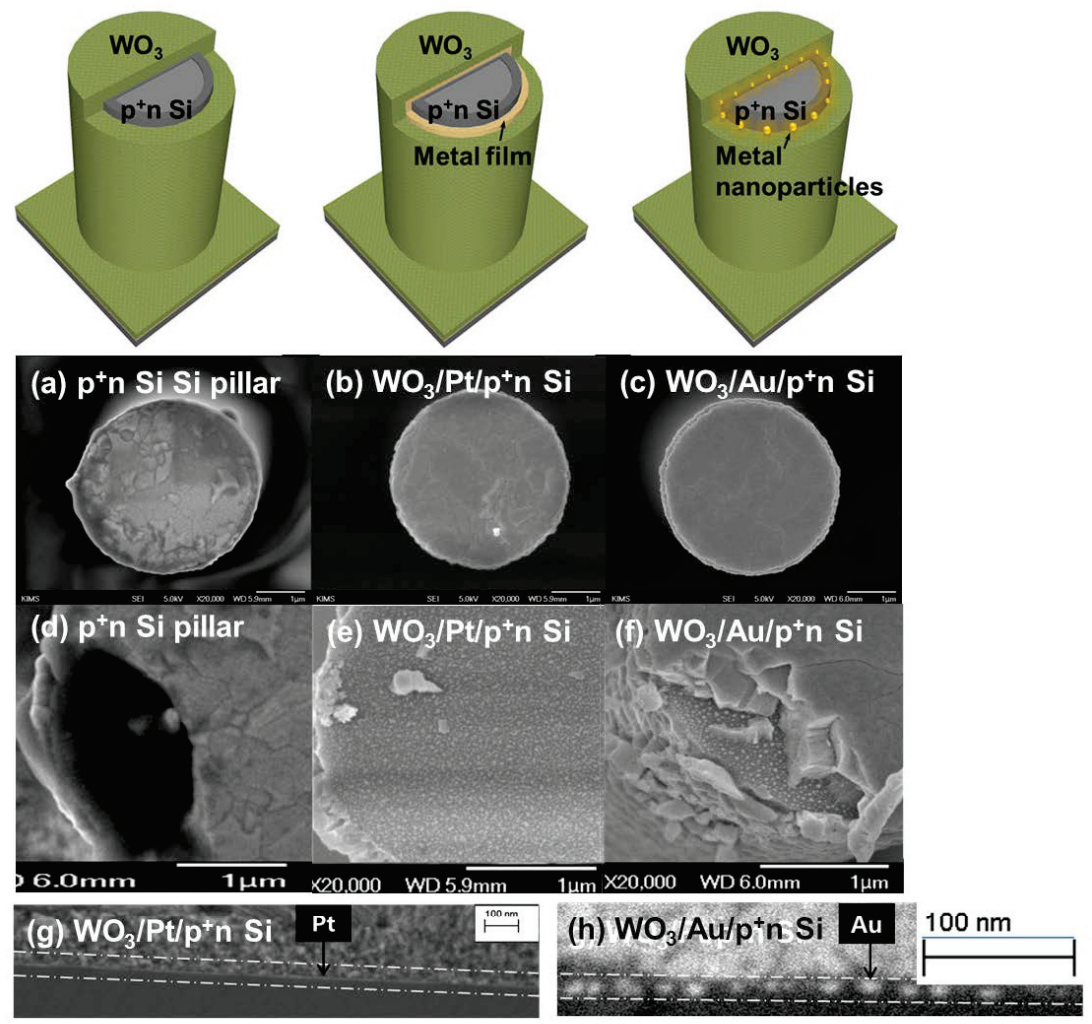

Figure 5.1. FE-SEM images of $\mathrm{WO}_{3}$ coated $\mathrm{p}^{+} \mathrm{n}$ Si pillars. (a-f) Top view of prepared samples as a function of interfacial layer, (g-h) cross sectional images of the Pt and Au interfacial layer between $\mathrm{WO}_{3}$ and $\mathrm{p}^{+} \mathrm{n} \mathrm{Si}$.

\subsubsection{Performance of tandem device}

Figure 5.2 shows the photoelectrochemical response of the three pillared devices constructed under simulated 1 sun illumination conditions. A photocurrent turn-on potential of $0.2 \mathrm{~V} v s$. RHE was observed for the three photo-anodes, which is significantly lower than the potential of $0.6 \mathrm{~V}$ vs. RHE usually reported for $\mathrm{WO}_{3}$ photo-anodes on FTO glass. ${ }^{22,23}$ This potential shift can be explained by the additional photovoltage $(0.4 \mathrm{~V})$ generated by the $\mathrm{p}^{+} \mathrm{n} \mathrm{Si}$ pillars upon illumination, and confirms that light is effectively transmitted through the metal interfaces.

When comparing photocurrent densities at a bias potential of $1.23 \mathrm{~V} v s$. RHE, the Pt interfacial layer improved the photocurrent density of the tandem photo-anode significantly, from 0.21 to $0.41 \mathrm{~mA} / \mathrm{cm}^{2}$. The Au interfacial layer showed an even higher photocurrent 
density of $0.71 \mathrm{~mA} / \mathrm{cm}^{2}$. The internal photon to current efficiency (IPCE (\%)) as a function of wavelength, is shown in Figure A5.5 for the planar $\mathrm{WO}_{3} / \mathrm{p}^{+} \mathrm{n} \mathrm{Si}$ configuration with and without the $\mathrm{Au}$ interfacial layer, corroborating the beneficial effect of $\mathrm{Au}$. Based on these results, the photoelectrochemical response of our tandem photo-anode is apparently largely determined by resistances in the $\mathrm{WO}_{3} / \mathrm{Si}$ interface. The result also implies that the resistance is decreased and (desired) recombination of electrons $\left(\mathrm{WO}_{3}\right)$ and holes $\left(\mathrm{p}^{+} \mathrm{n} \mathrm{Si}\right)$ promoted by the interfacial layer.

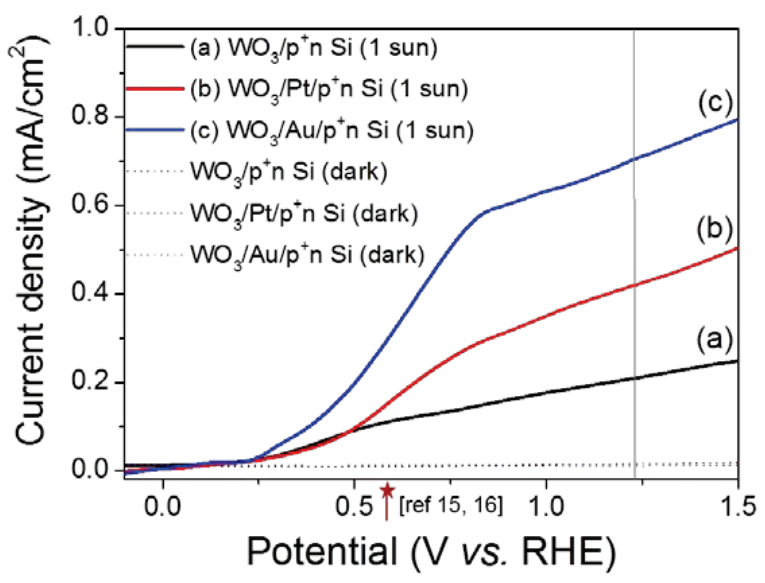

Figure 5.2. LSV plots under 1 sun conditions for (a) $\mathrm{WO}_{3} / \mathrm{p}^{+} \mathrm{n}$ Si pillar configuration (black) (b) $\mathrm{WO}_{3} / \mathrm{Pt} / \mathrm{p}^{+} \mathrm{n} \mathrm{Si}$ pillar configuration (red), and (c) $\mathrm{WO}_{3} / \mathrm{Au} / \mathrm{p}^{+} \mathrm{n}$ Si pillar configuration (blue). The star represents the reported conventional turn-on potential for $\mathrm{WO}_{3}$ photo-anodes on FTO glass.

To further improve the performance of the pillar configuration of $\mathrm{WO}_{3} / \mathrm{Au} / \mathrm{p}^{+} \mathrm{n} \mathrm{Si}$, the thickness of $\mathrm{WO}_{3}$ was increased. The result is shown in Figure 5.3. Clearly a thicker $\mathrm{WO}_{3}$ film increases the performance of the pillar configuration of $\mathrm{WO}_{3} / \mathrm{Au} / \mathrm{p}^{+} \mathrm{n}$ Si yielding a photocurrent density of $1.09 \mathrm{~mA} / \mathrm{cm}^{2}$ at $1.23 \mathrm{~V} v s$. RHE (as compared to $0.71 \mathrm{~mA} / \mathrm{cm}^{2}$ for the thinner $\mathrm{WO}_{3}$ film, see Figure 5.2). Figure 5.3 also demonstrates the advantage of the pillar configuration: a similar planar configuration of $\mathrm{WO}_{3} / \mathrm{Au} / \mathrm{p}^{+} \mathrm{n}$ Si shows a lower photocurrent density of $0.94 \mathrm{~mA} / \mathrm{cm}^{2}$ at $1.23 \mathrm{~V}$ vs. RHE. These photocurrent densities are significantly higher than the ones reported in other studies for photo-anodes combining metal oxides with (doped) Si (table 1.1, chapter 1). 


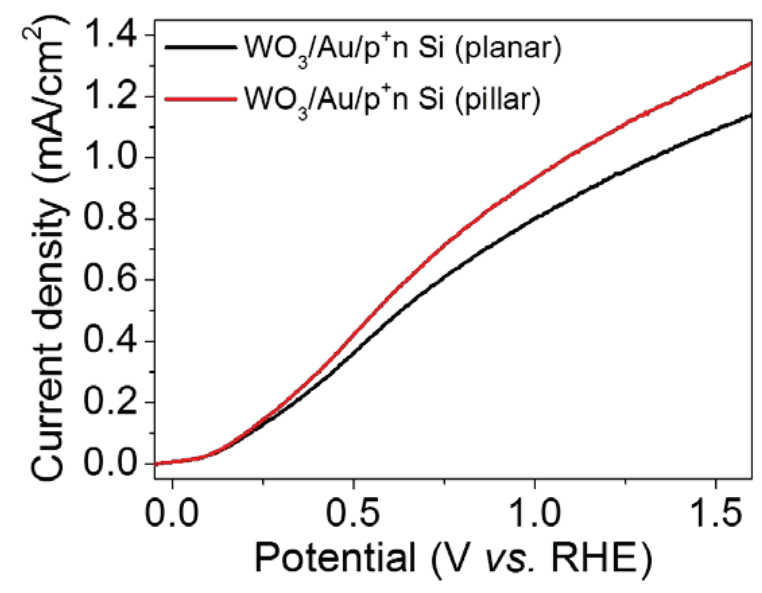

Figure 5.3. LSV plots under 1 sun condition for $\mathrm{WO}_{3} / \mathrm{Au} / \mathrm{p}^{+} \mathrm{n}$ Si planar configuration (black) and $\mathrm{WO}_{3} / \mathrm{Au} / \mathrm{p}^{+} \mathrm{n}$ Si pillar configuration (red). The power of magnetron sputtering for the deposition of a thick $\mathrm{WO}_{3}$ film was increased from $50 \mathrm{~W}$ to $250 \mathrm{~W}$, while annealing was performed at $600{ }^{\circ} \mathrm{C}$ for $4 \mathrm{hr}$.

\subsubsection{Optical characteristic of tandem device by Raman spectroscopy}

Based on the absence of any specific (plasmonic) absorptions of Pt (Figure A5.3), the positive effects of $\mathrm{Pt}$ on performance can only be related to favorable electrical conductivity. The improved photocurrents by the presence of the Au interfacial layer might also be related to optical effects, and/or specific properties in moderating electrical resistance at the interface. Raman spectroscopy was applied to analyze the consequences of Au plasmon absorption for modification of the optical properties of the photo-anode. Figure 5.4 shows Raman intensities at $518 \mathrm{~cm}^{-1}$ and at 710 and $805 \mathrm{~cm}^{-1}$ of the (planar) tandem photo-anode configurations, which can be attributed to $\mathrm{Si}-\mathrm{Si}\left(518 \mathrm{~cm}^{-1}\right)$ and $\mathrm{W}-\mathrm{O}-\mathrm{W}$ stretching modes, respectively. ${ }^{24,25}$ Depending on the composition of the interface, only the peak intensity of Si changes. The relative Si intensity was lowered by the presence of $\mathrm{Pt}$, likely because of absorption of (Raman) photons by the Pt film, in agreement with the $20 \%$ reduction in transmittance (Figure A5.3). On the other hand, Au resulted in a higher relative Raman intensity of Si as compared to $\mathrm{WO}_{3}$. The high $\mathrm{Si}$ over $\mathrm{WO}_{3}$ ratio was confirmed by analyzing Au-containing samples prepared by other methods (Figures A5.6 and A5.7). The higher intensity of Si can be understood by assuming an SPR effect induced by the Au nanoparticles. Wavelengths absorbed by $\mathrm{Au}$ in the visible region are similar to those absorbed by $\mathrm{Si}$ : a prerequisite for plasmon-induced electromagnetic field enhancement of Raman intensities, as well as stimulated light absorption by $\mathrm{Si}$, relevant for the performance of the $\mathrm{WO}_{3} / \mathrm{Au} / \mathrm{p}^{+} \mathrm{n} \mathrm{Si}$ tandem photo-anode. ${ }^{26}$ The presence of these Au SPR-based phenomena is in agreement with the 
IPCE curves (Figure A5.5), showing dominant enhancement in the 500-700 nm wavelength range. Since the $\mathrm{WO}_{3}$ absorption edge is located at smaller wavelengths than visible absorption by $\mathrm{Au}$, these Raman bands are hardly enhanced by the presence of the $\mathrm{Au}$ nanoparticles, and therefore we conclude that $\mathrm{Au}$-induced attenuation of light absorption by $\mathrm{WO}_{3}$ is less likely to contribute to the relatively high performance of the $\mathrm{WO}_{3} / \mathrm{Au} / \mathrm{p}^{+} \mathrm{n} \mathrm{Si}$ tandem photo-anode as compared to the studied analogues.
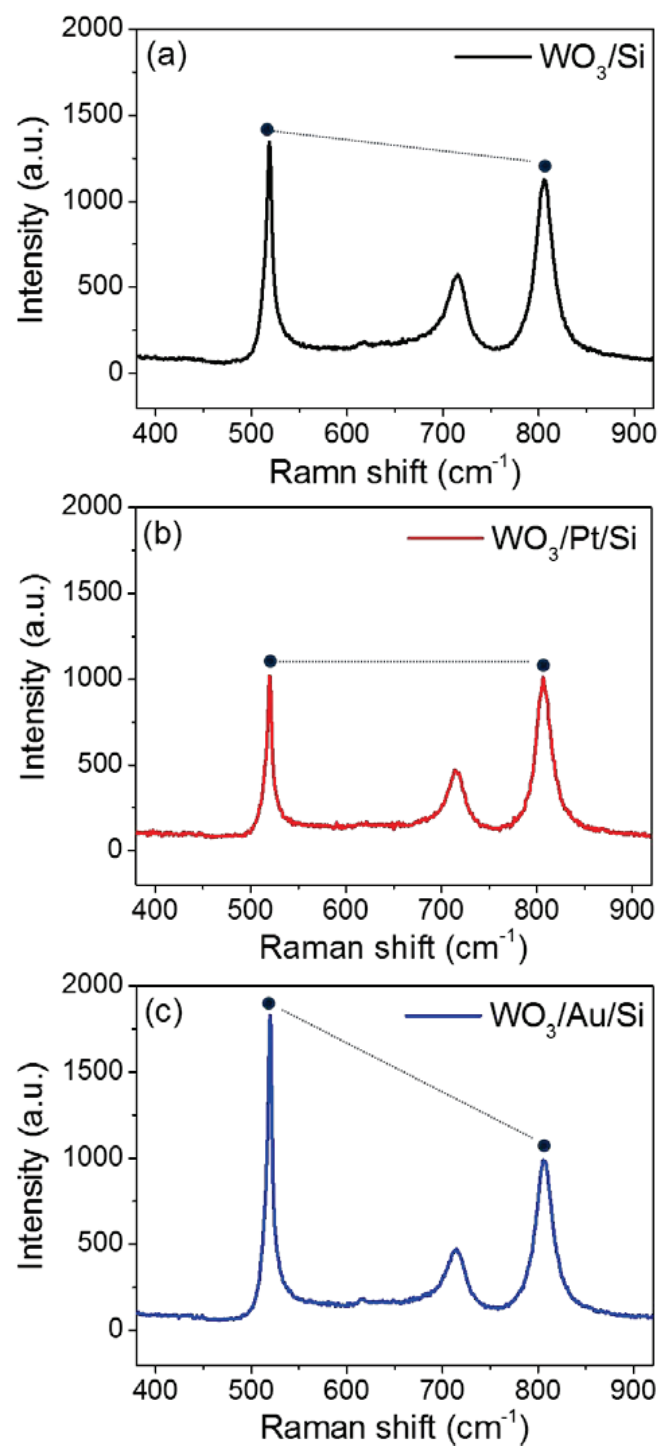

Figure 5.4. Raman spectra of the tandem devices. a) $\mathrm{WO}_{3} / \mathrm{Si}$, b) $\mathrm{WO}_{3} / \mathrm{Pt} / \mathrm{Si}$, c) $\mathrm{WO}_{3} / \mathrm{Au} / \mathrm{Si}$. 


\subsubsection{Electrical characteristic of tandem device by PC-AFM}

Further analysis of the conductive properties of the interfacial layers was performed by PC-AFM using the planar $\mathrm{WO}_{3} / \mathrm{Pt} / \mathrm{p}^{+} \mathrm{n} \mathrm{Si}$ and $\mathrm{WO}_{3} / \mathrm{Au} / \mathrm{p}^{+} \mathrm{n} \mathrm{Si}$ wafers. Figure 5.5 shows the geometrical PC-AFM scans of the surfaces of the two configurations under dark and light conditions. Clearly the currents and photocurrents were three orders of magnitude larger for the Au-containing substrate, suggesting higher conductance is induced by the Au-containing interfacial layer, corroborating the improved photo-electrochemical performance shown in Figures 5.2 and 5.3. Furthermore, the geometrical inhomogeneity in the photocurrents is likely related to the porous morphology of the $\mathrm{WO}_{3}$ films.
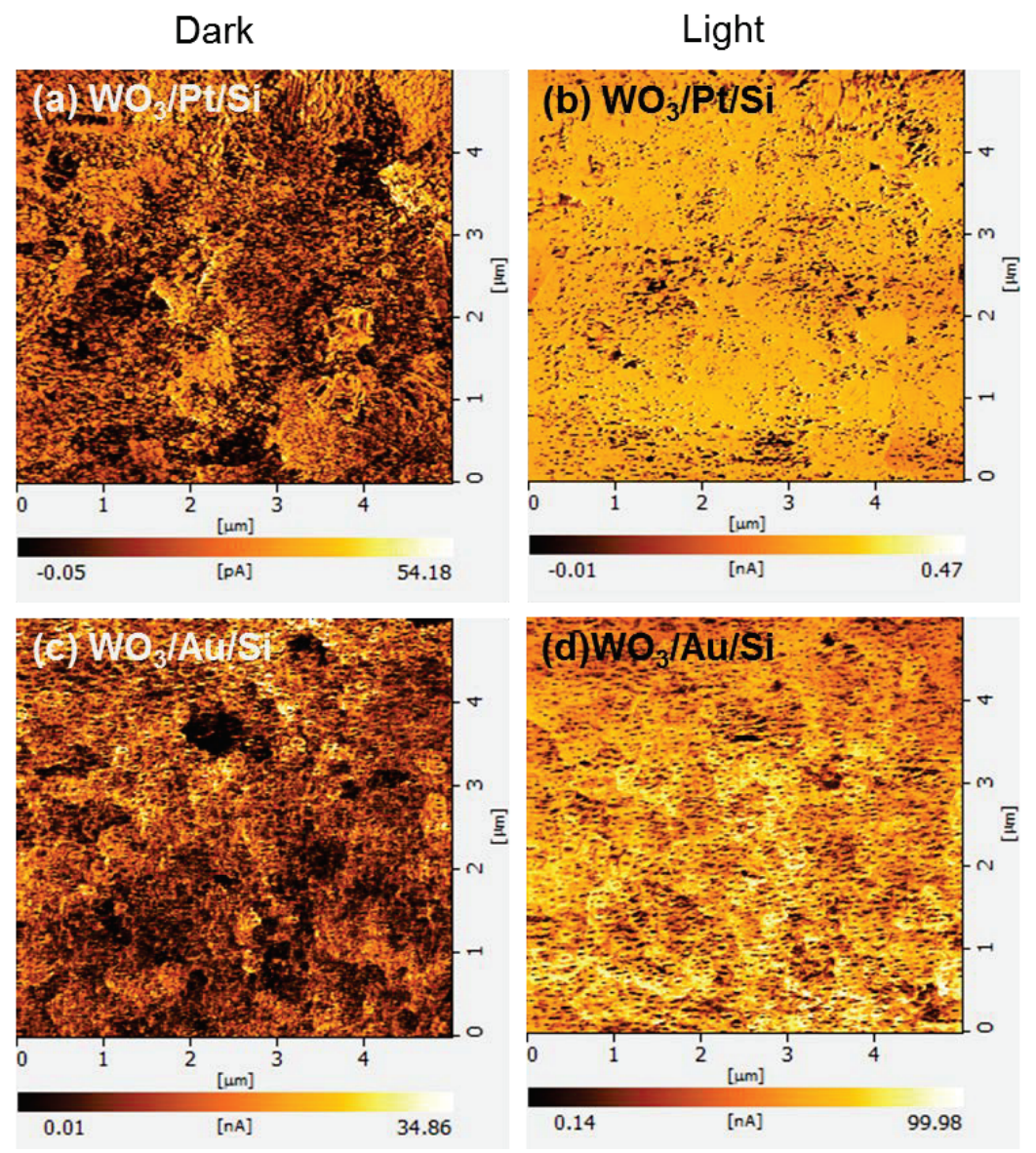

Figure 5.5. PC-AFM mapping of the current (at $1 \mathrm{~V}$ ) in dark and light conditions of the planar $\mathrm{WO}_{3} / \mathrm{Pt} / \mathrm{p}^{+} \mathrm{n} \mathrm{Si}$ (top) and $\mathrm{WO}_{3} / \mathrm{Au} / \mathrm{p}^{+} \mathrm{n} \mathrm{Si}$ (bottom) configurations. 
Characteristic I-V curves by PC-AFM of the prepared tandem photo-anodes, as a function of increasing power of illumination (varying power of the halogen lamp from $0 \mathrm{~W}$ to $100 \mathrm{~W}$ ), are shown in Figure 5.6. For both samples, I-V curves are shifted to less positive potentials with increasing light intensity, in agreement with the built-in potential $\left(\mathrm{V}_{\mathrm{bi}}\right)$ offset induced by $\mathrm{p}^{+} \mathrm{n}$ Si junction, and again confirming that the metal films are significantly light transparent. Threshold voltages $\left(\mathrm{V}_{\mathrm{th}}\right)$ of the devices as a function of light intensity are shown in Figure A5.8. More importantly, while for the photo-anode with the Pt interfacial layer the slope of the I-V curve (reciprocal resistance) is independent on light intensity, the slope of the I-V curve of the device with the $\mathrm{Au}$ interfacial layer increased markedly as a function of increasing light intensity. Photo-generated charge-carriers from $\mathrm{WO}_{3}$ and $\mathrm{p}^{+} \mathrm{n}$ Si are apparently recombined with constant resistance at the Pt interfacial layer, but with decreasing resistance at the $\mathrm{Au}$ interface when the light intensity is increased. This important observation implies that, besides optically based stimulation of $\mathrm{Si}$ by the Au nanoparticles (Figures 5.4, A5.3, A5.6, A5.7), plasmonic effects also contribute to enhancing photocurrent efficiency by lowering charge recombination resistances.

To explain this, we speculate that plasmon coupling forces beneficially affect charge transport and recombination properties of photo-excited electrons and holes. ${ }^{27,28}$ Near-field plasmon coupling forces at the inter-particle gaps of the Au nanoparticles give rise to a strong enhancement of the localized electromagnetic field induced by current flowing from $\mathrm{Si}$ to $\mathrm{WO}_{3}$. This (light intensity dependent) electromagnetic field enhancement might contribute to the experimentally observed reduction in electrical resistance of the interface of $\mathrm{WO}_{3}$ and $\mathrm{p}^{+} \mathrm{n}$ Si when Au nanoparticles are present. 

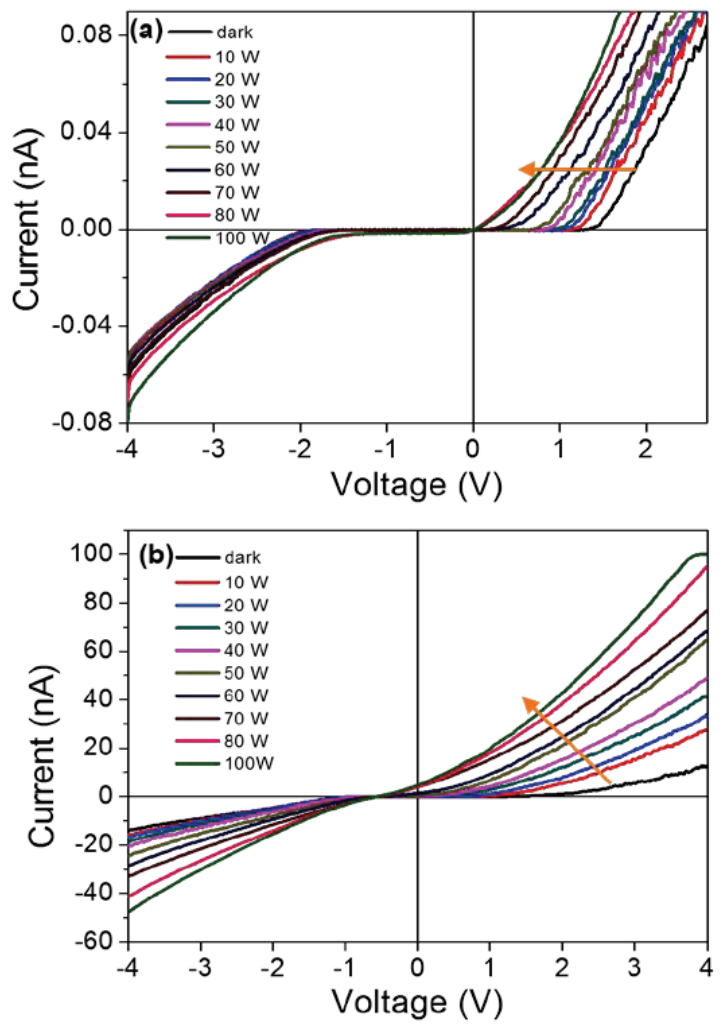

Figure 5.6. $\mathrm{I}-\mathrm{V}$ characteristics measured by $\mathrm{PC}-\mathrm{AFM}$ as a function of induced light intensity (a) $\mathrm{WO}_{3} / \mathrm{Pt} / \mathrm{p}^{+} \mathrm{n} \mathrm{Si} \mathrm{(b)} \mathrm{WO}_{3} / \mathrm{Au} / \mathrm{p}^{+} \mathrm{n} \mathrm{Si}$.

\subsection{Conclusions}

In summary, we have constructed efficient tandem photoeletrochemical devices, based on the $\mathrm{Z}$-scheme of $\mathrm{WO}_{3}$ and $\mathrm{p}^{+} \mathrm{n} \mathrm{Si}$, through the incorporation of a metal interfacial layer, which provides favorable recombination centers of photo-excited electrons and holes. Based on the Raman spectra and results of the PC-AFM analysis, the remarkable behavior of the Au interfacial layer can be understood by favorable optical and electrical effects. In particular plasmonic effects of Au nanoparticles on Si light absorption, and charge recombination have been demonstrated. Our results suggest that the optical and electrical properties of photoanodes and cathodes in tandem junction devices can be improved by introduction of plasmonically active metal interfacial layers, necessary for efficient and practically feasible STH conversion. 


\subsection{References}

1. Fujishima, A.; Honda, K. Nature 1972, 238, 37-38.

2. Takechi, K.; Shiga, T.; Akiyama, T.; Yamada, S. Photochem. Photobiol. Sci. 2010, 9, 1085-1087.

3. Ishii, T.; Kato, H.; Kudo, A. J. Photochem. Photobiol., A 2004, 163, 181-186.

4. Abdi, F. F.; Han, L.; Smets, A. H. M.; Zeman, M.; Dam, B.; van de Krol, R. Nat. Commun. 2013, 4, 1-7.

5. Kocha, S. S.; Montgomery, D.; Peterson, M. W.; Turner, J. A. Sol. Energy Mater. Sol. Cells 1998, 52, 389-397.

6. Noh, S. Y.; Sun, K.; Choi, C.; Niu, M.; Yang, M.; Xu, K.; Jin, S.; Wang, D. Nano Energy 2013, 2, 351-360.

7. Lin, Y.; Battaglia, C.; Boccard, M.; Hettick, M.; Yu, Z.; Ballif, C.; Ager, J. W.; Javey, A. Nano Lett. 2013, 13, 5615-5618.

8. Wang, X.; Peng, K.-Q.; Hu, Y.; Zhang, F.-Q.; Hu, B.; Li, L.; Wang, M.; Meng, X.-M.; Lee, S.-T. Nano Lett. 2014, 14, 18-23.

9. Wang, W.; Chen, S.; Yang, P.-X.; Duan, C.-G.; Wang, L.-W. J. Mater. Chem. A 2013, 1, 1078-1085.

10. Shaner, M. R.; Fountaine, K. T.; Ardo, S.; Coridan, R. H.; Atwater, H. A.; Lewis, N. S. Energy Environ. Sci. 2014, 7, 779-790.

11. Prevot, M. S.; Sivula, K. J. Phys. Chem. C 2013, 117, 17879-17893.

12. Ameri, T.; Dennler, G.; Lungenschmied, C.; Brabec, C. J. Energy Environ. Sci. 2009, 2 , 347-363.

13. Anderson, P. A. Phys. Rev. 1959, 115, 553-554.

14. Orf, N. D.; Baikie, I. D.; Shapira, O.; Fink, Y. Appl. Phys. Lett. 2009, 94, 113504.

15. de Boer, B.; Hadipour, A.; Mandoc, M. M.; van Woudenbergh, T.; Blom, P. W. M. Adv. Mater. 2005, 17, 621-625.

16. Wilson, R. G. J. Appl. Phys. 1966, 37, 2261-2267.

17. Elbersen, R.; Tiggelaar, R. M.; Milbrat, A.; Mul, G.; Gardeniers, H.; Huskens, J. Adv. Energy Mater. 2014, 1401745.

18. Pinardi, A. L.; Leake, S. J.; Felici, R.; Robinson, I. K. Phys. Rev. B 2009, 79, 045416.

19. Kelly, K. L.; Coronado, E.; Zhao, L. L.; Schatz, G. C. J. Phys. Chem. B 2003, 107, 668677.

20. Peng, S.; McMahon, J. M.; Schatz, G. C.; Gray, S. K.; Sun, Y. G. Proc. Natl. Acad. Sci. U. S. A. 2010, 107, 14530-14534.

21. Haupl, K.; Lang, M.; Wissmann, P. Surf. Interface Anal. 1986, 9, 27-30.

22. Park, S.-Y.; Lim, D. C.; Hong, E. M.; Lee, J.-Y.; Heo, J.; Lim, J. H.; Lee, C.-L.; Kim, Y. D.; Mul, G. ChemSusChem 2015, 8, 172-176.

23. Liu, X.; Wang, F.; Wang, Q. Phys. Chem. Chem. Phys. 2012, 14, 7894-7911.

24. Valova, E.; Georgieva, J.; Armyanov, S.; Sotiropoulos, S.; Hubin, A.; Baert, K.; Raes, M. J. Electrochem. Soc. 2010, 157, D309-D315. 
25. Vernardou, D.; Drosos, H.; Spanakis, E.; Koudoumas, E.; Savvakis, C.; Katsarakis, N. J. Mater. Chem. 2011, 21, 513-517.

26. Ingram, D. B.; Linic, S. J. Am. Chem. Soc. 2011, 133, 5202-5205.

27. Liu, H.; Ng, J.; Wang, S. B.; Lin, Z. F.; Hang, Z. H.; Chan, C. T.; Zhu, S. N. Phys. Rev. Lett. 2011, 106, 087401.

28. Liu, H.; Ng, J.; Wang, S. B.; Hang, Z. H.; Chan, C. T.; Zhu, S. N. New Journal of Physics 2011, 13, 073040. 


\subsection{Appendix}

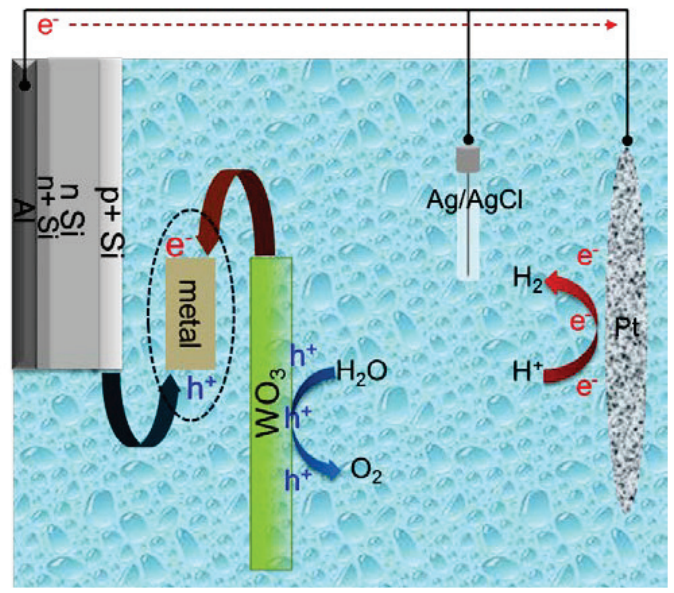

Figure A5.1. Schematic illustration of the photoelectrochemical cell used in this study.

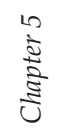

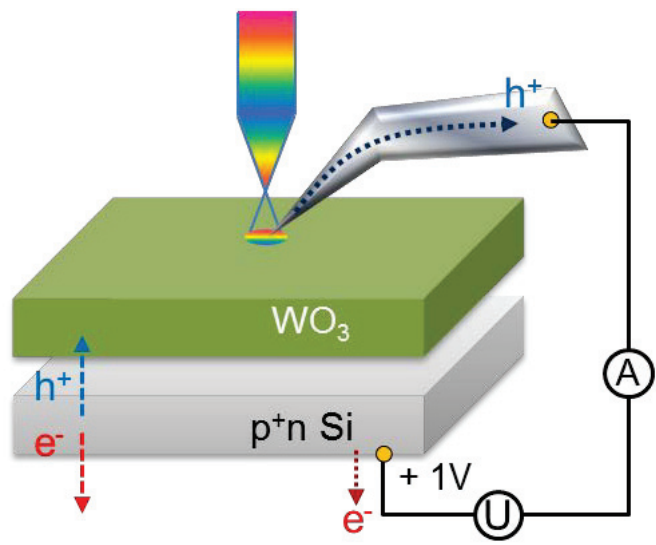

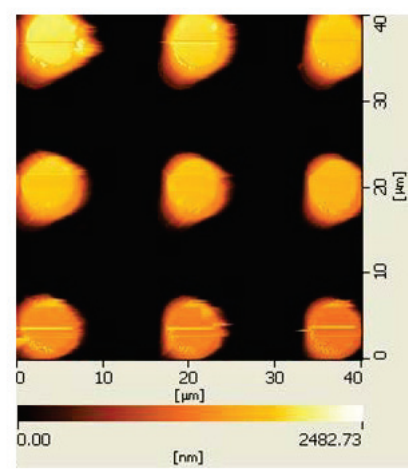

Figure A5.2. Schematic illustration of a PC-AFM measurement and the photocurrent mapping image of the pillared substrate applied in this study (top view). Photocurrents are dominant in the areas where the pillars are located. 


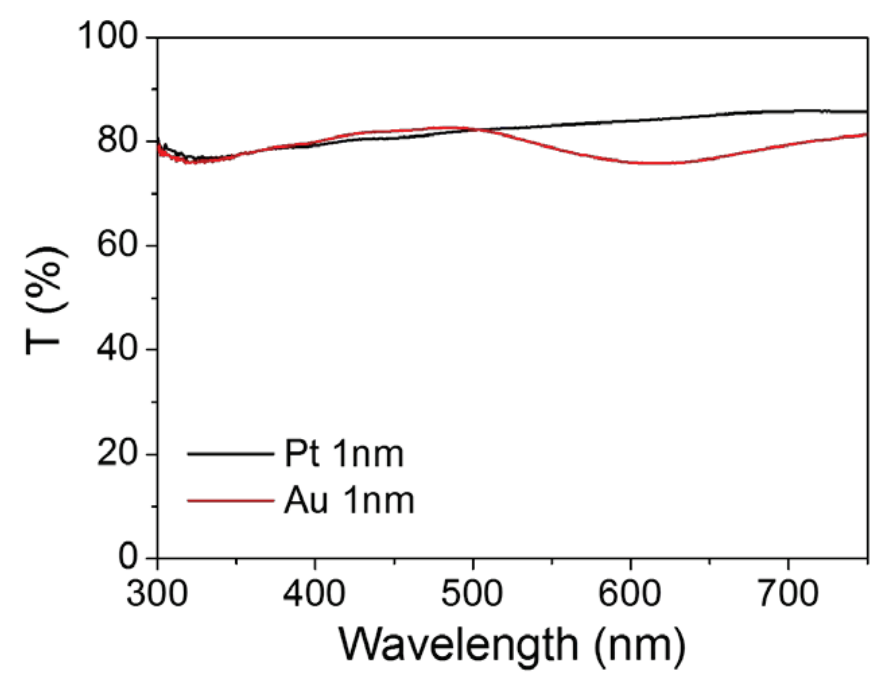

Figure A5.3. Transmittance ( $\mathrm{T}$ in \%) of Pt and Au films coated on FTO glass, using FTO as reference spectrum. The absorption features of the $\mathrm{Au}$ film are evident from the broad absorption between 500 and $700 \mathrm{~nm}$.

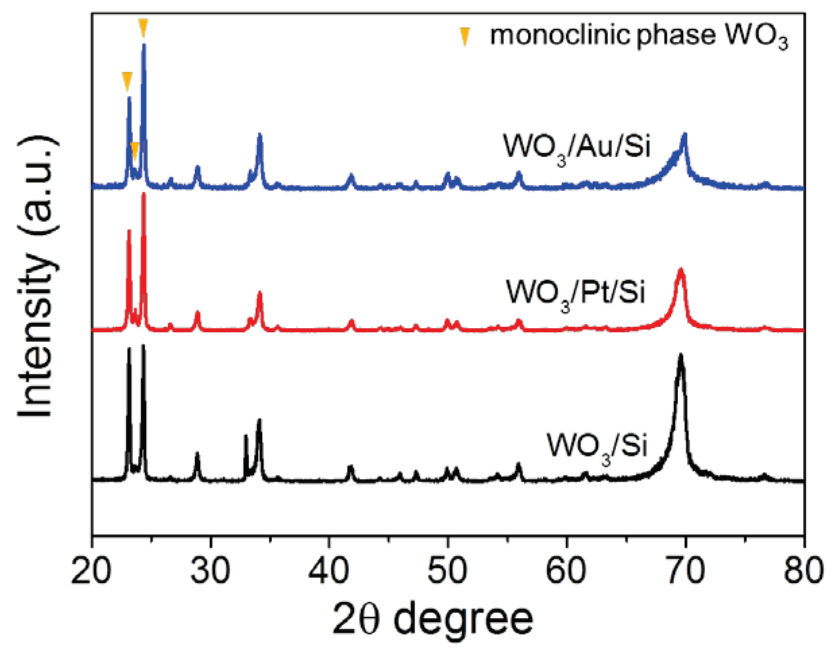

Figure A5.4. XRD patterns of the samples. The diffraction lines, in particular between $2 \theta=$ 23 and $25^{\circ}$, correspond to crystalline $\mathrm{WO}_{3}$ in the monoclinic phase (JCPDF 83-0951). 


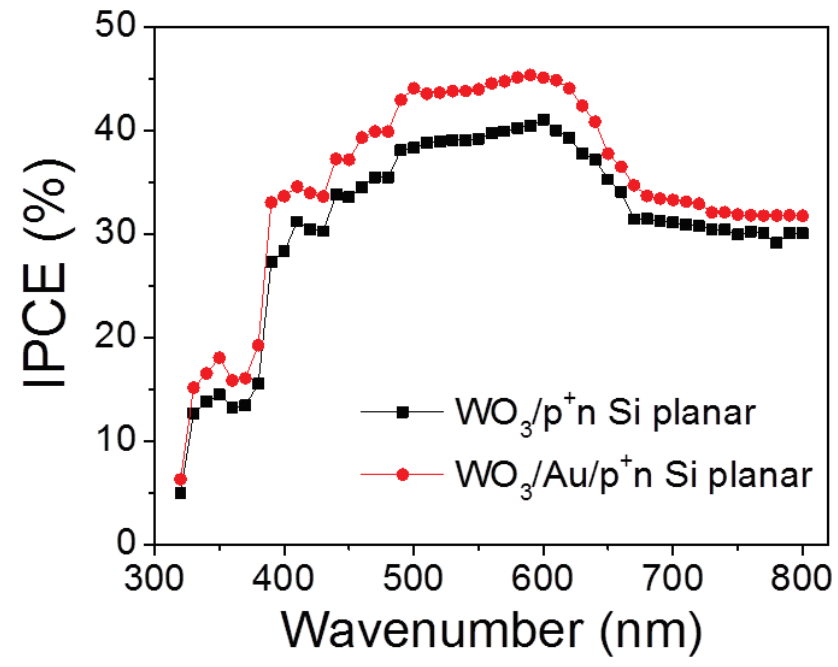

Figure A5.5. Internal Photon to Current Efficiency (IPCE (\%)) as a function of wavelength, showing the beneficial effect of Au.

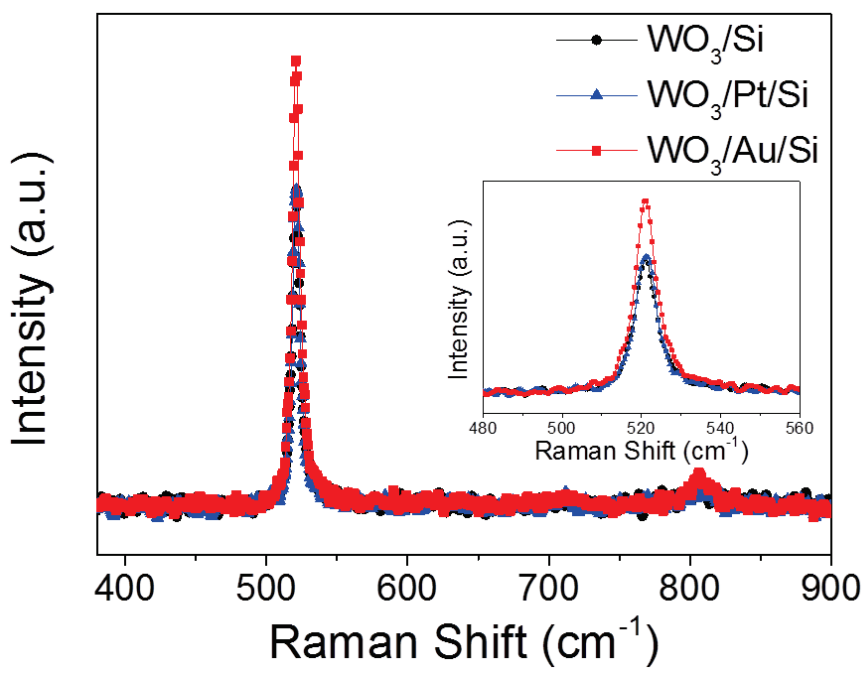

Figure A5.6. Raman spectra of the devices which have a thin $\mathrm{WO}_{3}$ film of less than $50 \mathrm{~nm}$ in thickness. 


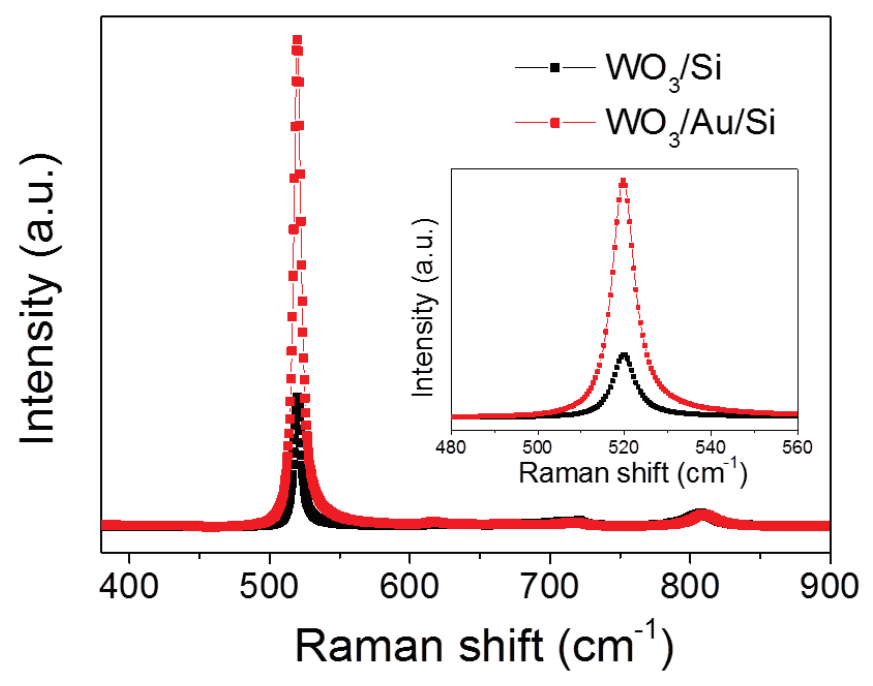

Figure A5.7. Raman spectra of the devices with and without Au nanoparticles $(5 \mathrm{~nm}$ in diameter) which were deposited from aqueous solution on the surface of $\mathrm{Si}$.

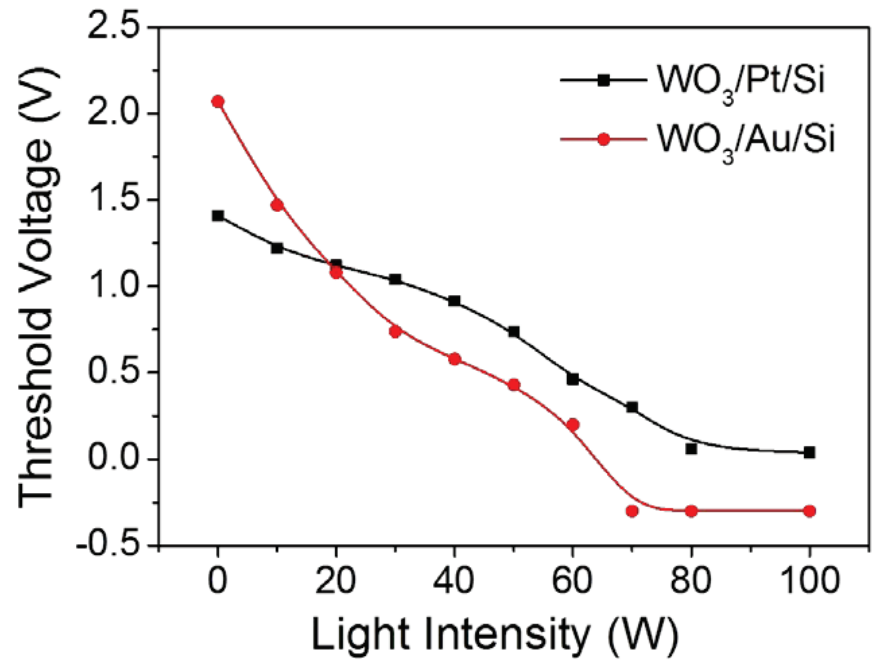

Figure A5.8. Variation in the threshold voltage depending on the applied light intensity. 



\section{Chapter 6}

\section{ATR infrared study of the photocatalytic behavior of $\mathrm{TiO}_{2}$ in physical contact with $\mathrm{SiO}_{2}$ or $\mathrm{Ag} @ \mathrm{SiO}_{2}$}

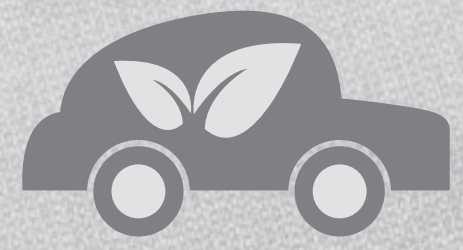

This chapter has been submitted: S.-Y. Park, M.S. Hamdy, G. Mul, ATR infrared study of the photocatalytic behavior of $\mathrm{TiO}_{2}$ in physical contact with $\mathrm{SiO}_{2}$ or $\mathrm{Ag} @ \mathrm{SiO}_{2}$. 


\begin{abstract}
The effect of variable amount of $\mathrm{SiO}_{2}$ (TUD-1) or $\mathrm{Ag} @ \mathrm{SiO}_{2}$ core-shell particles, on the photocatalytic performance of $\mathrm{TiO}_{2}$ layers deposited on $\mathrm{ZnSe}$ ATR crystals was monitored in the selective photocatalytic oxidation of methylcyclohexane to methylcyclohexanone at 375 $\mathrm{nm}$ by infrared spectroscopy. The results show that the selectivity to methylcyclohexanone of the composite layers increases as a function of increasing $\mathrm{SiO}_{2} / \mathrm{TiO}_{2}$ ratio. This effect of $\mathrm{SiO}_{2}$ is explained by assuming $\mathrm{SiO}_{2}$ to provide sorption sites for the product of selective oxidation (methylcyclohexanone), and hence to prevent over-oxidation reactions on the $\mathrm{TiO}_{2}$ surface. Above 10 wt- $\%$, a negative effect on the activity of $\mathrm{TiO}_{2}$ by either $\mathrm{SiO}_{2}$, or $\mathrm{Ag} @ \mathrm{SiO}_{2}$ coreshell particles was found. These results imply that scattering induced by $\mathrm{SiO}_{2}$ diminishes the effective absorption of light by $\mathrm{TiO}_{2}$, and that the photocatalytic activity is not significantly enhanced by Plasmon Resonance absorption of the $\mathrm{Ag} @ \mathrm{SiO}_{2}$ core-shell particles. Finally, instability of $\mathrm{Ag} @ \mathrm{SiO}_{2}$ core-shell particles in methylcyclohexane was observed when illuminated, of which the origin and implications are briefly discussed.
\end{abstract}




\subsection{Introduction}

Photocatalysis by semiconductor oxides is a promising methodology for 1) degradation of organic pollutants present in liquid or vapor phase waste streams, 2) conversion of solar energy into chemical energy (solar fuel processes), and 3) synthesis of organic compounds by oxidation. ${ }^{1,2}$ Concerning organic synthesis, photocatalytic oxidation routes often provide more selective synthetic pathways to obtain (fine) chemicals than conventional thermally activated processes. ${ }^{3} \mathrm{TiO}_{2}$ has been studied extensively in selective oxidation reactions ${ }^{4,5}$, with focus on optimizing light absorption properties ${ }^{6}$, enhancement of photonic efficiency ${ }^{7,8}$, and deactivation by product accumulation on the catalyst surface. ${ }^{9-11}$ To address the above indicated issues, many researchers have devoted effort to modifying $\mathrm{TiO}_{2}$ by deposition of metal nanoparticles of e.g. Pt, Ag, and Au. Metal deposition can lead to multiple beneficial effects: 1) nanoparticles promote charge separation when $\mathrm{TiO}_{2}$ is activated by UV light (band gap absorption usually requires wavelengths smaller than $400 \mathrm{~nm}$ ), 2) the reduction reaction of oxygen to superoxide anions is catalyzed, which concurrently usually has a beneficial effect on catalyst stability, and 3) in the case of $\mathrm{Ag}$ and $\mathrm{Au}$, plasmon enhanced photocatalysis by visible light absorption might be induced. In particular the latter effect has received significant attention in the literature, in which two theories are mostly advocated: 1) the hot electron transfer (HET) theory, which implies transfer of an electron from the plasmonic nanoparticle to the semiconductor, in which physical contact between the nanoparticles appears necessary, and 2) plasmon resonance energy transfer (PRET) stimulating light absorption and creation of electron-hole pairs in the semiconductor, in which (intimate) physical contact does not appear to be necessary. Generally, to demonstrate PRET over HET, one could analyze the effect of reactivity of semiconductors in the absence or presence of $\mathrm{Au} @ \mathrm{SiO}_{2}$ or $\mathrm{Ag} @ \mathrm{SiO}_{2}$ core-shell particles, in which the $\mathrm{SiO}_{2}$ shell will prevent electron transfer, while the shell might allow PRET induced activity enhancement, if not too thick.

When studying the implications of $\mathrm{Ag} @ \mathrm{SiO}_{2}$ core-shell particles on selective photocatalytic processes induced by $\mathrm{TiO}_{2}$, it is highly relevant to also study the effect of $\mathrm{SiO}_{2}$ when physically mixed with $\mathrm{TiO}_{2} . \mathrm{SiO}_{2}$ might affect selective photocatalytic oxidation in various ways, acting as an adsorbent for reactants or products, while also affecting light attenuation of catalyst coatings. Adsorption of the reactant provides pre-concentration of the material near the photoactive sites and might enhance the activity. This has been demonstrated for example in photocatalytic decomposition of rhodamine-6G, in which mixed oxides of $\mathrm{TiO}_{2}$ and $\mathrm{SiO}_{2}$ show higher efficiency than pure $\mathrm{TiO}_{2}{ }^{12}$ Additionally, $\mathrm{TiO}_{2}$ particles embedded in mesoporous $\mathrm{SiO}_{2}$ show higher phenol selectivity in benzene hydroxylation. ${ }^{13}$

In this study, we report on the effect of mixing $\mathrm{SiO}_{2}$ with $\mathrm{TiO}_{2}$ on the activity and selectivity in photocatalytic oxidation of methylcyclohexane to form methylcyclohexanone: a model reaction for selective photocatalytic oxidation, which is also practically relevant. ${ }^{14}$ Different interfaces of $\mathrm{TiO}_{2}$ and (mesoporous) $\mathrm{SiO}_{2}$ were assembled on Internal Reflection Elements (IRE, $\mathrm{ZnSe}$ ) and the photocatalytic behavior evaluated by attenuated total reflection fourier transform infrared (ATR-FTIR) spectroscopy. It will be demonstrated that $\mathrm{SiO}_{2}$ 
generally improves the ketone selectivity, while activity of $\mathrm{TiO}_{2}$ is reduced above a $\mathrm{SiO}_{2}$ loading of 10 wt- $\%$. The data are compared to those obtained for composites of $\mathrm{Ag} @ \mathrm{SiO}_{2}$ core-shell particles and $\mathrm{TiO}_{2}$, demonstrating that plasmon resonance enhancement was not observed, and $\mathrm{Ag} @ \mathrm{SiO}_{2}$ core-shell particles suffer from instability upon illumination.

\subsection{Experimental section}

\subsubsection{Materials}

$\mathrm{TiO}_{2}$ (P25, Evonik, Germany) and methylcyclohexane (Sigma Aldrich) were used as received without further purification. The 3-D mesoporous $\mathrm{SiO}_{2}$ (TUD-1) material was prepared as reported in ${ }^{15} . \mathrm{Ag} @ \mathrm{SiO}_{2}$ core-shell nanoparticles were synthesized using a sol-gel method. A typical preparation procedure is as follows. ${ }^{16}$ A $500 \mathrm{ml}$ beaker was filled with 180 $\mathrm{ml}$ of aqueous solution including $0.145 \mathrm{~g}$ of hexadecyltrimethylammonium bromide (Sigma Aldrich) under vigorous magnetic stirring. $10 \mathrm{ml}$ of an aqueous solution of $0.1 \mathrm{M}$ silver nitrate (Sigma Aldrich) was added to this solution. $20 \mathrm{ml}$ of $0.1 \mathrm{M}$ ascorbic acid (Sigma Aldrich) in aqueous solution was subsequently drop-wise added in a period of approximately $5 \mathrm{~min}$. Afterwards, the mixture was stirred for $10 \mathrm{~min}$, and $0.1 \mathrm{M}$ sodium hydroxide (Sigma Aldrich) was added to accelerate the chemical reaction, and to adjust the $\mathrm{pH}$ of the mixed solution to about 6.6. Subsequently, $50 \mathrm{ml}$ of ethanol and $1 \mathrm{ml}$ of tetraethyl orthosilicate (Sigma Aldrich) were added to the silver colloid suspension, to create the $\mathrm{SiO}_{2}$ shell. The solution was stirred for three more hours at room temperature. The thus synthesized $\mathrm{Ag} @ \mathrm{SiO}_{2}$ core-shell particles were separated from the solution by a centrifuge and dried in an oven at $80^{\circ} \mathrm{C}$ in air, yielding a yellowish powder.

\subsubsection{Characterization of the $\mathrm{Ag} @ \mathrm{SiO}_{2}$ core-shell particles}

The $\mathrm{Ag} @ \mathrm{SiO}_{2}$ core-shell particles were characterized by multiple techniques, including UV-Vis spectroscopy (Thermo Scientific Evolution 600 spectrophotometer), and transmission electron microscopy (TEM, Philips CM300ST-FEG microscope equipped with a Kevex EDX detector). The prepared films of $\mathrm{TiO}_{2}$ and $\mathrm{SiO}_{2}$ on a $\mathrm{Si}$ wafer were characterized by fieldemission scanning electron microscopy (FE-SEM, Zeiss LEO 1550).

\subsubsection{Measurement of the scattering properties of the $\mathrm{TiO}_{2} / \mathrm{SiO}_{2}$ composites}

Reflectance measurements were performed using a UV/Vis probe connected to an Ocean Optics USB4000 spectrometer. Distilled water suspensions containing $\mathrm{TiO}_{2}(0.146 \mathrm{~g} / 50 \mathrm{ml})$ or TUD-1 $(0.146 \mathrm{~g} / 50 \mathrm{ml})$ were prepared. $1 \mathrm{ml}$ of these prepared suspensions were dropcasted on a glass substrate $(25 \mathrm{~mm} \times 25 \mathrm{~mm})$ and dried in a desiccator containing silica gel at 
room temperature in vacuum overnight. The distance between samples and probe was fixed at $0.4 \mathrm{~mm}$ to obtain accurate measurement.

\subsubsection{Preparation of catalyst coatings on ATR crystals}

For the preparation of a composite layer of $\mathrm{TiO}_{2}$ on $\mathrm{ZnSe}$ crystals, a distilled water suspension containing $\mathrm{TiO}_{2}(0.146 \mathrm{~g} / 50 \mathrm{ml})$ was treated for $30 \mathrm{~min}$ in a $35 \mathrm{kHz}$ Elmasonic ultrasonic bath. For the preparation of the composite films, different weight percentages of $\mathrm{SiO}_{2}$ (5 wt- \%, 10 wt- $\%$, and 15 wt- $\%$ ) or $\mathrm{Ag@} \mathrm{SiO}_{2}$ core-shell particles (15 wt- $\%$ ) against the amount of $\mathrm{TiO}_{2}$ were physically mixed with $\mathrm{TiO}_{2}$. Subsequently, $2 \mathrm{ml}$ of these prepared suspensions were drop-casted on the ZnSe crystal, and dried in a desiccator containing silica gel at room temperature in vacuum overnight. For the preparation of a layered configuration, a suspension of $\mathrm{SiO}_{2}$ was prepared with the same concentration $(0.146 \mathrm{~g} / 50 \mathrm{ml})$ used for $\mathrm{TiO}_{2}$ deposition. Then, $1 \mathrm{ml}$ of the prepared $\mathrm{SiO}_{2}$ or $\mathrm{Ag} @ \mathrm{SiO}_{2}$ core-shell particles suspension was drop-casted on the $\mathrm{ZnSe}$ crystal first, and dried in a desiccator containing silica gel at room temperature in vacuum overnight. Subsequently $1 \mathrm{ml}$ of the $\mathrm{TiO}_{2}$ suspension was dropcasted over the $\mathrm{SiO}_{2}$ coating or $\mathrm{Ag} @ \mathrm{SiO}_{2}$ core-shell particles, to create a layered configuration with $\mathrm{TiO}_{2}$-up, $\mathrm{SiO}_{2}$ (or $\mathrm{Ag} @ \mathrm{SiO}_{2}$ core-shell particles)-down. A similar procedure was used to create a layered configuration with $\mathrm{SiO}_{2}$-up, $\mathrm{TiO}_{2}$-down.

\subsubsection{ATR-FTIR set up}

In situ ATR-FTIR was used for the evaluation of the performance of the composite layers in photocatalytic oxidation of methylcyclohexane as described in detail elsewhere. ${ }^{17}$ Methylcyclohexane was saturated with $\mathrm{O}_{2}$ from air using an $8 \mathrm{~mL} / \mathrm{min}$ flow through the liquid for $1 \mathrm{hr} .1 \mathrm{ml}$ of such oxygen saturated methylcyclohexane was carefully added to the well of the ATR accessory, holding the photocatalyst coated ZnSe crystal. UV induced photooxidation of methylcyclohexane was induced by an array of four $375 \mathrm{~nm}$ LEDs $\left(1.5 \mathrm{~mW} / \mathrm{cm}^{2}\right)$, and continued for $100 \mathrm{~min}$, recording a spectrum every $1 \mathrm{~min}$ from 4000-700 $\mathrm{cm}^{-1}$ averaged from 64 scans with a resolution of $4 \mathrm{~cm}^{-1}$. For the samples containing $\mathrm{Ag} @ \mathrm{SiO}_{2}$ core-shell particles, we used three $425 \mathrm{~nm}$ LEDs and four $375 \mathrm{~nm}$ LEDs simultaneously, to optimize light absorption by the $\mathrm{Ag} @ \mathrm{SiO}_{2}$ core shell particles (at $425 \mathrm{~nm}$ ) and the $\mathrm{TiO}_{2}$ film. The LEDs of different wavelengths could be switched on/off independently. We turned on the 425 $\mathrm{nm}$ LEDs in the first $10 \mathrm{~min}$ to evaluate visible light activity of the films, followed by switching on the $375 \mathrm{~nm}$ LEDs. 


\subsection{Results and discussion}

\subsubsection{Characterization of the Ag@SiO $\mathrm{Si}_{2}$ core-shell particles}

Figure 6.1a shows the transmission electron microscopy (TEM) images of the as synthesized $\mathrm{Ag} @ \mathrm{SiO}_{2}$ core-shell particles. Spherical nanoparticles with a diameter of $\sim 20 \mathrm{~nm}$ of the $\mathrm{Ag}$ core, and a shell thickness of $\mathrm{SiO}_{2}$ of $\sim 20 \mathrm{~nm}$, were obtained. The energy-dispersive X-ray spectroscopy (EDX) spectra of the core and the shell of the $\mathrm{Ag} @ \mathrm{SiO}_{2}$ core-shell particles are shown in Figure 6.1b, confirming the core consists of Ag, and the shell of Si. The $\mathrm{Cu}$ signature is due to the grid applied for the TEM analysis. A UV-Vis absorption spectrum of the $\mathrm{Ag} @ \mathrm{SiO}_{2}$ core-shell particles, when present in suspension in distilled water, is shown in Figure 6.1c. The maximum absorption peak is located around $420 \mathrm{~nm}$, in agreement with literature. $^{16}$ 


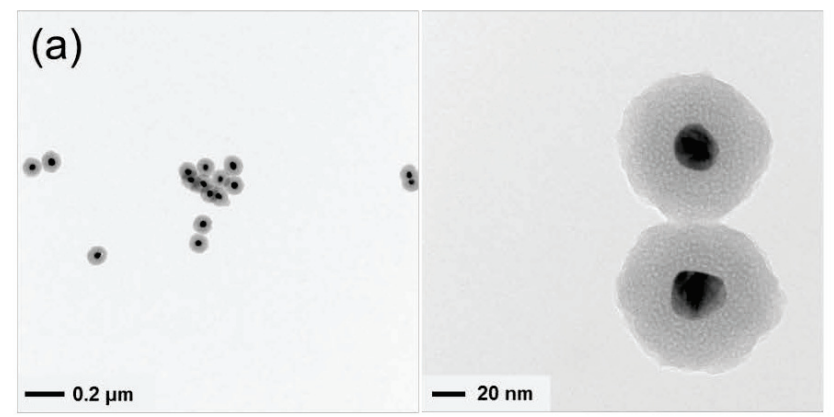

(b)
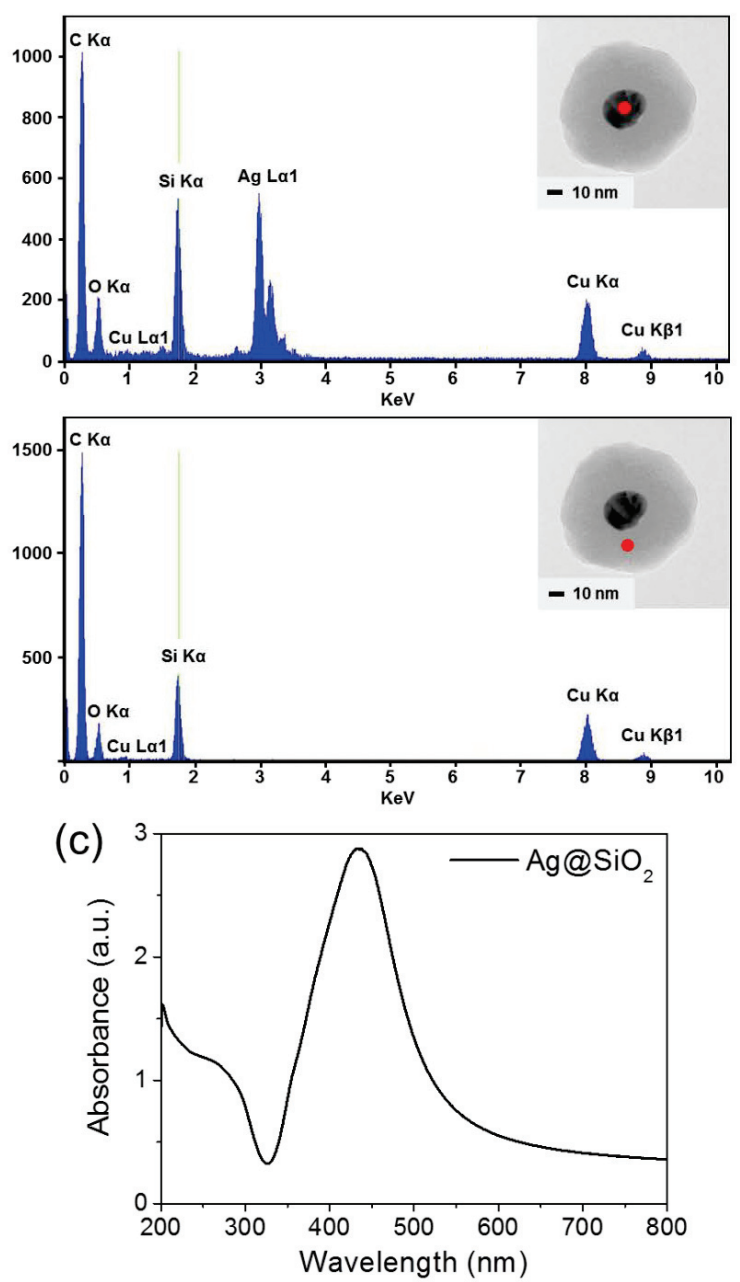

Figure 6.1. Characterization of the $\mathrm{Ag} @ \mathrm{SiO}_{2}$ core-shell particles. (a) TEM (b) EDX spectra, and (c) UV-Vis spectrum. The core-shell structure is confirmed, and the plasmon absorption at around $420 \mathrm{~nm}$ in agreement with literature. ${ }^{16}$ 


\subsubsection{Layer characterization}

SEM images of the layers obtained on $\mathrm{Si}$ wafers are shown in Figure 6.2. $\mathrm{TiO}_{2}(\mathrm{P} 25)$ forms a dense film of small agglomerated particles in the size range of 20 to $30 \mathrm{~nm}$. On the contrary, a film of $\mathrm{SiO}_{2}$ (TUD-1) consists of relatively large crystals, of a broad size distribution. A relatively homogenous mixture of $\mathrm{TiO}_{2}$ and $\mathrm{SiO}_{2}$ (50 wt-\%) is obtained when deposited simultaneously (Figure 6.2c), while a layered configuration of $\mathrm{SiO}_{2}$-up, and $\mathrm{TiO}_{2}$-down was also successfully prepared, as evident from the image shown in Figure 6.2d.
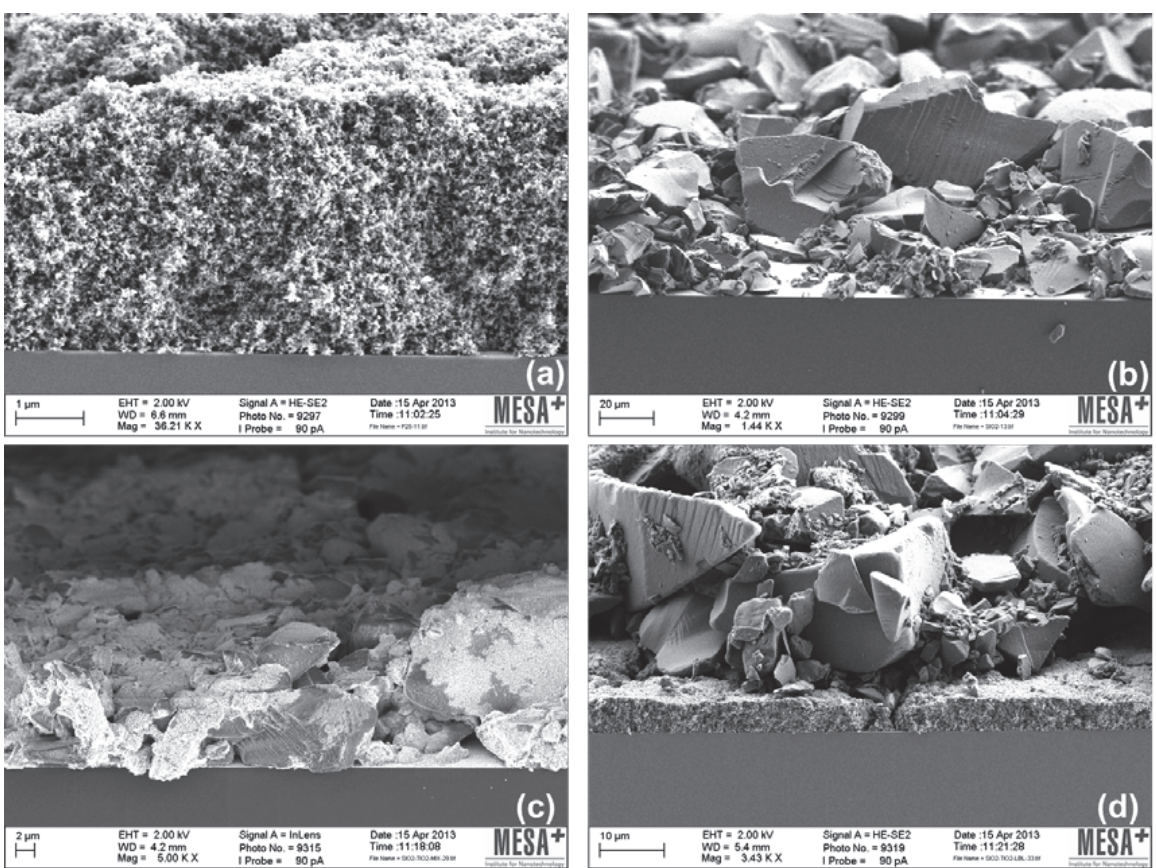

Figure 6.2. $\mathrm{SEM}$ images of (a) $\mathrm{TiO}_{2}(\mathrm{P} 25)$ (b) $\mathrm{SiO}_{2}$ (TUD-1) (c) mixture of $\mathrm{TiO}_{2}$ and $\mathrm{SiO}_{2}(50$ wt-\%), and (d) $\mathrm{SiO}_{2}$ on $\mathrm{TiO}_{2}$, when deposited on Si wafers.

\subsubsection{Photocatalytic performance of $\mathrm{TiO}_{2}$ in the absence of $\mathrm{SiO}_{2}$}

To be able to draw any conclusions regarding changes in reaction activity and selectivity induced by $\mathrm{SiO}_{2}$ and $\mathrm{Ag} @ \mathrm{SiO}_{2}$ core-shell particles, it is important to demonstrate the reproducibility of the film of $\mathrm{TiO}_{2}$ on $\mathrm{ZnSe}$ crystals in the photon induced conversion of methylcyclohexane to methylcyclohexanone derivatives. Three series of experiments are compared in Figures 6.3a, 6.3b and 6.3c. Several bands develop as a function of time of light 
exposure of methylcylohexane in contact with the $\mathrm{TiO}_{2}$ (P25) films. The assignment of these bands has been discussed in detail elsewhere. ${ }^{18}$ Briefly, the band(s) developing at $\sim 1710 \mathrm{~cm}^{-1}$ can be assigned to ketone derivative(s) formed by selective oxidation of methylcyclohexane. The band at around $1550-1600 \mathrm{~cm}^{-1}$ is the result of the formation of carboxylates, such as acetate and formate, while the band at $1440 \mathrm{~cm}^{-1}$ can be assigned to surface carbonates. Negative features in the spectra are the result of the conversion of methylcyclohexane. What is obvious comparing the three measurements shown in Figure 6.3, is that the absolute intensities are different and a function of the $\mathrm{ZnSe}$ crystal used. The reason for the differences in intensities as a function of the used ZnSe crystal is very likely that the light path for each crystal is not identical. If the angle of incidence of IR light is somewhat different for each crystal, this will affect the light path and depth of penetration in the sample layer, affecting in turn the spectral intensity. Another observation is that the carboxylate band seems to grow to much higher intensity for the first series, as compared to the second or third series. One factor to explain this, is the extent of hydration of the methylcylohexane and $\mathrm{TiO}_{2}$ films used for the oxidation experiments. Although we tried to keep the procedures as similar as possible (time of air saturation of methylcyclohexane, drying time of the $\mathrm{TiO}_{2}$ film, and time of exposure of the film to lab environment when removed from the desiccator), differences in hydration during the measurements cannot be excluded. Since the affinity of water for the $\mathrm{TiO}_{2}$ surface is high, an increase in the level of hydration of the surface can be expected, dependent on the water concentration in methylcyclohexane after dosing to the $\mathrm{TiO}_{2}$ film. The band of adsorbing water has significant intensity in the $1615 \mathrm{~cm}^{-1}$ region, and is therefore likely to contribute to the intensity of the $1580 \mathrm{~cm}^{-1}$ band, formed during photocatalysis. Indeed, besides the $1615 \mathrm{~cm}^{-1}$ intensity, strong and variable intensities were observed in the wavenumber region $>3000 \mathrm{~cm}^{-1}$ (not shown in here), indicative of water sorption on the catalyst mixtures. In all three experiments the surface of $\mathrm{TiO}_{2}(\mathrm{P} 25)$ saturates with products after approximately $30 \mathrm{~min}$ of illumination. The relative intensity of ketones over carboxylates can be used as a measure of selectivity. As obvious from the time dependent intensity profiles, the apparent selectivity of the three identical catalyst films is very much a function of the $\mathrm{ZnSe}$ crystal used (and thus date when the experiment was performed). Therefore, to evaluate the effect of mixing of $\mathrm{SiO}_{2}$ or $\mathrm{Ag} @ \mathrm{SiO}_{2}$ core-shell particles, different reference series were used. Since the $\mathrm{ZnSe}$ crystal resulting in the spectra of $\mathrm{TiO}_{2}$ in Figure 6.3a was used to measure the activity of the $\mathrm{SiO}_{2}$ containing mixtures, this particular spectral development series of $\mathrm{TiO}_{2}$ was used for comparison. For the layered configuration of $\mathrm{TiO}_{2} / \mathrm{SiO}_{2}$ composites, the series of the spectra shown in Figure $6.3 \mathrm{~b}$ was used. Finally, for the $\mathrm{Ag} @ \mathrm{SiO}_{2}$ core-shell particle containing samples, Figure 6.3a was used for comparison in the case of homogeneous mixtures, and the reference series shown in Figure $6.3 \mathrm{c}$ for comparison of a layered configuration. Please note that for this reference series, initially the film was illuminated exclusively by $425 \mathrm{~nm}$, resulting in only a very small intensity increase of ketone and carboxylate bands. After $10 \mathrm{~min}, 375 \mathrm{~nm}$ illumination was initiated, and high intensity of the absorption bands of the products (ketones and carboxylates) were obtained. 

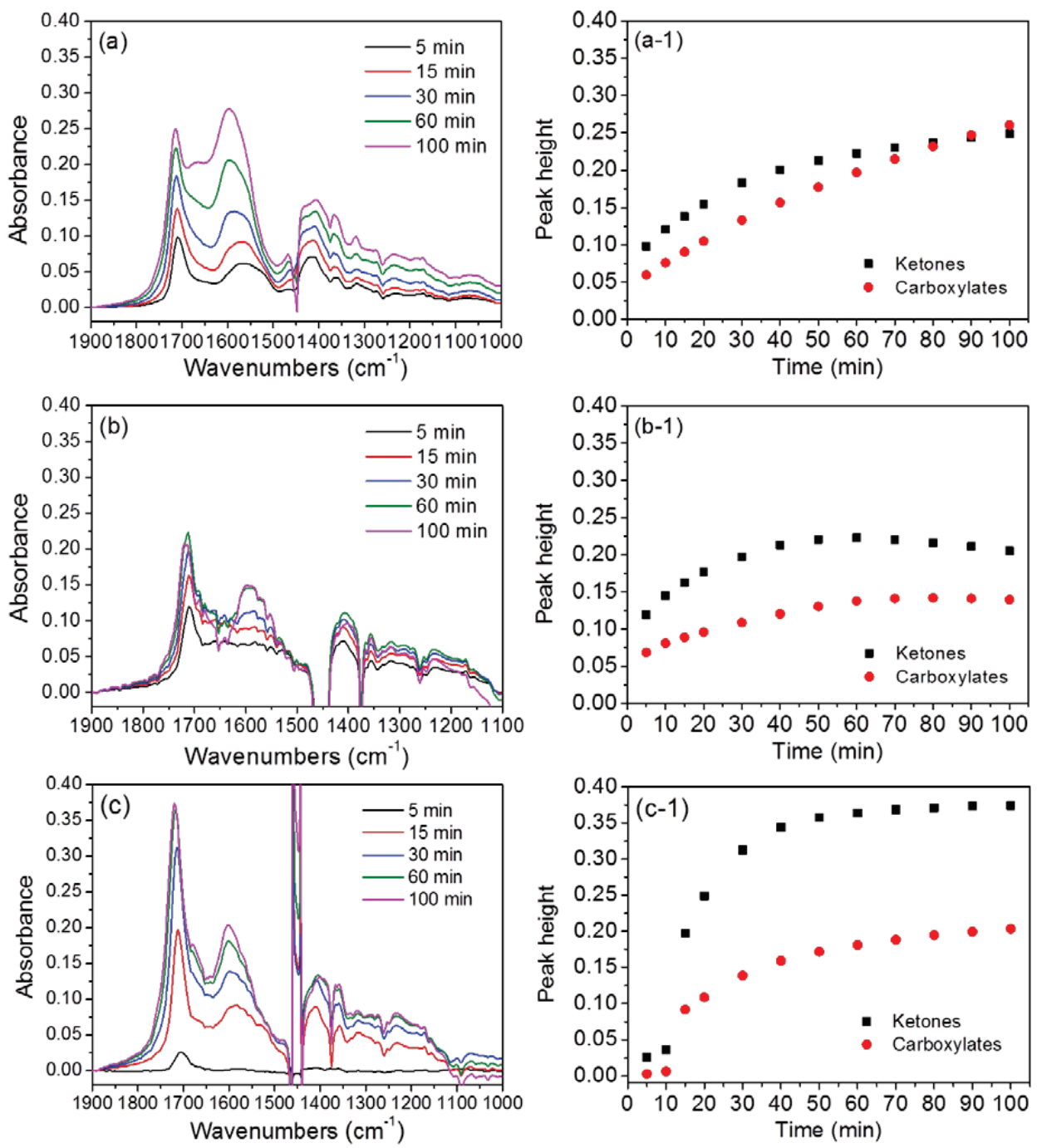

Figure 6.3. ATR-FTIR Spectra as a function of reaction time and the corresponding time dependent intensity profiles for the formation of ketones (at $1712 \mathrm{~cm}^{-1}$ ) and carboxylates (at $1586 \mathrm{~cm}^{-1}$ ). Clearly the ZnSe crystal applied has a strong effect on the absolute intensity of IR bands, as well as the ketone over carboxylate ration obtained for an identical layer of $\mathrm{TiO}_{2}$ (P25). 


\subsection{4 $\mathrm{TiO}_{2}$ performance in the presence of $\mathrm{SiO}_{2}$}

Figure 6.4 shows the surface concentration profiles, determined by the peak height of the absorption wavelength representative of ketones and carboxylates, respectively, as a function of reaction time, for four different catalyst layers consisting of: bare $\mathrm{TiO}_{2}$ (see Figure 6.3a), (a) 5 wt- $\% \mathrm{SiO}_{2}$ mixed with $\mathrm{TiO}_{2}$, (b) 10 wt- $\% \mathrm{SiO}_{2}$ mixed with $\mathrm{TiO}_{2}$, and (c) 15 wt- $\% \mathrm{SiO}_{2}$ mixed with $\mathrm{TiO}_{2}$. The corresponding series of ATR-FTIR spectra that were used for construction of these concentration profiles are presented in the Appendix (Figure A6.1). On the basis of Figure 6.4, it can be concluded that the productivity toward ketone species is similar for bare $\mathrm{TiO}_{2}$ and the $5 \mathrm{wt}-\%$ and $10 \mathrm{wt}-\% \mathrm{SiO}_{2}$ containing $\mathrm{TiO}_{2}$ samples.

However, at $15 \mathrm{wt}-\% \mathrm{SiO}_{2}$, the productivity in forming ketones is significantly reduced. In the case of the carboxylate species (assuming levels of surface hydration are similar), bare $\mathrm{TiO}_{2}$ shows higher productivity than the $\mathrm{SiO}_{2}$ containing samples, which is particularly lower at $15 \mathrm{wt}-\% \mathrm{SiO}_{2}$. The photo-activity of each sample thus decreases as a function of increasing $\mathrm{SiO}_{2}$ concentration, while the selectivity likely increases. For all samples, the rate of product formation reaches a plateau after 100 min of reaction, indicative of surface saturation with the carboxylate and ketone products. 

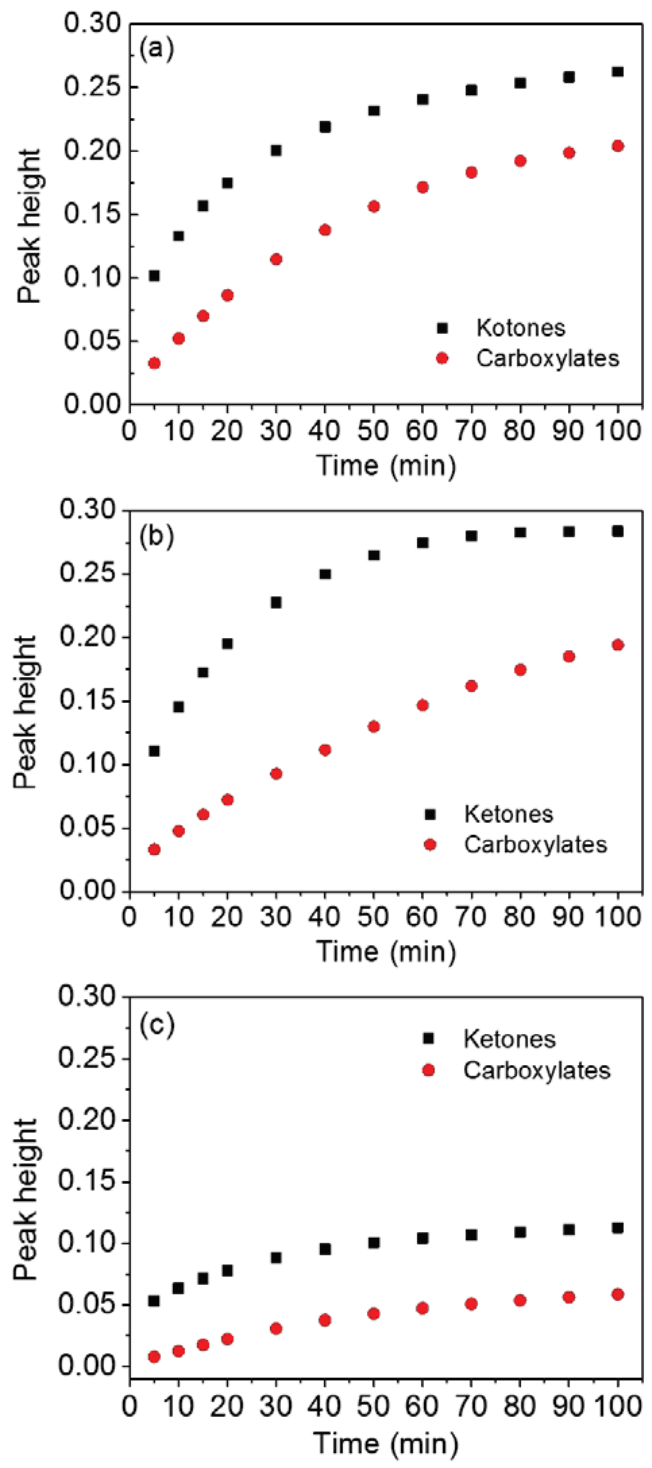

Figure 6.4. The peak height intensity profiles for the formation of ketones and carboxylates 96 for (a) 5 wt- $\% \mathrm{SiO}_{2}$ mixed $\mathrm{TiO}_{2}$ (b) $10 \mathrm{wt}-\% \mathrm{SiO}_{2}$ mixed $\mathrm{TiO}_{2}$, and (c) $15 \mathrm{wt}-\% \mathrm{SiO}_{2}$ mixed $\mathrm{TiO}_{2}$ as determined by ATR-FTIR.

To illustrate differences in selectivity, Figure 6.5a shows ketone selectivity (peak height of ketone over carboxylate) for each sample as a function of reaction time (representing conversion). In Figure 6.5b, the ketone selectivity after $5 \mathrm{~min}$, and in Figure $6.5 \mathrm{c}$ after 100 
min is determined for each sample as a function of concentration of $\mathrm{SiO}_{2}$ mixed into $\mathrm{TiO}_{2}$. Clearly, $\mathrm{SiO}_{2}$ induces a higher selectivity to the selective oxidation products, while the overall reaction rate is diminished. Direct comparison of the initial product formation rate between ketone and carboxylate species (Figure 6.5) indicates that the enhanced ketone selectivity during the photocatalytic reaction in the presence of $\mathrm{SiO}_{2}$ is mainly based on a decrease in quantity of produced carboxylate species. The initial reaction profiles in produced ketone and carboxylate species are shown in Figure A6.2.
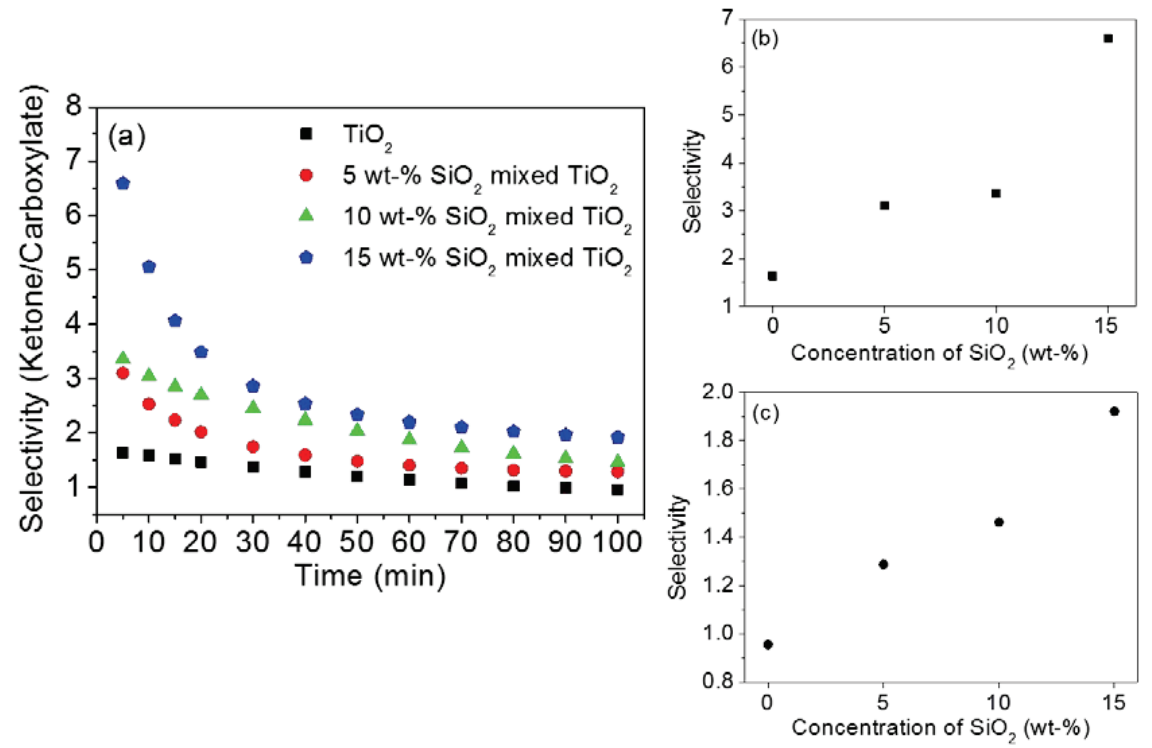

Figure 6.5. (a) The ketone selectivity of methylcyclohexane photo-oxidation as a function of reaction time. (b) and (c) show ketone selectivity after $5 \mathrm{~min}$ and $100 \mathrm{~min}$ of photocatalytic reaction as a function of concentration of $\mathrm{SiO}_{2}$ mixed into $\mathrm{TiO}_{2}$.

\subsubsection{Layered configurations}

To further evaluate the effects of $\mathrm{SiO}_{2}$ on light absorption and scattering, the photo-activity and ketone selectivity of $\mathrm{TiO}_{2}$ and $\mathrm{SiO}_{2}$ containing $\mathrm{TiO}_{2}$ samples was compared for two layered configurations. The layered configurations are illustrated in Figure 6.6, and the concentration profiles obtained with these configurations are also shown (for the spectra of $\mathrm{TiO}_{2}$ used for comparison, see Figure 6.3b). The ATR-FTIR spectra used to construct these concentration profiles are shown in Figure A6.3. Again, the $\mathrm{SiO}_{2}$ containing samples show high ketone selectivity, but low photo-activity especially in case of the $\mathrm{SiO}_{2}$-up and $\mathrm{TiO}_{2}$ - 
down layered configuration. The reduced activity of the $\mathrm{SiO}_{2}$-up layered configuration, is likely related to scattering and reduction of effective photon absorption by the $\mathrm{TiO}_{2}$ film. We have measured reflectance spectra of $\mathrm{TiO}_{2}$ (P25) and $\mathrm{SiO}_{2}$ (TUD-1) on a glass substrate, and these are shown in Figure 6.7. $\mathrm{TiO}_{2}$ or $\mathrm{SiO}_{2}$ exhibited a reflectance of of $27 \%$ or $169 \%$ at 375 $\mathrm{nm}$, respectively, relative to the reflecting white coating (PEEK (polyether ether ketone)) of the probe accessory. Relative to $\mathrm{TiO}_{2}$, the reflectance of $\mathrm{SiO}_{2}$ was thus higher by a factor $\sim 6.2$. This result confirms that optical reflection by $\mathrm{SiO}_{2}$ should diminish photon absorption by $\mathrm{TiO}_{2}$.
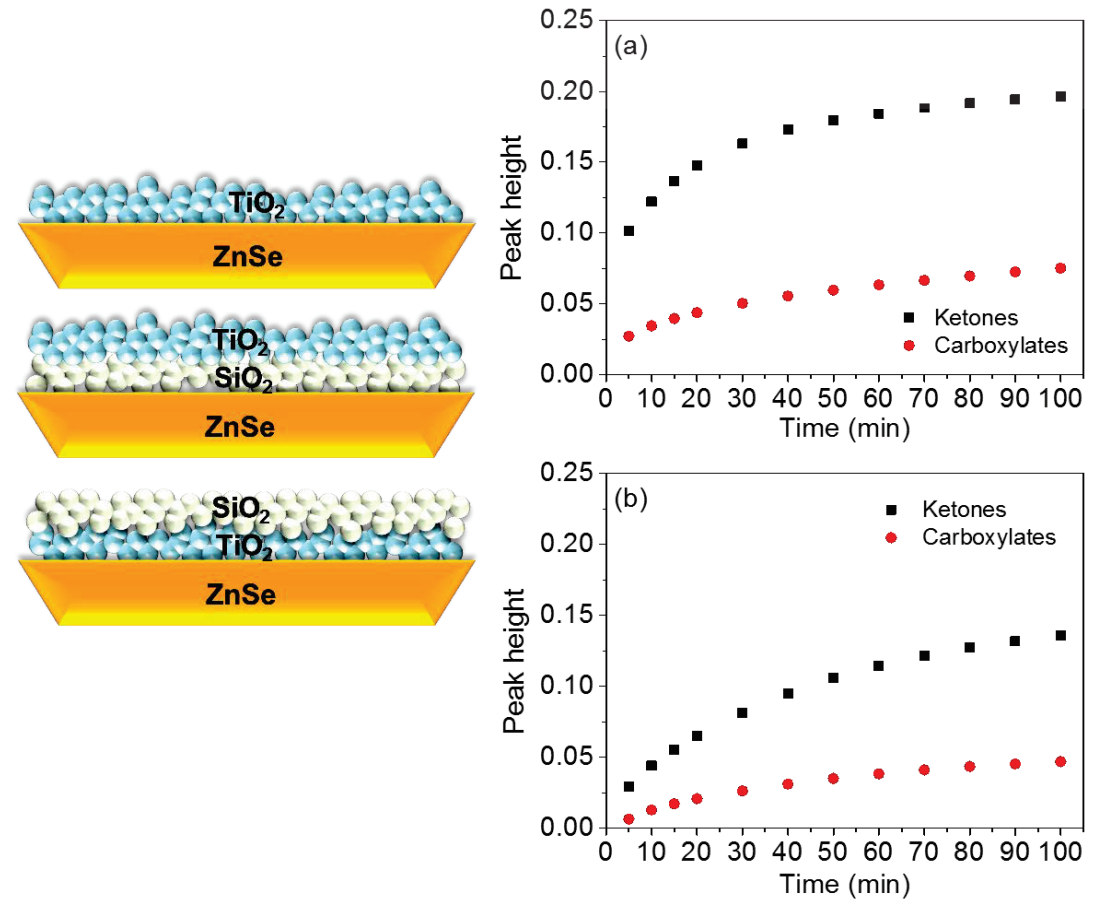

Figure 6.6. The surface concentration profiles as a function of reaction time for the formation of ketones and carboxylates for (a) $\mathrm{TiO}_{2}$-up and $\mathrm{SiO}_{2}$-down, and (b) $\mathrm{SiO}_{2}$-up and $\mathrm{TiO}_{2}$-down. Corresponding illustrations of layer morphology are shown for clarity. 


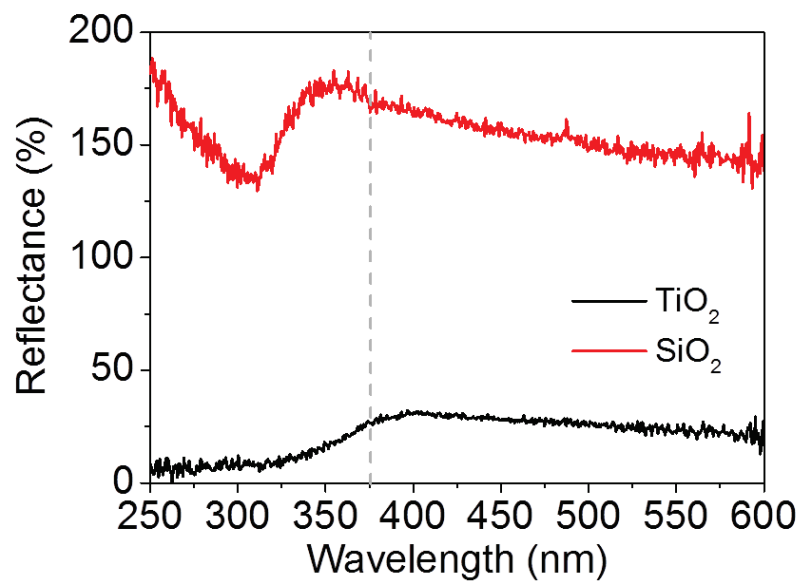

Figure 6.7. Reflectance of $\mathrm{TiO}_{2}(\mathrm{P} 25)$ and $\mathrm{SiO}_{2}$ (TUD-1), determined relative to the white surface of the probe accessory.

\subsubsection{Selectivity comparison}

A possible mechanism for the higher selectivity in the photocatalytic oxidation of methylcyclohexane is shown in Scheme 6.1. Generally, selective oxidation of methylcyclohexane leads to $o$-methylcyclohexanone and/or $p$-methylcyclohexanone as primary products. Over-oxidation can take place by consecutive reactions with hydroxyl radicals, opening the ring and forming several secondary products (carboxylates, carbonates, and so on). On the other hand, the addition of $\mathrm{SiO}_{2}$ to $\mathrm{TiO}_{2}$ diminishes over-oxidation. We postulate that ketone species desorbing from $\mathrm{TiO}_{2}$ re-adsorb on $\mathrm{SiO}_{2}$, where they are less prone to consecutive oxidation, while still observable in the viewing zone of the ATR crystal. To confirm this mechanism, Figure 6.8 shows the trend in absorbance of $o$ methylcyclohexanone (at $1720 \mathrm{~cm}^{-1}$ ) after a mixture of o-methylcyclohexanone in methylcyclohexane was dosed to a film of $\mathrm{TiO}_{2}$ or $\mathrm{SiO}_{2}$ on the $\mathrm{ZnSe}$ crystal. While initially the quantity of the ketone is higher for $\mathrm{TiO}_{2}$, exchange of adsorbed ketone with methylcyclohexane causes a decrease in intensity as a function of time. Contrary, in case of the $\mathrm{SiO}_{2}$ sample, the absorbance of $o$-methylcyclohexanone dramatically increases within 20 $\min$. These data confirm that in equilibrium conditions, sorption of $o$-methylcyclohexanone is favored on $\mathrm{SiO}_{2}$ as compared to $\mathrm{TiO}_{2}$. The corresponding ATR-FTIR spectra in the 1700$1800 \mathrm{~cm}^{-1}$ range are shown for $\mathrm{TiO}_{2}$ (Figure A6.4) and $\mathrm{SiO}_{2}$ (Figure A6.5) in the Appendix. 


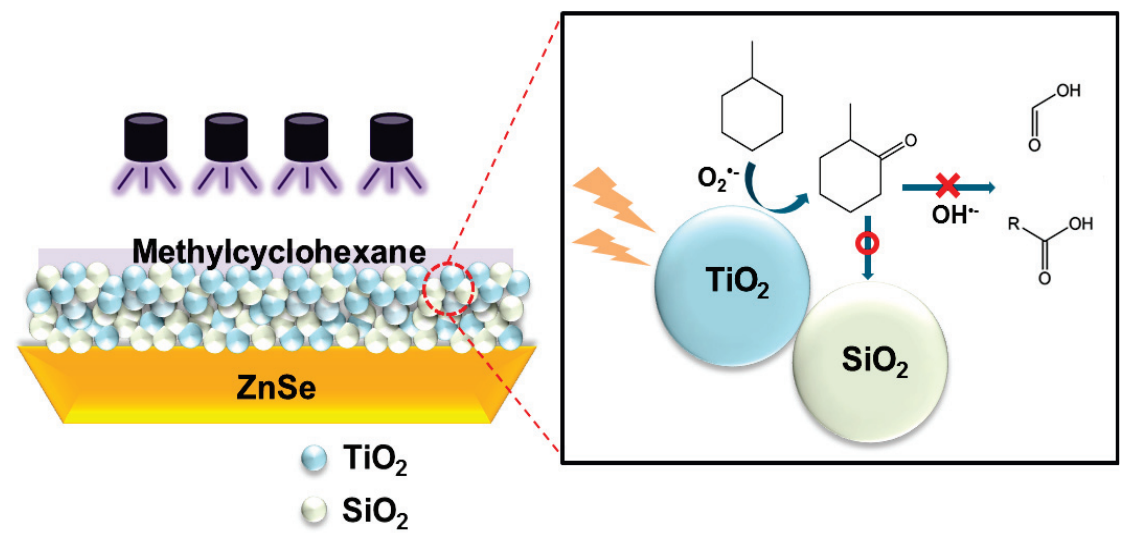

Scheme 6.1. Surface reaction mechanism of photocatalytic oxidation of methylcyclohexane.

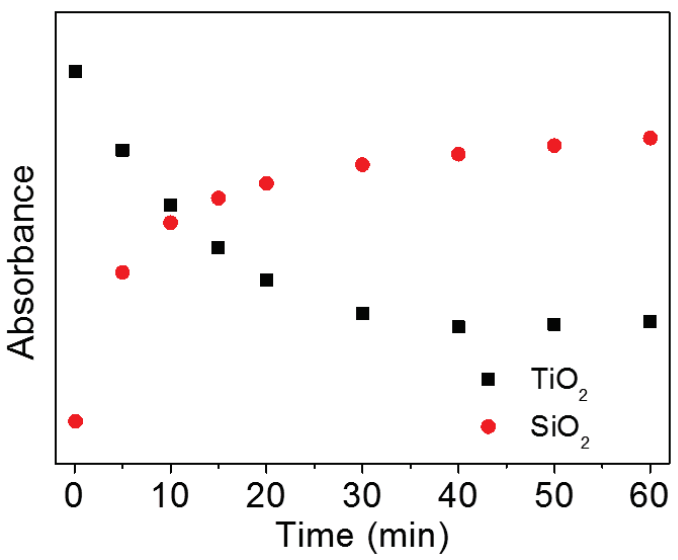

Figure 6.8. Absorbance of $o$-methylcyclohexanone on $\mathrm{TiO}_{2}$ and $\mathrm{SiO}_{2}$ as a function of time in the absence of illumination.

\subsection{7 $\mathrm{TiO}_{2}$ performance in the presence of $\mathrm{Ag} @ \mathrm{SiO}_{2}$ core-shell particles}

Figure 6.9 shows the spectral development of $\mathrm{TiO}_{2}$ induced methylcyclohexane oxidation in the presence of $\mathrm{Ag} @ \mathrm{SiO}_{2}$ core-shell particles. Specially, when comparing the data to those previously shown in Figure 6.1c, and Figure 6.9b $\left(\mathrm{TiO}_{2}\right.$-up and $\mathrm{Ag} @ \mathrm{SiO}_{2}$-down), it is evident that the signal intensities of the oxidized products are significantly smaller in the presence than in the absence of the $\mathrm{Ag} @ \mathrm{SiO}_{2}$ core-shell particles. In other words, the activity is 
diminished. What is also evident, is that the spectra are largely attenuated in the $\sim 1100 \mathrm{~cm}^{-1}$ range (Figure A6.6), where the $\mathrm{Ag} @ \mathrm{SiO}_{2}$ core-shell particles can be expected to show $\left(\mathrm{SiO}_{2}\right)$ absorptions. The lower activity is in agreement with the lower activity of $\mathrm{SiO}_{2}$ and $\mathrm{TiO}_{2}$ composites.
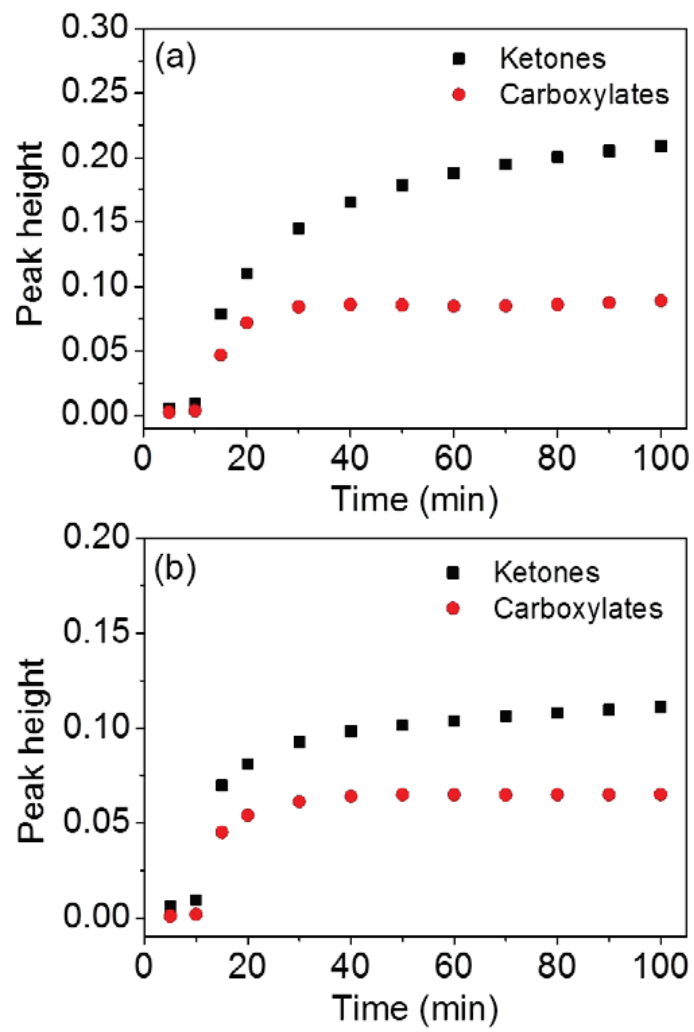

Figure 6.9. Surface concentration profiles for the formation of ketones and carboxylates for (a) 15 wt-\% Ag@SiO 2 core-shell particles mixed with $\mathrm{TiO}_{2}$, and (b) $\mathrm{TiO}_{2}$-up and $\mathrm{Ag} @ \mathrm{SiO}_{2}$ coreshell particles-down. In the first $10 \mathrm{~min}$ the samples were exposed to illumination at $425 \mathrm{~nm}$ only.

In addition, the $\mathrm{Ag} @ \mathrm{SiO}_{2}$ core-shell particles induce a color change during the reaction under the illumination, which we suggest is caused by the oxidation and hydroxylation of $\mathrm{Ag}$

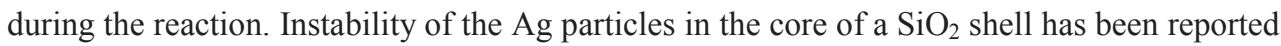
previously. Suryanarayanan et al. assign oxidation of the core to porosity of the $\mathrm{SiO}_{2}$ shell for oxidative radicals, generated on the $\mathrm{TiO}_{2}$ surface by reaction of water, oxygen, or hydroxyl 
groups with photo-excited holes. ${ }^{19}$ The oxidation of Ag appears light induced, since color changes are dominant at the position of the $375 \mathrm{~nm}$ LEDs (Figure A6.6).

SEM analysis was performed to determine the morphology of the $\mathrm{Ag} @ \mathrm{SiO}_{2}$ core-shell particles before and after the reaction. Figure 6.10a and 6.10b show the SEM and STEM mode images of $\mathrm{Ag} @ \mathrm{SiO}_{2}$ core-shell particles mixed with $\mathrm{TiO}_{2}$ before the photocatalytic reaction. The nanoparticulate $\mathrm{TiO}_{2}$ (bright) can be clearly distinguished from the $\mathrm{Ag} @ \mathrm{SiO}_{2}$ core-shell particles of around $60 \mathrm{~nm}$ in size (circular particles). In STEM mode, the integrity of the $\mathrm{Ag} @ \mathrm{SiO}_{2}$ core-shell particles is clearly demonstrated. Figure 6.10c confirms the instability of $\mathrm{Ag} @ \mathrm{SiO}_{2}$ core-shell particles in conditions of photocatalysis. After the photocatalytic oxidation reaction, it is evident that additional bright particulates are present on $\mathrm{TiO}_{2}$, of variable size in the nanometer range, which can be assigned to Ag particles, as confirmed by EDX spectra in Figure A6.7. We postulate the following reaction scheme to explain the formation of ex-shell $\mathrm{Ag}$ particles, involving oxidation of the $\mathrm{Ag}$ core to $\mathrm{Ag}^{+}$ under illumination. Hydroxyl groups on the (hydrated) surface of $\mathrm{TiO}_{2}$ are converted to $\mathrm{OH}$ radicals by photo-excited holes (reaction (1)) under illumination (reaction (2)). In agreement with Suryanarayanan et al. ${ }^{19}$, we postulate that $\mathrm{SiO}_{2}$ shell is permeable for these radicals, allowing reaction (3) to occur, which is oxidation of $\mathrm{Ag}$ to $\mathrm{Ag}^{+}$by the hydroxyl radicals. We then assume $\mathrm{Ag}^{+}$ions are permeable through the $\mathrm{SiO}_{2}$ shell as well, which are then reduced and photo-deposited on the $\mathrm{TiO}_{2}$ surface by photo-excited electrons (reaction (4)). In conclusion, besides the $\mathrm{SiO}_{2}$ based scattering effects, disintegration of $\mathrm{Ag} @ \mathrm{SiO}_{2}$ core-shell particles and photo-deposition of $\mathrm{Ag}$ particles on $\mathrm{TiO}_{2}$ will contribute to the lower activity of $\mathrm{TiO}_{2}$ in methylcyclohexane oxidation in the presence of the $\mathrm{Ag} @ \mathrm{SiO}_{2}$ core-shell particles.

$$
\mathrm{TiO}_{2} \rightarrow \mathrm{e}^{-}+\mathrm{h}^{+} \text {(under illumination) }
$$

$\mathrm{OH}\left(\right.$ surface of $\left.\mathrm{TiO}_{2}\right)+\mathrm{h}^{+} \rightarrow \mathrm{OH} \bullet$

$$
\mathrm{OH} \bullet+\mathrm{Ag}\left(\text { core of } \mathrm{Ag} @ \mathrm{SiO}_{2}\right) \rightarrow \mathrm{Ag}^{+}+\mathrm{OH}^{-}
$$

$$
\mathrm{Ag}^{+} \text {(diffuses to solution from } \mathrm{Ag} @ \mathrm{SiO}_{2} \text { core-shell particles) }+\mathrm{e}^{-} \rightarrow \mathrm{Ag}
$$



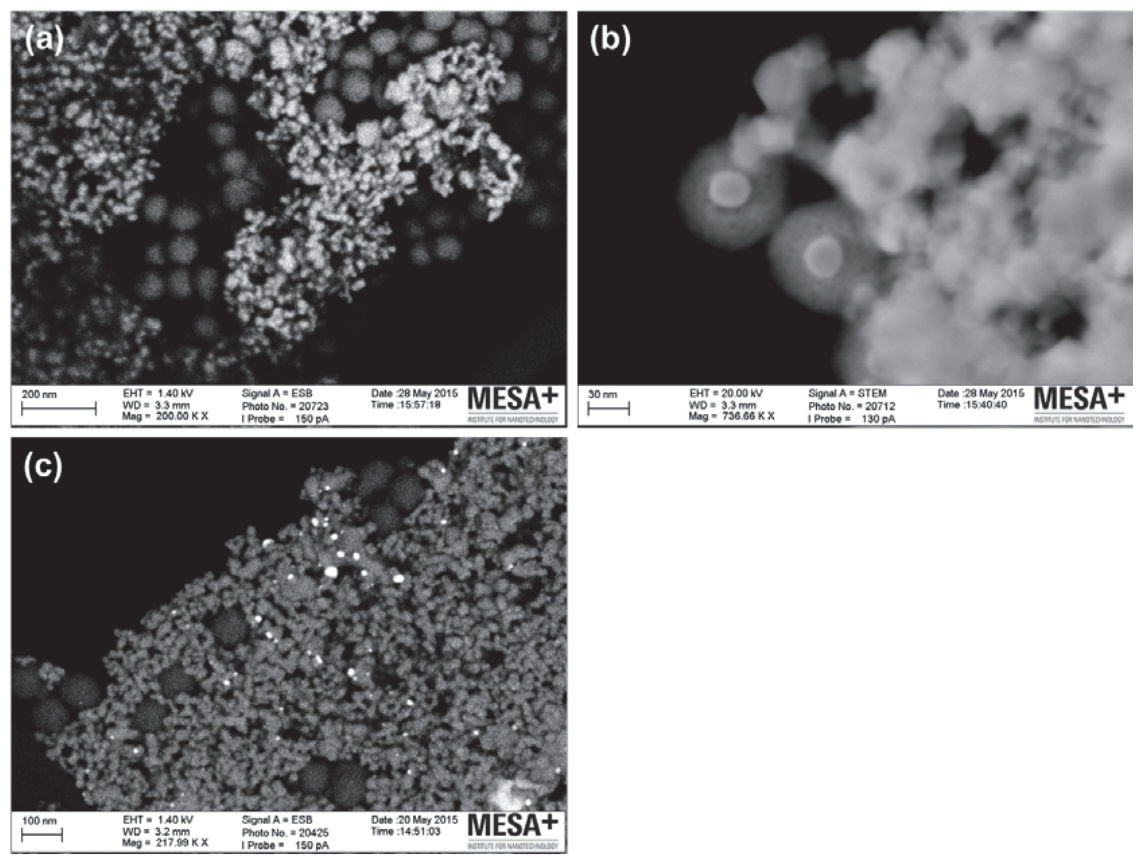

Figure 6.10. $\mathrm{SEM}$ images of (a) $\mathrm{Ag} @ \mathrm{SiO}_{2}$ core-shell particles mixed with $\mathrm{TiO}_{2}$ before the $\mathrm{MCH}$ reaction, (b) $\mathrm{Ag} @ \mathrm{SiO}_{2}$ core-shell particles mixed with $\mathrm{TiO}_{2}$ before the $\mathrm{MCH}$ reaction by STEM mode, and (c) $\mathrm{Ag} @ \mathrm{SiO}_{2}$ core-shell particles mixed with $\mathrm{TiO}_{2}$ after the $\mathrm{MCH}$ reaction.

\subsection{Conclusions}

In summary, we have demonstrated increased ketone selectivity of $\mathrm{TiO}_{2}$ in photocatalytic oxidation of methylcyclohexane by physical mixing of mesoporous $\mathrm{SiO}_{2}$ with $\mathrm{TiO}_{2}$, as analyzed by ATR-FTIR spectroscopy. Even at relatively high surface saturation (i.e. conversion), a ketone preferred selectivity is apparent for all $\mathrm{SiO}_{2}$ percentages studied. The higher selectivity is likely related to strong adsorption affinity of the $\mathrm{SiO}_{2}$ particles for methylcyclohexanone isomers, preventing to some degree the consecutive oxidation to carboxylates and carbonates when the ketones remain adsorbed on the surface of $\mathrm{TiO}_{2}$. We assign the lower activity at weight percentages larger than $10 \mathrm{wt}-\% \mathrm{SiO}_{2}$ to outward light scattering properties of the $\mathrm{SiO}_{2}$ particles, diminishing effective illumination of the $\mathrm{TiO}_{2}$ particles. Compared to $\mathrm{SiO}_{2}$, similar phenomena have been observed for $\mathrm{Ag} @ \mathrm{SiO}_{2}$ core-shell particles, accompanied by light induced disintegration of the $\mathrm{Ag} @ \mathrm{SiO}_{2}$ core-shell particles and photo-deposition of Ag particles. Positive plasmonic effects of the Ag core or in situ deposited Ag particles on the efficacy of the $\mathrm{TiO}_{2}$ film have not been found. 


\subsection{References}

1. Palmisano, G.; Garcia-Lopez, E.; Marci, G.; Loddo, V.; Yurdakal, S.; Augugliaro, V.; Palmisano, L. Chem. Commun. 2010, 46, 7074-7089.

2. Palmisano, G.; Augugliaro, V.; Pagliaro, M.; Palmisano, L. Chem. Commun. 2007, 3 4253437.

3. Yurdakal, S.; Tek, B. S.; Alagöz, O.; Augugliaro, V.; Loddo, V.; Palmisano, G.; Palmisano, L. ACS Sustainable Chem. Eng. 2013, 1, 456-461.

4. Friedmann, D.; Mendive, C.; Bahnemann, D. Appl. Catal., B 2010, 99, 398-406.

5. Daghrir, R.; Drogui, P.; Robert, D. Ind. Eng. Chem. Res. 2013, 52, 3581-3599.

6. Shiraishi, Y.; Hirai, T. J. Photochem. Photobiol., C 2008, 9, 157-170.

7. Shiraishi, Y.; Saito, N.; Hirai, T. J. Am. Chem. Soc. 2005, 127, 12820-12822.

8. Yurdakal, S.; Palmisano, G.; Loddo, V.; Augugliaro, V.; Palmisano, L. J. Am. Chem. Soc. 2008, 130, 1568-1569.

9. Almeida, A. R.; Berger, R.; Moulijn, J. A.; Mul, G. Phys. Chem. Chem. Phys. 2011, 13, 1345-1355.

10. Carneiro, J. T.; Almeida, A. R.; Moulijn, J. A.; Mul, G. Phys. Chem. Chem. Phys. 2010, $12,2744-2750$.

11. Almeida, A. R.; Calatayud, M.; Tielens, F.; Moulijn, J. A.; Mul, G. J. Phys. Chem. C 2011, $115,14164-14172$.

12. Anderson, C.; Bard, A. J. J. Phys. Chem. B 1997, 101, 2611-2616.

13. Shiraishi, Y.; Sugano, Y.; Inoue, D.; Hirai, T. J. Catal. 2009, 264, 175-182.

14. Amrollahi, R.; Hamdy, M. S.; Mul, G. J. Catal. 2014, 319, 194-199.

15. Jansen, J. C.; Shan, Z.; Marchese, L.; Zhou, W.; Puil, N. v. d.; Maschmeyer, T. Chem. Commun. 2001, 713-714.

16. Xu, K.; Wang, J.-X.; Kang, X.-L.; Chen, J.-F. Mater. Lett. 2009, 63, 31-33.

17. Almeida, A. R.; Moulijn, J. A.; Mul, G. J. Phys. Chem. C 2008, 112, 1552-1561.

18. Hamdy, M. S.; Amrollahi, R.; Mul, G. ACS Catal. 2012, 2, 2641-2647.

19. Suryanarayanan, V.; Nair, A. S.; Tom, R. T.; Pradeep, T. J. Mater. Chem. 2004, 14, 2661 2666. 


\subsection{Appendix}
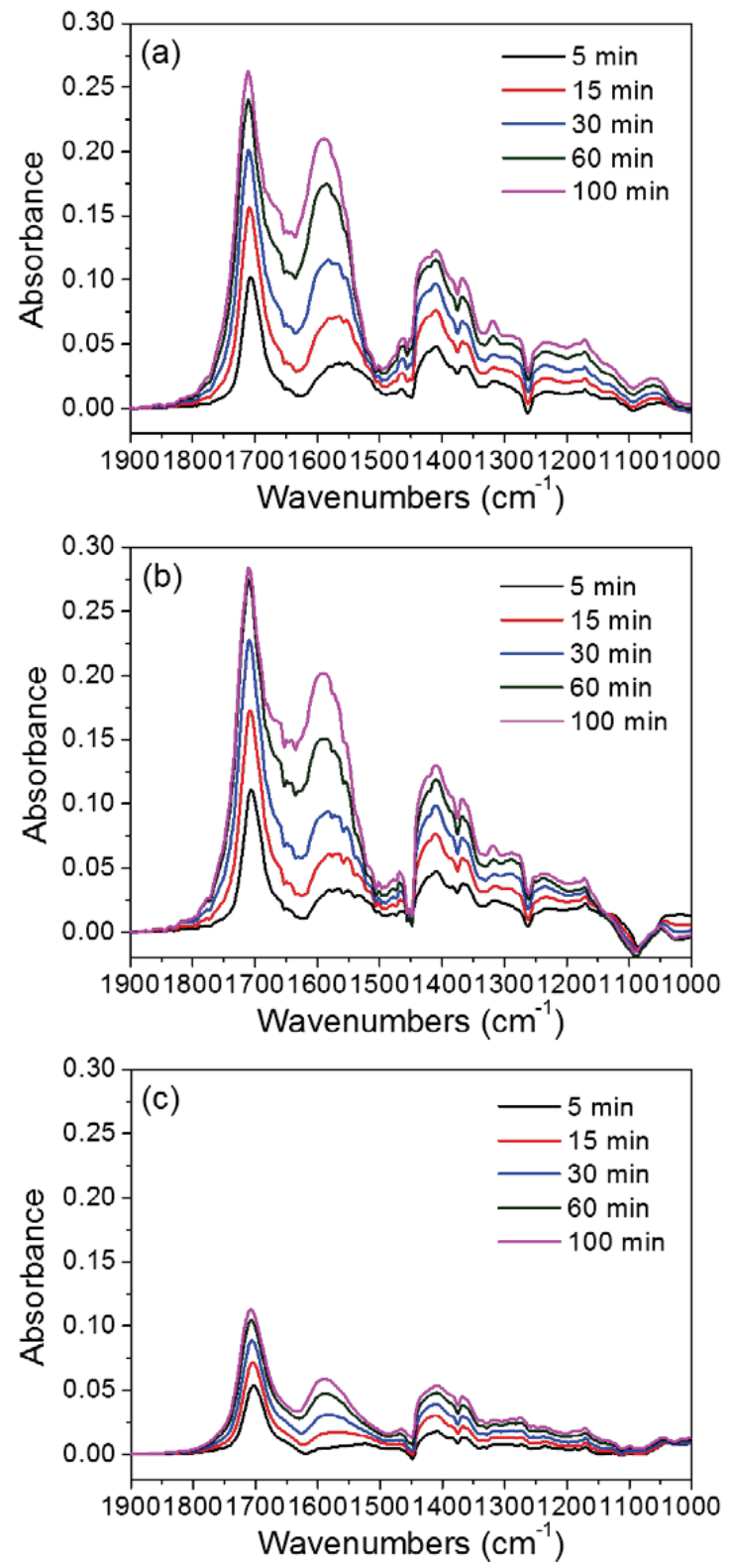

Figure A6.1. ATR-FTIR Spectra as a function of reaction time for (a) 5 wt- $\% \mathrm{SiO}_{2}$ mixed $\mathrm{TiO}_{2}$, (b) 10 wt- $\% \mathrm{SiO}_{2}$ mixed $\mathrm{TiO}_{2}$, and (c) 15 wt- $\% \mathrm{SiO}_{2}$ mixed $\mathrm{TiO}_{2}$. 

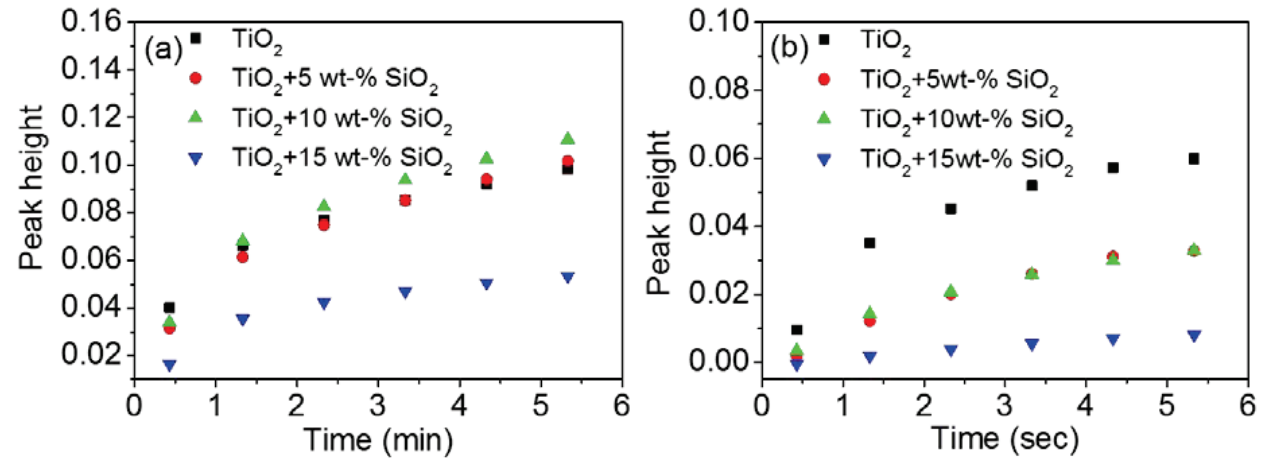

Figure A6.2. The reaction profiles for the formation of (a) ketones and (b) carboxylates as a function of concentration of $\mathrm{SiO}_{2}$ during 5 min.
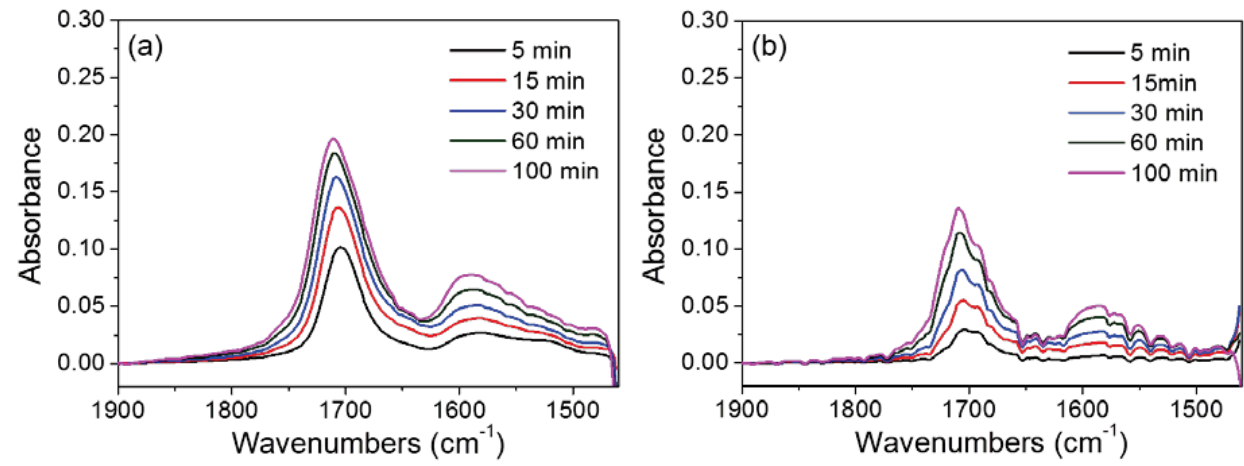

Figure A6.3. ATR-FTIR Spectra as a function of reaction time for (a) $\mathrm{TiO}_{2}$-up and $\mathrm{SiO}_{2}$ down, and (b) $\mathrm{SiO}_{2}$-up and $\mathrm{TiO}_{2}$-down. 


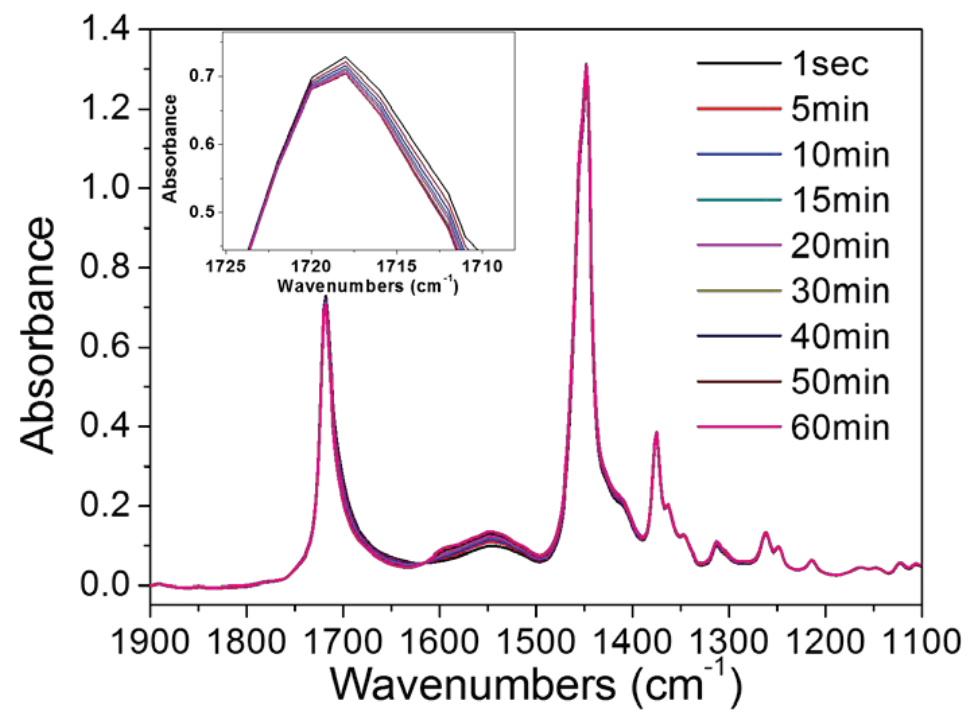

Figure A6.4. ATR-FTIR spectra of a mixture of Methylcyclohexane and $o$ methylcyclohexanone on $\mathrm{TiO}_{2}$ recorded for a period of $1 \mathrm{hr}$ without light.

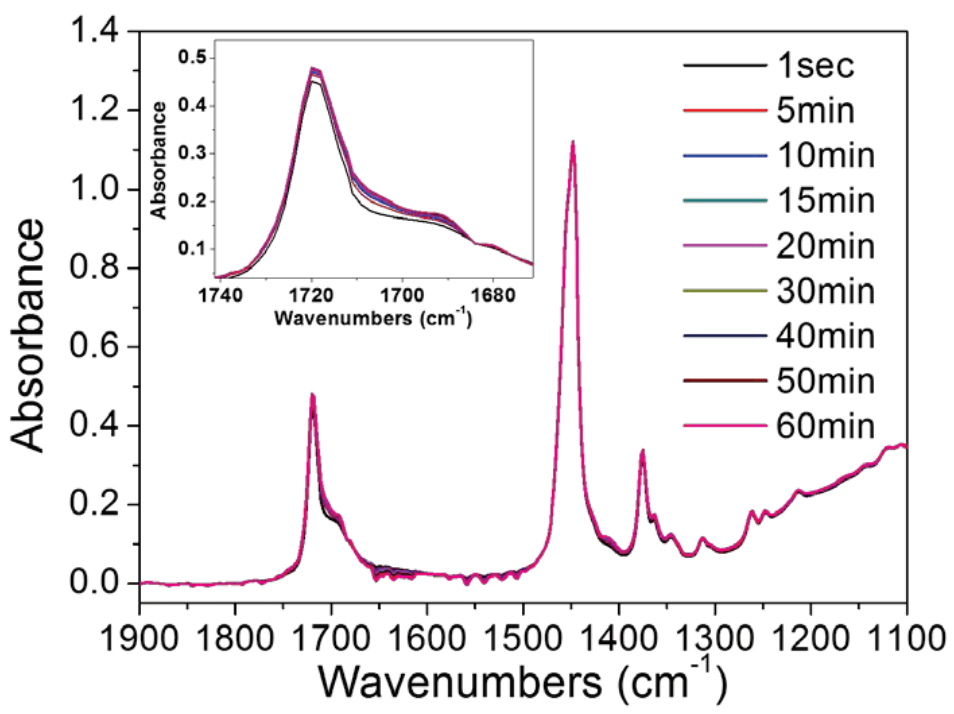

Figure A6.5. ATR-FTIR spectra of a mixture of Methylcyclohexane and $o$ methylcyclohexanone on $\mathrm{SiO}_{2}$ during $1 \mathrm{hr}$ without light. 

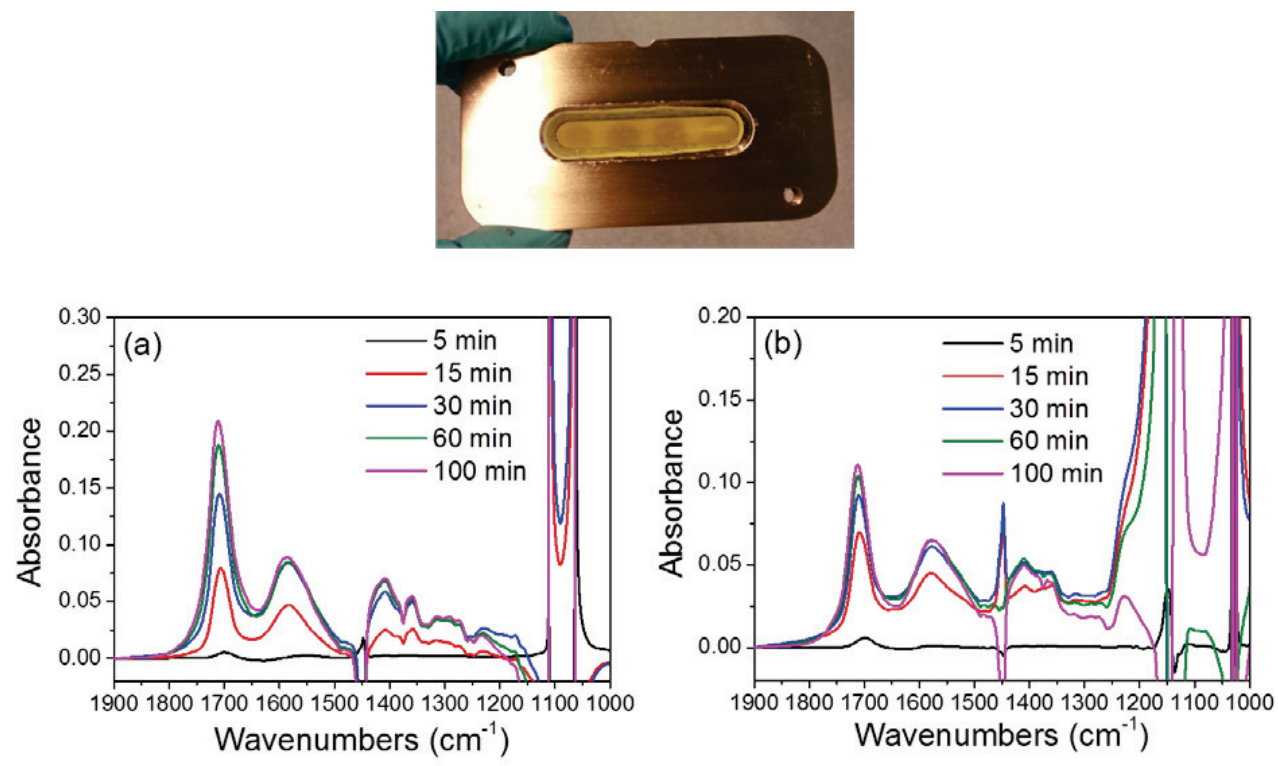

Figure A6.6. Photo of the $\mathrm{Ag} @ \mathrm{SiO}_{2}$ core-shell particles containing sample after the reaction under illumination. ATR-FTIR Spectra as a function of reaction time for (a) $15 \mathrm{wt}-\%$ of $\mathrm{Ag} @ \mathrm{SiO}_{2}$ core-shell particles mixed $\mathrm{TiO}_{2}$ and (b) $\mathrm{TiO}_{2}$-up and $\mathrm{Ag} @ \mathrm{SiO}_{2}$ core-shell particlesdown on $\mathrm{ZnSe}$. 

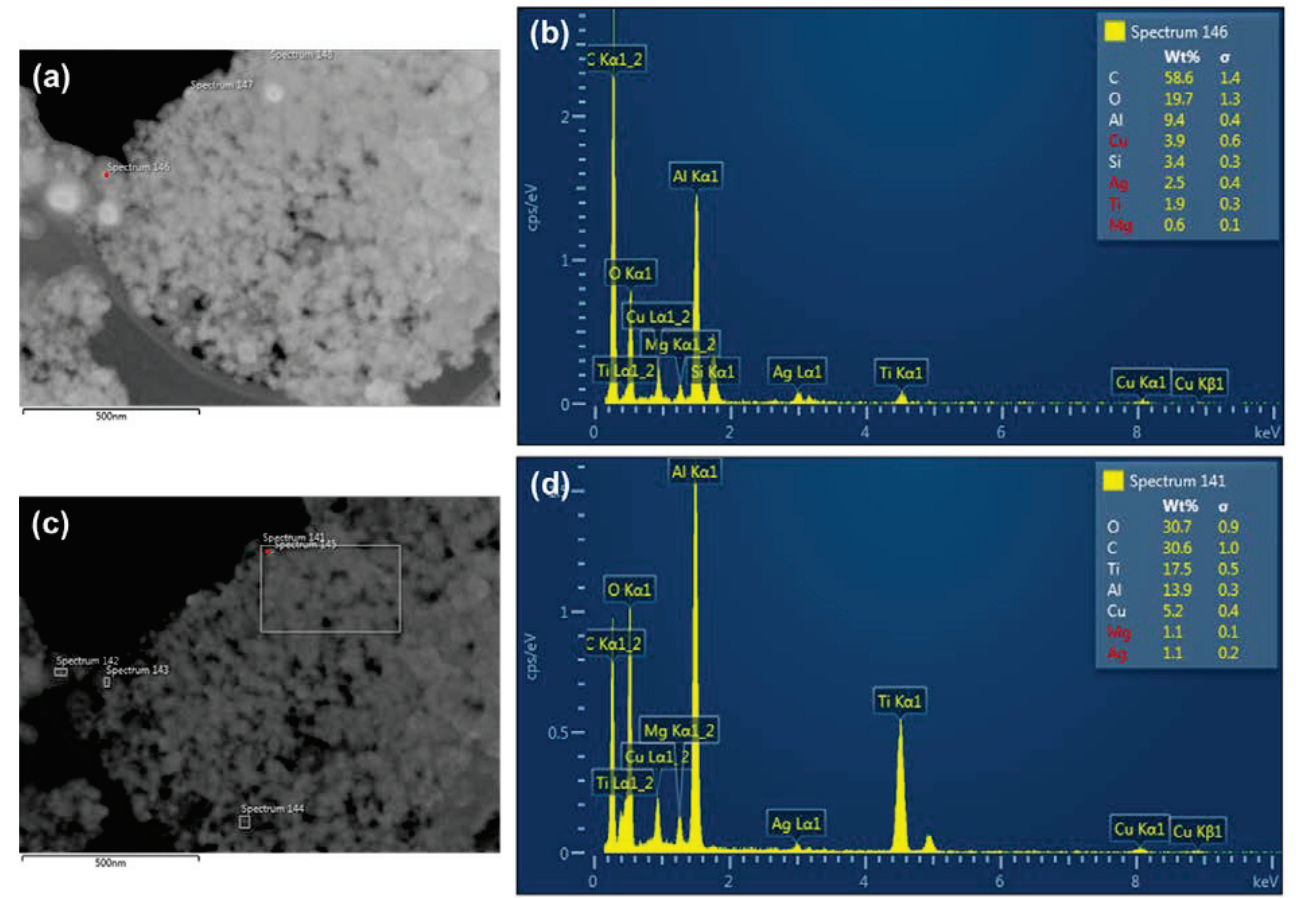

Figure A6.7. (a) STEM image and (b) EDX spectrum of the core of $\mathrm{Ag} @ \mathrm{SiO}_{2}$ core-shell particles before reaction (c) SEM image and (d) EDX spectrum of bright particle on $\mathrm{TiO}_{2}$ after photocatalytic $\mathrm{MCH}$ oxidation. 



\section{Chapter 7}

Stability and effect of $\mathrm{Ag} @ \mathrm{SiO}_{2}$ core-shell particles on efficacy of $\mathrm{WO}_{3}$ and $\mathrm{ZnO}$ in photocatalytic overall water splitting

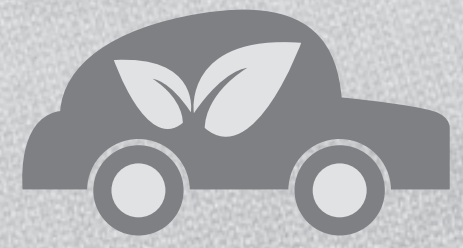

This chapter has been submitted: S.-Y. Park, G. Mul, Stability and effect of Ag@SiO 2 core-shell particles on efficacy of $\mathrm{WO}_{3}$ and $\mathrm{ZnO}$ in photocatalytic overall water splitting. 


\begin{abstract}
Core-shell nanoparticles containing plasmonic metals (Ag or $\mathrm{Au}$ ) have been frequently reported to enhance performance of electrical devices or photocatalysts. Much less is known regarding the applicability and stability of these particles in overall water splitting in a photoelectrochemical (PEC) cell. We demonstrate that $\mathrm{Ag} @ \mathrm{SiO}_{2}$ core-shell particles have very little effect on the performance of photo-anodes consisting of $\mathrm{WO}_{3}$ or $\mathrm{ZnO}$, independent of electrode structure, and are instable in the conditions in which the PEC cells operate. In particular for $\mathrm{Ag} @ \mathrm{SiO}_{2}$ core-shell particles, oxidation of $\mathrm{Ag}$ to either $\mathrm{Ag}^{+}$-ions, or solid state (hydr)oxide, is evident from scanning voltammetry studies of the anode composites. $\mathrm{Ag} @ \mathrm{SiO}_{2}$ core-shell particles give some improvement in $\mathrm{H}_{2}$ evolution activity of Pt-loaded $\mathrm{ZnO}$ in photocatalytic water splitting in a slurry reactor. The wavelength independent nature of the enhancement suggests this is due to scattering, rather than plasmon induced. Interestingly, in agreement with the PEC experiments, the $\mathrm{Ag} @ \mathrm{SiO}_{2}$ core-shell particles were instable in conditions of the photocatalysis experiment, and deposition of Ag nanoparticles on the Pt-loaded $\mathrm{ZnO}$ catalyst was observed in TEM micrographs obtained after reaction.
\end{abstract}




\subsection{Introduction}

Hydrogen is used in many different applications, such as production of electricity in fuel cells, synthesis of ammonia, and desulfurization of oil fractions in refineries. Photocatalytic solar water splitting is one of the most promising technologies to produce hydrogen sustainably, without significant $\mathrm{CO}_{2}$ emissions associated with e.g. methane steam reforming or coal gasification. Since the first demonstration of this concept in 1972 by Honda and Fujishima based on $\mathrm{TiO}_{2}$, ${ }^{1}$ a lot of attention has been paid to develop improved semiconductor materials which could be used as photo-electrode. Challenges such as utilizing longer wavelengths of solar light, long term stability, high energy conversion efficiency, and affordable cost, have to be addressed in development of practical devices.

Many studies focus on the synthesis and evaluation of new semiconductors to enhance the performance of solar water splitting devices. One can also design and modify well-known materials to improve efficiency. $\mathrm{WO}_{3}$ is one of the most frequently studied metal oxides to be applied in the water oxidation reaction, functioning as photo-anode when deposited on a conductive substrate. It has a high stability in aqueous solutions (under $\mathrm{pH} 4$ ), and a longer hole diffusion length $(\sim 150 \mathrm{~nm})$ than other metal oxides, which is beneficial for separation and efficacy of photo-generated electron-hole pairs. ${ }^{2,}{ }^{3}$ However, $\mathrm{WO}_{3}$ has a relatively wide band gap $(\sim 2.6-2.8 \mathrm{eV})$ as compared to for example $\mathrm{BiVO}_{4}(\sim 2.4 \mathrm{eV})^{4}$ or $\mathrm{Fe}_{2} \mathrm{O}_{3}(\sim 2.1 \mathrm{eV}){ }^{5}$ Therefore, based on band gap energy, the maximum solar to hydrogen efficiency of $\mathrm{WO}_{3}$ is limited $\sim 6 \%{ }^{6-8}$ To overcome the optical absorption limitations of $\mathrm{WO}_{3}$, several approaches have been followed, including metal-ion and non-metal doping. For example, variations of $\mathrm{CuWO}_{4}$ or $\mathrm{ZnWO}_{4}$ absorb photons of significantly longer wavelengths than $\mathrm{WO}_{3} .{ }^{9}, 10$ Another approach to enhance solar to hydrogen (STH) efficiency is by incorporating plasmonic metal nanoparticles in photoactive films, which absorb visible light photons inducing plasmonic resonance, thereby stimulating/enhancing photocatalytic activity of the semiconductor. Indeed plasmonic metal nanostructures have been demonstrated to enhance performance in photocatalysis. $^{11-13}$

Generally, metal nanoparticles are positioned in direct contact with the semiconductor to induce plasmonic effects. A drawback of such configuration is that adverse recombination of electrons and holes at the metal/semiconductor interface might occur, or metal corrosion/oxidation, eventually extinguishing the plasmonic enhancement. To resolve these issues, and in particular metal corrosion, utilization of core-shell particles might be promising, preventing direct contact of the metal with the electrolyte used in PEC cell configurations, as well as slurry based photocatalytic reactors. ${ }^{11}$ Several examples confirming this hypothesis have been reported in the literature. Thomann et al. demonstrate plasmonic enhancement of $\mathrm{Fe}_{2} \mathrm{O}_{3}$ with bare $\mathrm{Au}$ or $\mathrm{Au} @ \mathrm{SiO}_{2}$ core-shell particles in water splitting applications. ${ }^{14}$ The $\mathrm{SiO}_{2}$ shell is proposed to protect the $\mathrm{Au}$ (core) particles against corrosion. However, these authors imply that the integrity of the shell might be affected by deformation as a result of thermal processing. Abdi et al. explored plasmonic enhancement of $\mathrm{Ag} @ \mathrm{SiO}_{2}$ core-shell particles in contact with a $\mathrm{BiVO}_{4}$ film. ${ }^{15}$ The observed enhancement of $\mathrm{BiVO}_{4}$ performance 
by the $\mathrm{Ag} @ \mathrm{SiO}_{2}$ core-shell particles was demonstrated to be mainly due to scattering. In that study, instability of the core-shell particles was not observed.

Herein, we further evaluate the applicability of core-shell metal-insulator nanoparticles of $\mathrm{Ag} @ \mathrm{SiO}_{2}$ core-shell configuration in PEC cell and photocatalytic application, as a strategy to enhance optical absorption of FTO supported $\mathrm{WO}_{3}$ or $\mathrm{ZnO}$ photo-anodes. We evaluate three different structures of the photo-anodes in water oxidation efficacy, i.e. 1) an embedded configuration, 2) a $\mathrm{Ag} @ \mathrm{SiO}_{2}-\mathrm{WO}_{3}-\mathrm{FTO}$ layered configuration (surface configuration), and 3) a $\mathrm{WO}_{3}-\mathrm{Ag} @ \mathrm{SiO}_{2}-\mathrm{FTO}$ layered configuration (enclosed configuration) to optimize the effect of the $\mathrm{Ag} @ \mathrm{SiO}_{2}$ core-shell particles. The photoelectrochemical performance of $\mathrm{Ag} @ \mathrm{SiO}_{2}$ core-shell particles will be shown to depend on the structure and composition of the photoanode. Finally we have investigated potential beneficial effects of $\mathrm{Ag} @ \mathrm{SiO}_{2}$ core-shell particles on performance of Pt-loaded $\mathrm{ZnO}$ catalysts when the photocatalytic water decomposition reaction was performed in a slurry reactor.

\subsection{Experimental section}

\subsubsection{Synthesis and characterization of $\mathrm{Ag@SiO}$ core-shell nanoparticles}

See chapter 6 . The synthesis and characterization has been described on page 88 and is illustrated in Figure 6.1.

\subsubsection{Preparation of $\mathrm{WO}_{3}$ films on FTO glass}

See chapter 3. The preparation has been described on page 31 .

\subsubsection{Preparation of Ag@SiO $\mathrm{S}_{2}$ core-shell particles solution and coating}

For the preparation of an embedded configuration, $\mathrm{Ag} @ \mathrm{SiO}_{2}$ core-shell particles (5 wt- $\%$ ) were dispersed in a $\mathrm{WO}_{3}$ sol-gel solution for $30 \mathrm{~min}$ in a $35 \mathrm{kHz}$ Elmasonic ultrasonic bath. The prepared suspension was spin coated on FTO glass at $600 \mathrm{rpm}$ for $40 \mathrm{sec}$. An embedded configuration film thickness was $\sim 100 \mathrm{~nm}$. For the preparation of a surface configuration, an ethanol suspension containing $\mathrm{Ag} @ \mathrm{SiO}_{2}$ core-shell particles $(2 \mathrm{mg} / 4 \mathrm{ml}$ ) was treated for 30 min in an ultrasonic bath. $100 \mu \mathrm{L}$ of the prepared suspension was spin coated on a preprepared $\mathrm{WO}_{3}$ film at $1000 \mathrm{rpm}$ for $40 \mathrm{sec}$. After spin coating, the glass was heated on a hot plate at $100{ }^{\circ} \mathrm{C}$ for $1 \mathrm{~min}$. This process was repeated consecutively to create a homogeneous layer of $\mathrm{Ag} @ \mathrm{SiO}_{2}$ core-shell particles. For the preparation of an enclosed configuration, a distilled water suspension containing $\mathrm{Ag} @ \mathrm{SiO}_{2}$ core-shell particles $(2 \mathrm{mg} / 4 \mathrm{ml}$ ) was treated for $30 \mathrm{~min}$ in an ultrasonic bath. $100 \mu \mathrm{L}$ of the prepared suspension was spin coated on FTO glass at $2000 \mathrm{rpm}$ for $40 \mathrm{sec}$. After coating, the glass was heated on a hot plate at $100{ }^{\circ} \mathrm{C}$ for 1 min. This process was repeated consecutively to create a homogeneous layer of $\mathrm{Ag} @ \mathrm{SiO}_{2}$ 
core-shell particles. Subsequently $\mathrm{WO}_{3}$ was deposited according to the previously described procedure. For the surface and enclosed configuration, the resulting $\mathrm{WO}_{3}$ film thickness was $\sim 300 \mathrm{~nm}$. For the samples with $\mathrm{ZnO}$ as photo-anode, a 1,2-dichlorobenzene suspension containing Ag@ $\mathrm{SiO}_{2}$ core-shell particles (1 mg / 1ml) was treated for $30 \mathrm{~min}$ in an ultrasonic bath. $100 \mu \mathrm{L}$ of the prepared suspension was spin coated on FTO glass (enclosed configuration), or on a pre-deposited $\mathrm{ZnO}$ film (surface configuration), respectively, at 2000 rpm for $40 \mathrm{sec}$. After coating, the glass was heated on a hot plate at $100{ }^{\circ} \mathrm{C}$ for $1 \mathrm{~min}$.

\subsubsection{Preparation of the $\mathrm{ZnO}$ film on FTO glass}

For the preparation of a $\mathrm{ZnO}$ sol-gel precursor solution, zinc acetate (Sigma Aldrich) was dissolved in 2-methoxyehanol (Sigma Aldrich) containing ethanolamine (Sigma Aldrich) as a stabilizer. ${ }^{16}$ The concentration of zinc acetate was $2 \mathrm{M}$. The prepared solution was dispersed in an ultrasonic bath for 30 min to obtain a homogeneous solution. The $\mathrm{ZnO}$ solution was spin coated on fluorine-doped tin oxide (FTO) glass at $2000 \mathrm{rpm}$ for $40 \mathrm{sec}$. After spin coating, the glass was heated on a hot plate at $350{ }^{\circ} \mathrm{C}$ for $10 \mathrm{~min}$. Each consecutive spin coating process creates an approximately $100 \mathrm{~nm}$ thick $\mathrm{ZnO}$ film. (Figure A7.1)

\subsubsection{Characterization of the PEC cell in water splitting}

The photoelectrochemical anodic properties of the $\mathrm{WO}_{3} / \mathrm{Ag} @ \mathrm{SiO}_{2}$ core-shell particle composites were determined in an aqueous electrolyte solution containing $0.1 \mathrm{M}$ of sodium sulfate $\left(\mathrm{pH} \sim 3.5\right.$ ). Anodic properties of the $\mathrm{ZnO} / \mathrm{Ag} @ \mathrm{SiO}_{2}$ core-shell particle composites were measured in an aqueous electrolyte solution containing $0.2 \mathrm{M}$ of potassium bicarbonate ( $\mathrm{pH} \sim 8.2$ ). The potential of the working electrode was controlled by a potentiostat (VERSASTAT 4, Princeton applied research). In the three-electrode measurements, a Pt wire and an $\mathrm{Ag} / \mathrm{AgCl}$ electrode ( $3 \mathrm{M} \mathrm{NaCl}, \mathrm{BASi}$ ) were used as the counter and reference electrode, respectively. The photoactive area was defined by an o-ring positioned in front of the $\mathrm{WO}_{3}$ anode, being $2.54 \mathrm{~cm}^{2}$. Photocurrents were measured under illumination of an AM 1.5 solar simulator $\left(100 \mathrm{~mW} / \mathrm{cm}^{2}\right)$, with a $300 \mathrm{Xe}$ lamp and air mass 1.5 global filter. The intensity of the simulated sunlight was calibrated using a standard reference Si solar cell.

\subsubsection{Photo-deposition of Pt nanoparticles on $\mathrm{ZnO}$}

$1 \mathrm{~g}$ of $\mathrm{ZnO}$ (Sigma Aldrich) suspended in Milli-Q water $(40 \mathrm{ml})$ was mixed with $7 \mathrm{ml}$ of $0.0019 \mathrm{M} \mathrm{H}_{2} \mathrm{PtCl}_{6} \cdot 6 \mathrm{H}_{2} \mathrm{O}$ (Sigma Aldrich) solution in a quartz glass beaker for $30 \mathrm{~min}$ in dark conditions. The beaker was capped by a quartz glass plate to prevent evaporation, and covered by aluminum foil. $3 \mathrm{ml}$ of methanol was added to the thus prepared solution as sacrificial agent, followed directly by illumination using UV light (18 W TL-D Blacklight Blue, Philips) for $1 \mathrm{hr}$. The total light intensity was $3.21 \mathrm{~mW} / \mathrm{cm}^{2}$ with the wavelength ranging from 360 to 
$380 \mathrm{~nm}$. The thus synthesized Pt-loaded $\mathrm{ZnO}$ was centrifuged and washed 3 times by Milli-Q water and then dried in an oven at $80{ }^{\circ} \mathrm{C}$ under atmospheric conditions.

\subsubsection{Characterization of photocatalyst activity by gas chromatography}

$\mathrm{H}_{2}$ evolution was measured for the Pt-loaded $\mathrm{ZnO}$ photocatalyst in a continuously stirred tank reactor (CSTR) connected to a gas chromatograph (CompactGC Interscience, equipped with a pulsed discharge detector). $25 \mathrm{mg}$ of photocatalyst was dispersed in $25 \mathrm{ml}$ of $0.01 \mathrm{M}$ potassium sulfate $(\mathrm{pH} \sim 7.7)$ within an optical glass cuvette of $50 \mathrm{~mL}$, used as the CSTR. After removing air from the reactor by continuous purging with purified $\mathrm{He}$, the suspension was illuminated by a solar simulator at $100 \mathrm{~mW} / \mathrm{cm}^{2}$ (Abet Technologies, Inc., $150 \mathrm{~W}$ ozone free arc lamp). The amount of $\mathrm{H}_{2}$ evolution was continuously measured using $\mathrm{He}$ as purge gas (10 $\mathrm{ml} / \mathrm{min}$ ). To determine the $\mathrm{Ag} @ \mathrm{SiO}_{2}$ core-shell particle effect on the water splitting efficiency, $\mathrm{Ag} @ \mathrm{SiO}_{2}$ core-shell particles were added after $4 \mathrm{hr}$ of illumination of the Pt-loaded $\mathrm{ZnO}$ sample in suspension. Before introduction of the $\mathrm{Ag} @ \mathrm{SiO}_{2}$ core-shell particles, the reactor was purged to remove $\mathrm{H}_{2}$ from the reactor in dark conditions.

\subsubsection{Analysis of photo-electrode}

The various photo-anodes and photocatalyst samples were analyzed using field emission scanning electron microscope (FE-SEM, Zeiss LEO 1550), high-resolution transmission electron microscopy (HR-TEM, FEI Instruments), X-ray photoelectron spectroscopy (XPS, Quantera SXM from Physical Electronics), X-ray diffraction (XRD, Bruker D2 phaser), and inductively coupled plasma atomic emission spectroscopy (ICP-AES, Varian Liberty II, Sequential ICP-AES). Pt and Ag particle sizes, oxidation states, crystallinity of the semiconductors and Pt loading, were thus obtained, respectively.

\subsection{Results and discussion}

\subsubsection{Photocurrent characteristic of an embedded configuration}

Figure 7.1 shows a comparison of photocurrent densities of $\mathrm{WO}_{3}$ photo-anodes in the absence or presence of embedded $\mathrm{Ag} @ \mathrm{SiO}_{2}$ core-shell particles. The LSV (Linear sweep voltammetry) curves were measured during front-side, or back-side illumination. The presence of the $\mathrm{Ag} @ \mathrm{SiO}_{2}$ core-shell particles results in a lower photocurrent at $1.23 \mathrm{~V} v \mathrm{~s}$. RHE, both during front or back-side illumination (Figures 7.1a and 7.1b). The absence of a significant positive effect might be associated with the following. Dark scan curves show a small, but anodic peak at approximately $0.65 \mathrm{~V} v s$. RHE (Figure 7.1c) in agreement with the oxidation potential of Ag. ${ }^{17,18}$ It seems the $\mathrm{Ag} @ \mathrm{SiO}_{2}$ core-shell particles are instable in the conditions of the photoelectrochemical experiments. We will provide further evidence for 
instability later. Other explanations for negative effects of $\mathrm{Ag} @ \mathrm{SiO}_{2}$ core-shell particles will be discussed in the following.
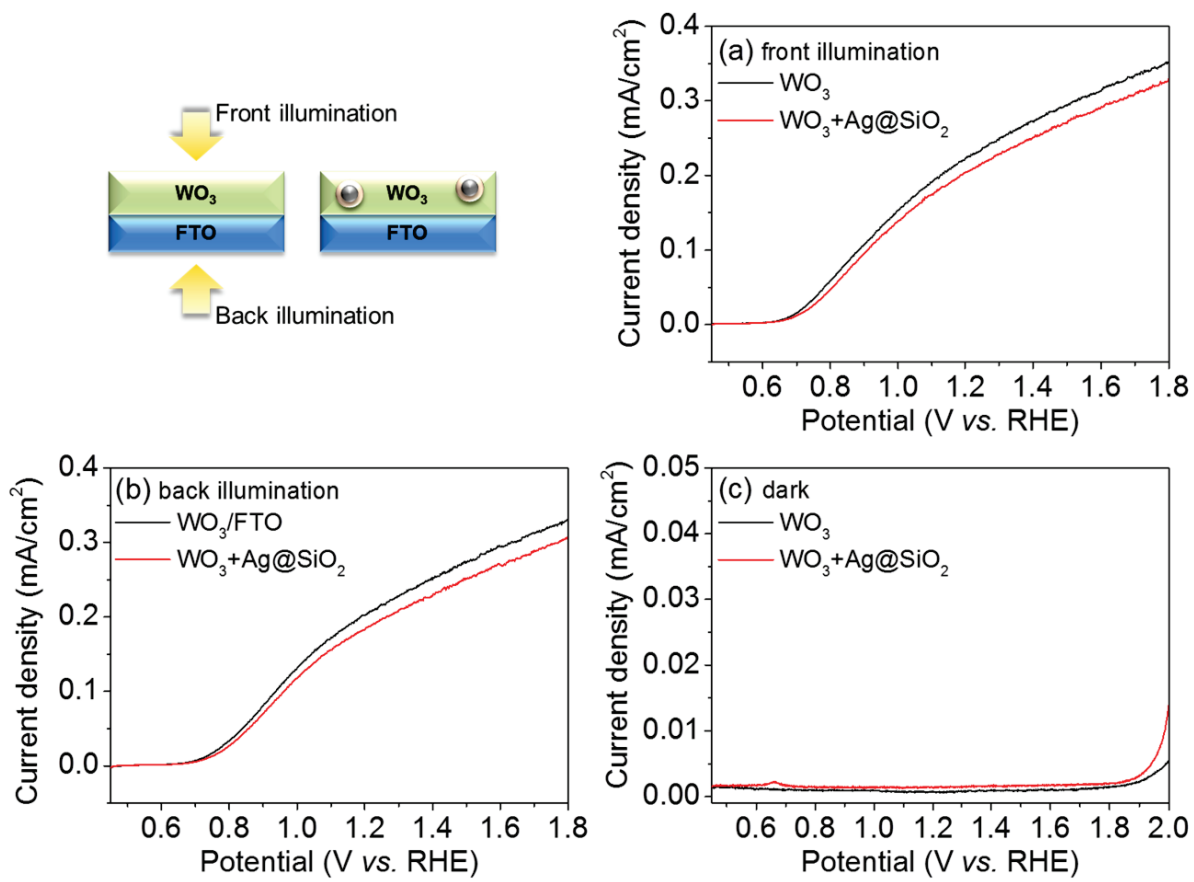

Figure 7.1. LSV curves of unmodified $\mathrm{WO}_{3}$ anode and $\mathrm{WO}_{3}$ anodes with $\mathrm{Ag} @ \mathrm{SiO}_{2}$ coreshell particles under (a) front-side illumination, (b) back-side illumination, and (c) dark conditions.

\subsubsection{Photocurrent characteristic of a surface configuration}

Figure 7.2 shows the photocurrent achieved for a configuration with $\mathrm{Ag} @ \mathrm{SiO}_{2}$ core-shell particles on top of the $\mathrm{WO}_{3}$ film. We controlled the amount of $\mathrm{Ag} @ \mathrm{SiO}_{2}$ core-shell particles on the $\mathrm{WO}_{3}$ film by increasing the number of spin coating cycles from 1 to 3 . The film created by a single cycle did not significantly affect the performance of the photo-anode, while increasing the amount of $\mathrm{Ag} @ \mathrm{SiO}_{2}$ core-shell particles on the $\mathrm{WO}_{3}$ film decrease the photocurrent density obtained at $1.23 \mathrm{~V} v s$. RHE for front-side illumination, as shown in Figure 7.2a. Besides previously suggested Ag oxidation, this decrease is likely also related to a reduction in effective light absorption of $\mathrm{WO}_{3}$ by out-scattering of light by the $\mathrm{Ag} @ \mathrm{SiO}_{2}$ core-shell particles. In the case of back-side illumination (Figure 7.2b), the $\mathrm{WO}_{3}$ behavior is also negatively affected. To explain this, we take a third factor into account. We assume an 
interfacial electrical resistance is introduced by the $\mathrm{Ag} @ \mathrm{SiO}_{2}$ core-shell particles between the electrolyte and the $\mathrm{WO}_{3}$ photo-anode, inhibiting hole transfer from $\mathrm{WO}_{3}$ to surface water molecules. In other words, $\mathrm{Ag} @ \mathrm{SiO}_{2}$ core-shell particles can reduce the active site density of $\mathrm{WO}_{3}$ for the water oxidation reaction due to the insulating nature of the $\mathrm{SiO}_{2}$ shell. In the surface configuration, dark scan curves didn't show the peak of anodic silver oxidation (Figure 7.2c).
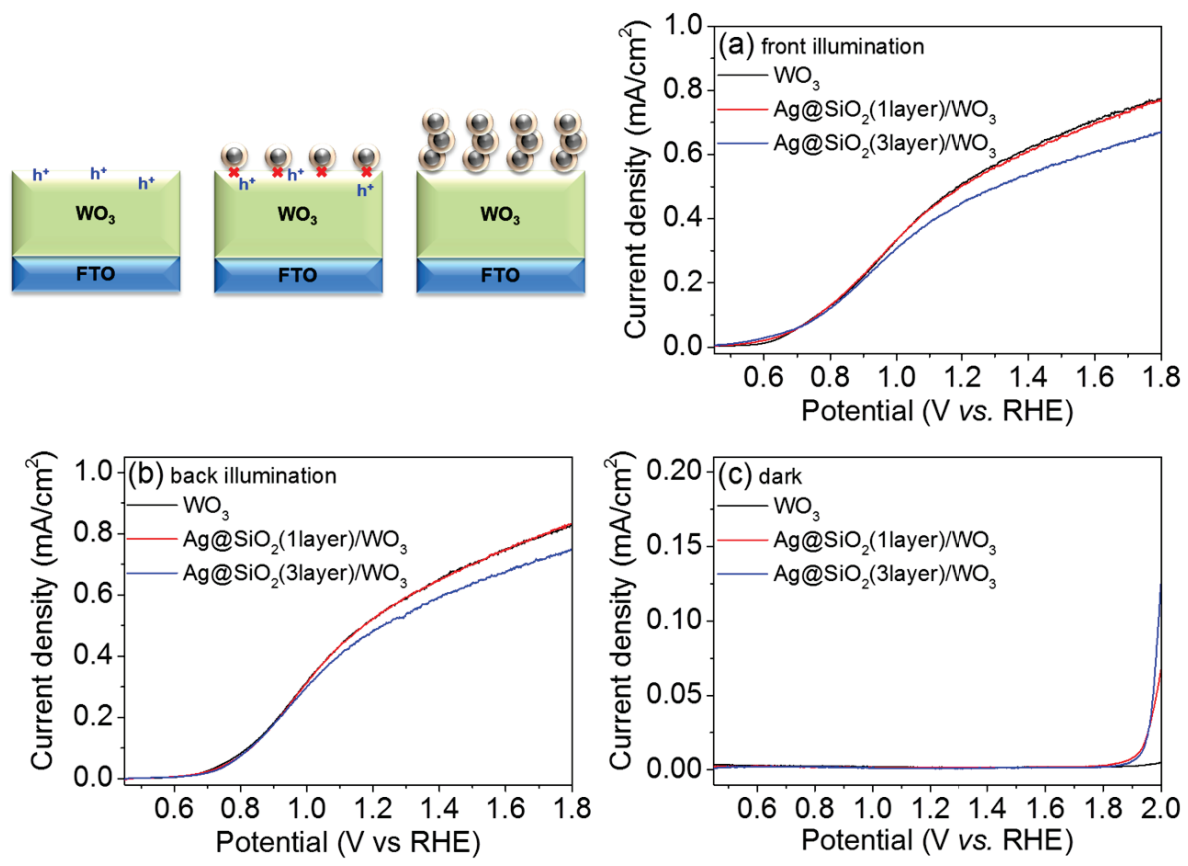

Figure 7.2. LSV curves of unmodified $\mathrm{WO}_{3}$ anode and $\mathrm{Ag} @ \mathrm{SiO}_{2}$ core-shell particles on $\mathrm{WO}_{3}$ film under (a) front-side illumination (b) back-side illumination, and (c) dark conditions.

\subsubsection{Photoelectrochemical characteristics of an enclosed configuration}

Figure 7.3a shows the current density for an enclosed configuration in which the $\mathrm{Ag} @ \mathrm{SiO}_{2}$ core-shell particles are positioned in between $\mathrm{WO}_{3}$ film and FTO. Again the effect is negative, now also for a single spin coating cycle. Similar to diminishing effective hole transfer in the surface configuration, this might be explained by additional resistance introduced by the $\mathrm{Ag} @ \mathrm{SiO}_{2}$ core-shell particles, now inhibiting electron flow from $\mathrm{WO}_{3}$ into FTO. This is in agreement with the fact that the photocurrent at $1.23 \mathrm{~V} v s$. RHE shows a continuous decrease with increasing amount of the $\mathrm{Ag} @ \mathrm{SiO}_{2}$ core-shell particles (three consecutive spin coating 
cycles). Interestingly, now the anodic peak of $\mathrm{Ag}$ oxidation in the dark scan is intense (especially for three consecutive spin coating cycles), broad, and extending over the range of 0.65 to $0.8 \mathrm{~V} v s$. RHE (Figure $7.3 \mathrm{~b}$ ).
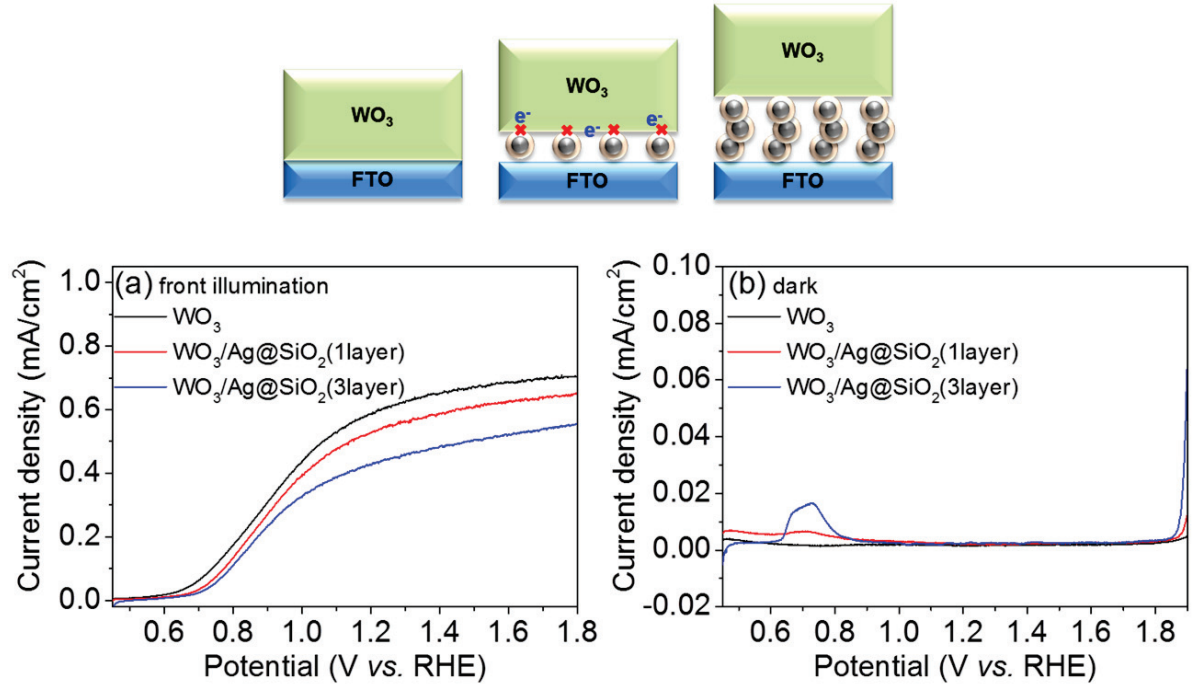

Figure 7.3. LSV curves of unmodified $\mathrm{WO}_{3}$ sample and $\mathrm{Ag} @ \mathrm{SiO}_{2}$ core-shell particles in between $\mathrm{WO}_{3}$ film and FTO glass under (a) front-side illumination and (b) dark condition.

To further analyze this anodic peak, dark scan curves of FTO, bare $\mathrm{SiO}_{2}$ on FTO glass, bare $\mathrm{Ag}$ nanoparticles on FTO glass, and $\mathrm{Ag} @ \mathrm{SiO}_{2}$ core-shell particles on FTO glass are compared in Figure 7.4. The $\mathrm{Ag} @ \mathrm{SiO}_{2}$ core-shell particles show a similar anodic current peak to the Ag nanoparticles without a shell, albeit of much lower intensity as evident from the magnified view (right Figure 7.4). In other words, we observe that the $\mathrm{SiO}_{2}$ shell does not fully protect the $\mathrm{Ag}$ core against oxidation in the conditions of the photoelectrochemical experiments, in agreement with literature, suggesting the porosity of the $\mathrm{SiO}_{2}$ shell is too high to completely prevent this. ${ }^{19}$ 

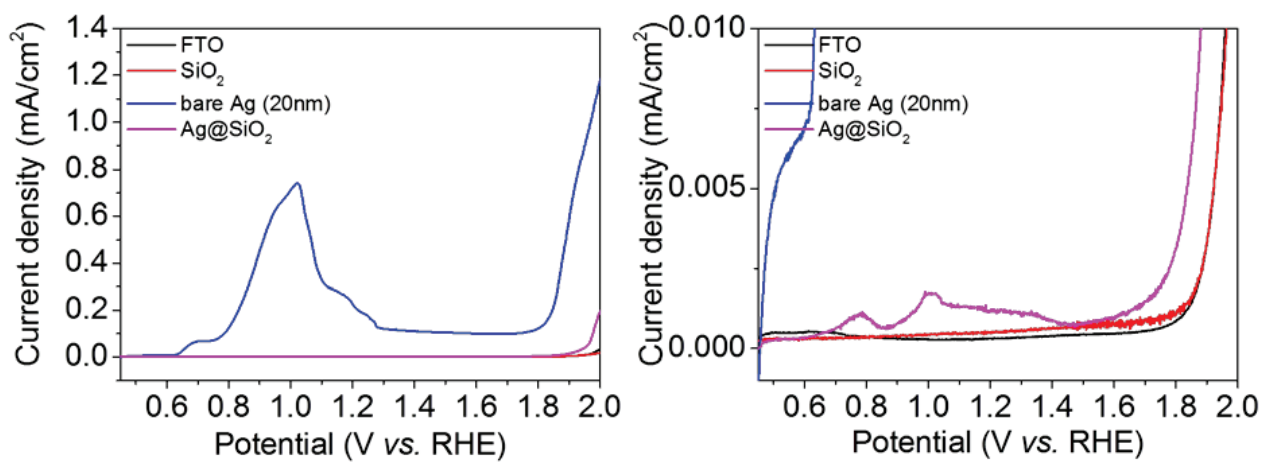

Figure 7.4. Dark scan curves of FTO glass, bare $\mathrm{SiO}_{2}$ on FTO glass, bare Ag nanoparticles on FTO glass, and $\mathrm{Ag} @ \mathrm{SiO}_{2}$ core-shell particles on FTO glass. The right Figure is a magnified view of the left Figure.

Based on the dark scan curves, the oxidation current can indeed be assigned to oxidation or dissolution of Ag which can be represented as,

$$
\mathrm{Ag}_{n} \rightarrow \mathrm{Ag}_{n}^{+}+\mathrm{e}
$$

$\mathrm{Ag}$ is instable at the applied (and generated) oxidation potential over a broad range of $\mathrm{pH}$ values. ${ }^{20}$ Ag metal can be dissolved and oxidized to $\mathrm{Ag}(\mathrm{OH})$ or $\mathrm{Ag}_{2} \mathrm{O}$, which explains the lack of plasmonic enhancement in performance of the $\mathrm{WO}_{3} / \mathrm{FTO}$ based PEC cell. To determine if plasmonic enhancement of the as-prepared $\mathrm{Ag} @ \mathrm{SiO}_{2}$ core-shell particles is feasible, we used Raman spectroscopy (Figure A7.2) to evaluate intensity differences in the $\mathrm{WO}_{3}$ induced Raman lines. The features at 710 and $805 \mathrm{~cm}^{-1}$ can be attributed to $\mathrm{W}-\mathrm{O}-\mathrm{W}$ stretching modes of the $\mathrm{WO}_{3}$ film. ${ }^{21}$ The presence of bare Ag nanoparticles $\left(\mathrm{WO}_{3} / \mathrm{Ag}\right.$ nanoparticles/FTO) results in higher relative Raman intensities of $\mathrm{WO}_{3}$, as compared to $\mathrm{WO}_{3} / \mathrm{FTO}$. The presence of $\mathrm{Ag} @ \mathrm{SiO}_{2}$ core-shell particles $\left(\mathrm{WO}_{3} / \mathrm{Ag} @ \mathrm{SiO}_{2} / \mathrm{FTO}\right.$ layers $)$ showed significantly less enhancement, suggesting that increasing the $\mathrm{SiO}_{2}$ shell thickness, for additional protection against Ag oxidation, is not feasible if plasmon enhancement needs to be maintained. Therefore, our results imply that metal nanoparticles need to be covered with a thin, but dense layer as shell.

\subsubsection{Photoelectrochemical characteristics of a $\mathrm{ZnO}$ photo-anode}

When $\mathrm{ZnO}$ is used as photo-anode instead of $\mathrm{WO}_{3}$ with $\mathrm{Ag} @ \mathrm{SiO}_{2}$ core-shell particles in an enclosed configuration, the photocurrent density is positively affected by $\mathrm{Ag} @ \mathrm{SiO}_{2}$ core-shell particles at $1.23 \mathrm{~V} v s$. RHE (Figure 7.5a), particularly evident in chronoamperometry at an applied potential of $1.23 \mathrm{~V} v s$. RHE under light chopping conditions (Figure 7.5b). 
Apparently, for UV sensitive $\mathrm{ZnO}$, resulting in significantly lower photocurrents as compared to $\mathrm{WO}_{3}$, light scattering provided by the $\mathrm{Ag} @ \mathrm{SiO}_{2}$ core-shell particles yields a positive effect, overcompensating for negative effects by increasing interfacial resistances. Plasmonic effects are less likely, since the optical absorption spectra of $\mathrm{ZnO}$ and $\mathrm{Ag} @ \mathrm{SiO}_{2}$ core-shell particles do not overlap.
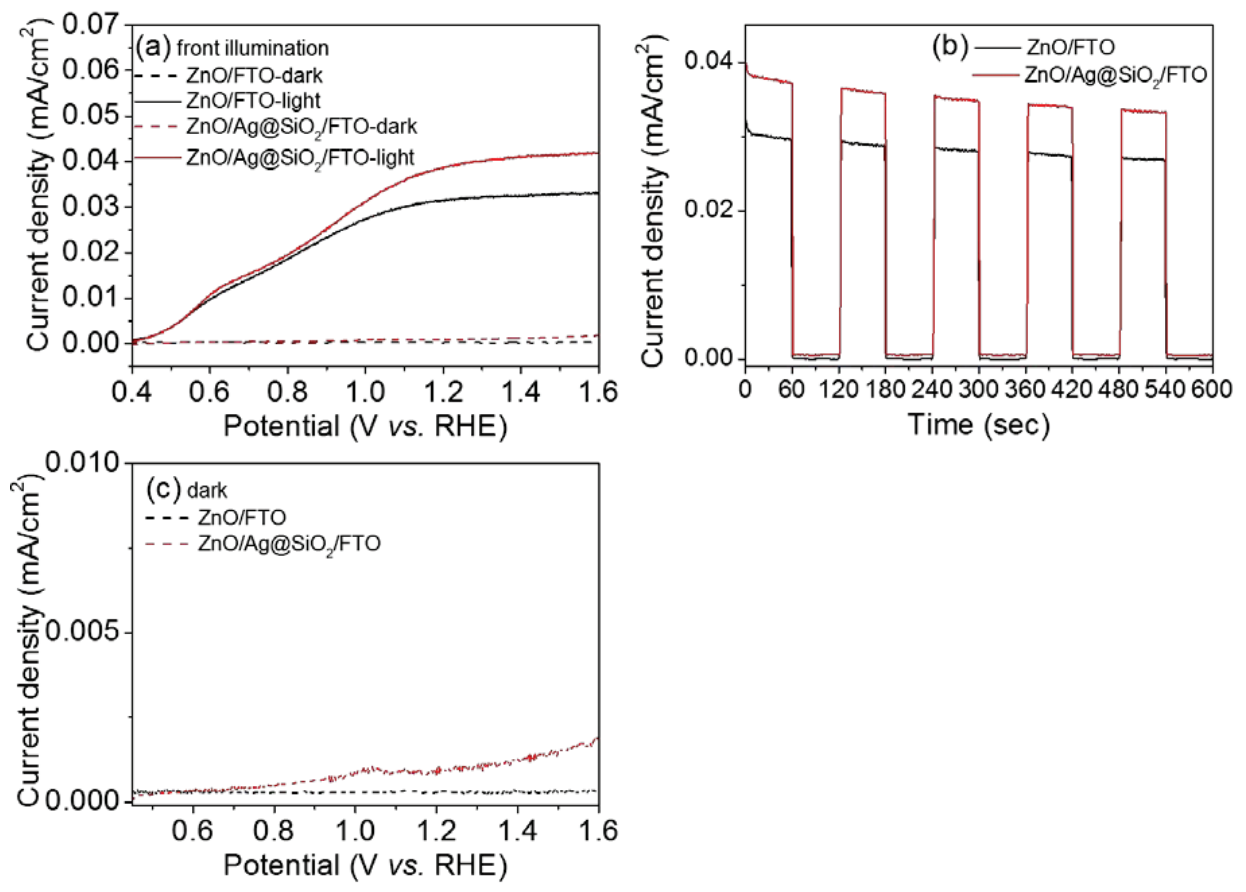

Figure 7.5. (a) LSV curves in simulated AM 1.5 illumination for the $\mathrm{ZnO}$ film with and without $\mathrm{Ag} @ \mathrm{SiO}_{2}$ core-shell particles layer in between $\mathrm{ZnO}$ film and FTO glass. (b) Chronoamperometry at an applied potential of $1.23 \mathrm{~V} v s$. RHE under light chopping conditions. (c) Magnified view of Figure (a) in dark conditions.

Again a small peak is evident in the LSV curve of the photo-anode containing the $\mathrm{Ag} @ \mathrm{SiO}_{2}$ core-shell particles, suggesting oxidation of $\mathrm{Ag}$ is again feasible. The positive effect of the $\mathrm{Ag} @ \mathrm{SiO}_{2}$ core-shell particles is corroborated by the surface configuration, as shown in Figure 7.6. In the presence of $\mathrm{Ag} @ \mathrm{SiO}_{2}$ core-shell particles, the photocurrent at $1.23 \mathrm{~V} v s$. RHE is enhanced. 

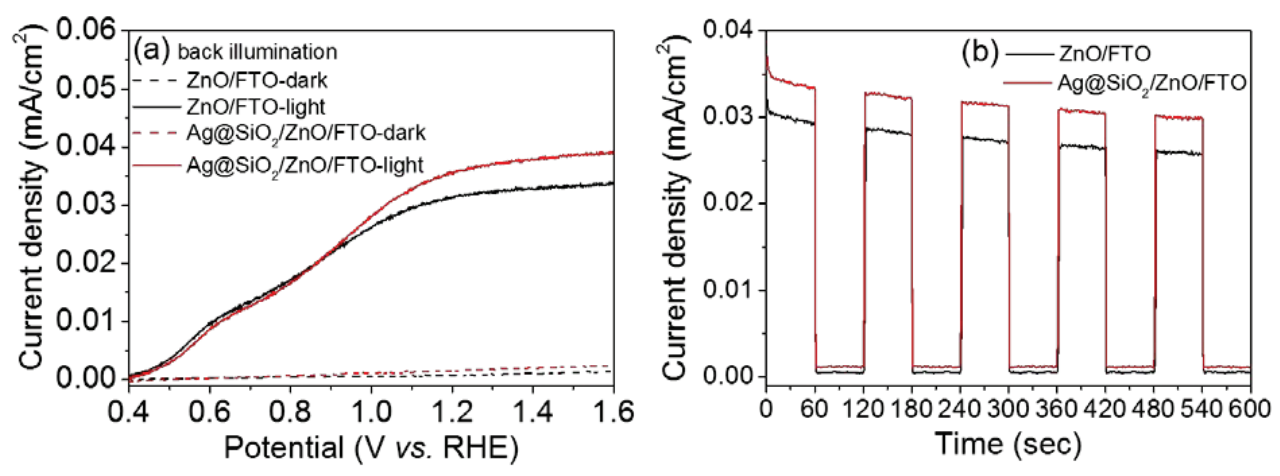

Figure 7.6. (a) LSV curves in simulated AM 1.5 illumination for the $\mathrm{ZnO}$ film with and without $\mathrm{Ag} @ \mathrm{SiO}_{2}$ core-shell particles layer on $\mathrm{ZnO}$ film. (b) Chronoamperometry at an applied potential of $1.23 \mathrm{~V} v s$. RHE under light chopping conditions.

\subsubsection{Gas chromatography measurement}

To further demonstrate potentially positive effects of $\mathrm{Ag} @ \mathrm{SiO}_{2}$ core-shell particles in the water splitting reaction, we analyzed the performance of Pt-loaded $\mathrm{ZnO}$ in the absence or presence of $\mathrm{Ag} @ \mathrm{SiO}_{2}$ core-shell particles, as shown in Figure 7.7. Pt deposition on $\mathrm{ZnO}$ using photo-deposition was confirmed by TEM and EDX analysis (Figure 7.8b and Figure A7.3). The average Pt particle size was in the order of $1.94 \mathrm{~nm}$ (standard deviation: $0.70 \mathrm{~nm}$ ). The Pt particle size was determined by ImageJ as shown in Figure A7.4. In addition, the loading of $\mathrm{Pt}$ on $\mathrm{ZnO}$ was determined using ICP-AES, indicating that photo-deposition of $\mathrm{Pt}$ on $\mathrm{ZnO}$ occurred with an efficiency of $99.5 \%$. 


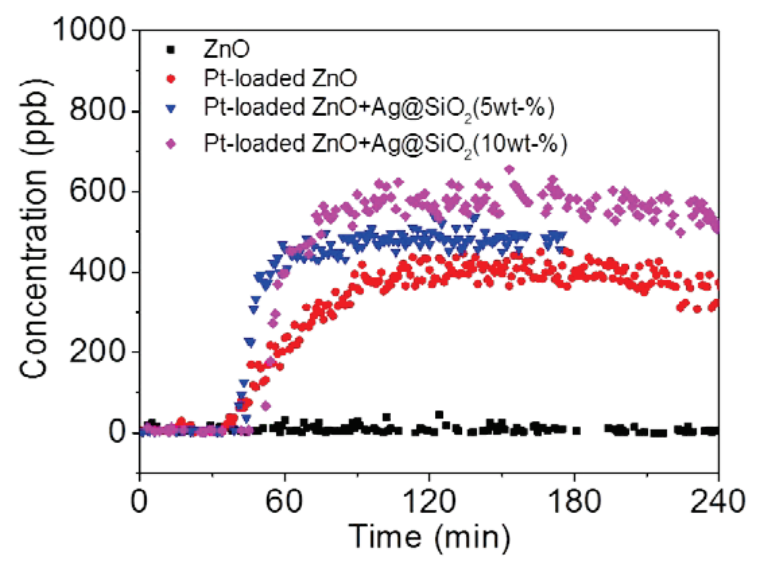

Figure 7.7. Gas chromatography measurement of Pt-loaded $\mathrm{ZnO}$ in the absence or presence of $\mathrm{Ag} @ \mathrm{SiO}_{2}$ core-shell particles.

Detailed information concerning ICP-AES analysis is provided in the Appendix A7.5. The

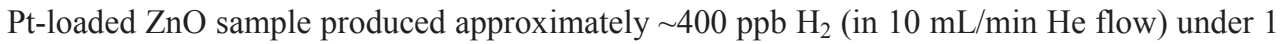
sun illumination, whereas without $\mathrm{Pt}, \mathrm{ZnO}$ did not yield any hydrogen. Adding the $\mathrm{Ag} @ \mathrm{SiO}_{2}$ core-shell particles enhanced $\mathrm{H}_{2}$ evolution activity. Specifically, a 50\% increase (from 400 to $600 \mathrm{ppb}$ ) was obtained in the presence of $10 \mathrm{wt}-\%$ of the $\mathrm{Ag} @ \mathrm{SiO}_{2}$ particles. The activity of the catalyst is in the order of $0.58 \mu$ mole $\mathrm{g}^{-1} \mathrm{~h}^{-1}$ (Appendix A7.6). Please note that the transient in $\mathrm{H}_{2}$ production rate was relatively slow in the case of the Pt-loaded $\mathrm{ZnO}$. This is likely related to the conversion of $\mathrm{Pt}^{2+} \mathrm{O}_{\mathrm{x}}$ to $\mathrm{Pt}^{0}$ (Appendix, Table A7.1), while hydrogen production at $\mathrm{Pt}^{0}$ is more effective than on $\mathrm{Pt}^{2+} \mathrm{O}_{\mathrm{x}}{ }^{22}$ Specifically, at the start of the reaction, photoexcited electrons convert $\mathrm{Pt}^{2+} \mathrm{O}_{\mathrm{x}}$ to metallic $\mathrm{Pt}$ and produce $\mathrm{H}_{2} \mathrm{O}$ (see Scheme 7.1).
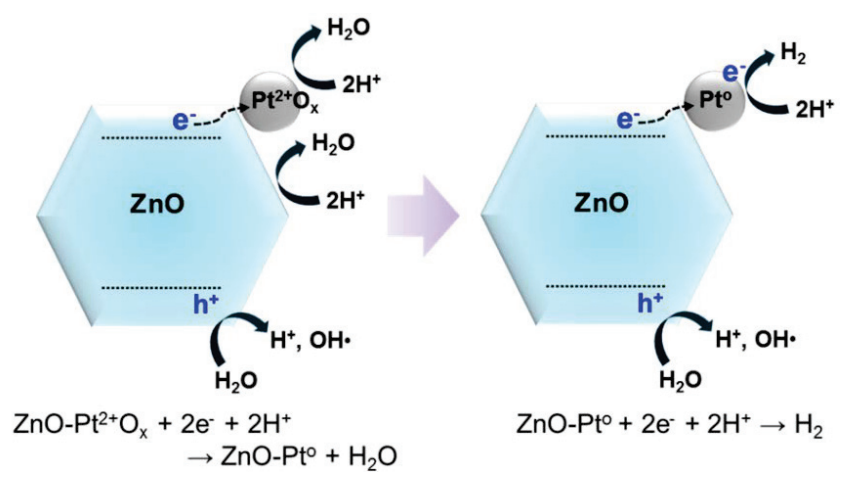

Scheme 7.1. The conversion of $\mathrm{Pt}^{2+} \mathrm{O}_{\mathrm{x}}$ to $\mathrm{Pt}^{\mathrm{o}}$ upon initiation of the reaction. 
For the analysis of the stability of $\mathrm{ZnO}$, we analyzed the powdered samples before and after the water splitting reaction, respectively by XRD, TEM, and XPS, as shown in Figure A7.7, Figure 7.8, and Figures A7.8 to A7.11. ZnO crystallinity was not significantly changed by the photo-deposition procedure and the photo-activity measurement, as evident from the XRD data. Also the oxidation state was not changed, and all $\mathrm{Zn}$ present as $\mathrm{Zn}^{2+}$ before and after reaction. For the Pt-loaded $\mathrm{ZnO}$ sample as prepared, a small contribution of $\mathrm{PtO}_{\mathrm{x}}$ can be observed in the Pt $4 \mathrm{f}$ region, besides a dominant fraction of metallic Pt. After the reaction, the $\mathrm{PtO}_{\mathrm{x}}$ contribution is no longer present, corroborating the above indicated in situ reduction of $\mathrm{PtO}_{\mathrm{x}}$ in the water splitting reaction.

The microscopy images were mainly recorded to analyze the stability of the $\mathrm{Ag} @ \mathrm{SiO}_{2}$ core-shell particles. Ag@ $\mathrm{SiO}_{2}$ core-shell particles are clearly visible in the images of the Ptloaded $\mathrm{ZnO}$ (Figure 7.8c), images taken before the photocatalytic reaction. Figure 7.8d shows images taken after the photocatalytic reaction. Several remarkable observations can be made.

First, the image shows a $\mathrm{Ag} @ \mathrm{SiO}_{2}$ core-shell particle in which the Ag core has clearly shrunk, leaving a void between the $\mathrm{SiO}_{2}$ shell and the $\mathrm{Ag}$ core. 

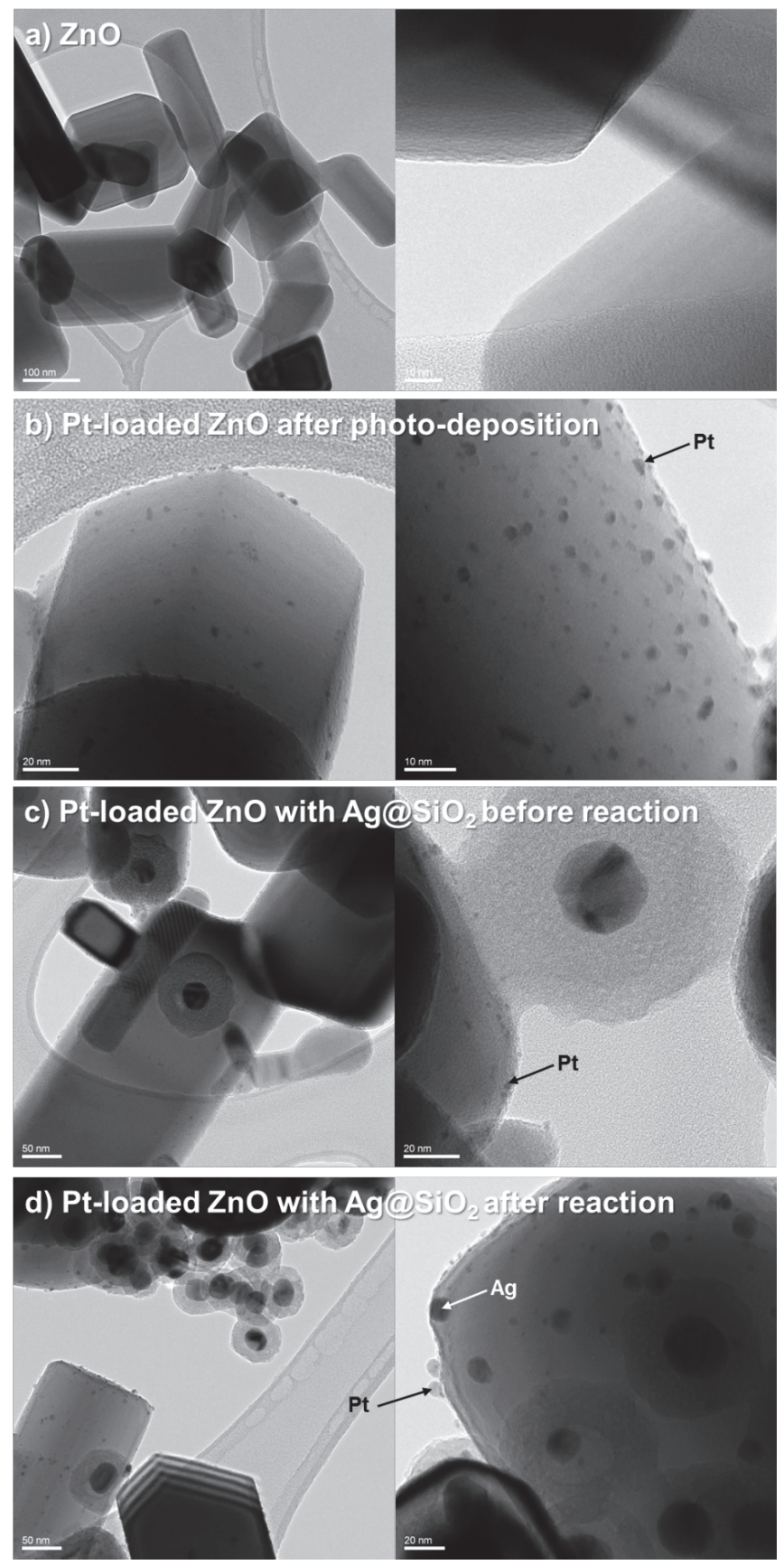

Figure 7.8. TEM images of (a) $\mathrm{ZnO}$, (b) Pt-loaded $\mathrm{ZnO}$ after photo-deposition, (c) a mixture of Pt-loaded $\mathrm{ZnO}$ with $\mathrm{Ag} @ \mathrm{SiO}_{2}$ before the water splitting reaction, and (d) a mixture of Ptloaded $\mathrm{ZnO}$ with $\mathrm{Ag} @ \mathrm{SiO}_{2}$ after the water splitting reaction. 
Second, relatively large Ag metal particles appear to have been deposited on the $\mathrm{ZnO}$ crystals, which can be clearly discerned from the Pt particles by EDX as shown in Figure A7.11.

To explain these phenomena, we have to assume that Ag is oxidized in the photocatalytic process. We propose the following reaction sequence. First, $\mathrm{ZnO}$ is photo-excited according to reaction (1). Second, the photo-excited hole oxidizes hydroxyl groups (or water) to hydroxyl radicals. Recent studies have demonstrated that these radicals can dissolve in water. These are also capable of penetrating the porous $\mathrm{SiO}_{2}$ shell, and oxidation of $\mathrm{Ag}$ to $\mathrm{Ag}^{+}$ according to reaction (3). Then we assume $\mathrm{Ag}^{+}$to diffuse out of the shell into solution, after which $\mathrm{Ag}^{+}$reacts with the photo-excited electron from $\mathrm{ZnO}$ to create $\mathrm{Ag}$ nanoparticles (reaction (4)), similar to a photo-deposition process.

$$
\begin{aligned}
& \mathrm{ZnO} \rightarrow \mathrm{e}^{-}+\mathrm{h}^{+} \text {(under the illumination) } \\
& \mathrm{OH}(\text { surface on } \mathrm{ZnO})+\mathrm{h}^{+} \rightarrow \mathrm{OH} \bullet \text { (in solution) } \\
& \mathrm{OH} \bullet+\mathrm{Ag}\left(\text { core of } \mathrm{Ag} @ \mathrm{SiO}_{2}\right) \rightarrow \mathrm{Ag}^{+}+\mathrm{OH}^{-} \\
& \mathrm{Ag}^{+} \text {(in solution) }+\mathrm{e}^{-} \rightarrow \mathrm{Ag}(\text { on } \mathrm{ZnO})
\end{aligned}
$$

Finally, the absence of $\mathrm{O}_{2}$ formation in the reaction needs to be discussed. We speculate on the basis of literature on water splitting with semiconductors that the following reactions might be relevant. ${ }^{23}$

1) Carbon containing contaminants are present, which are oxidized to $\mathrm{CO}$ or $\mathrm{CO}_{2}$ by hydroxyl radicals and/or activated oxygen (reaction (5)). Our GC was not able to measure $\mathrm{CO}_{2}$ during the reaction while $\mathrm{CO}$ was not formed.

$$
\text { "C" on } \mathrm{ZnO} \text { surface }+\mathrm{O}_{2} \rightarrow \mathrm{CO}+\mathrm{CO}_{2}
$$

2) Photo-excited holes react with water to produce hydroxyl radicals (reaction (6)). Such produced hydroxyl radicals recombine to hydrogen peroxide (reaction (7)). Subsequently hydrogen peroxide might react with surface $\mathrm{Zn}-\mathrm{OH}$ groups to $\mathrm{Zn}-\mathrm{OOH}$ and water in analogy to TS-1 based epoxidation catalysis. Alternatively hydrogen peroxide just remains in solution. 126 In any case, the surface of Pt-loaded $\mathrm{ZnO}$ then has to be assumed to be ineffective for decomposition of hydrogen peroxide to produce oxygen (reaction (9)).

$$
\begin{aligned}
& 4 \mathrm{~h}^{+}(\text {from } \mathrm{ZnO})+4 \mathrm{H}_{2} \mathrm{O} \rightarrow 4 \mathrm{OH} \bullet+4 \mathrm{H}^{+} \\
& 4 \mathrm{OH} \bullet \rightarrow 2 \mathrm{H}_{2} \mathrm{O}_{2}
\end{aligned}
$$




$$
\begin{aligned}
& \mathrm{OH} \bullet+\mathrm{H}_{2} \mathrm{O}_{2} \rightarrow \mathrm{Zn}-\mathrm{OOH}+\mathrm{H}_{2} \mathrm{O} \\
& 2 \mathrm{H}_{2} \mathrm{O}_{2} \rightarrow \mathrm{O}_{2}+2 \mathrm{H}_{2} \mathrm{O}
\end{aligned}
$$

\subsection{Conclusions}

In summary, we have constructed photoelectrochemical devices based on $\mathrm{WO}_{3}$ and $\mathrm{ZnO}$ in which $\mathrm{Ag} @ \mathrm{SiO}_{2}$ core-shell particles were introduced. The $\mathrm{Ag} @ \mathrm{SiO}_{2}$ core-shell particles generally induce a negative effect on device performance for $\mathrm{WO}_{3}$, providing a relatively high current density. For $\mathrm{ZnO}$ based photo-electrodes a slightly positive effect is observed for the $\mathrm{Ag} @ \mathrm{SiO}_{2}$ core-shell particles, while the photocurrents are significantly smaller than determined for $\mathrm{WO}_{3}$. Based on the results of photocatalytic water splitting obtained for Ptloaded $\mathrm{ZnO}$ in the presence of the $\mathrm{Ag} @ \mathrm{SiO}_{2}$ core-shell particles in a slurry reactor, this positive effect can be understood by advantageous optical scattering effects. The stability of $\mathrm{Ag}$ in the core of the $\mathrm{Ag} @ \mathrm{SiO}_{2}$ core-shell particles is lower than anticipated, both in photoelectrochemistry and photocatalysis experiments. Oxidation of Ag in PEC is evident in voltammetry measurements, and likely at the origin of the absence of plasmonic enhancement of photocurrents in our photoelectrochemical experiments. TEM images taken after photocatalytic experiments reveal hollow $\mathrm{Ag} @ \mathrm{SiO}_{2}$ core-shell particles and deposition of $\mathrm{Ag}$ on $\mathrm{ZnO}$. Our results suggest that the shell morphology of $\mathrm{Ag} @ \mathrm{SiO}_{2}$ core-shell particles should be optimized to minimize contact of $\mathrm{Ag}$ with the electrolyte, to prevent dissolution and oxidation of the Ag core, and to preserve plasmonic enhancement in solution based reactions.

\subsection{References}

1. Fujishima, A.; Honda, K. Nature 1972, 238, 37-38.

2. Zhu, T.; Chong, M. N.; Chan, E. S. ChemSusChem 2014, 7, 2974-2997.

3. Abdi, F. F.; Savenije, T. J.; May, M. M.; Dam, B.; van de Krol, R. J. Phys. Chem. Lett. 2013, 4, 2752-2757.

4. Abdi, F. F.; van de Krol, R. J. Phys. Chem. C 2012, 116, 9398-9404.

5. Sivula, K.; Formal, F, L.; Grätzel, M. ChemSusChem 2011, 4, 432-449.

6. Prévot, M. S.; Sivula, K. J. Phys. Chem. C 2013, 117, 17879-17893.

7. Murphy, A. B.; Barnes, P. R. F.; Randeniya, L. K.; Plumb, I. C.; Grey, I. E.; Horne, M. D.; Glasscock, J. A. Int. J. Hydrogen Energy 2006, 31, 1999-2017.

8. Chen, Z.; Jaramillo, T. F.; Deutsch, T. G.; Kleiman-Shwarsctein, A.; Forman, A. J.; Gaillard, N.; Garland, R.; Takanabe, K.; Heske, C.; Sunkara, M.; McFarland, E. W.; Domen, K.; Miller, E. L.; Turner, J. A.; Dinh, H. N. J. Mater. Res. 2010, 25, 3-16.

9. Yourey, J. E.; Bartlett, B. M. J. Mater. Chem. 2011, 21, 7651-7660. 
10. Leonard, K. C.; Nam, K. M.; Lee, H. C.; Kang, S. H.; Park, H. S.; Bard, A. J. J. Phys. Chem. C 2013, 117, 15901-15910.

11. Warren, S. C.; Thimsen, E. Energy Environ. Sci. 2012, 5, 5133-5146.

12. Hou, W.; Cronin, S. B. Adv. Funct. Mater. 2013, 23, 1612-1619.

13. Linic, S.; Christopher, P.; Ingram, D. B. Nat. Mater. 2011, 10, 911-921.

14. Thomann, I.; Pinaud, B. A.; Chen, Z.; Clemens, B. M.; Jaramillo, T. F.; Brongersma, M. L. Nano Lett. 2011, 11, 3440-3446.

15. Abdi, F. F.; Dabirian, A.; Dam, B.; van de Krol, R. Phys. Chem. Chem. Phys. 2014, 16, 15272-15277.

16. Lim, D. C.; Shim, W. H.; Kim, K.-D.; Seo, H. O.; Lim, J.-H.; Jeong, Y.; Kim, Y. D.; Lee, K. H. Sol. Energy Mater. Sol. Cells 2011, 95, 3036-3040.

17. Giovanni, M.; Pumera, M. Electroanalysis 2012, 24, 615-617.

18. Ivanova, O. S.; Zamborini, F. P. J. Am. Chem. Soc. 2010, 132, 70-72.

19. Suryanarayanan, V.; Nair, A. S.; Tom, R. T.; Pradeep, T. J. Mater. Chem. 2004, 14, 2661 2666.

20. Campbell, F. W.; Compton, R. G. Anal. Bioanal. Chem. 2010, 396, 241-259.

21. Xu, L.; Yin, M.-L.; Liu, S. Sci. Rep. 2014, 4, 1-7.

22. Parayil, S. K.; Kibombo, H. S.; Wu, C.-M.; Peng, R.; Kindle, T.; Mishra, S.; Ahrenkiel, S. P.; Baltrusaitis, J.; Dimitrijevic, N. M.; Rajh, T.; Koodali, R. T. J. Phys. Chem. C 2013, $117,16850-16862$.

23. Abe, T.; Suzuki, E.; Nagoshi, K.; Miyashita, K.; Kaneko, M. J. Phys. Chem. B 1999, 103, 1119-1123. 


\subsection{Appendix}
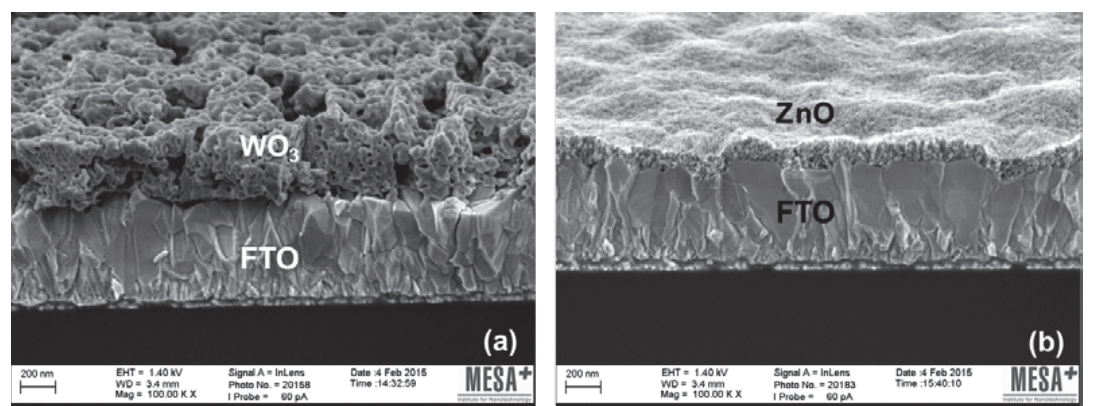

Figure A7.1. SEM images of $\mathrm{WO}_{3}$ film and $\mathrm{ZnO}$ film on FTO glass.

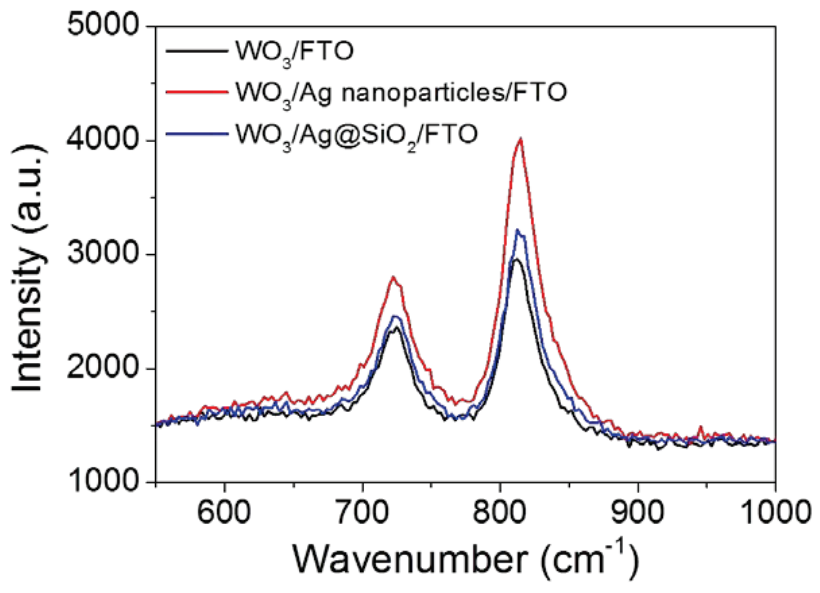

Figure A7.2. Raman spectra of samples (a) $\mathrm{WO}_{3} / \mathrm{FTO}$ (b) $\mathrm{WO}_{3} / \mathrm{Ag}$ nanoparticles/FTO, and (c) $\mathrm{WO}_{3} / \mathrm{Ag} @ \mathrm{SiO}_{2}$ core-shell particles/FTO. 


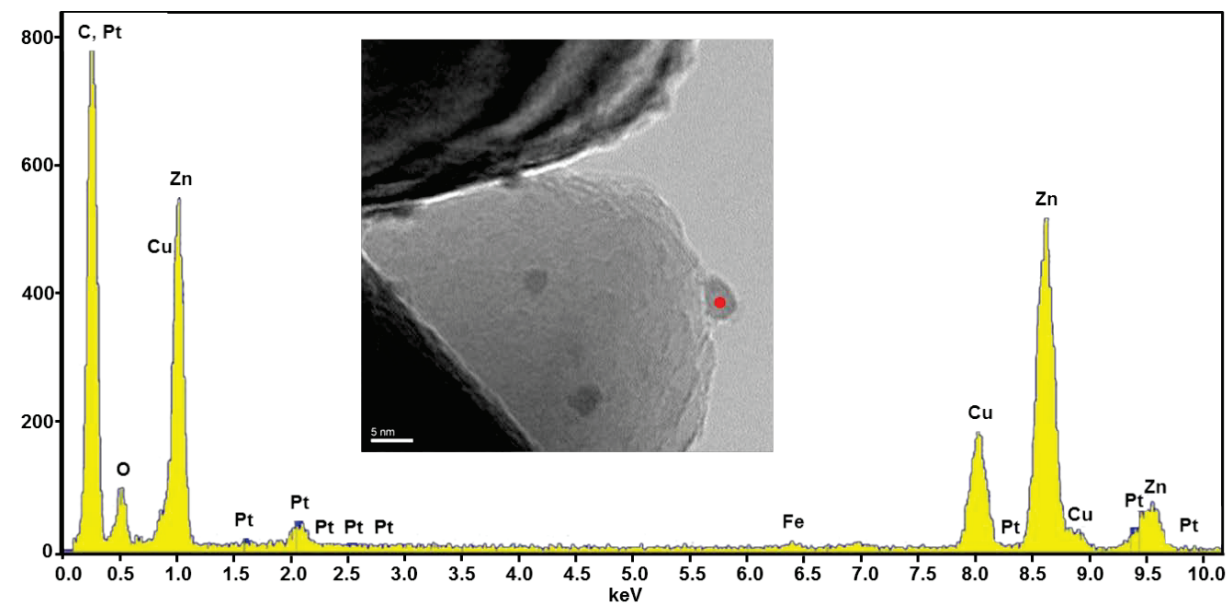

Figure A7.3. EDX spectra of Pt-loaded ZnO.

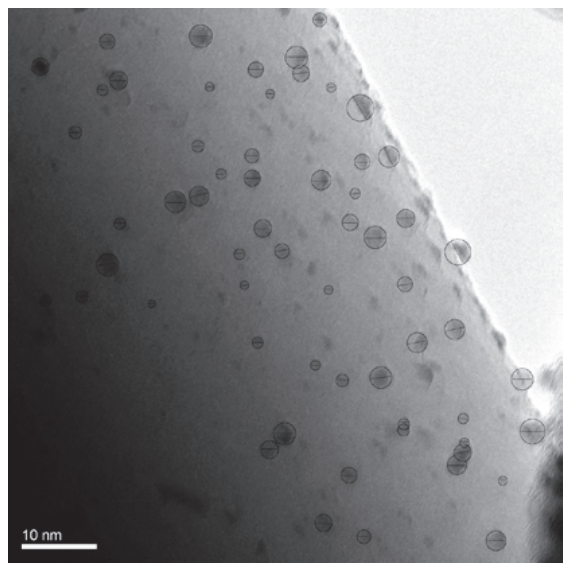

Figure A7.4. Determination of the Pt size using the program imageJ. 
A7.5. Calculation of the amount of Pt on $\mathrm{ZnO}$ after photo-deposition.

To measure the loading of Pt on the Pt-loaded ZnO samples using ICP-AES, we used the residual solution after removal of the solid $\mathrm{ZnO}$ by centrifugation. $5 \mathrm{ml}$ of this residual solution was diluted with $25 \mathrm{ml}$ of demineralized water and analyzed in the ICP spectrometer. A calibration curve was made using aqueous solutions of $10,20,40$, and $80 \mathrm{mg} / \mathrm{L}$ of $\mathrm{Pt}$ in $\mathrm{H}_{2} \mathrm{PtCl}_{6} \cdot 6 \mathrm{H}_{2} \mathrm{O}$ solution. Using this calibration, $1.8 \mathrm{mg} / \mathrm{L}$ of $\mathrm{Pt}$ was detected in the residual solution. The ratio in molar mass amounts to:

$$
\frac{195.08 \frac{\mathrm{g}}{\mathrm{mol}}(\mathrm{Pt} \text { molar mass })}{517.90 \frac{\mathrm{g}}{\mathrm{mol}}\left(\mathrm{H}_{2} \mathrm{PtCl}_{6} \cdot 6 \mathrm{H}_{2} \mathrm{O} \text { molar mass }\right)} \times 100=37.66 \%
$$

Thus $1 \mathrm{~g}$ of $\mathrm{H}_{2} \mathrm{PtCl}_{6} \cdot 6 \mathrm{H}_{2} \mathrm{O}$ yields $0.3766 \mathrm{~g}$ of $\mathrm{Pt}$ in $1 \mathrm{~L}$ of demineralized water.

The percentage of $\mathrm{Pt}$ from solution deposited on $\mathrm{ZnO}$ is then:

$$
\frac{376.6-1.8}{376.6} \times 100=99.52 \%
$$

And the amount of $\mathrm{Pt}$ deposited on $\mathrm{ZnO}$

$$
\frac{2.63 \mathrm{mg}\left(\mathrm{Pt} \text { amount in } 7 \mathrm{ml} \text { of } \mathrm{H}_{2} \mathrm{PtCl}_{6} \cdot 6 \mathrm{H}_{2} \mathrm{O}\right)}{1000 \mathrm{mg}(\mathrm{ZnO})+2.63 \mathrm{mg}} \times 0.9952=0.260 \mathrm{wt}-\%
$$


A7.6. Calculation of the number of moles of produced $\mathrm{H}_{2}$ during the reaction.

Pt-loaded $\mathrm{ZnO}$ with 10 wt-\% Ag@ $\mathrm{SiO}_{2}$ core-shell particles produced $\sim 600$ ppb $\mathrm{H}_{2}$.

$600 \mathrm{ppb} \times 10 \mathrm{ml} / \mathrm{min}($ He flow rate $)=600 \times 10^{-9} \times 10=6 \times 10^{-6} \mathrm{ml} \mathrm{min}^{-1}$ of $\mathrm{H}_{2}$

1 mole gas $=24.5 \mathrm{~L}(\mathrm{~T}=298 \mathrm{~K}, \mathrm{p}=1 \mathrm{~atm})$

1 mmole gas $=24.5 \mathrm{ml}$

$1 \mathrm{mmol}$ gas $\cdot 24.5 \mathrm{ml}=\mathrm{x} \mathrm{mmole} \cdot 6 \times 10^{-6} \mathrm{ml}$

$\mathrm{x}=2.44 \times 10^{-7} \mathrm{mmole}^{-1} \mathrm{~min}^{-1}$ of $\mathrm{H}_{2}$, which is equal to: $0.58 \mu$ mole $\mathrm{g}^{-1} \mathrm{~h}^{-1}$ of $\mathrm{H}_{2}$

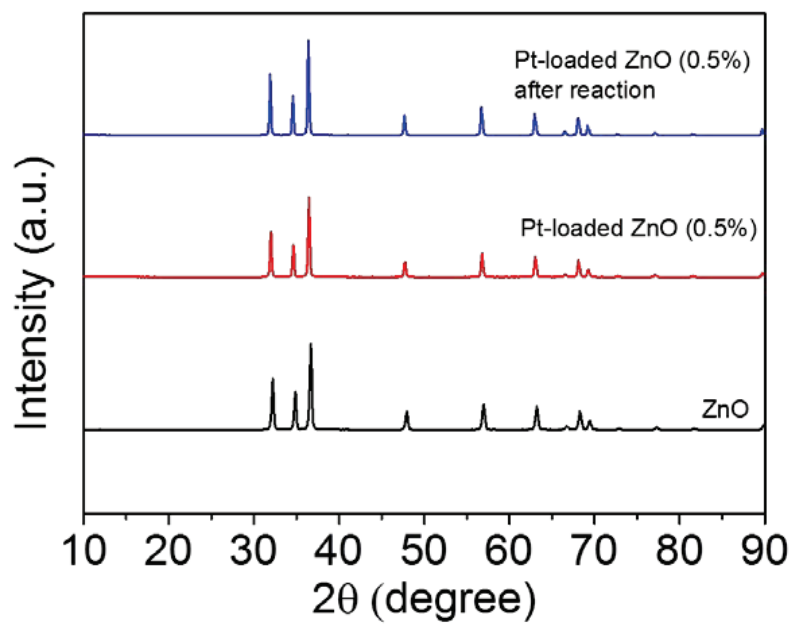

132 Figure A7.7. XRD patterns of bare $\mathrm{ZnO}$, Pt-loaded $\mathrm{ZnO}$ using photo-deposition, and Ptloaded $\mathrm{ZnO}$ after the water splitting reaction. 

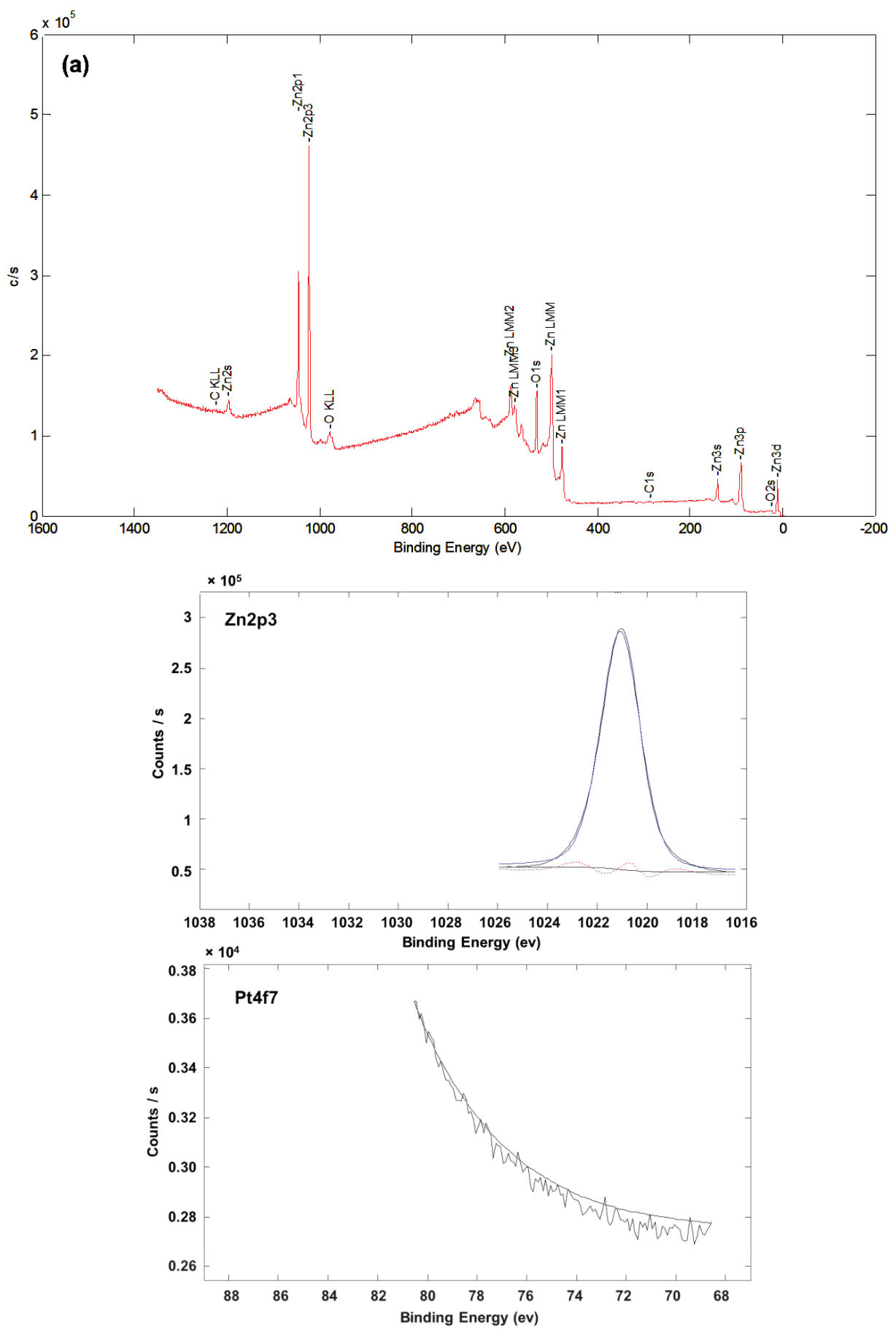

Figure A7.8. XPS spectra of $\mathrm{ZnO}$. 


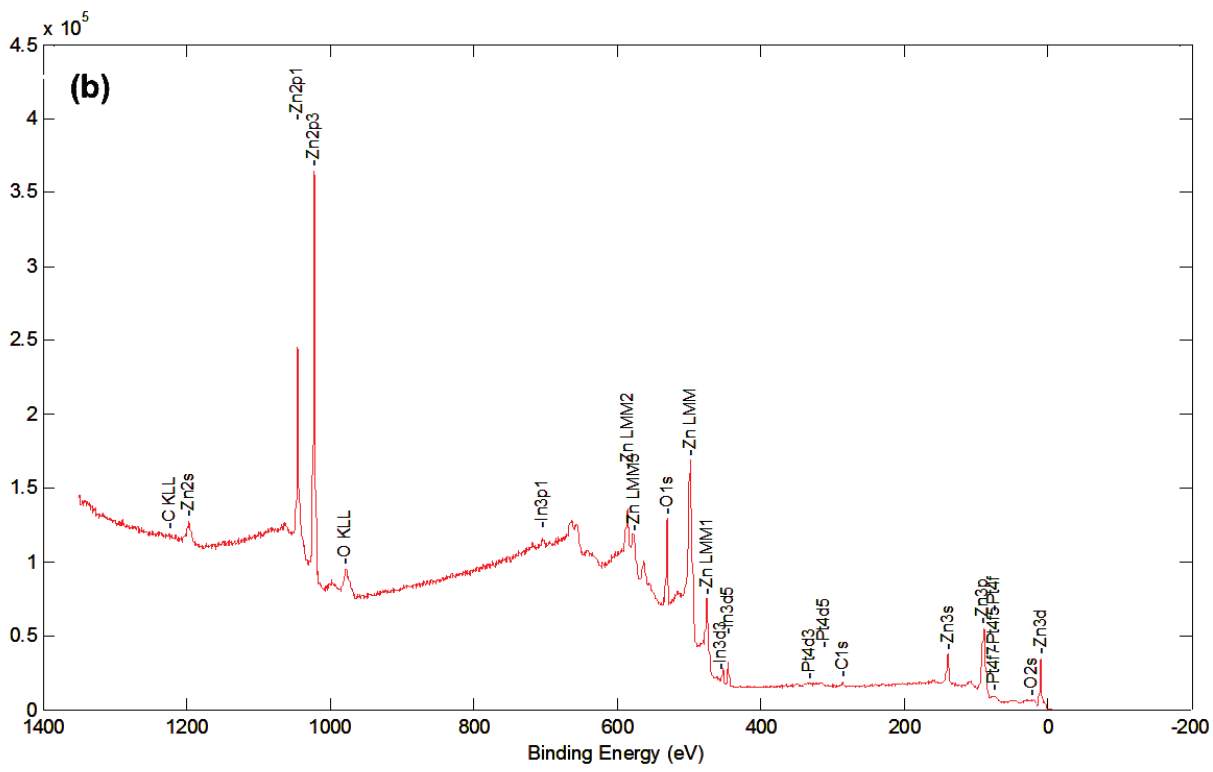

$\frac{0}{\frac{0}{2}}$

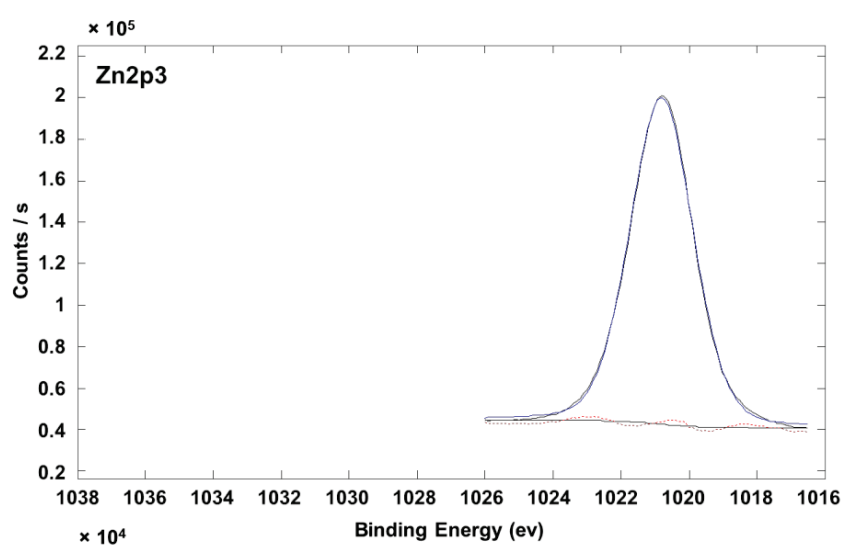

134

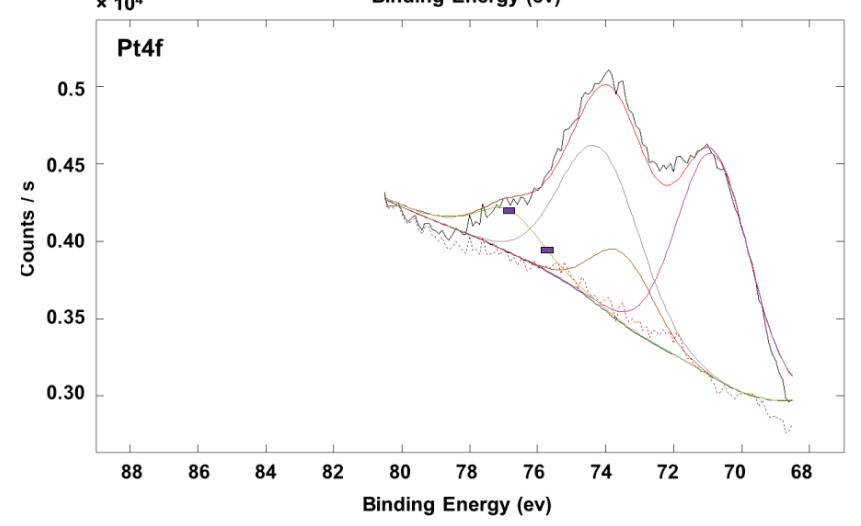

Figure A7.9. XPS spectra of Pt-loaded $\mathrm{ZnO}$ after photo-deposition. 

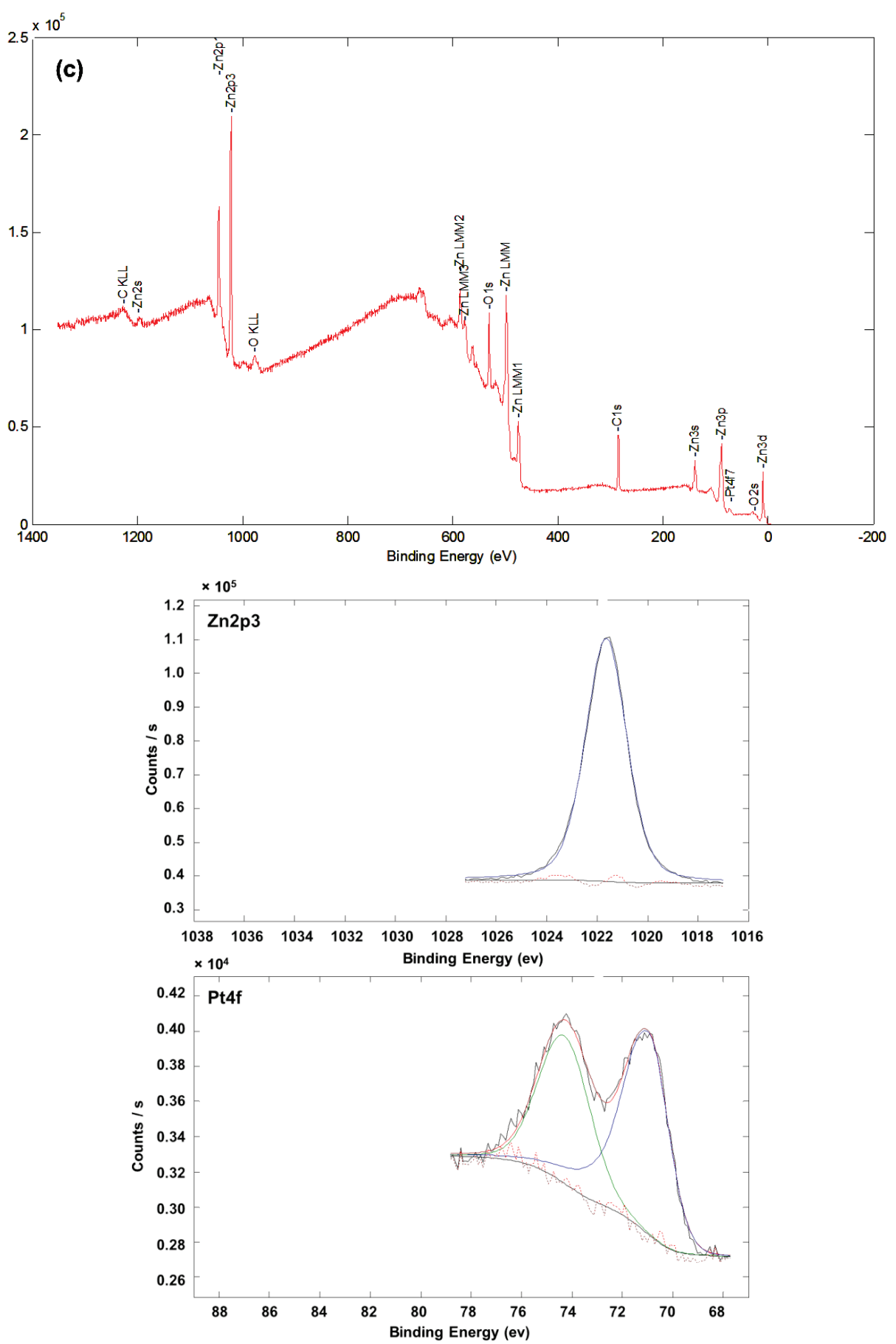

Figure A7.10. XPS spectra of Pt-loaded $\mathrm{ZnO}$ after the water splitting reaction. 
Table A7.1. Overview of XPS data.

\begin{tabular}{c|c|c}
\hline \multirow{2}{*}{ samples } & \multicolumn{2}{|c}{$\mathrm{BE}(\mathrm{eV})$} \\
\cline { 2 - 3 } & $\mathrm{Zn}$ & $\mathrm{Pt}$ \\
\hline $\mathrm{ZnO}$ & $1021.1\left(\mathrm{Zn}^{2+}\right)$ & - \\
\hline Pt-loaded $\mathrm{ZnO}$ before water splitting & $1020.8\left(\mathrm{Zn}^{2+}\right)$ & $70.8(\mathrm{Pt}) / 73.5\left(\mathrm{Pt}^{2+}\right)$ \\
\hline Pt-loaed $\mathrm{ZnO}$ after water splitting & $1021.7\left(\mathrm{Zn}^{2+}\right)$ & $71.0(\mathrm{Pt})$ \\
\hline
\end{tabular}
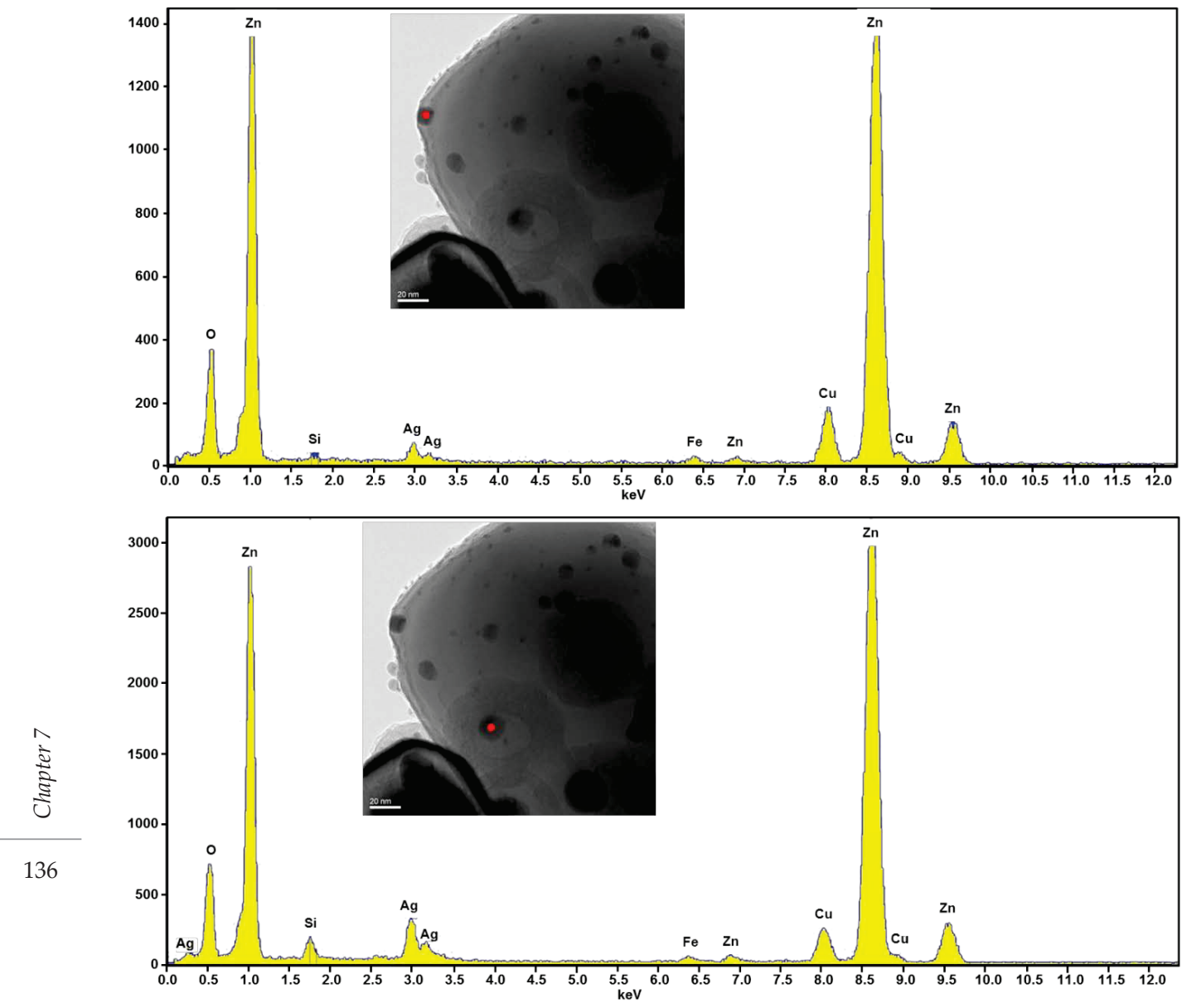

Figure A7.11. EDX spectra of Pt-loaded $\mathrm{ZnO}$ with $\mathrm{Ag} @ \mathrm{SiO}_{2}$ core-shell particles after the water splitting reaction. 


\section{Chapter 8}

Summary and outlook

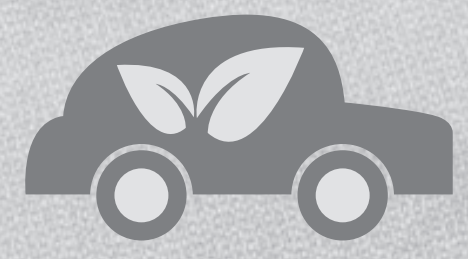

$3=0$ 


\begin{abstract}
The first section of this chapter summarizes the main results described and discussed in this thesis. $\mathrm{WO}_{3}$ films, either on FTO surfaces, or deposited on Si micro-pillars, were determined to be photoelectrochemically effective in the oxidation of water to oxygen, when applied as photo-anodes in a photoelectrochemical cell. Limitations in photocurrent densities were shown to be introduced by increasing the size of the photo-electrodes, caused predominantly by interfacial resistances. To reduce these resistances, modifying the interfaces by fullerene derivatives or Au metal nanoparticles was shown to be feasible. Furthermore, enhancement of photocurrents or photocatalysis by core-shell nanoparticles of $\mathrm{Ag}$ encapsulated in $\mathrm{SiO}_{2}$, was evaluated. Significant beneficial effects were not observed in organic media, nor in conditions of overall water splitting. This can likely be explained by insufficient protection of the $\mathrm{Ag}$ particles towards oxidation, which was observed in three conditions (organic media methylcyclohexane, alkaline water in photocatalysis, and acidified or alkaline water in photoelectrochemistry).

In the second section of this chapter, implications of the results for further development of solar to hydrogen devices are discussed, and a perspective is given on the use of polymer photovoltaic materials to construct effective solar to hydrogen devices.
\end{abstract}




\subsection{Summary}

In this thesis several photoelectrochemical water splitting devices based on semiconductor materials were investigated. The aim was the design, characterization, and fabrication of solar-to-fuel devices which can absorb solar light and split water to produce hydrogen. First, an introductory chapter is provided that summarizes recent findings in the domain of solar to fuel devices. For example, highly efficient bias-free tandem photo-electrodes with $\mathrm{BiVO}_{4}$ and $\mathrm{Si}$ are discussed, as well as application of dye sensitized solar cells (DSSCs) in a photoelectrochemical cell.

In the second chapter, an overview is given of the set-up that was constructed in the PhotoCatalytic Synthesis group to evaluate the performance of photoelectrochemical cells.

In the chapter $3, \mathrm{WO}_{3}$ was focused on as a prospective photo-anode material for water oxidation. In particular, the activity of a layer of $\mathrm{WO}_{3}$ was evaluated as a function of the dimensions of the photo-electrode. The graphical abstract of this study is shown in Figure 8.1.
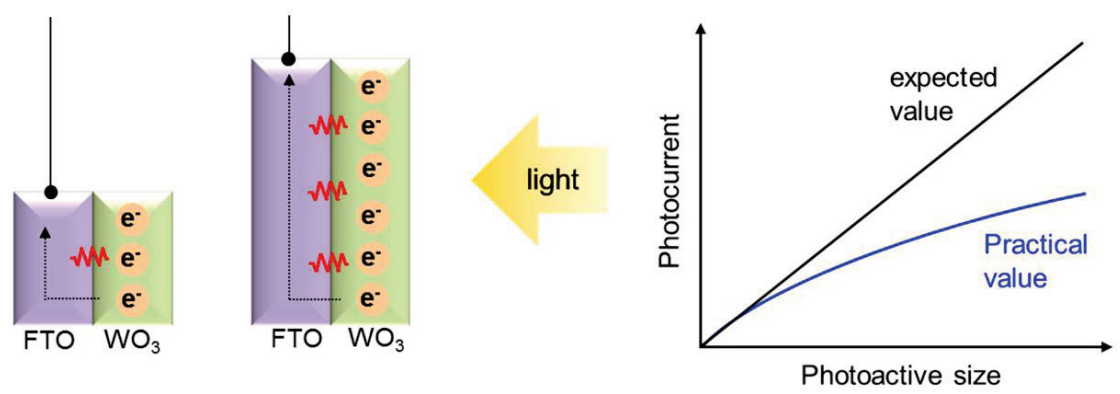

Figure 8.1. Graphical abstract of chapter 3, showing that the photocurrent achievable in a photoelectrochemical cell is dependent on the size of the photoactive area.

We demonstrate that the achievable photocurrent does not scale linearly with the size of the light exposed area (see Figure 8.1). To understand the origin of the relatively low performance of electrodes of relatively large surface area, resistance properties were determined by electrochemical impedance spectroscopy (EIS). A non-linear decrease in resistance of the interface between the conducting FTO electrode and the photoactive material $\left(\mathrm{WO}_{3}\right)$, was determined. Figure 8.1 shows a schematic comparison of the number of chargecarriers formed upon illumination, and the number of highly resistive paths present for small or large electrode areas. We aim to illustrate that the decrease in the number of charge-carriers due to the electrode area increase is accompanied by an increasing number of resistive paths. We anticipate that this will lower the photo-electron transfer efficiency, and therefore will increase the probability of electron-hole recombination. Overall this results in a less effective 
photo-electrode and lower photocurrent density. It should be mentioned that the high resistance in $\mathrm{WO}_{3}$ itself, as determined by Hall measurements, will reduce the probability that a photo-electron generated in the proximity of a highly resistive path will migrate to locations where low resistive paths are present. It is recommended that photocurrent densities reported in the literature are considered with caution, in particular when up-scaling and practical application of photoelectrochemical cells is aimed for. This study implies that reduction of the resistance of the interface is important. Indeed, when a film of graphitized $\mathrm{C}_{70}$ was inserted in between the $\mathrm{WO}_{3}$ and FTO layers, interfacial resistances decreased, and the photocurrent density improved for relatively large photoactive area electrodes. This is schematically illustrated in Figure 8.2, and discussed in more detail in chapter 4.
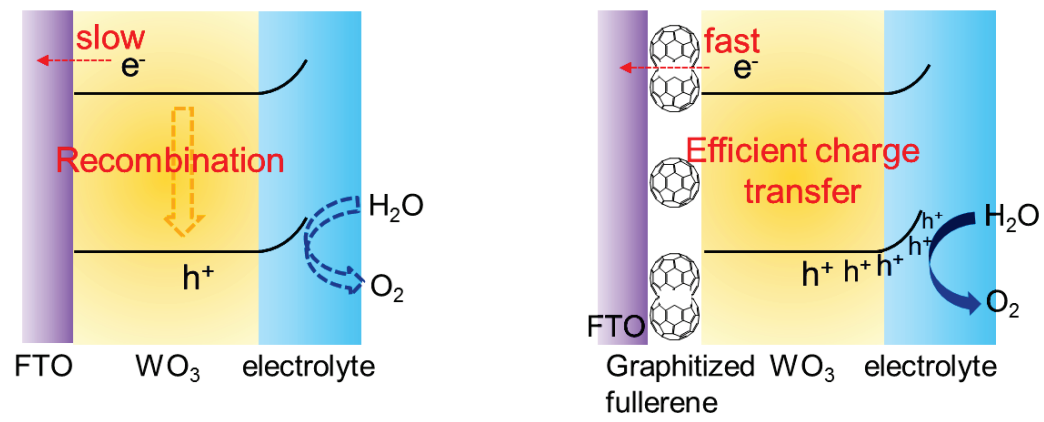

Figure 8.2. Schematic overview of the reduction in resistance of $\mathrm{WO}_{3}$ based photo-anodes, by introduction of a graphitized fullerene interfacial layer in between FTO and $\mathrm{WO}_{3}$.

Generally, fullerene materials have high electron affinity and transport ability. However, the thermal stability is limited. Fullerene was demonstrated to convert in graphitic carbon during the annealing process of the $\mathrm{WO}_{3}$ film deposited on FTO. Still, improved separation of photo-generated charges was demonstrated by photoconductive atomic force microscopy (PCAFM) measurements, which we explain by decreased accumulation and trapping of photogenerated charges at the interface between $\mathrm{WO}_{3}$ and FTO glass. In addition, EIS and photoluminescence (PL) studies were also contributing to explain the enhanced charge separation properties. Because of these enhanced interfacial characteristics, the photoelectrochemical cell with the graphitized fullerene interfacial layer exhibits a higher photocurrent as compared to the sample without interfacial layer.

A disadvantage of $\mathrm{WO}_{3}$ is that, despite the high water oxidation activity, the maximum attainable solar to hydrogen efficiency is in fact not that great, because of the relatively large band gap. Improved configurations of photoelectrochemical cells are usually based on tandem device. The common configuration in tandem devices is that two photons are required to generate two electron-hole pairs. One electron and one hole need to recombine, whereas the 
two charge-carriers of highest energy need to be available and of sufficient energy to initiate overall water splitting. As an example of such device, photovoltaic cells can be connected to a metal cathode to produce hydrogen, and functionalized with an effective catalyst to drive water oxidation. We evaluated the performance of $\mathrm{p}^{+} \mathrm{n}$ Si micro-pillar arrays, when combined with the previously investigated $\mathrm{WO}_{3}$ layers. The configuration is illustrated in Figure 8.3.

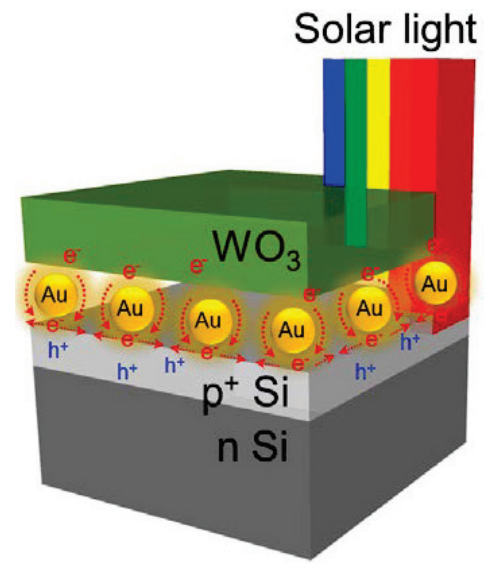

Figure 8.3. Concept of the $\mathrm{WO}_{3}$ - Si tandem photoelectrochemical cell.

To achieve efficient interaction between $\mathrm{WO}_{3}$ and $\mathrm{Si}$, again an efficient interface is required. Besides conductivity, the interlayer has to fulfill the following requirements: 1) it has to be transparent enough to absorb the light source into the bottom cell, in this case the $\mathrm{Si}$ micro-pillars and 2) proper band gap alignment is required to allow recombination of electron-hole pairs from each side of the Z-scheme based system. Generally, transparent conducting oxide materials are used as interfacial layer in tandem devices. We demonstrate the performance of a tandem device based on a thin metal layer in between $\mathrm{WO}_{3}$ and $\mathrm{p}^{+} \mathrm{n} \mathrm{Si}$ micro-pillar arrays. To make ohmic contact between $\mathrm{WO}_{3}$ and $\mathrm{Si}, \mathrm{Au}$ and Pt metal thin films were introduced. In particular an interfacial layer between $\mathrm{WO}_{3}$ and $\mathrm{Si}$ of $\mathrm{Au}$ nanoparticles, induces a significant cathodic shift of the onset potential, and enhances photocurrents. The results are reported in chapter 5. Comparing the performance of the Au nanoparticles with a film of Pt, and recording of Raman spectra, confirms that optical properties of the $\mathrm{Au}$ particles are relevant in establishing the performance observed. PC-AFM was used to determine the opto-electrical properties, confirming the favorable conductive properties of the Au nanoparticles. Our results imply that a thin film of nanoparticulate Au can also be applied as an efficient interfacial layer in tandem based photoelectrochemical cells. The remaining chapters of this thesis discuss a study which aimed to improve photoelectrochemical, and photocatalytic performance of $\mathrm{TiO}_{2}, \mathrm{WO}_{3}$, and $\mathrm{ZnO}$ by $\mathrm{Ag} @ \mathrm{SiO}_{2}$ core-shell particles. In 
particular in chapter 6, we investigated selective photo-oxidation of organic compounds induced by $\mathrm{TiO}_{2}$ (P25) as photocatalyst, and evaluated the effect of $\mathrm{SiO}_{2}$ (TUD-1) or $\mathrm{Ag} @ \mathrm{SiO}_{2}$ core-shell particles on activity. We used methylcyclohexane as a model compound. Incorporation of $\mathrm{SiO}_{2}$ particles up to $10 \mathrm{wt} \%$ in $\mathrm{TiO}_{2}$ shows enhancement in selectivity of photocatalytic reaction, but no activity improvement. Above $10 \mathrm{wt}-\%, \mathrm{SiO}_{2}$ decreased the activity in the reaction due to optical scattering. However, $\mathrm{Ag} @ \mathrm{SiO}_{2}$ core-shell particles were instable in the methylcyclohexane oxidation reaction, resulting in the dissolution of the $\mathrm{Ag}$ core from $\mathrm{Ag} @ \mathrm{SiO}_{2}$ core-shell particles. We confirm the $\mathrm{Ag}^{+}$ions diffused through the $\mathrm{SiO}_{2}$ shell from the Ag core, and subsequently deposits as $\mathrm{Ag}$ nanoparticles on $\mathrm{TiO}_{2}$.

The effect of $\mathrm{Ag} @ \mathrm{SiO}_{2}$ core-shell particles on the performance of a photoelectrochemical cell or photocatalysis, is discussed in chapter 7. Again, Ag@ $\mathrm{SiO}_{2}$ core-shell particles were instable during the water oxidation reaction in photoelectrochemical cells, either induced by $\mathrm{WO}_{3}$, or $\mathrm{ZnO}$. Instability was also observed when the $\mathrm{Ag} @ \mathrm{SiO}_{2}$ core-shell particles were added to a slurry of Pt-loaded $\mathrm{ZnO}$ particles, and Ag particles demonstrated to be deposited on $\mathrm{ZnO}$ by transmission electron microscopy (TEM). Plasmonic enhancement of the performance of the photoelectrochemical cell or photocatalytic slurry was not observed, and the slight improvement for $\mathrm{ZnO}$ electrodes and photocatalysts assigned to scattering effects. The results suggest that the $\mathrm{SiO}_{2}$ shell morphology of $\mathrm{Ag} @ \mathrm{SiO}_{2}$ we applied was insufficient to stabilize the Ag particles. The phenomena reported in chapters 6 and 7 are summarized in Figure 8.4.

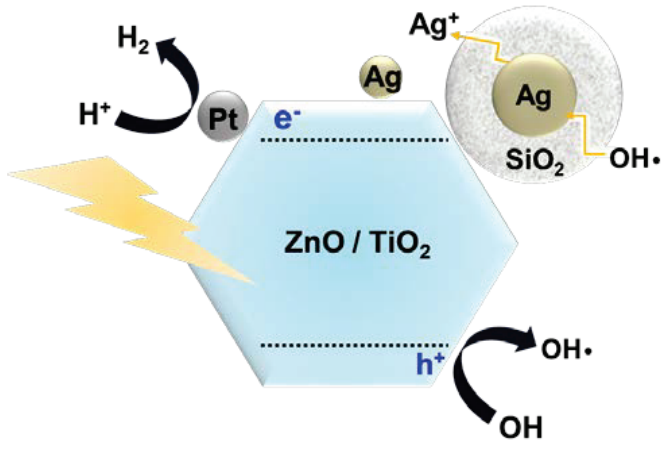

Figure 8.4. Schematic overview of the photocatalytic processes occurring on the surface $\mathrm{Pt}$ functionalized $\mathrm{ZnO}$ during photocatalysis. 


\subsection{Outlook}

Production of hydrogen via solar energy driven photoelectrochemistry or photocatalysis can significantly contribute to further implementation of renewable energy production, providing a viable means to mitigate the problems associated with the intermittency in solar energy availability. To reach a solar to hydrogen efficiency of $10 \%$, a lot of critical challenges remain. To improve a photoelectrochemical cell involves various research avenues, such as solar reactor development, and optimizing electrical connections/interfaces, electrocatalysis, and band gap (light absorption) optimization of materials. Therefore, intensive collaboration of experts in various fields of material science can be helpful to reach the targeted efficiency.

This thesis has focused on the use of inorganic semiconductors, which until now, have only partly fulfilled the requirements for efficient water splitting. New materials need to be developed, which should be stable and cheap. In addition, the preparation of materials is needed in large quantities, and also needs easy and cheap processing routes. Much is to learn from the scientific community investigating photovoltaic materials (PV). Besides simple inorganic materials, the PV community investigates novel photovoltaic cells such as CIGS, perovskites, quantum dots, and dye sensitized solar cells (DSSCs). An interesting class of materials encompasses polymer photovoltaic cells. These have not been frequently applied in a photoelectrochemical cell.

The efficiency of polymer photovoltaic cells is rapidly increasing in the past years. The efficiency of one specific polymer photovoltaic cell is now over $12 \%$. The advantages of polymer photovoltaic cells include an ability to absorb a broad range of the solar spectrum, while the open-circuit voltage of a single polymer photovoltaic cell is $0.5-0.9 \mathrm{~V}$. This is relatively large as compared to other types of photovoltaic cells. ${ }^{1-4}$ It is possible to tune the voltage, by adapting the donor and acceptor materials or introduction of multiple junctions. 5,6 In addition, fabrication processing is simple and easy based on mainly a solution based process. However, the stability in water of polymer solar cells needs to be improved. To overcome the issues of instability of materials based on polymer photovoltaic cell in water, a protection strategy might be applied, as follows.

The construction of an effective photoelectrochemical cell based on polymer photovoltaic cell is illustrated in Figure 8.5. The surface of a polymer photovoltaic cell is likely to be hydrophobic. Therefore, a first step is to convert the hydrophobic surface to a hydrophilic surface. The concept is shown in Figure 8.5. In the scheme, coating of the polymer photovoltaic cell by PEDOT:PSS is feasible, which is hydrophilic and conducting. In addition, a catalyst layer needs to be deposited, capable of extraction of holes efficiently for water oxidation. For example, this could be a metal oxide based catalyst such as $\mathrm{CoO}_{\mathrm{x}}, \mathrm{NiO}_{\mathrm{x}}$, or $\mathrm{MnO}_{\mathrm{x}}$ etc. ${ }^{7-10}$ 

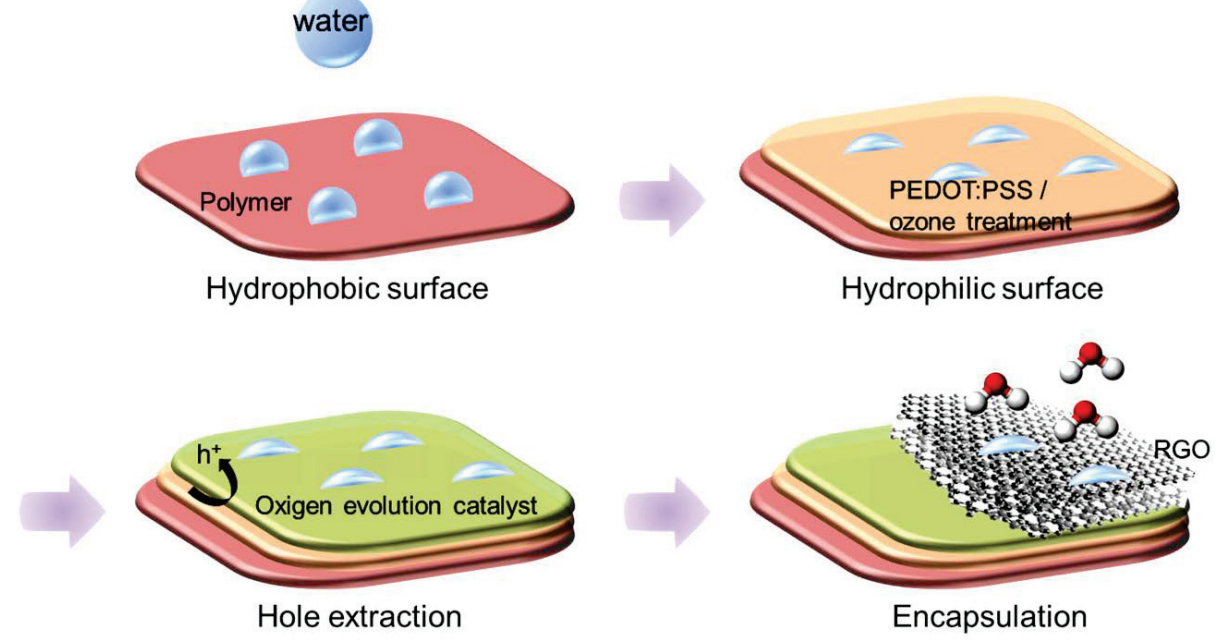

Figure 8.5. Surface modification steps to obtain stable and effective photoelectrochemical cell based on polymer photovoltaic cells.

To enhance stability and performance, one can suggest to use reduced graphene oxide. Graphene oxide (GO) and reduced graphene oxide (RGO) have tunable bandgaps and exhibit many physiochemical properties similar to those of graphene. The surface of graphene is hydrophobic in nature. Polar functional groups in RGO, associated with residual oxygenated functional groups, could produce a hydrophilic film surface. In addition, graphene oxide could act as a hole acceptor and water oxidation catalyst, to work in conjunction with other semiconductors. Therefore, graphene is a suitable material for the encapsulation of devices.

Another avenue for future research is to further investigate the mechanism of water oxidation. Many issues still need to be resolved to understand $\mathrm{H}_{2}$ and $\mathrm{O}_{2}$ evolution during the water splitting reaction. An example is the effectiveness of Pt-loaded $\mathrm{TiO}_{2}$ in overall water splitting. Few reports claim stoichiometric $\mathrm{H}_{2}$ and $\mathrm{O}_{2}$ formation, but most reports show that stoichiometric $\mathrm{H}_{2}$ and $\mathrm{O}_{2}$ evolution does not take place with the photocatalyst.

In terms of development of new materials to reach the targeted efficiency of solar to hydrogen, not only a high photocurrent is important, but also understanding of the chemical reactions is crucial to improve solar to hydrogen efficiency. 


\subsection{References}

1. Chen, H.-Y.; Hou, J.; Zhang, S.; Liang, Y.; Yang, G.; Yang, Y.; Yu, L.; Wu, Y.; Li, G. Nat. Photonics 2009, 3, 649-653.

2. Li, G.; Zhu, R.; Yang, Y. Nat. Photonics 2012, 6, 153-161.

3. Warnan, J.; Cabanetos, C.; Bude, R.; Labban, A. E.; Li, L.; Beaujuge, P. M. Chem. Mater. 2014, 26, 2829-2835.

4. He, Z.; Xiao, B.; Liu, F.; Wu, H.; Yang, Y.; Xiao, S.; Wang, C.; Russell, T. P.; Cao, Y. Nat. Photonics 2015, 9, 174-179.

5. Chen, C.-C.; Chang, W.-H.; Yoshimura, K.; Ohya, K.; You, J.; Gao, J.; Hong, Z.; Yang,Y. Adv. Mater. 2014, 26, 5670-5677.

6. Li, W.; Furlan, A.; Hendriks, K. H.; Wienk, M. M.; Janssen, R. A. J. J. Am. Chem. Soc. 2013, 135, 5529-5532.

7. Singh, A.; Spiccia, L. Coord. Chem. Rev. 2013, 257, 2607-2622.

8. Yang, J.; Wang, D.; Han, H.; Li, C. Acc. Chem. Res. 2013, 46, 1900-1909.

9. Galán-Mascarós, J. R. ChemElectroChem 2015, 2, 37-50.

10. Zhong, D. K.; Gamelin, D. R. J. Am. Chem. Soc. 2010, 132, 4202-4207. 



\section{Samenvatting}

Diverse duurzame energiebronnen zijn van nature niet constant. Met name zonlicht is een bron die niet alleen op dagelijkse basis (dag-nacht ritme, variaties in bewolking), maar ook op basis van seizoenen sterk fluctueert. Daarom is opslag van zonne-energie ten tijde van een overschot nodig, om aan de vraag ten tijde van schaarste te kunnen voldoen. Het doel van het onderzoek beschreven in dit proefschrift was het ontwerpen, karakteriseren en fabriceren van een foto-elektrochemische cel, waarmee door zonlicht absorptie water kan worden gesplitst in waterstof en zuurstof. Waterstof is dan een 'zonnebrandstof' die opgeslagen kan worden en met behulp van een brandstofcel in elektriciteit kan worden omgezet. Eerst worden in een inleidend hoofdstuk recente ontdekkingen op het gebied van dergelijke concepten samengevat, zoals een hoog efficiënte tandem foto-elektrode met bismut vanadaat $\left(\mathrm{BiVO}_{4}\right)$ en silicium $(\mathrm{Si})$ als basis, en de toepassing van dye sensitized solar cells (DSSC). Tevens worden de overige hoofdstukken kort ingeleid.

In het tweede hoofdstuk wordt een overzicht gegeven van de opstelling die werd gebouwd in de PhotoCatalytic Synthesis groep van de Universiteit Twente om de prestaties van fotoelektrochemische apparaten te evalueren. Ook worden kort andere technieken beschreven om foto-elektrochemisch effectieve films te karakteriseren.

In hoofdstuk 3 wordt er gefocust op wolfraam oxide $\left(\mathrm{WO}_{3}\right)$ als een beoogd foto-anode materiaal voor water oxidatie. Met name de activiteit van een laag $\mathrm{WO}_{3}$ wordt geëvalueerd als functie van de afmetingen van de foto-elektrode. De grafische samenvatting van deze studie is weergegeven in Figuur 1.
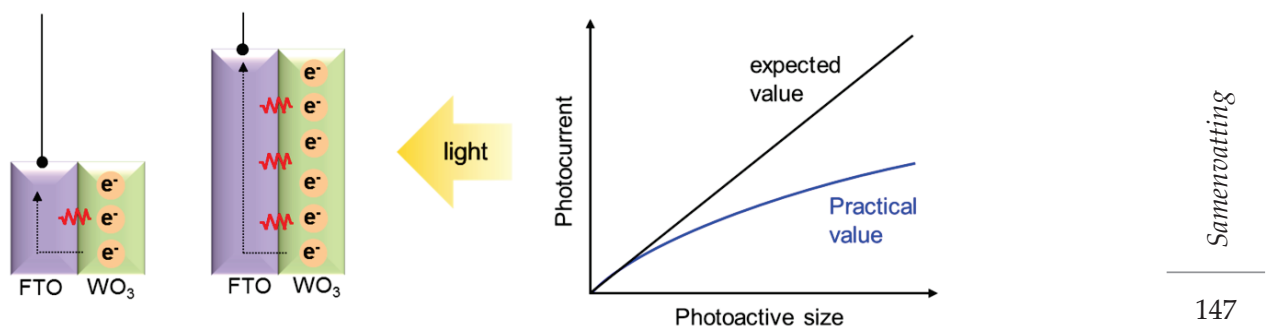

Figuur 1. Grafische samenvatting van hoofdstuk 3, waaruit blijkt dat de haalbare fotostroom in een foto-elektrochemische cel afhankelijk is van de grootte van het foto-actieve oppervlak.

We demonstreren dat de haalbare fotostroom niet lineair schaalt met de grootte van het aan licht blootgestelde oppervlak (zie Figuur 1). Om de oorzaak van de relatief lage prestaties van de elektrodes met een relatief groot oppervlak te begrijpen, werden weerstandseigenschappen 
bepaald met EIS (elektrochemische impedantie spectroscopie). Een niet-lineaire afname van de weerstand van het grensvlak tussen de geleidende FTO (fluor gedoteerd tin oxide) elektrode en het foto-actieve materiaal $\left(\mathrm{WO}_{3}\right)$ werd bepaald. Figuur 1 (links) toont een schematische vergelijking van het aantal ladingsdragers gevormd bij belichting en het aantal hoog resistieve paden aanwezig voor kleine of grote elektrode-oppervlakken. Deze figuur beoogt te illustreren dat de toename van het aantal ladingsdragers vanwege de oppervlakte toename gepaard gaat met een relatief sterker toenemend aantal resistieve paden. We verwachten dat deze resistieve paden de foto-elektron overdracht efficiëntie zullen verlagen en daarom de kans van elektron-gat recombinatie zullen verhogen. Over het geheel genomen resulteert dit in een minder effectieve foto-elektrode en een lagere fotostroom dichtheid. Noemenswaardig is dat de hoge weerstand in $\mathrm{WO}_{3}$ zelf, zoals bepaald door Hall metingen, de waarschijnlijkheid zal verlagen dat een foto-elektron gegenereerd in de nabijheid van een sterk resistief pad zal migreren naar locaties waar laag resistieve paden aanwezig zijn. Aanbevolen wordt dat fotostroom dichtheden gerapporteerd in de literatuur zorgvuldig worden overwogen, met name wanneer schaalvergroting en praktische toepassing van fotoelektrochemische cellen worden nagestreefd.

Deze resultaten van hoofdstuk 3 impliceren dat vermindering van de weerstand van het grensvlak tussen foto-actieve halfgeleider en elektrode substraat belangrijk is. Om dit te realiseren kan een film van $\mathrm{C}_{70}$ tussen de $\mathrm{WO}_{3}$ en FTO lagen worden aangebracht. Dit principe wordt schematisch weergegeven in Figuur 2 en wordt gedetailleerd besproken in hoofdstuk 4.
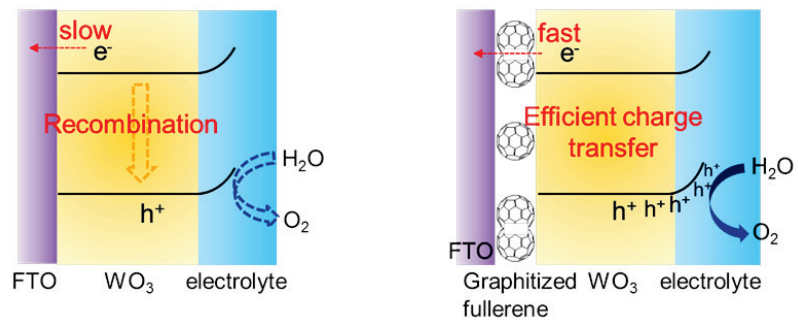

Figuur 2. Schematisch overzicht van de vermindering van de weerstand van $\mathrm{WO}_{3}$ gebaseerde foto-anodes door het inbrengen van een gegrafitiseerde fullereen film tussen FTO en $\mathrm{WO}_{3}$.

In het algemeen hebben fullereen materialen een hoge elektronen affiniteit en transport capaciteit. Echter, de thermische stabiliteit bleek beperkt te zijn. Er werd aangetoond dat fullereen, afgezet op FTO, veranderde in grafietkoolstof tijdens een verhittingsproces, benodigd voor het verkrijgen van een actieve $\mathrm{WO}_{3}$ film. Toch werd verbeterde scheiding van foto-gegenereerde ladingen aangetoond door photoconductive atomic force microscopy (PCAFM) metingen, die we toeschrijven aan verminderde accumulatie door het vastlopen van foto-gegenereerde ladingen op het raakvlak tussen $\mathrm{WO}_{3}$ en FTO glas. Daarnaast droegen EIS en PL (fotoluminescentie) studies bij aan het begrip van de verbeterde ladingsscheiding.

Een nadeel van $\mathrm{WO}_{3}$ is dat, ondanks de hoge water oxidatie activiteit, de maximaal haalbare zonne-energie naar waterstof efficiëntie eigenlijk niet zo groot is vanwege de relatief grote band gap. Verbeterde configuraties van foto-elektrochemische cellen zijn gewoonlijk 
gebaseerd op het tandem principe. Het tandem principe behelst dat twee fotonen benodigd zijn om twee elektron-gat paren te genereren. Eén elektron en één gat moeten recombineren, terwijl de twee ladingsdragers met de hoogste energie beschikbaar moeten zijn en voldoende energie moeten hebben om de algehele water splitsing te initiëren. Als voorbeeld van een dergelijk principe kunnen fotovoltaïsche cellen aangesloten worden op een metalen kathode om waterstof te produceren, terwijl deze cellen dan gefunctionaliseerd moeten worden met een effectieve katalysator om water oxidatie tot stand te brengen. In dit proefschrift wordt de prestatie van $\mathrm{p}^{+} \mathrm{n}$ gedoteerd $\mathrm{Si}$ in een micro pilaren morfologie, in combinatie met de eerder onderzochte $\mathrm{WO}_{3}$ lagen, geëvalueerd. De configuratie is te zien in Figuur 3.

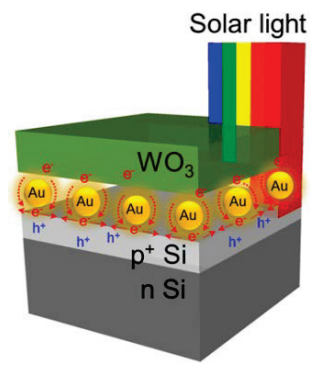

Figuur 3. Concept van de $\mathrm{WO}_{3}$-Si tandem foto-elektrochemische cel.

Om efficiënte interactie tussen $\mathrm{WO}_{3}$ en $\mathrm{Si}$ te bereiken, is een hoog-geleidende grenslaag vereist. Behalve geleidbaarheid moet de tussenlaag aan de volgende eisen voldoen: 1) voldoende transparant zijn om de lichtbron te absorberen in de onderste cel, in dit geval de $\mathrm{Si}$ micro-pillaren en 2) de juiste band gap uitlijning hebben om recombinatie van elektron-gat paren, geproduceerd aan beide zijden van de grenslaag, toe te staan. In het algemeen worden transparante, geleidende oxide materialen gebruikt als tussenlaag in dergelijke configuraties. Wij tonen aan dat een tandem apparaat gebaseerd op een dunne metaallaag tussen $\mathrm{WO}_{3}$ en de $\mathrm{p}^{+} \mathrm{n}$ overgang met Si micro-pilaar arrays ook efficiënt kan zijn. Afhankelijk van het soort metaal, de grootte en de vorm kunnen naast elektrische eigenschappen ook optische eigenschappen van metallische nanodeeltjes worden benut. De resultaten worden gerapporteerd in hoofdstuk 5. Om Ohmisch contact tussen $\mathrm{WO}_{3}$ en $\mathrm{p}^{+} \mathrm{n}$ Si te maken, werden dunne films van $\mathrm{Au}$ en Pt geïntroduceerd als grenslaag tussen $\mathrm{WO}_{3}$ en $\mathrm{p}^{+} \mathrm{n}$ Si. In het bijzonder leidt een grenslaag van $\mathrm{Au}$ nanodeeltjes tussen $\mathrm{WO}_{3}$ en $\mathrm{p}^{+} \mathrm{n}$ Si tot een significante kathodische verschuiving van de onset potentiaal, en vergroot het de behaalde fotostromen. Het vergelijken van de prestaties van de Au nanodeeltjes met een laag van Pt enerzijds en het meten van Raman spectra anderzijds, bevestigt dat de optische eigenschappen van de $\mathrm{Au}$ deeltjes relevant zijn voor de waargenomen prestatie. We introduceerden ook een relatief nieuwe techniek om het gedrag van het grensvlak te karakteriseren in hoofdstuk 5. PC-AFM werd toegepast om de foto-elektrische eigenschappen te bepalen. De resultaten bevestigen de gunstige eigenschappen van de $\mathrm{Au}$ nanodeeltjes. In het algemeen impliceren deze resultaten dat een dunne film van $\mathrm{Au}$ nanodeeltjes ook toegepast kan worden als een efficiënte tussenlaag in andere, op het tandem principe gebaseerde foto-elektrochemische apparaten. 
De overige hoofdstukken van het proefschrift beschrijven stimulering van fotokatalytische prestaties van $\mathrm{WO}_{3}, \mathrm{ZnO}$ en $\mathrm{TiO}_{2}$ door de nabijheid van $\mathrm{Ag} @ \mathrm{SiO}_{2}$ kern-schil deeltjes. In hoofdstuk 6 wordt beschreven hoe deze deeltjes de activiteit van $\mathrm{TiO}_{2}$ (P25) als fotokatalysator in selectieve foto-oxidatie van organische substanties beïnvloeden. Methylcyclohexaan werd toegepast als modelsubstantie. Opname van $\mathrm{SiO}_{2}$ (TUD-1) deeltjes tot 10 gewichts- $\%$ in $\mathrm{TiO}_{2}$ vertoonde verhoging in selectiviteit van de fotokatalytische reactie, maar geen verbetering in activiteit. Boven 10 gewichts- $\%$ verlaagden $\mathrm{SiO}_{2}$ deeltjes de activiteit in de reactie als gevolg van optische verstrooiing. Bovendien werd duidelijk dat $\mathrm{Ag} @ \mathrm{SiO}_{2}$ kern-schil deeltjes instabiel zijn in de reactieomstandigheden van de methylcyclohexaan oxidatiereactie. Het oplossen van de Ag kern van $\mathrm{Ag} @ \mathrm{SiO}_{2}$ kern-schil deeltjes werd waargenomen met elektronenmicroscopie. Diverse beelden vormen bewijs dat $\mathrm{Ag}$ nanodeeltjes werden afgezet op $\mathrm{TiO}_{2}$ tijdens het oxidatie proces. Toepassing van de $\mathrm{Ag} @ \mathrm{SiO}_{2}$ kern-schil deeltjes wordt dan ook niet aanbevolen.

Het effect van $\mathrm{Ag} @ \mathrm{SiO}_{2}$ kern-schil deeltjes op de prestaties van een foto-elektrochemische cel voor het splitsen van water wordt besproken in hoofdstuk 7. Wederom waren $\mathrm{Ag} @ \mathrm{SiO}_{2}$ kern-schil deeltjes instabiel, geïnduceerd door hetzij activering met licht van $\mathrm{WO}_{3}$ of activering met licht van $\mathrm{ZnO}$. De metallische $\mathrm{Ag}$ kern werd geoxideerd tot $\mathrm{Ag}^{+}$, dat diffundeerde door de poreuze $\mathrm{SiO}_{2}$ schil. Deze $\mathrm{Ag}^{+}$ionen werden omgezet in $\mathrm{Ag}$ nanodeeltjes door fotodepositie op het oppervlak van $\mathrm{ZnO}$, gelijktijdig met de uitvoering van de water splitsings reactie. Soortgelijke instabiliteit werd ook waargenomen wanneer de $\mathrm{Ag} @ \mathrm{SiO}_{2}$ kern-schil deeltjes werden toegevoegd aan een suspensie van Pt-geladen $\mathrm{ZnO}$ deeltjes. Opnieuw werd aangetoond met transmissie-elektronenmicroscopie dat Ag deeltjes werden afgezet op $\mathrm{ZnO}$. Plasmonische verbetering van de prestaties van een foto-elektrochemische cel of een fotokatalytische suspensie in water splitsing werd niet waargenomen. De lichte verbetering voor op $\mathrm{ZnO}$ gebaseerde elektroden en fotokatalytische processen werd toegeschreven aan verstrooiingseffecten. De verschijnselen beschreven in hoofdstukken 6 en 7 zijn samengevat in Figuur 4. De resultaten suggereren dat de $\mathrm{SiO}_{2}$ schil morfologie van $\mathrm{Ag} @ \mathrm{SiO}_{2}$ die we toegepast hebben onvoldoende is om de Ag deeltjes te stabiliseren.

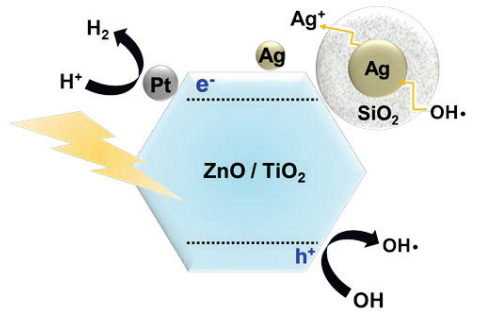

Figuur 4. Schematisch overzicht van de processen die op het oppervlak van $\mathrm{Pt}$ en $\mathrm{Ag} / \mathrm{SiO}_{2}$ gefunctionaliseerd $\mathrm{ZnO}$ plaatsvinden tijdens fotokatalyse.

Ten slotte worden in het laatste gedeelte van het proefschrift de resultaten samengevat en suggesties gedaan voor toekomstig onderzoek. 


\section{Acknowledgements}

At these last moments, I feel like closing a large book of memories. But new stories are to come, and movies to be made. Surely, this has been a great time and I take with me all the challenges it was to move, and stay in the Netherlands. In this important part, I would like to thank everyone who took a part in the episodes which appear beautiful moments. They are part of me and will be helpful for my future life.

I would like to thank Guido Mul and Jennifer Herek as my promotors. Thanks a lot for giving me the opportunity to come to the Netherlands and join this interesting project.

Guido, thanks for the nice discussions during the last four years. You gave me a big chance to drive a project based on my interest. I have learned from you that patience and a comprehensive mind are important virtues as a scientist. I will not forget what you told me 'I love science!'

Jennifer, thanks for your listening and concerning about my life. Your kindness gave me big energy to finish this $\mathrm{PhD}$.

I would like to say that I truly appreciated that my committee members Han Gardeniers, Jurriaan Huskens, Roel van de Krol, Kevin Sivula and Bernard Dam have given me the honor of being part of this important moment of my academic career.

Thanks to my paranymphs Joana Romão and David Barata, with you I had a lot of incredible moments. You guys were my friends, family and colleagues during the last four years in the Netherlands. Thanks a lot for all of your help and concern about me. I can't believe we will not meet every day anymore. I will miss you a lot.

Thanks to all the TBSC members: to Rick, thanks for the nice collaboration. Annemarie, Qing, Janneke, Pieter, Wouter, it was nice meeting and brainstorming with you for the project.

Thanks to Mark Smithers for contributing with great SEM and TEM images to my research done in Twente.

To all the PCS group members, my thanks, and specially: to Robert, for all your technical support for my work in the PCS lab; to Lidy, for being very helpful. Kasper, Michel, Hamdy, Kai, Rezvaneh, Recep, Alexander, Zheng, Bindikt, Yi, Yan, Khalid, thank you a lot for the nice moments in the group, including the group trips to Berlin, to Valencia, and the group activities. These moments were important to better know each other and share memories. I 
could laugh a lot with you guys during many unexpected and funny situations. I wish you all the best of success in your future.

누구보다 언제나 제가 하고자 하는 일과 선택을 믿어주시고 든든한 후원자가 되어주시는 아빠, 엄마, 동생 경이에게 감사의 마음을 전합니다. 우리가족 덕분에 걱정 없이 건강하게 이곳에서 공부하고 학위 마칠 수 있었습니다. 감사합니다.

항상 아낌없는 지원과 조언해 주시는 재료연구소 박사님들께 감사드립니다. 정용수 박사님, 임동찬 박사님, 이주열 박사님, 허진희 박사님. 바쁘신 중에도 함께 디스커션 해주시고, 의견주신 박사님들 도움으로 보다 더 좋은 결과로 이 책을 마무리 할 수 있었습니다. 앞으로 더욱 더 노력하는 모습으로 보답하겠습니다.

전북대학교 강재욱 교수님, 부경대학교 김주현 교수님, 성균관대학교 김영독 교수님 감사합니다. 교수님들께서 해주신 조언들이 큰 힘이 되었습니다.

낯설기만 했던 엔스헤데에서 많은 추억을 만들 수 있게 해주신 윤선언니, 노훈석 박사님, 홍정진 박사님과 사모님, 강원이, 서영이, 오정민 박사님, 유충렬 박사님, 희운언니, 은혜언니, 김재복 박사님, 승희, 오준철 박사님, 은영언니, 인석이, 민석이. 모두 감사합니다. 좋은 분들과 함께 보낸 시간들 즐거웠습니다.

많은 분들 덕분에 좋은 기회를 얻었고 값진 경험 할 수 있었습니다. 그 동안 학위를 잘 마무리 할 수 있도록 응원과 격려해주신 모든 분들께 감사드립니다. 새로운 도전을 위한 발걸음을 내 딛고자 하는 지금, 또 다른 꿈을 가지고 인생을 즐기는 사람이 되고자 합니다. 모두 행복하시고 건강하시길 바라며 이 책을 마칩니다.

2015 년 8 월 엔스헤데에서 박선영 올림 


\section{List of Publications}

1. Size-dependent electrochemical characteristics of photoelectrochemical cells, S.-Y. Park, E.M. Hong, J.-Y. Lee, D.C. Lim, G. Mul, submitted

2. Metal assisted opto-electrical enhancement of tandem photoelectrochemical cells, $\underline{\text { S.-Y }}$. Park, E.M. Hong, R. Elbersen, Y. Song, J. Huskens, H. Gardeniers, J.-Y. Lee, J. Heo, D.C. Lim, G. Mul, submitted

3. ATR infrared study of the photocatalytic behavior of $\mathrm{TiO}_{2}$ in physical contact with $\mathrm{SiO}_{2}$

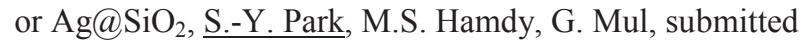

4. Stability and effect of $\mathrm{Ag} @ \mathrm{SiO}_{2}$ core-shell particles on efficacy of $\mathrm{WO}_{3}$ and $\mathrm{ZnO}$ in

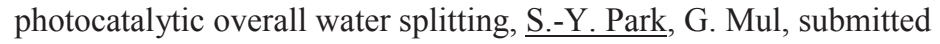

5. Selective modulation of charge-carrier transport of a photoanode in a photoelectrochemical cell by a graphitized fullerene interfacial layer, S.-Y. Park, D.C. Lim, E.M. Hong, J.-Y. Lee, J. Heo, J.H. Lim, C.-L. Lee, Y.D. Kim, G. Mul, ChemSusChem, 8, 172, (2015)

6. Emissive nanoclusters based on subnanometer-sized Au38 cores for boosting the performance of inverted organic photovoltaic cells, D.C. Lim, B.Y. Seo, S. Nho, D.H. Kim, E.M. Hong, J.-Y. Lee, S.-Y. Park, C.-L. Lee, Y.D. Kim, S. Cho, Adv. Energy Mater., 1500393, (2015)

7. Towards fabrication of high-performing organic photovoltaics: new donor-polymer, atomic layer deposited thin buffer layer and plasmonic effects, D.C. Lim, K.-D. Kim, S.-Y. Park, E.M. Hong, H.O. Seo, J.H. Lim, K.H. Lee, Y. Jeong, C. Song, E. Lee, Y.D. Kim, S. Cho, Energy Environ. Sci., 5, 9803 (2012)

8. Organic photovoltaic with high stability sustained for 100 days without encapsulation fabricated using atomic layer deposition, S.-Y. Park, H.O. Seo, K.-D. Kim, J.E. Lee, J.-D. Kwon, Y.D. Kim, D.C. Lim, Phys. Status Solidi RRL, 5, 196-198 (2012)

Selected Best of pss 2012

9. Organic solar cells fabricated by one-step deposition of a bulk heterojunction mixture and

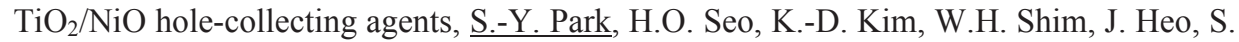
Cho, Y.D. Kim, K.H. Lee, D.C. Lim, J. Phys. Chem. C, 29, 15348-15352 (2012)

10. Ultrathin $\mathrm{TiO}_{2}$ films on $\mathrm{ZnO}$ electron-collecting layers of inverted organic solar cell, H.O. Seo, S.-Y. Park, W.H. Shim, K.-D. Kim, K.H. Lee, M.Y. Jo, J.H. Kim, E. Lee, D.-W. Kim, Y.D. Kim, D.C. Lim, J. Phys. Chem. C, 115, 21517-21520 (2011)

11. Influence of surface roughness of aluminum-doped zinc oxide buffer layers on the performance of inverted organic solar cells, S.-W. Cho, Y.T. Kim, W.H. Shim, S.-Y. Park, 
K.-D. Kim, H.O. Seo, N.K. Dey, J.-H. Lim, Y. Jeong, K.H. Lee, Y.D. Kim, D.C. Lim, Appl. Phys. Lett., 98, 023102 (2011)

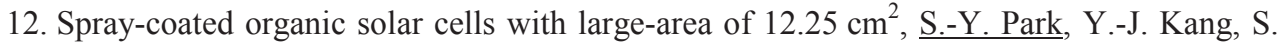
Lee, D.-G. Kim, J.-K. Kim, J.H. Kim, J.-W. Kang, Sol. Energy Mater. Sol. Cells, 95, 852855 (2011)

13. Multifunctional SWCNT-ZnO nanocomposites for enhancing performance and stability of organic solar cells, W.H. Shim, S.-Y. Park, M.Y. Park, H.O. Seo, K.-D. Kim, Y.T. Kim, Y.D. Kim, J.-W. Kang, K.H. Lee, Y. Jeong, Y.D. Kim, D.C. Lim, Adv. Mater., 23, 519522 (2011)

Selected Nature Asia Materials Highlight, Solar cells: In line for success $(2010,208)$

14. $\mathrm{ZnO}$ nanosheets decorated with $\mathrm{CdSe}$ and $\mathrm{TiO}_{2}$ for the architecture of dye-sensitized solar cells, Y.T. Kim, M.Y. Park, K.H. Choi, W.S. Tai, W.H. Shim, S.-Y. Park, K.H. Lee, Y. Jeong, Y.D. Kim, D.C. Lim, J. Nanosci. Nanotechnol., 11, 2263-2268 (2011)

15. Reduction of collection efficiency of charge carriers with increasing cell size in polymer bulk heterojunction solar cells, W.-I. Jeong, J. Lee, S.-Y. Park, J.-W. Kang, J.-J. Kim, Adv. Funct. Mater., 21, 343-347 (2011)

16. Large-area organic solar cells with metal sub-electrode on indium tin oxide anode, $\underline{\mathrm{S} .-\mathrm{Y} \text {. }}$ $\underline{\text { Park, }}$ W.-I. Jeong, D.-G. Kim, J.-K. Kim, D.C. Lim, J.H. Kim, J.-J. Kim, J.-W. Kang, Appl. Phys. Lett., 96, 173301 (2010)

17. Organic solar cells employing magnetron sputtered p-type nickel oxide thin film as the anode buffer layer, S.-Y. Park, H.-R. Kim, Y.-J. Kang, D.-H. Kim, J.-W. Kang, Sol. Energy Mater. Sol. Cells, 94, 2332-2336 (2010)

18. Effect of hybrid carbon nanotubes-bimetallic composite particles on the performance of polymer solar cells, S.-Y. Park, W.-D. Kim, D.-G. Kim, J.-K. Kim, Y.-S. Jeong, J.H. Kim, J.K. Lee, S.H. Kim, J.-W. Kang, Sol. Energy Mater. Sol. Cells, 94, 750-754 (2010)

19. Reduction of series resistance in organic photovoltaic using low sheet resistance of ITO electrode, J.-W. Kang, S.-P. Lee, D.-G. Kim, S. Lee, G.-H. Lee, J.-K. Kim, S.-Y. Park, J.H. Kim, H.-K. Kim, Y. Jeong, Electrochem. Solid-State Lett., 12, H64-H66 (2009) 


\section{Curriculum Vitae}

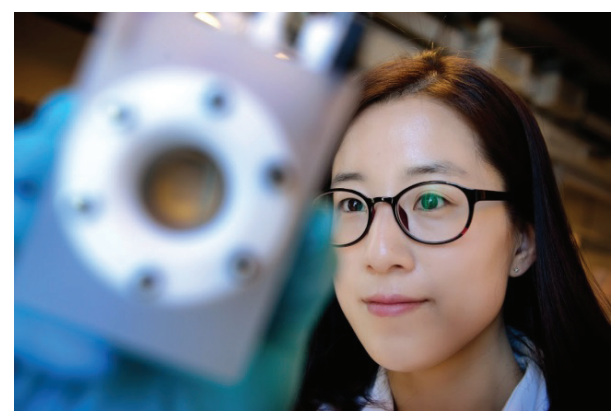

Sun-Young Park was born on 15 January 1987 in Changwon, Republic of Korea. In 2008, she graduated with a degree of Bachelor, majoring in applied chemical engineering. In 2010, she graduated with a degree of Master, majoring in polymer engineering at Pukyong National University in the Republic of Korea. Simultaneously, she worked as student researcher at the Korea Institute of Materials Science. The title of her master thesis is Fabrication and Characterization of Large-area Organic Solar Cells based on Poly(3-hexylthiophene). Since 2011, she started her PhD study in the group of photocatalytic synthesis at the University of Twente in the Netherlands. During her PhD, she has been working on the development of nanostructured solar to fuel devices. 
